Florida International University FIU Digital Commons

$11-4-2009$

\title{
Integrated Surface-Ground Water Modeling in Wetlands With Improved Methods to Simulate Vegetative Resistance to Flow
}

\author{
Mauro Nalesso \\ Florida International University, mnale001@fiu.edu
}

DOI: $10.25148 /$ etd.FI09120822

Follow this and additional works at: https://digitalcommons.fiu.edu/etd

Part of the Civil Engineering Commons

\section{Recommended Citation}

Nalesso, Mauro, "Integrated Surface-Ground Water Modeling in Wetlands With Improved Methods to Simulate Vegetative Resistance to Flow" (2009). FIU Electronic Theses and Dissertations. 122.

https://digitalcommons.fiu.edu/etd/122 


\section{FLORIDA INTERNATIONAL UNIVERSITY}

Miami, Florida

\section{INTEGRATED SURFACE-GROUND WATER MODELING IN WETLANDS WITH IMPROVED METHODS TO SIMULATE VEGETATIVE RESISTANCE TO FLOW}

A dissertation submitted in partial fulfillment of the requirements for the degree of DOCTOR OF PHILOSOPHY in CIVIL ENGINEERING

by

Mauro Nalesso 
To: Dean Amir Mirmiran

College of Engineering and Computing

This dissertation, written by Mauro Nalesso, and entitled Integrated Surface-Ground Water Modeling in Wetlands with Improved Methods to Simulate Vegetative Resistance to Flow, having been approved with respect to style and intellectual content, is referred to you for judgment.

We have read this dissertation and recommend that it be approved.

Fang Zhao

Hector R. Fuentes

Assefa M. Melesse

Reinaldo García

Fernando Miralles-Wilhelm, Major Professor

Date of Defense: November 4, 2009

The dissertation of Mauro Nalesso is approved.

$\begin{array}{r}\text { Dean Amir Mirmiran } \\ \text { College of Engineering and Computing } \\ \hline \begin{array}{r}\text { Dean George Walker } \\ \text { University Graduate School }\end{array}\end{array}$

Florida International University, 2009 


\section{DEDICATION}

To my incredible wife, Vanesa, who with her infinite love and patience has kept me afloat throughout this hard but beautiful effort.

To my dearest parents, Clara Milanese and Enzo Nalesso, who supported me since I was a child and who did everything they could to help me fulfill each one of my dreams.

To Jandro, Kemy, Pino, Wilmay and the rest of my Miami's "adoptive” family, thank you so much for everything you guys did along these three and a half years. 


\section{ACKNOWLEDGMENTS}

I would like to express my deepest gratitude to Dr. Fernando Miralles-Wilhelm and Dr. Reinaldo García, first of all for bringing me to FIU almost four years ago, and of course for all the guidance and support they have given to me along this defining experience and for sharing their knowledge with me. My gratitude to Reinaldo comes even from much earlier than that.

I would like to thank also the rest of my dissertation committee, Dr. Fang Zhao, Dr. Hector R. Fuentes, and Dr. Assefa M. Melesse for all their collaborations and for teaching me so many great things. This research was possible thanks to Dr. Jim O'Brien from FLO-2D Software, Inc. and Riada Engineering, who gave me the permission to use and modify the FLO-2D source code and who provide me all the technical support I needed. The numerical modeling of the Loxahatchee Impoundment Landscape Assessment (LILA) was possible thanks to Dr. Rene Price, Dr. Pete Harlem and to Pamela Sullivan who shared with me invaluable information.

I want to thank all my colleagues at the Institute of Fluid Mechanics (IMF-UCV)

for their support and collaboration and for introducing me into the wonderful world of research. And of course, for all the official and unofficial help and support given to me from behind the desk at the Institute of Fluid Mechanics, I am deeply grateful to Yilda Sierra and Mayeli Orozco. 


\begin{abstract}
OF THE DISSERTATION
INTEGRATED SURFACE-GROUND WATER MODELING IN WETLANDS WITH

IMPROVED METHODS TO SIMULATE VEGETATIVE RESISTANCE TO FLOW

by
\end{abstract}

Mauro Nalesso

Florida International University, 2009

Miami, Florida

\title{
Professor Fernando Miralles-Wilhelm, Major Professor
}

In topographically flat wetlands, where shallow water table and conductive soil may develop as a result of wet and dry seasons, the connection between surface water and groundwater is not only present, but perhaps the key factor dominating the magnitude and direction of water flux. Due to their complex characteristics, modeling waterflow through wetlands using more realistic process formulations (integrated surface-ground water and vegetative resistance) is an actual necessity.

This dissertation focused on developing an integrated surface - subsurface hydrologic simulation numerical model by programming and testing the coupling of the USGS MODFLOW-2005 Groundwater Flow Process (GWF) package (USGS, 2005) with the 2D surface water routing model: FLO-2D (O'Brien et al., 1993). The coupling included the necessary procedures to numerically integrate and verify both models as a single computational software system that will heretofore be referred to as WHIMFLO2D (Wetlands Hydrology Integrated Model). An improved physical formulation of flow resistance through vegetation in shallow waters based on the concept of drag force was also implemented for the simulations of floodplains, while the use of the classical 
methods (e.g., Manning, Chezy, Darcy-Weisbach) to calculate flow resistance has been maintained for the canals and deeper waters.

A preliminary demonstration exercise WHIMFLO-2D in an existing field site was developed for the Loxahatchee Impoundment Landscape Assessment (LILA), an 80 acre area, located at the Arthur R. Marshall Loxahatchee National Wild Life Refuge in Boynton Beach, Florida. After applying a number of simplifying assumptions, results have illustrated the ability of the model to simulate the hydrology of a wetland. In this illustrative case, a comparison between measured and simulated stages level showed an average error of $0.31 \%$ with a maximum error of $2.8 \%$. Comparison of measured and simulated groundwater head levels showed an average error of $0.18 \%$ with a maximum of $2.9 \%$.

The coupling of FLO-2D model with MODFLOW-2005 model and the incorporation of the dynamic effect of flow resistance due to vegetation performed in the new modeling tool WHIMFLO-2D is an important contribution to the field of numerical modeling of hydrologic flow in wetlands. 


\section{TABLE OF CONTENTS}

CHAPTER

PAGE

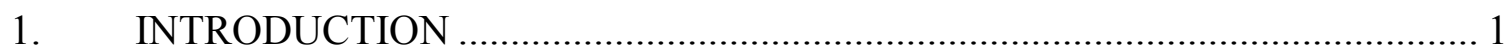

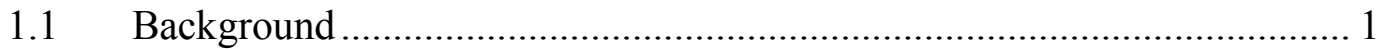

1.2 Research Objectives and Contribution..................................................... 4

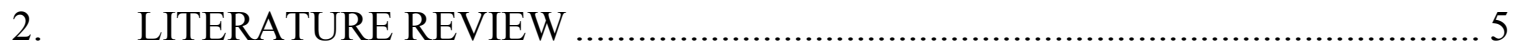

2.1 Previous Experiences on Modeling Wetlands Hydrology .......................... 5

2.2 Recent Surface-Groundwater Coupled Models ........................................ 14

2.3 Flow Resistance Due to Vegetation ........................................................... 17

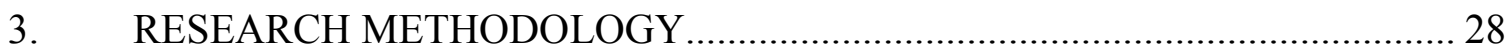

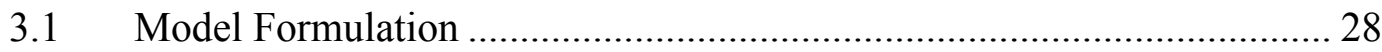

3.2 Coupling surface water and groundwater models.................................... 33

3.2.1 Coupling procedures for infiltration between surface and subsurface .......................................................................... 36

3.2.2 Coupling procedures for interaction between channels and

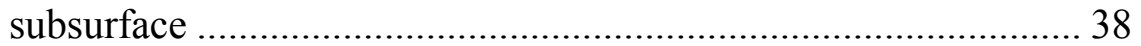

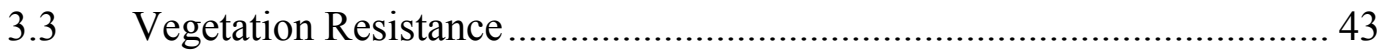

3.4 Model Verification, Analysis and Discussion ............................................ 49

3.4.1 Island Recharge Simulation (Steady-State Simulation)................. 54

3.4.2 Multiple Layer Test (Steady-State Simulation) ............................. 59

3.4.3 Comprehensive Scenario (Transient-State Simulation)................. 65

3.4.4 Vegetation Resistance Approach. .................................................. 72

4. MODEL ILLUSTRATIVE APPLICATION ………............................................ 76

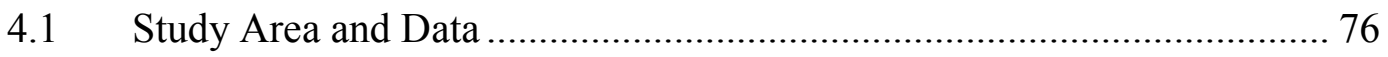

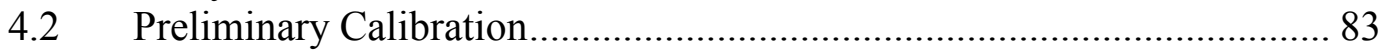

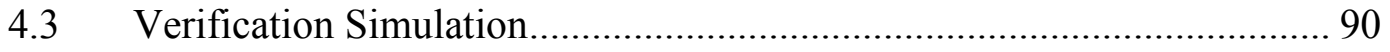

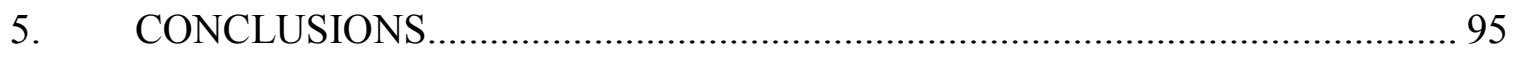

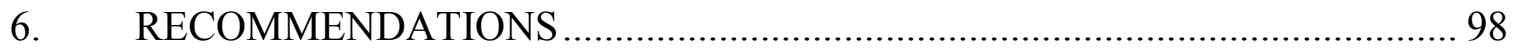

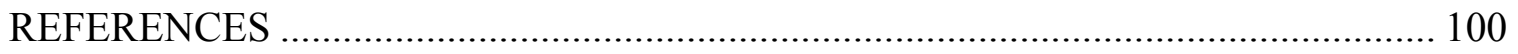

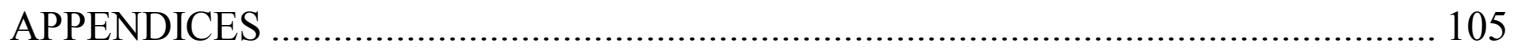

VITA … 


\section{LIST OF TABLES}

TABLE

PAGE

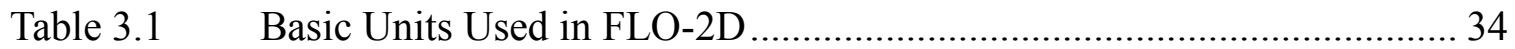

Table $3.2 \quad$ WCA 1 Cross Section Width................................................................ 51

Table 3.3 Estimated Recharge Rate Values........................................................ 59

Table 3.4 Final Cumulative Volumes and Final Rates Comparison ........................59

Table 3.5 Final Cumulative Volumes and Final Rates Comparison ........................ 61

Table 3.6 Final Cumulative Volumes and Final Rates Comparison for Stress

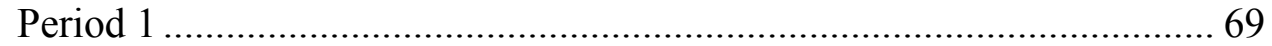

Table 3.7 Final Cumulative Volumes and Final Rates Comparison for Stress

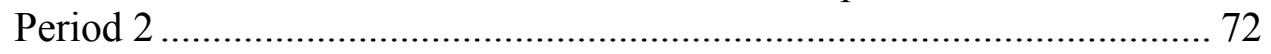

Table 4.1 Tree Island Vegetation Characteristics by Island Quadrant .................... 81

Table 4.2 Estimated and Calibrated Hydraulic Conductivity Values...................... 83

Table 4.3 Calculated Vegetation Roughness Coefficients ................................... 87

Table 4.4 Calculated Vegetation Roughness Coefficients .................................... 92 


\section{LIST OF FIGURES}

FIGURE

PAGE

Figure 2.1 SFWMM Grid for the Central and Southern Florida Region (SFWMD) 6

Figure 2.2 Richardson Model: Grid for the hydrological model of WCA 1 (Richardson et al., 1990). 7

Figure 2.3 HSE Model: Location and Mesh Discretization (Lal et al., 1998) ............ 8

Figure 2.4 Bolster and Saiers Model: Study Area Location (Bolster et al., 2002) 10

Figure 2.5 Comparison Between Observed, InSAR and Modeled Water Levels (Wdowinski et al., 2004). 13

Figure 2.6 CLMPar Model scheme (Maxwell and Miller, 2004)........................... 15

Figure 2.7 Panday's model spatial discretization (Panday and Huyakorn, 2004) 16

Figure 2.8.a Composite Channel Resistance Equations (Yen, B.C., 2002)................. 20

Figure 2.8.b Composite Channel Resistance Equations (Yen, B.C., 2002).................. 21

Figure 2.9 Regressions from Flume Data and Everglades Field Data (Lee et al., 2004) .................................................................................. 24

Figure 3.1 FLO-2D Scheme of Components (O’Brien, 2009) ............................... 29

Figure 3.2 FLO-2D 8 Potential Flow Directions (O’Brien, 2009).......................... 31

Figure 3.3 General Discretized Aquifer (Harbaugh, 2005) .................................. 32

Figure $3.4 \quad$ Flow Chart for Time Coupling.................................................... 35

Figure $3.5 \quad$ Flow Chart for Infiltration Methodology .......................................... 39

Figure 3.6 Scheme for Infiltration with Head Levels Bellow Channel Bed ............. 41

Figure 3.7 Scheme for Infiltration with Head Levels Above the Bottom of The Channel 
Figure 3.8 Flow Chart for the Vegetation Resistance Approach ............................ 48

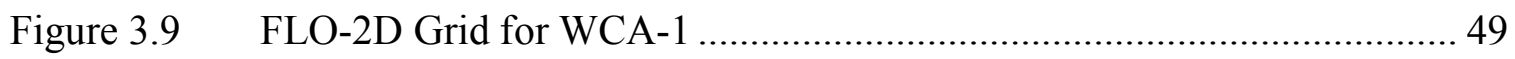

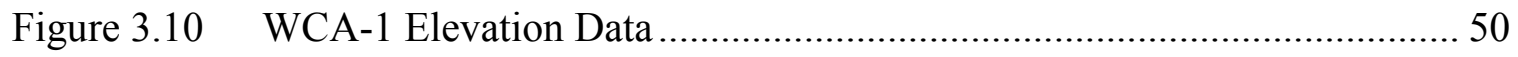

Figure 3.11 WCA-1 Model Maximum Elevations ............................................... 52

Figure 3.12 WCA-1 InSar Image (from Wdowinski et al., 2004)............................ 53

Figure 3.13 WCA-1 Maximum Modeled Velocities ............................................. 53

Figure 3.14 Conceptual Model Discretization .................................................... 55

Figure 3.15 Head Comparison for Cross Section at the Center of the Island -

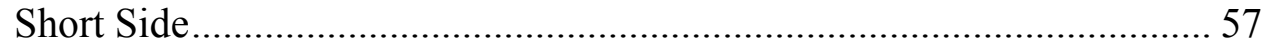

Figure 3.16 Head Comparison for Cross Section at the Center of the Island -

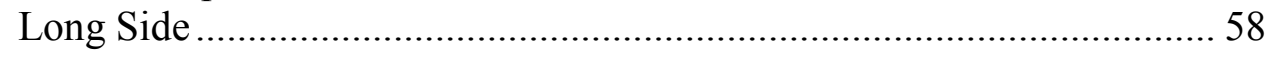

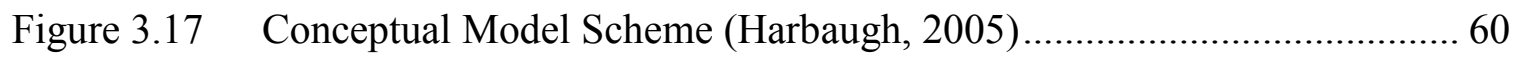

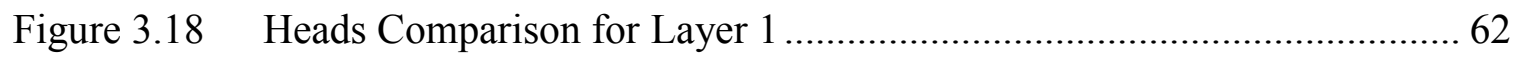

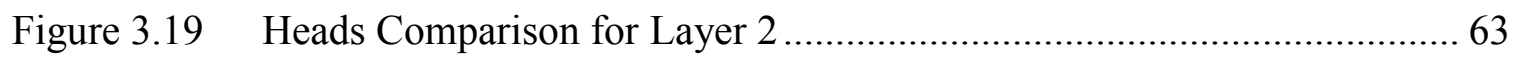

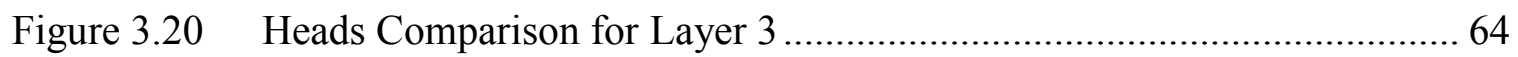

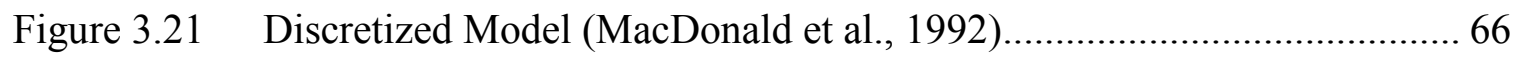

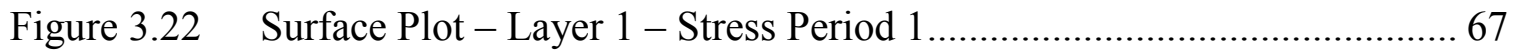

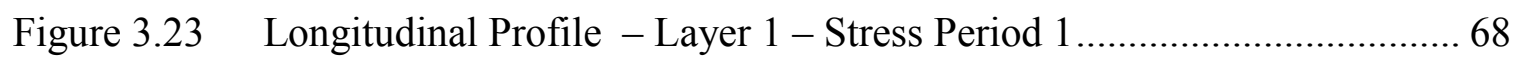

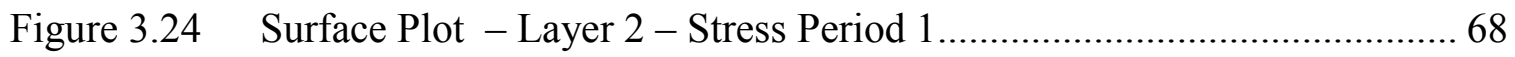

Figure 3.25 Longitudinal Profile - Layer 2 - Stress Period 1 ................................ 69

Figure 3.26 Surface Plot - Layer 1 - Stress Period 2 ....................................... 70

Figure 3.27 Longitudinal Profile - Layer 1 - Stress Period 2 ................................ 70

Figure 3.28 Surface Plot - Layer 1 - Stress Period 2........................................ 71

Figure 3.29 Longitudinal Profile - Layer 1 - Stress Period 2 ................................ 71 


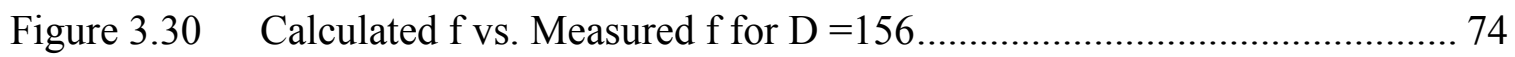

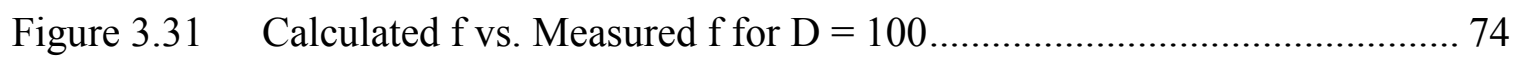

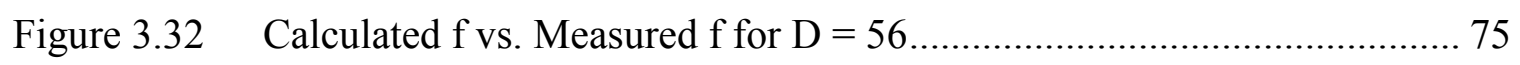

Figure 3.33 Manning's n vs. Reynolds for Calculated Values .................................. 75

Figure 4.1 Loxahatchee Impoundment Landscape Assessment (LILA) location (SFWMD) ................................................................. 76

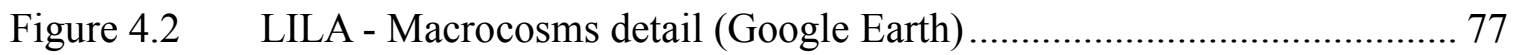

Figure $4.3 \quad$ LILA - M1 Computational Domain ............................................... 79

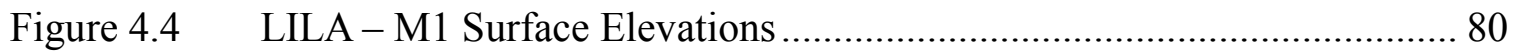

Figure 4.5 LILA - M1 Bed Manning's Coefficient Distribution ............................ 80

Figure 4.6 Scheme for the Tree Island quadrants division .................................... 81

Figure 4.7 Scheme for the estimated \% of Impervious Area................................. 82

Figure 4.8 Scheme for the Well Location at Each Tree Island ............................... 84

Figure 4.9 Comparisons between Measured and Simulated Stages from the Pre-Calibration at Station LILA1O (System Outlet) ............................ 86

Figure 4.10 Velocity values from Pre-Calibration Simulation at time $=1488$

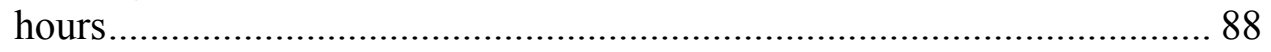

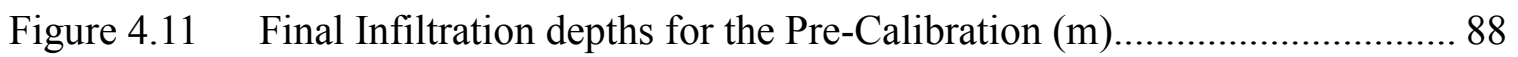

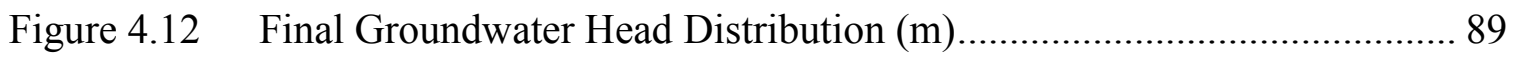

Figure 4.13 Comparison for Groundwater Head at M1W8P Well ............................. 90

Figure 4.14 Comparisons between Measured and Simulated Stages at Station LILA1O (System Outlet) .......................................................... 91

Figure 4.15 Velocity ranges from Calibration Simulation at time $=1224 \ldots \ldots \ldots \ldots \ldots \ldots . . . . . . . .33$

Figure 4.16 Comparisons for Groundwater Head at M1W8P Well........................... 93

Figure 4.17 Final Groundwater Head Distribution $(\mathrm{m})$.......................................... 94 


\section{LIST OF SYMBOLS}

\begin{tabular}{|c|c|}
\hline$A_{1 v}$ & Empirical coefficient of vegetation \\
\hline$B_{l v}$ & Empirical coefficient of vegetation \\
\hline $\mathrm{B}$ & Vegetated cross channel width \\
\hline $\mathrm{C}$ & Chezy's roughness coefficient \\
\hline $\mathrm{C}_{\mathrm{D}}$ & Drag coefficient \\
\hline $\mathrm{C}^{\prime}{ }_{\mathrm{D}}$ & Drag coefficient of vegetation \\
\hline $\mathrm{C}_{\mathrm{RIV}}$ & Hydraulic conductance of a river \\
\hline$d$ & Diameter of the plant \\
\hline $\mathrm{D}$ & Depth of flow for the vegetation resistance analysis \\
\hline $\mathrm{D}_{50}$ & Grain diameter at which $50 \%$ of the sample is finer than \\
\hline $\mathrm{E}$ & Stiffness modulus \\
\hline $\mathrm{F}_{\mathrm{D}}$ & Drag force \\
\hline $\mathrm{f}$ & Darcy-Weisbach's roughness coefficient \\
\hline g & Acceleration of gravity \\
\hline $\mathrm{H}_{\mathrm{RIV}}$ & Free surface elevation at the channel \\
\hline $\mathrm{H}$ & Flow depth / potentiometric head \\
\hline$h_{i, j}$ & MODFLOW-2005 ground water head level \\
\hline h' & Non bending plant height \\
\hline I & Inertia modulus \\
\hline $\mathrm{i}$ & Rainfall intensity \\
\hline
\end{tabular}




\begin{tabular}{|c|c|}
\hline $\mathrm{K}$ & Hydraulic conductivity \\
\hline $\mathrm{K}_{0}$ & Coefficient of the plant \\
\hline $\mathrm{k}$ & Deflected plant height \\
\hline $\mathrm{L}$ & Length of the channel reach \\
\hline M & Vegetation density \\
\hline MAE & Mean absolute error \\
\hline MRE & Mean relative error \\
\hline $\mathrm{n}$ & Manning's roughness coefficient \\
\hline$n_{b}$ & Manning's coefficient for vegetation roughness \\
\hline $\mathrm{p}$ & Pressure \\
\hline Q & Flow rate \\
\hline $\mathrm{Q}_{\text {RIV }}$ & Infiltrated flow rate for channel \\
\hline $\mathrm{R}$ & Recharge rate \\
\hline $\mathrm{R}_{\text {Вот }}$ & Elevation of the bottom of the channel \\
\hline S & Wetted area \\
\hline $\mathrm{S}_{\mathrm{V}}$ & Vegetated area \\
\hline$S_{\mathrm{f}}$ & Friction slope \\
\hline $\mathrm{S}_{\mathrm{o}}$ & Bed slope \\
\hline $\mathrm{S}_{\mathrm{s}}$ & Specific storage \\
\hline se & stem separation \\
\hline s & Length of vegetation perpendicular to flow \\
\hline $\mathrm{T}$ & Transmissivity \\
\hline $\mathrm{T}_{\mathrm{V}}$ & Height of vegetation \\
\hline
\end{tabular}




\begin{tabular}{ll}
$\mathrm{U}$ & \multicolumn{1}{l}{ Time } \\
$\mathrm{U}^{*}$ & Depth average velocity \\
$\mathrm{V}$ & Shear velocity \\
$\mathrm{W}$ & Velocity \\
$\mathrm{W}_{\mathrm{n}}$ & Volumetric flux per unit volume \\
$\gamma$ & Width of channel reach \\
$\rho$ & Specific weight \\
$\lambda$ & Density
\end{tabular}




\section{LIST OF ACRONYMS AND ABBREVIATIONS}

\begin{tabular}{ll} 
CLM-hybrid & Common Land Model \\
CSL & Canopy Shear Stress \\
CERP & Comprehensive Everglades Restoration Plan \\
DBHYDRO & District Data Base Hydro \\
EDEN & Everglades Depth Estimation Network \\
EPA & United States Environmental Protection Agency \\
EFDC & Environmental Fluid Code \\
ENP & Everglades National Park \\
ENR & Everglades Nutrient Removal Model \\
EWHM & Everglades Wetland Hydrodynamic Model \\
FEMA & Federal Emergency Management Agency \\
FLDOT & Florida Department of Transportation \\
FLO-2D & Fullerton, Lenzotti and O'Brien 2D Model \\
GWS & Ground Water System Package \\
GSFLOW & Ground-Water and Surface-Water Flow Model \\
HSE & Hydrologic Simulation Engine \\
InSAR & Interferometric Synthetic Aperture Radar \\
JERS-1 & Japanese Earth Resources Satellite \\
LILA & Loxahatchee Impoundment Landscape Assessment \\
MODFLOW & Modular Three-Dimensional Finite-Difference Groundwater Flow Model \\
NAD83 & North American Datum 1983 \\
\hline
\end{tabular}




$\begin{array}{ll}\text { PRMS } & \text { Precipitation-Runoff Modeling System } \\ \text { SAR } & \text { Synthetic Aperture Radar } \\ \text { SCS-CN } & \text { Soil Conservation Service - Curve Number } \\ \text { SFRSM } & \text { South Florida Regional Simulation Model } \\ \text { SFWMM } & \text { South Florida Water Management Model } \\ \text { SOFIA } & \text { South Florida Information Acces } \\ \text { SWIFT2D } & \text { Surface-Water Integrated Flow and Transport Two Dimensional Model } \\ \text { USCOE } & \text { United States Corp of Engineers } \\ \text { USGS } & \text { United States Geological Survey } \\ \text { WCA-1 } & \text { Water Conservation Area 1 } \\ \text { WHIMFLO-2D } & \text { Wetlands Hydrology Integrated Model }\end{array}$




\section{INTRODUCTION}

\subsection{Background}

Several definitions apply to wetlands. Cowardin (1979) states that wetlands are lands where saturation with water is the dominant factor determining the nature of soil development and the types of plants and animal communities living in the soil and on its surface. The United States Environmental Protection Agency (EPA) defines wetlands as those areas that are inundated or saturated by surface or ground water at a frequency and duration sufficient to support, and that under normal circumstances do support, a prevalence of vegetation typically adapted for life in saturated soil conditions. For the Florida Department of Transportation (FLDOT), wetlands are those areas where the water table is at, near or above the land surface for a significant portion of most years. All the definitions imply that wetlands derive in a wide group of landscapes that will be characterized by the differences in soils, topography, climate, hydrology, water chemistry, vegetation and also human activity and can be found from the tundra to the tropics and on every continent except Antarctica.

Wetlands are very sensible environments that can react even to the smallest changes. Due to their characteristics, wetlands have a vital importance for the environment. Wetlands have the capacity to serve as a filter for the removal of pollutants, as the same time that represent an important habitat for vegetation due to the nutrients that can be found in the sediments. The vegetation provides food for animals in land as well as in the water. Therefore, wetlands are natural wildlife reserves vital for the preservation of species. For human life, wetlands serve not only as recharge for ground 
water supplies but also as temporary storage area for the excess of water produce in storms, protecting nearby settlements of possible flood damages.

There are several classifications of wetlands that will depend on specific characteristics like hydrodynamics and/or vegetation. The Environmental Protection Agency of the United States (EPA) classifies wetlands as Marshes, defined as areas frequently or continually inundated with water, characterized by emergent soft-stemmed vegetation adapted to saturated soil conditions. Swamps, defined as any wetland dominated by woody plants. Bogs, characterized by spongy peat deposits, acidic waters, and a floor covered by a thick carpet of sphagnum moss (Bogs are one of North America's most distinctive kinds of wetlands) and Fens that are peat-forming wetlands that receive nutrients from sources other than precipitation.

Hydrological studies on wetlands are vital in order to improve the understanding of the behavior of these important environments and therefore to optimize their use and ensure their conservation. These studies also represent the main source of information for any other types of ecological and biological studies.

In flat wetland locations where there is a very shallow water table and a highly conductive soil, the connection between surface water and groundwater is not only present, but perhaps the key factor dictating the flux of water. Moreover, most models applied so far in the Everglades (and reviewed in this work) use the diffusive wave approximation of the shallow water equations in which the convective and local acceleration terms are neglected, which can be a valid approximation at a regional scale and for cases with relatively high friction, low flow velocities, and shallow flow depths. 
However, this approximation is not capable of simulating backwater and other local effects due high velocity induced by extreme events or some wind-driven conditions.

In addition to the importance of the interaction between surface and ground water, flow in flat wetlands is also highly influenced by the effect of vegetation drag. Most models that are being used to simulate the hydrology of wetlands use the conventional formulas (e.g. Chezy, Manning) for calculating flow velocity because of their simplicity, but it is recognized that these formulas are accurate only in optimal draining conditions similar to the laboratory flume conditions where they initially come from, like regular sections, small slopes and smooth draining (García Diaz, 2005). It is also known that these formulas begin to become less accurate when those conditions start to diverge from the optimal. Flat wetlands are as far as they can from this optimal lab flume conditions, and include irregular shallow sections, slow flows and especially presence of dense vegetation. The influence of the vegetation in flow patterns in this kind of environment has been reported in the literature (e.g. Wilson, 2003, Nepf, 2007, Lee et al., 2004,) and even if conventional formulas may be suitable for regional modeling that only need to represent the general flow patterns, any model that aims to simulate local processes needs to be more accurate in the way it represents the flow pattern. Therefore, a coupled surface - subsurface model that uses the complete non-linear 2D Saint-Venant equations and accounts for frictional stresses due to vegetation drag, and integrates with 3D groundwater mode was developed in this thesis. The resulting model helps to improve the knowledge of the hydrological processes in flat wetlands and the interaction between surface flow and groundwater by simulating more accurately the flow patterns and water balance. 


\subsection{Research Objectives and Contribution}

The research subject of this dissertation was focused on achieving two objectives. The first objective of this dissertation was to develop an integrated surface - subsurface model by programming, testing and coupling of the USGS MODFLOW-2005 Groundwater Flow Process (GWF) package with the 2D surface water routing model FLO-2D (O'Brien et al., 1993). The coupling includes the necessary procedures to integrate both models as a single computational software system that will be called WHIMFLO-2D. The second objective was to include an improved physical formulation of flow resistance through vegetation in shallow waters (e.g. Wilson, 2003, Nepf, 2007, Lee et al., 2004) while using classical methods (e.g., Manning, Chezy, Darcy-Weisbach) to calculate the flow resistance for the canals and deeper waters. An illustration exercise to illustrate the potential of the developed WHIMFLO-2D with the improved vegetative flow resistance approach was developed in an existing field site, including a preliminary calibration using ground-based data.

The research outcome of this dissertation has resulted in a coupled model for surface and groundwater flow that represents an important improvement in wetlands modeling through more realistic process formulations that included integrated surfaceground water hydrology and vegetation resistance to flow. The real wetland illustration case has shown the capability of the model to simulate the surface and ground water behavior with practicable accuracy. 


\section{LITERATURE REVIEW}

\subsection{Previous Experiences on Modeling Wetlands Hydrology}

Several efforts have been taken to model the hydrology of wetlands, such as the Everglades in Florida. Lin \& Shih (1979) made an early attempt by adapting and modifying the Receiving Water Quantity Model (EPA, 1971) in order to make it applicable to analyze the impact of additional inflow produced by different backpumping cases in the Everglades Water Conservation Areas, a man managed impoundment areas created with the intention of restore the natural hydroperiods and hydrological conditions of the Everglades National Park. The model was modified to include among others, the Manning's roughness coefficient, the depth of flow, the width of channels through marsh areas, the rainfall input, and the seepage rate. Lin's model was a surface model and did not include the effects of groundwater flows.

The South Florida Water Management Model (SFWMD, 2005) is a regional-scale model developed to simulate the hydrology and water management from Lake Okeechobee to Florida Bay. The model uses a rectangular grid with a spacing of two by two miles and covers an area of 7600 square miles (Figure 2.1). The SFWMM model takes into account the hydrologic cycle by including rainfall, evapotranspiration, infiltration, overland and groundwater flow, canal flow, canal-groundwater seepage, levee seepage and groundwater pumping. MacVicar et al. (1984) present in the "South Florida Water Management Model Documentation Report" the application for the South Florida Lower East Coast. The model uses a diffusion flow approximation based on Manning's equation. Homogeneity in physical as well as hydrologic characteristics 
is assumed within each grid cell and a fixed time step of one day is used. There is no exchange between surface water and groundwater routines within a time step. The latest version of the SFWMM is the 5.5 from November 2005.

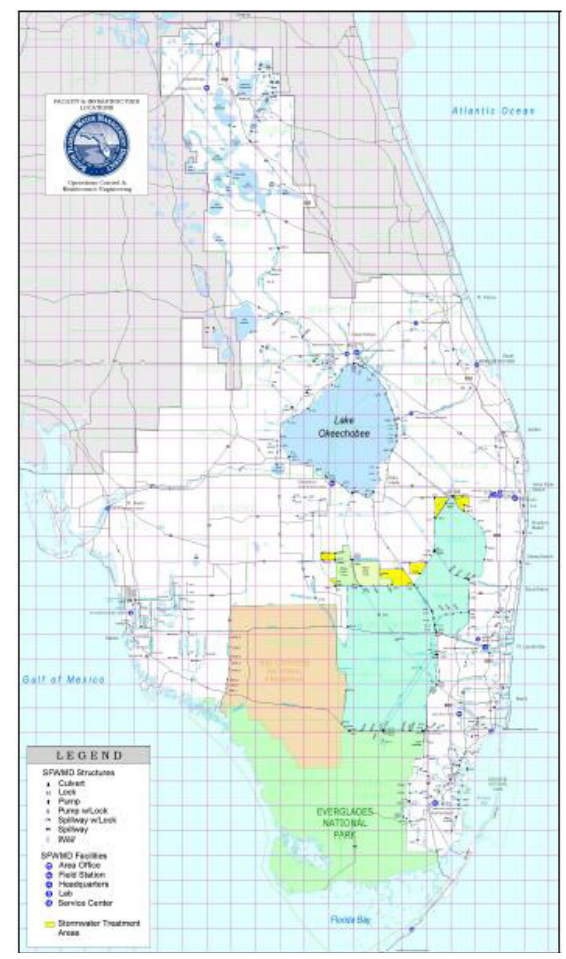

Figure 2.1 SFWMM Grid for the Central and Southern Florida Region (SFWMD)

In order to understand how hydroperiods were affecting the vegetation on the WCA-1, Richardson et al. (1990) developed a surface hydrological model based on the 1989 Carl Walters's Everglades hydrologic model. This cell based model was implemented at the WCA-1 using a polygon with a resolution of 3,000 $\mathrm{ft}$ by $3,000 \mathrm{ft}$ (914.4 m) and used Manning's equation to calculate flux between cells. A sixteen years time period was used to run the model and any cell with a water level below 0.075 feet was considered a dry cell. Three gages: G 1-7, G 1-8 and G 1-9 (Figure 2.2) were use to validate the results. The monthly hydroperiod variance for the 16 year period showed that the northern part has a higher variance than the southern part. Results showed that during 
dry years the north end of the refuge has the tendency to stay dry for long periods, while the south part always tends to present water in the marshes.

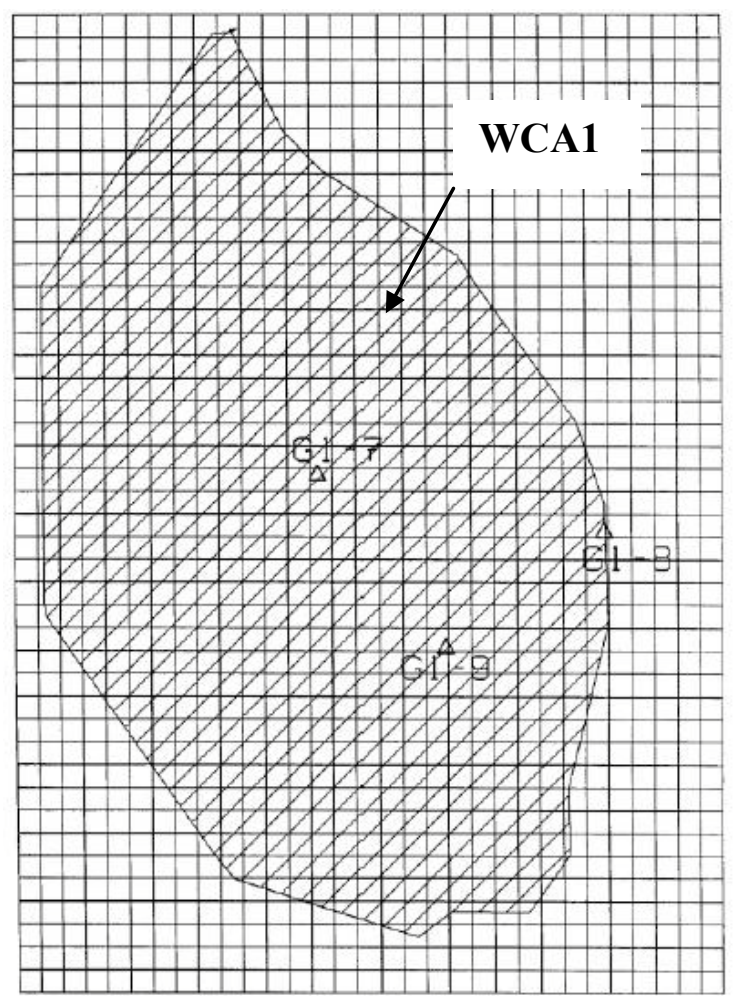

Figure 2.2 Richardson Model: Grid for the hydrological model of WCA 1 (Richardson et al., 1990)

Lal et al. (1998) developed a weighted implicit finite volume model called Hydrologic Simulation Engine (HSE) that was incorporated into the South Florida Regional Simulation Model (SFRSM) to simulate overland and groundwater flow in the Everglades National Park. The model engine used the diffusion approximation when solving simultaneously the Manning equation for overland flow and the Darcy equation for ground water flow. The model was calibrated using a conjugate gradient method developed also by Lal, during which local crop coefficients in the evapotranspiration equations and the Manning roughness coefficients were adjusted to reflect local water level variations more accurately in the output. The computational domain includes the 
southern part of the Everglades National Park (ENP) (Figure 2.3). Results showed that values from the model compare better to the measured values at the center of the natural areas than in the areas near urban influence.

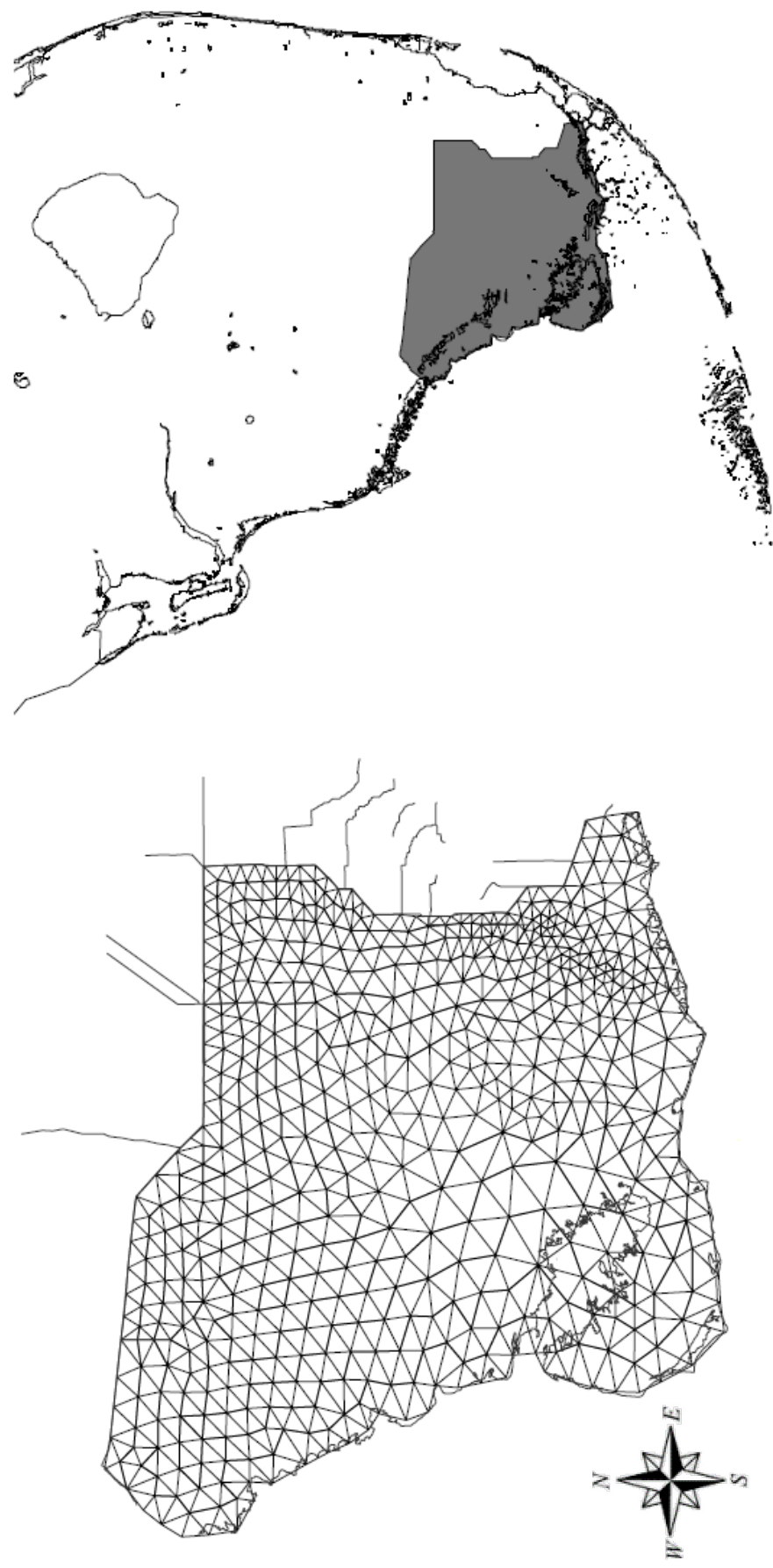

Figure 2.3 HSE Model: Location and Mesh Discretization (Lal et al., 1998) 
Moustafa et al. (2000) calibrated the Everglades Wetland Hydrodynamic Model (EWHM) to the Everglades Nutrient Removal Model (ENR) which is a component of the Everglades protection effort that is developed by the SFWMD and that has the objective of re-route runoff from the agricultural areas through canals in order to be treated inside the project wetlands. The EWHM is a modified version of the environmental fluid code (EFDC) developed at the Virginia Institute of Marine Science. The model solves the depth integrated momentum and continuity equations in two dimensions and calculates vegetation resistance and bottom stress internally. The model contains no adjustable constants, and requires no computational fitting of parameters to observed data, as is necessary in many previous obstructed flow schemes. The study was set up because despite of the importance of water motion to the life processes of aquatic vegetation there is an existing lack of basic knowledge regarding the hydraulic properties of surface flows through dense marsh vegetation. The objective was to calibrate the EWHM to the ENR Project using field data collected from April 3, 1995 through July 1, 1996. The study included a 16 square kilometers area part of the Everglades Nutrient Removal Project located west of West Palm Beach, bordering the northwest corner of WCA-1. The model was able to successfully reproduce observed water depths coming from daily inflows but underestimate values from extreme events.

Bolster and Saiers (2002) developed a two dimensional diffusion model for surface-water movement with the intention of helping to fulfill the lack of mathematical models for describing the surface-water movement through wetlands. The model used a predictor-corrector finite difference scheme to solve the diffusive approximation of the Saint Venant equations. The model assumed that the evaporation rate is uniform, the 
water exchanges between the subsurface and surface are negligible and that the groundwater surface slope was uniform. The study area was a region of Shark River Slough that measure $27 \mathrm{~km}$ in length and $10 \mathrm{~km}$ in width (Figure 2.4). Data sets from 1996 to 1998 were used for calibration and modeling. The model found agreement between measured and modeled hydraulic heads and also was able to reproduce the short temporal fluctuations in head at the monitoring sites.

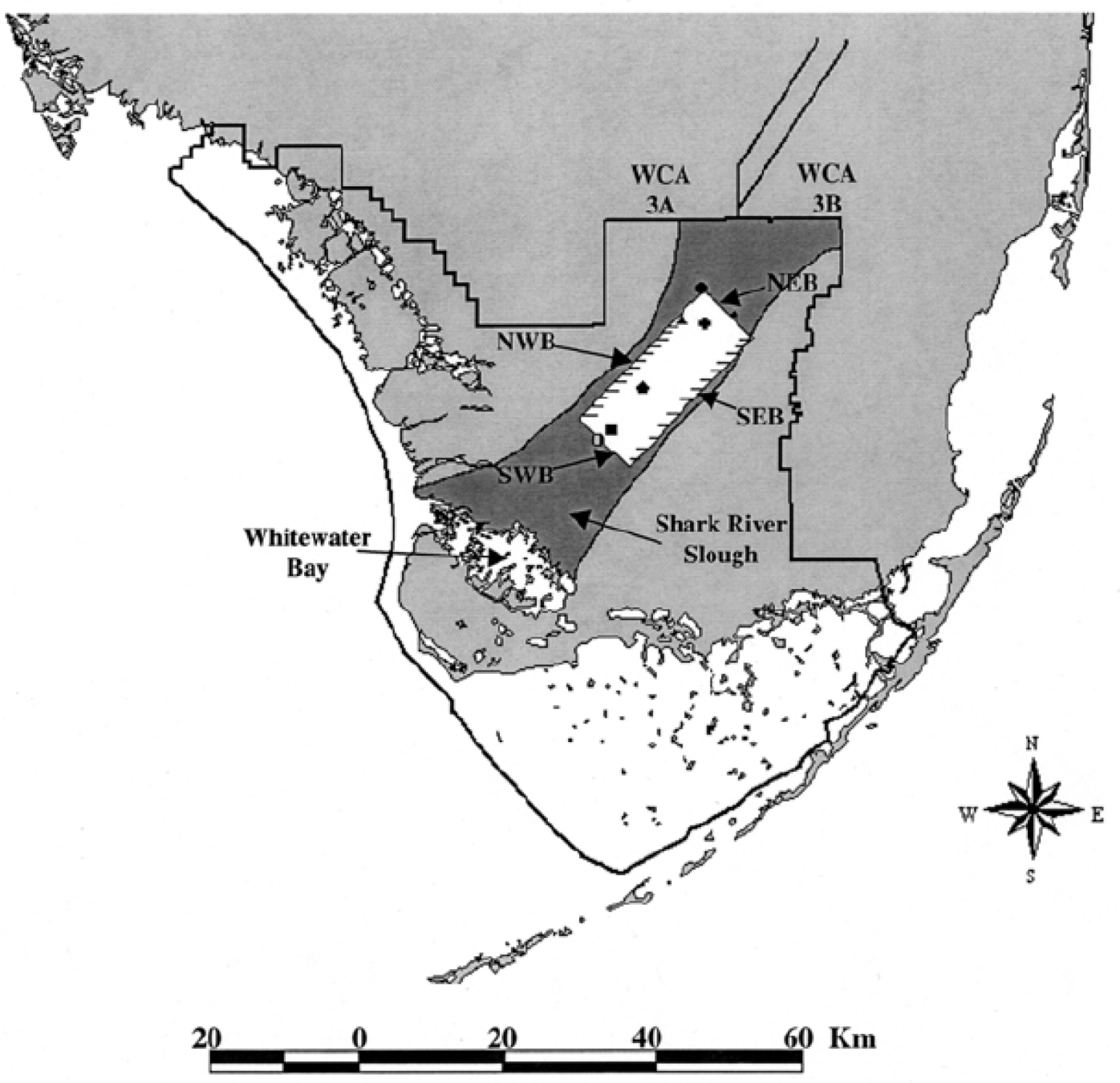

Figure 2.4 Bolster and Saiers Model: Study Area Location (Bolster et al., 2002) 
Welter (2002) applied the South Florida Regional Simulation Model (SFRSM) to the WCA-1. The model uses triangular cells with an average size of $650 \mathrm{ft}$ and takes in account overland, canals and a simplified groundwater flow with the assumption that overland processes were more important. Welter used data from 1988 to 1990 for calibration and from 1991 to 1994 for validation. Results showed agreement between measured and calculated values and the differences were attributed to the limited number of gauging stations inside the refuge.

Wdowinski et al. (2004) used Interferometric Synthetic Aperture Radar (InSAR) to capture dynamic water level topography in order to produce snapshots of wetlands sheet flow with high accuracy (5 to $10 \mathrm{~cm})$. The Interferometric processing of L-Band SAR data can be used to detect changes in wetland by using data acquired at different times. The methodology was applied to the Water Conservation Areas of the Everglades, South Florida. Data of three SAR passes over South Florida at the beginning, middle and end of the wet season of 1994 were used. Absolute water levels were calculated by using the December data, which represent a period of negligible water flow and that was assumed to be the datum, to obtain water levels with the data from August and June. A 1D linearized diffusion flow model was used to validate the results. The model results showed that even if some differences appeared between the observations, there was a good agreement between the observed stage, the InSAR and the best-fit modeled water levels (Figure 2.5) and hence is was demonstrated that the L-band InSAR can be used to estimate water levels in wetlands. Results also suggest that some of the differences may be influenced by the effect of vegetation that was not taken into account in the model. 
Langevin et al. (2005) coupled the SWIFT2D surface-water and transport model with the SEAWAT variable-density groundwater model to represent two-dimensional overland flow and three-dimensional fully saturated ground-water flow. SWIFT2D uses the two dimensional vertically averaged complete form of the Saint Venant equations, which allows better horizontal resolution at the cost of vertical resolution. The SEAWAT is based on the know groundwater model MODFLOW-2005 and uses a variable-density form of the fully saturated, three-dimensional ground-water flow equation. The two models were explicitly coupled with a one-time step lag using a variable-density form of Darcy's Law for flow exchange and non-diffusive salt flux between models. Square cells of $1000 \mathrm{ft}(305 \mathrm{~m})$ were used to apply the model in a 900 square kilometers area of the southern Everglades and northeastern Florida Bay with the purpose to evaluate the dominant hydrologic processes, including surface-water and ground-water interactions, and to evaluate the mechanisms of freshwater delivery to northeastern Florida Bay. The period from 1996 from 2002 was used to evaluate the effect of hydrologic processes and to simulate overtopping of the coastal embankment and submarine ground-water discharge as mechanisms for delivering freshwater from the coastal wetlands into Florida Bay. Comparison between measured and simulated values showed that despite of some limitations, the model represent very well the hydrologic processes in the wetland and in the aquifers. Results showed also that the embankment overtopping is infrequent but possible due to tropical storms.

Schaffranek et al. (2006) used the coupled SWIFT2D-SEAWAT model (Langevin et al., 2005) in an extended area in order to include the entire wetlands and coastal ecotone of ENP to evaluate inflows to the Gulf of Mexico. The model used a rectangular 
grid of 194 east-west and 174 north-south 500-m-square cells. The model domain extended from the northern Florida Bay in the south to a northern boundary along US-41 starting west from Miami. Inflows to the model domain were regional rainfall, and wetland and coastal boundary fluxes. Vegetation classifications were assigned from 1997 Landsat Thematic Mapper images to evaluate hydrologic processes and empirical coefficients in the model. Four month period from May to August 1999 were used to demonstrate the model capability. Result showed that flow direction, water depths and all the main flow features were reasonably simulated by the model.

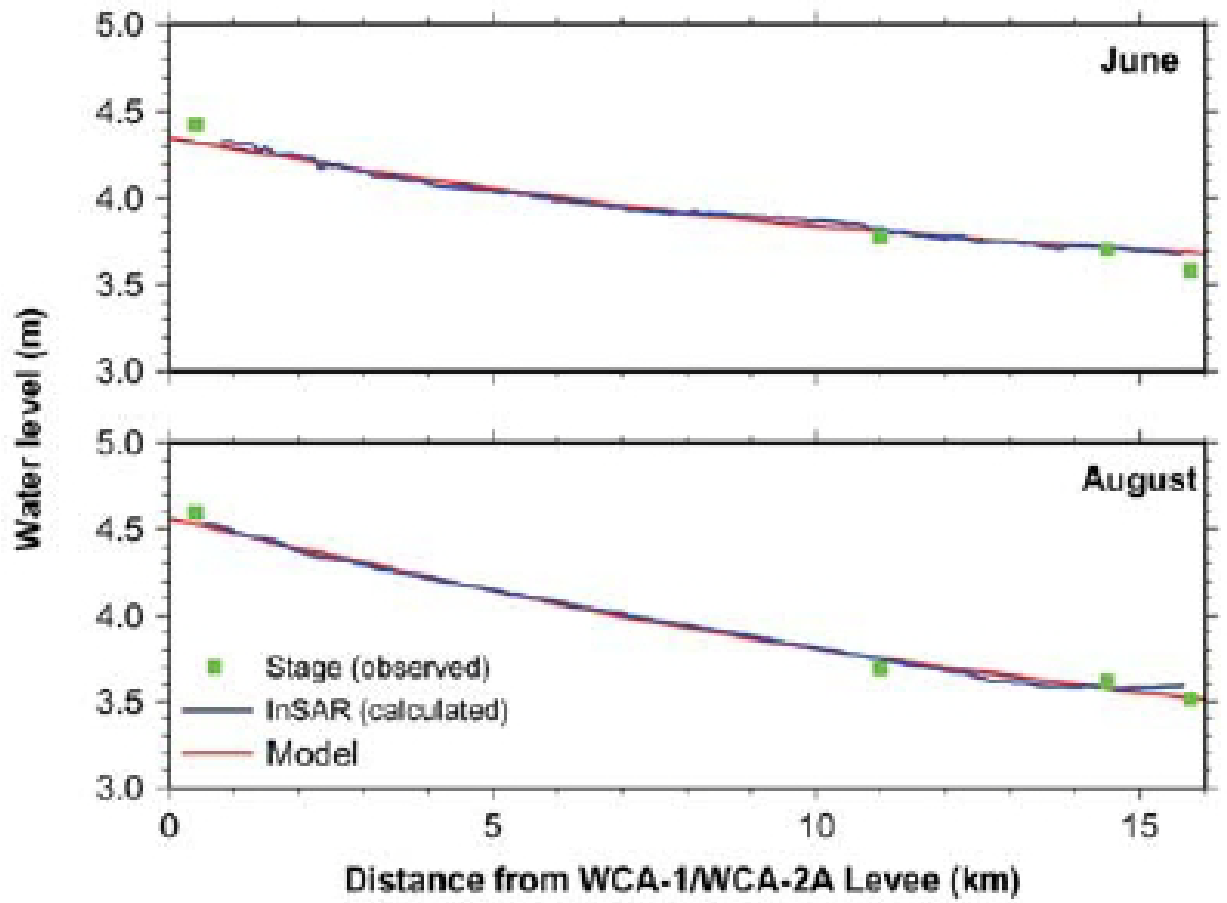

Figure 2.5 Comparison Between Observed, InSAR and Modeled Water Levels (Wdowinski et al., 2004)

Wdowinski et al. (2007) used L-band SAR data to study water level changes and derived hydrological conditions in the Everglades wetlands using data acquired during the years 1993 to 1996 by the Japanese Earth Resources Satellite (JERS-1). Two tracks 
with seven repeat orbits were used. Nine strip interferograms of South Florida were produced showing phase changes between 44 and 396 days. Interferograms showed good coherence throughout the area but the coherence decreased with the increasing of the time-spam, so, the year-long interferograms showed a significant area with no coherence. Coherence showed also to be higher in woody wetlands and urban areas and lower in herbaceous wetlands and agricultural areas. Stage and flow data were used to validate the InSAR observations. Results from this analysis showed the possibility to produce high spatial resolution maps of surface water level changes with a good agreement between the InSAR and the in site stage data.

\subsection{Recent Surface-Groundwater Coupled Models}

Maxwell and Miller (2004) developed a fully integrated model by coupling the Common Land Model (CLM-hybrid) which was a land surface based model that included soil-snow-vegetation biogeochemical features with ParFlow, a groundwater flow code developed by the Lawrence Livermore National Laboratory in California that can solve steady state saturated conditions and transient conditions with variable saturation. For this coupling, models were connected through the root zone layers (Figure 2.6). Infiltration, evaporation and root zone drainage were calculated by the CLM while the ParFlow managed the groundwater flow. The authors used real weather data to compare runoff and soil saturation results obtained by using the couple model with results obtained from the Common Land Model (CLM) that only take in account water loss through evapotranspiration. Results from the simulations showed important differences in runoff and in soil saturation. 


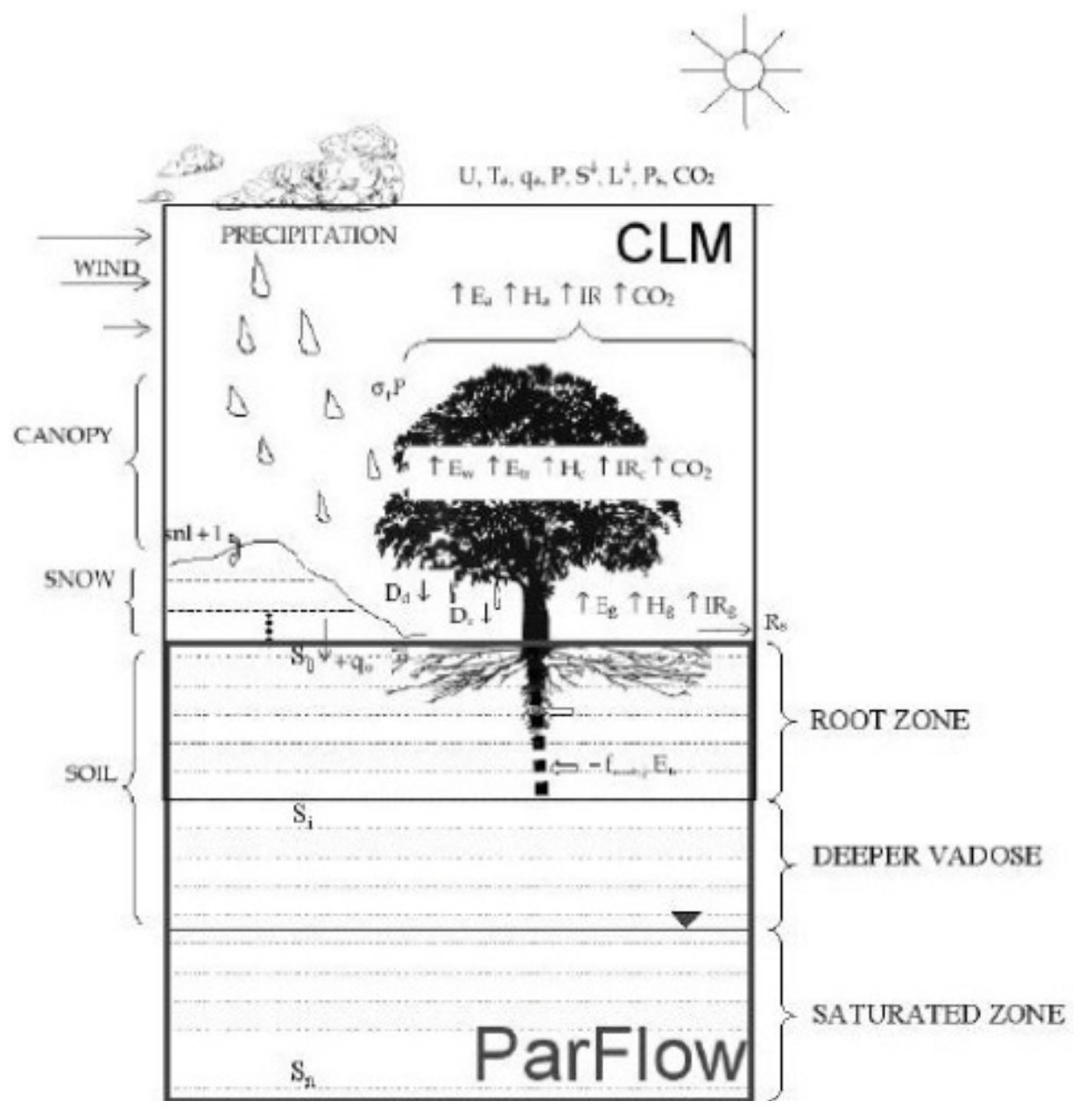

Figure 2.6 CLMPar Model scheme (Maxwell and Miller, 2004)

Panday and Huyakorn (2004) presented a fully coupled model that included subsurface, overland and channel flow. The two dimensional diffusion wave approximation to the Saint Venant equations was used for the overland flow, the three dimensional Richard's equation was used for the variable-saturated subsurface flow and the one dimensional diffusion wave approximation to the Saint Venant equations was used for the channels. The model included losses due to depression and obstruction storages and the coupling was reached by using fully coupled and time iterative linked approaches. Model domain was discretized using centered block finite difference scheme 
with square cells (Figure 2.7). Simulations using MODHMS benchmarks were realized and results for coupled system showed that convergence problems for the iterative time linked approach appeared for simulations with high fluxes interchanges.

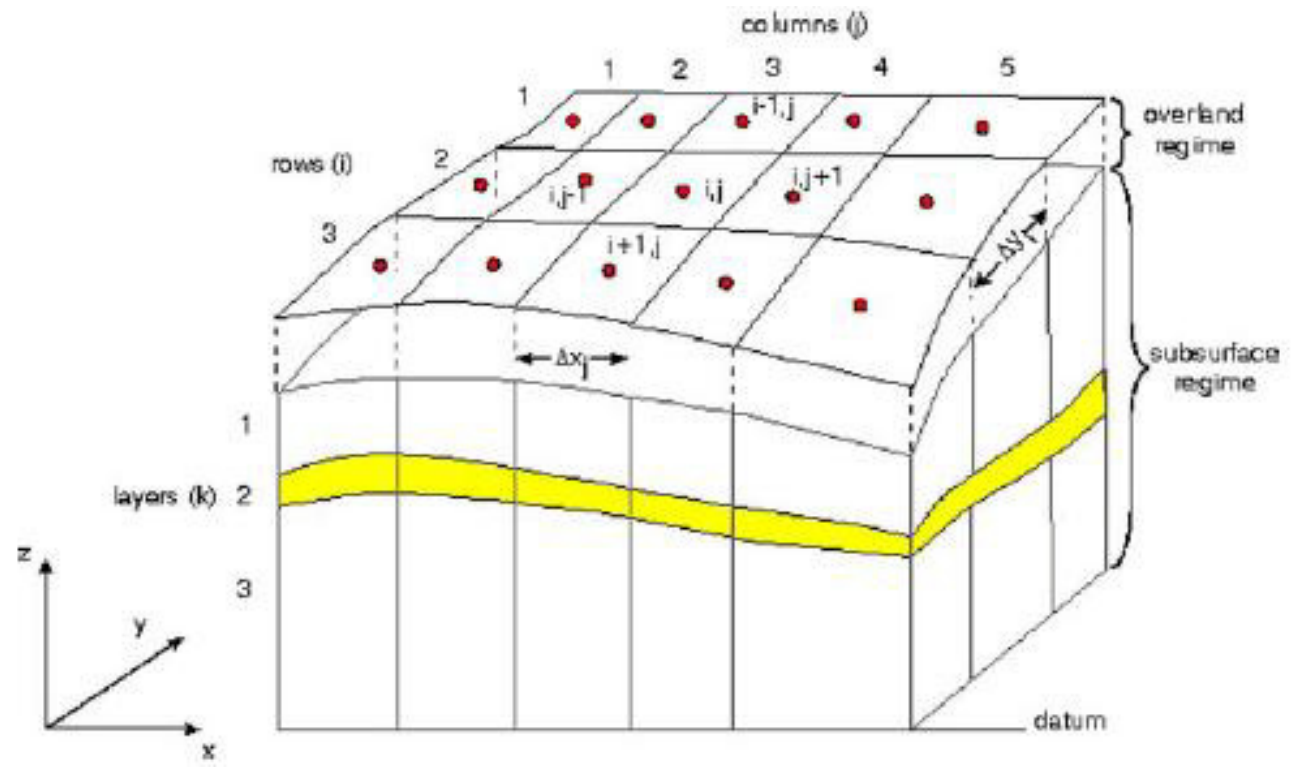

Figure 2.7 Panday's model spatial discretization (Panday and Huyakorn, 2004)

Zhiguo He et al. (2008) developed a couple finite volume model to simulate two dimensional surface and three dimensional groundwater flows. Surface water was simulated by using the two dimensional diffusion wave approximation to the Saint Venant equations while groundwater flow was simulated by using the mixed form of Richard's equation for variable saturated flow. The system was discretized using finite volumes with rectangular hexahedral cells for space and an implicit scheme for time. Flow exchange was possible from subsurface to surface and vice versa. The model was tested using experimental and field data bringing very good results with errors less the $18 \%$ for shallow water flow.

Markstrom et al. (2008) developed for the USGS the Coupled Ground-Water and Surface-Water Flow Model (GSFLOW) by coupling the Precipitation-Runoff Modeling 
System (PRMS) with the Modular Ground-Water Flow Model (MODFLOW) but allowing the use of original model packages from each model. The model was intended to work on daily bases, and for that reason, step times smaller than one day were not allowed, this had the disadvantage of producing errors for the so called near-land surface flows. Flows from floodplains were calculated by PRMS while Flows from Lakes and streams were calculated by MODFLOW-2005. Model was calibrated and validated using real data from the Sagehen Creek watershed near Truckee, California. Data from 1981 to 1995 was used and result showed a very good fit between observed and modeled values for long period simulations.

\subsection{Flow Resistance Due to Vegetation}

Because of its simplicity and the wide range of demonstrated validity, almost all of the actual hydrological models use bulk energy loss coefficients (e.g., Manning's $n$ o Chezy's $C$ ) for calibration and calculations. Even though vegetation could be considered as a type of superficial roughness, depending on its high, density, distribution and type, it can significantly reduce the capacity of a canal, increasing flow resistance, change backwater profiles and modify sediment transport and deposition (Yen, B.C., 2002). Recently, some field, laboratory and numerical studies have been made in order to improve the understanding of the effect of vegetation in the flow by relating some resistance parameters, like drag coefficients and Manning's n values to plant properties, including height, density and flexibility.

Arcement and Schneider (1990) presented a guide with methodologies to obtain Manning's coefficient for floodplains. They revised the Modified Method, obtained by 
adding additional terms like surface irregularities and vegetation to a base Manning's coefficient and the Vegetation Density Method; this methodology was based in the determination of the density of the vegetation based in the height, density and resistance as a function of water depth. Two ways to obtain the vegetation density were presented: the direct and indirect Petryk and Bosmajian method (Petryc and Bosmajian, 1975) and the Photography method.

Fathi-Maghadam and Kouwen (1997) developed a model to estimate the roughness in floodplains with nonrigid and unsubmerged vegetation. Authors used the concept of drag force originally introduced by Petryc and Bosmajian (Petryc and Bosmajian, 1975) in order to introduce the effect of vegetation into the common concept of friction factor. Laboratory experiments were used to verify the model and to establish the effect that flow depth had on roughness coefficients and a relationship was obtain to estimate the variations of Manning's $n$ due to flow depth and vegetation depth.

Wu, Shen and Chou (1999) studied the effect that flow depth has on roughness coefficient related with unsubmerged and submerged vegetation. They used the concept of drag force to introduce the effect of vegetation and developed expressions to relate drag coefficients with Manning roughness coefficient for unsubmerged and submerged conditions. The analysis was conducted using experimental data and final values for drag coefficients were obtained by using regression analysis.

Fischer-Antze et al. (2001) computed the velocity distributions in channels partially covered with vegetations using a three dimensional model. They solved the three dimensional Reynolds averaged Navier-Stokes equations with the continuity equations. The effects of submerged vegetation were taken into account as a drag force and its 
contribution was added as a source term. The model was then compared with laboratory experiments. All their tests gave fairly good correspondence between computed and measured velocity profiles. The authors also remark the fact that this approach allows to take in account the effects of vegetation over the whole water depth.

Yen, B.C. (2002) presents a comprehensive review of the flow resistance in channels starting from the boundary layer theory. For the case of vegetated channel resistance the author emphasize the fact that the presence of vegetation increases the flow resistance, change the backwater profiles and modifies sediment transport and deposition. This review also covers the effect of vegetation on the shear velocity depending on the water depth. If the submergence of vegetation is less than half of the flow depth, the universal velocity distribution laws such as the logarithmic distribution may prevail in the upper non-vegetated part of the depth, so the apparent shear velocity may be determined indirectly from the velocity distribution. In the same way, for high submergence or predominant flexible vegetation, the drag of the vegetation and not the bed shear will be the predominant resistance factor. Finally, this review also showed that a better way to proceed in vegetated channels could be to manage the cross section or reach as a composite channel and obtain a different resistance coefficient for the vegetated part, after what the final resistance coefficient could be computed using one of the composite channel resistance equations (Figure 2.8.a and Figure 2.8.b). 


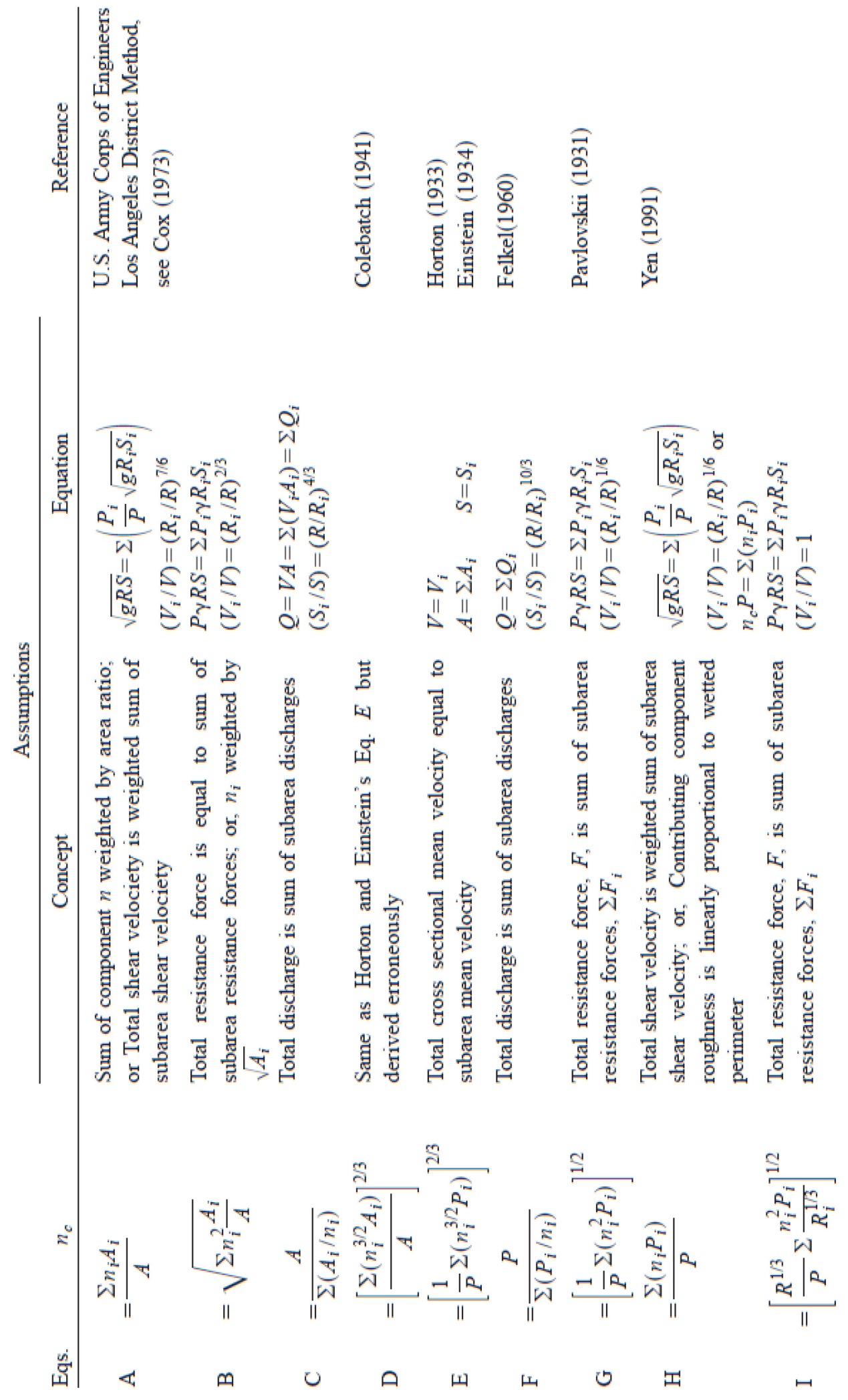

Figure 2.8.a Composite Channel Resistance Equations (Yen, B.C., 2002) 

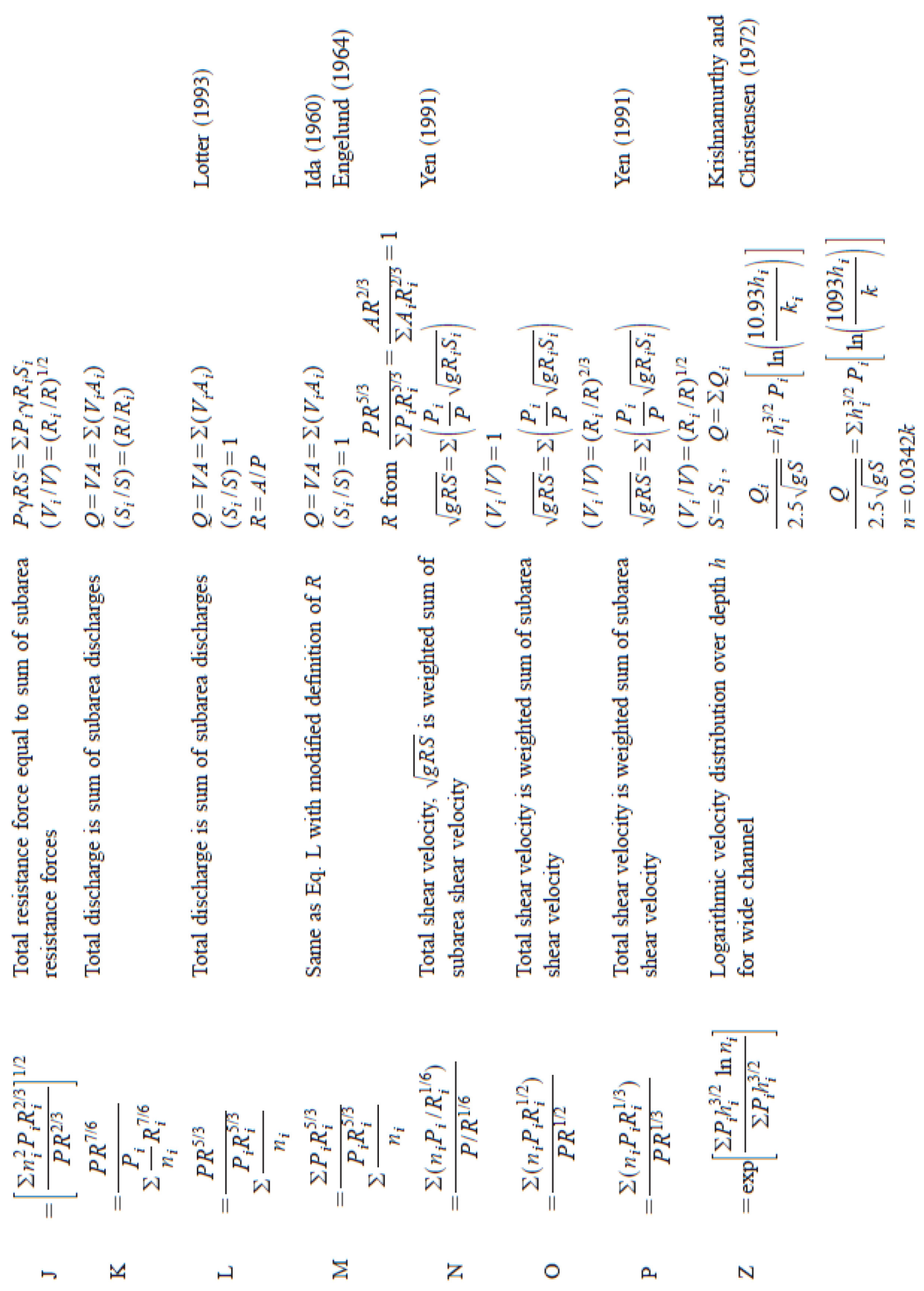

Figure 2.8.b Composite Channel Resistance Equations (Yen, B.C., 2002) 
Wilson et al. (2003) developed laboratory experiments in order to demonstrate the influence of vegetation for the determination of the flow fields. Replica plants were scaled using the Froude law and reduced to a scale of 1/10 and were divided in two groups, one with foliage in order to simulate the aquatic species and frond canopies, and one without foliage in order to simulate long grasses. The uniform flow experiments were conducted in a flume $0.5 \mathrm{~m}$ in width and $10 \mathrm{~m}$ in length, with longitudinal bed slope set at 1/1,000. Results showed that in both cases at the plant layers (with and without foliage), the mean flow was retarded and did not followed the logarithmic law profile. Meanwhile, turbulence was higher in the presence of the rods alone, lowers for the frond canopy simulation and did not influence the upper surface regions for higher water depths.

Velasco et al. (2003) performed experimental test using plastic plants seeded in gravel and sand beds in order to analyze the hydro-mechanic interaction between the flow and flexible plants. Experiments were performed in a $20 \mathrm{~m}$ long and $1 \mathrm{~m}$ wide concrete flume. Gravel particles were added in order to establish a Manning-Stickler friction factor $\mathrm{n}=0.025$ while sand particles were uniform with a $\mathrm{D}_{50}=1 \mathrm{~mm}$. Plastic plants were 0.15 $\mathrm{m}$ high and had thin strips attached to simulate foliage. Several vegetation densities were simulated as well as different discharges in order to produce different submergences of the plants. Results showed that the relative roughness of flexible plants decreases for increasing Reynolds numbers or hydraulic power (relation between the velocity and the hydraulic radius); it was also observed that velocity also reduced the effect of the plant density. Experiments also showed that while for non vegetated test, vertical stresses were dominant and lateral stresses were negligible, for vegetated test the transversal test increases and overcome the vertical ones. 
James et al. (2004) introduced an alternative equation to calculated flow that take in account the effect of resistance due to emergent vegetation. Several experiments were carried out to analyze the effects of stem density, suspended sediment and rigid vegetation. Values obtained for drag coefficients were then compared with numerical values obtained by using a formulation based on the concepts of drag force, bed shear and friction factor. Values obtained conform very well with the experimental data and shows that drag force diminish with flow depth and velocity.

Lee et al. (2004) studied the laminar, free surface flow through emergent inland vegetation using vertically averaged data collected by the United State Geological Survey (USGS) in flume experiments and at field sites in the Everglades National Park in Florida. The main objective was to determine the vertically averaged drag coefficient as a function of vegetation characteristics. In this study the viscous dissipation and the vegetation resistance were lumped in one term that was applied as an additional term to the momentum equation. The Reynolds number included in the vegetation drag coefficient included an exponent that depends on the biomechanical properties of the vegetation. Coefficients were obtained empirically from measurements in the flume and the applied in the field. The regression analysis showed that the coefficients fit the data well (Figure 2.9). The results showed, for low Reynolds numbers, the inverse relationship between the drag coefficient and the stem spacing.

Helmio (2005) developed a one dimensional unsteady flow model based on the Saint Venant equations to estimate hydrodynamics parameters in main channels and floodplains simultaneously. The model use Nuding's method to obtain the friction resistance parameters. The model was divided in two modules; the first module was a 
preprocessing program that managed the field data and subdivides the channel cross section into six geometric components with five to seven different resistance parameters on the floodplains and one in the main channel. The second module was the unsteady flow model which was based on the conservative matrix form of the Saint Venant equations. Nuding's method was based on the uniform flow equation and was used to obtain the composite friction factors by using a modification of the Darcy-Weisbach friction factor computed from the Colebrook equation. The procedure also took into account the hydraulic radius of the cross section as composite. The model was applied to the upper river Rhine area and the results showed that the model did take in account the floodplains as an additional boundary resistance instead that just storage areas, however the model underestimate the composite friction factors in vegetated areas for high water depths and overestimate the resistance values for low water depths.

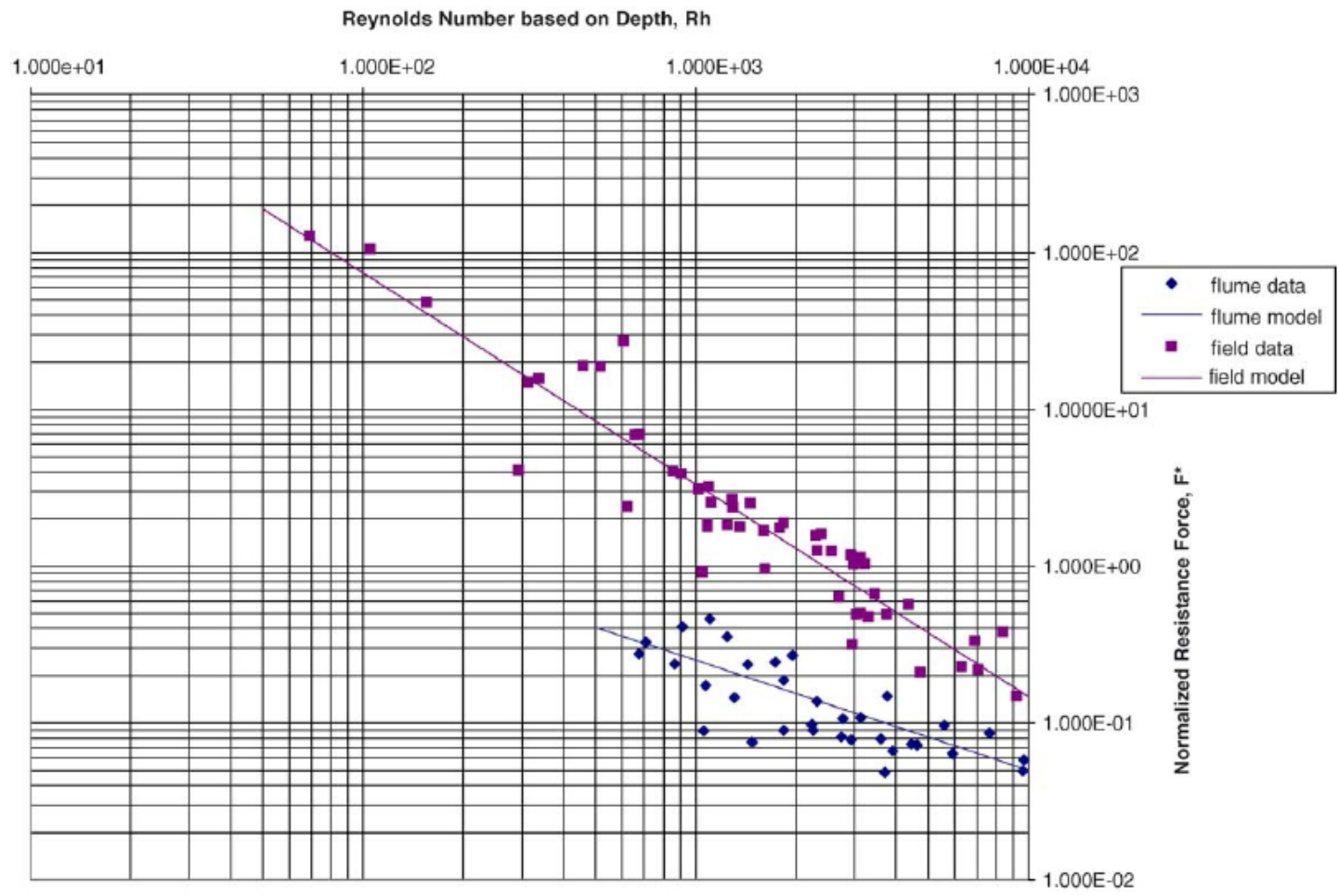

Figure 2.9 Regressions from Flume Data and Everglades Field Data (Lee et al., 2004) 
Carollo et al. (2005) have used experimental data collected in a $14.4 \mathrm{~m}$ long and $0.60 \mathrm{~m}$ wide flume covered with grasslike vegetation in order to test the applicability of Kouwen's method to estimate flow resistance for flexible submerged elements. Kouwen's method is founded on experimental results obtained from model a flume bed covered by strips of plastic material that simulate natural grasslike vegetation and is based on three assumptions; the first indicates that the flow resistance due to the bed in which the vegetation is rooted is negligible if compared with the resistance due only by the vegetation. The second assumption was that the vegetation was uniformly distributed along the bed and the third was that the flow regime was fully turbulent. Results showed that there was a strong relation between the concentration, submergence and the resistance. Also, as can be seen in other works, for a given concentration and for a fixed depth-vegetation height ratio the increasing of the flow velocity implies that the resistance due to vegetation decrease and, thus, the flow resistance increase.

Wilson et al. (2006) analyzed the effect in the computation of the bed shear of different approaches used to calculate the drag force in order to obtain the flow resistance due to vegetation. Two different approaches were applied; the first one used an equivalent diameter for the plant projected area while the second used non-uniform cylinders. Eight trees were used for this study along velocity measurements conducted in the Wienfluss River. Numerical simulations were performed using hypothetical test cases based on the data collected. From the results was observed that compared to the values obtained when using the non-uniform approach, the use of an equivalent diameter resulted in lower computed drag force below mid-tree height due to the underestimation of the projected area and also because the equivalent diameter was less than the actual 
basal diameter (Basal diameter is the diameter measured at the plant base near ground level), the opposite was also expected. In all the study cases the uniform approach resulted in relatively greater velocities in the region close to the bed and lower velocities in the upper region, compared to the non-uniform approach this resulted in a relative difference of $150 \%$ in the computed bed shear stress between the two approaches.

Lightbody and Nepf (2006) developed a method for the estimation of the velocity profile and longitudinal dispersion that included the influence of the vegetation drag. The formulation took into account the fact that when the emergent vegetation is dense enough, the vegetation drag is more important than the viscous or turbulent stress and the influence of the bed is limited basically to the bed bottom. For the developing of the method, emergent aquatic vegetation was assumed as an array of rigid circular stems. Field measurements were carried out at the Plum Island Estuary in Rowley, Massachusetts in order to test the method and the results show good agreement between measured and modeled velocity profiles and even if the measured values were always higher than the modeled, it was demonstrated that the vertical diffusion is related to the stem density.

Nepf et al. (2007) developed a physical model for water renewal within a submerged canopy (area covered by vegetation). The model was based on the region of strong shear created by the discontinuity in the drag and that is located at the edge of a submerged canopy. A canopy shear layer (CSL) was defined to represent the balance between the shear production and the canopy dissipation. Results showed that the canopy drag has a major influence on the water movement, and therefore, on the water renewal. When the drag was small, the shear-scale turbulence penetrates far into the canopy and 
the renewal occurs in a matter of minutes but when the drag is high (dense canopy) the shear-scale turbulence cannot penetrate far into the canopy and the water renewal can take hours.

As could be seen, an important source of uncertainty in simulating the resistance of flow due to vegetation is coming from the fact that even if an important amount of studies about the effect of vegetation in flow resistance can be found, these studies have not been adequately addressed (Jarvela, 2004). In this matter, it can be found that most of these investigations try to implement new forms for the drag coefficient that includes the effect of the Reynolds number based on the depth. This is a repetitive scenario that always returns the same well known conclusion: the effect of vegetation is related with the depth and velocity of flow. All these new expressions are then related with a parameter that involves the presence of vegetation but not much importance is given to it, even if this is the clue factor that needs to be studied. Sometimes, this vegetation factor is used as a calibration constant or a simple relation between wet area and vegetated area without any relation to the type of vegetation and there are only few expressions that involve these variables. 


\section{RESEARCH METHODOLOGY}

\subsection{Model Formulation}

Several models are being applied to wetlands, some of them, as the South Florida Water Management Model (SFWMM) or the South Florida Regional Simulation Model (SFRSM) are conceived to take into account only the natural movement of the flow and for this reason they neglect the inertial terms in the floe equations. Moreover, these are large scale models and need to be very simplified in order to be applied to smaller areas like the WCA-1. Other models such as MIKE SHE/11 that are being applied to the WCA1 can use the fully dynamic approach of the motion equation so the backwater effect that may occur due to the operation of the flow structures could be take into account, but the current application of this model is assuming the overland flow as the dominating process so the groundwater flow is not being taken into account. Finally, independently of the approach used to solve the motion equation, all the models compute the flow resistance using the classical bed friction equations (e.g. Manning, Chezy or Darcy-Weisbach) for the channels and for the marsh despite of the fact that the use of those equations in very shallow waters with vegetation and slow flow velocities can be theoretically and physically not applicable.

An improved understanding of the hydrology of wetlands, and especially in artificially controlled ones, relies on improved accuracy in the quantification and interpretation of all the different processes that take place in flow through emergent vegetation. For this reason, this research focused on the development of a new model capable to simulate the physics of flow through wetlands with spatially and temporally 
varying hydrological conditions. This was achieved by dynamically coupling the surface water routing FLO-2D model (O’Brien et al., 1993) with the USGS MODFLOW-2005 (USGS, 2005) Groundwater Flow Process (GWF).

FLO-2D is a two dimensional free surface flow model based on Cartesian square finite difference grids that is included in FEMA's list of approved hydraulic models for riverine and unconfined alluvial fan flood studies. The model computes flow depths and velocities on each grid and accounts for rainfall, evaporation, hydraulic structures, rivers and canals, hydraulic structures and several other components (Figure 3.1). At this moment, infiltration (losses) to groundwater is calculated using either the SCS-CN procedure or the Green-Ampt method. Channels are simulated in one dimension with the possibility to work with natural, rectangular or trapezoidal cross sections. FLO-2D includes bidirectional flow interchange between channel flow and overland flow.

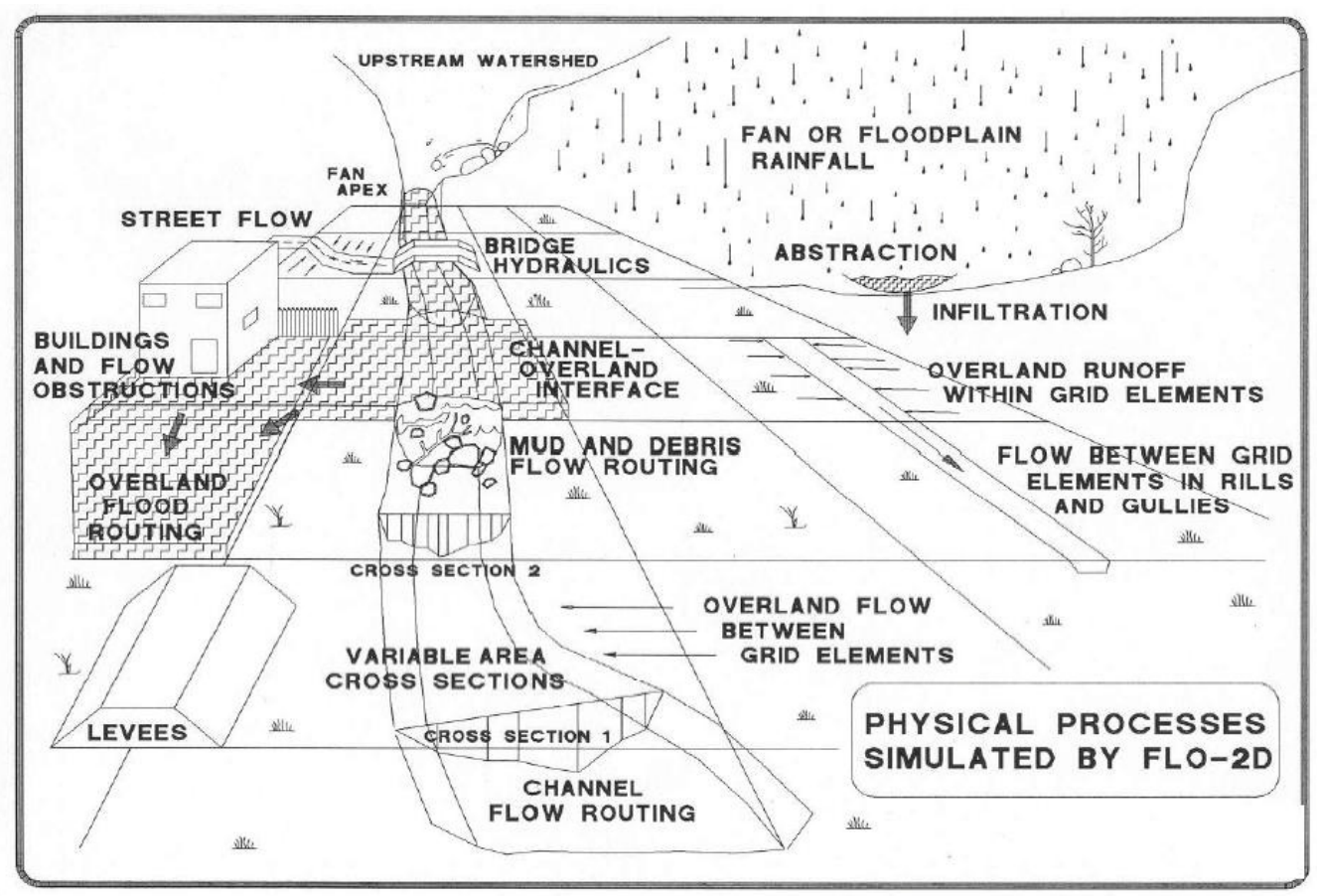

Figure 3.1 FLO-2D Scheme of Components (O'Brien, 2009) 
The FLO-2D model assumes that there is a steady flow condition for the duration of the time step, that the pressure distribution is hydrostatic, that the hydraulic roughness is based on steady, uniform turbulent flow resistance and that a channel element is represented by uniform channel geometry and roughness.

FLO-2D solves the vertically-averaged shallow water equations, the continuity equation and the momentum equation as:

$$
\begin{gathered}
\frac{\partial h}{\partial t}+\frac{\partial h V_{x}}{\partial x}=i \\
S_{F x}=S_{o x}-\frac{\partial h}{\partial x}-\frac{V_{x}}{g} \frac{\partial V_{x}}{\partial x}-\frac{V_{x}}{g} \frac{\partial V_{x}}{\partial x}-\frac{1}{g} \frac{\partial V_{x}}{\partial t}
\end{gathered}
$$

where: $h$ is the flow depth, $V$ is the depth-average velocity component, $i$ is the excess rainfall intensity, $S_{F x}$ is the friction slope component based in Manning's equation and $S_{0 x}$ is the bed slope.

For every grid element, the model computes each average flow velocity across the boundary one direction at time as a one-dimensional compound. There are eight potential flow directions, the four main horizontal and vertical directions and four diagonal directions as can be seen in Figure 3.2.

As can be seen, the momentum equation can be solved following the fully Dynamic Wave, approach that can be necessary in cases when inertial forces are presents in the same intensity as pressure forces.

The model takes in account precipitation losses by including interception and infiltration. Interception is assumed by using two variables, the depression storage variable, which involves all the water that is retained in small depressions and that does 
not form part either of runoff or infiltration, and the percentage of impervious area that involve all the amount of the area were infiltration is not possible.

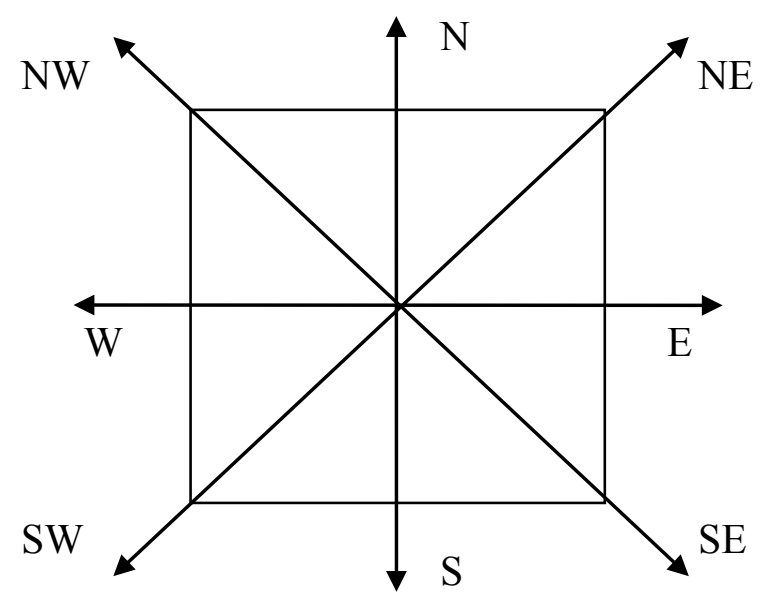

Figure 3.2 FLO-2D 8 Potential Flow Directions (O’Brien, 2009)

Infiltration is simulated using the Green Ampt infiltration model with spatial variability of Hydraulic conductivities and soil suction. Infiltration is assumed to be uniform along each grid element. Infiltration in channel is also simulated in FLO-2D.

The FLO-2D flow chart can be seen in Appendix A.

MODFLOW-2005 is a new version of the finite-difference ground-water model commonly called MODFLOW. Groundwater flow for confined or unconfined layers is simulated using a block-centered finite-difference approach. The model discretizes an area by obtaining for the horizontal direction, the number of rows, the number of columns, and the width of each row and column, then the vertical direction is handled in the model by specifying the number of layers to be used, and by specifying the top and bottom elevations of every cell in each layer (Figure 3.3). 


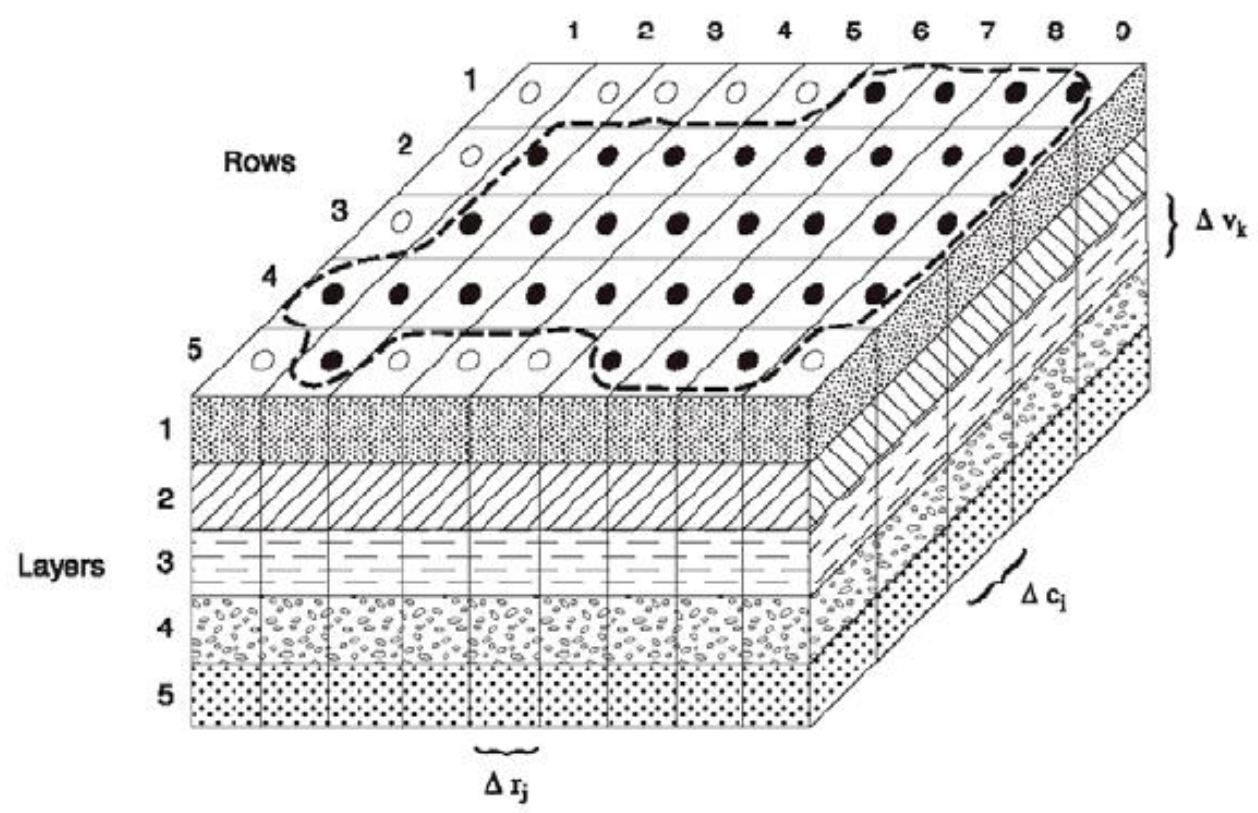

Figure 3.3 General Discretized Aquifer (Harbaugh, 2005)

MODFLOW-2005 uses the three-dimensional equation for movement of ground water of constant density through porous earth material:

$$
\frac{\partial}{\partial x}\left(K_{x x} \frac{\partial h}{\partial x}\right)+\frac{\partial}{\partial y}\left(K_{y y} \frac{\partial h}{\partial y}\right)+\frac{\partial}{\partial z}\left(K_{z z} \frac{\partial h}{\partial z}\right)+W=S_{S} \frac{\partial h}{\partial t}
$$

where $K_{x x}, K_{y y}$, and $K_{z z}$ are values of hydraulic conductivity along the $x, y$, and $z$ coordinate axes, which are assumed to be parallel to the major axes of hydraulic conductivity, $h$ is the potentiometric head, $W$ is a volumetric flux per unit volume representing sources and/or sinks of water, with $W<0.0$ for flow out of the ground-water system, and $W>0.0$ for flow into the system, $S_{S}$ is the specific storage of the porous material; and $t$ is time.

Balance of flow with the assumption that the density of ground water is constant is given in finite difference by the continuity equation as: 


$$
\sum Q_{i}=S_{S} \frac{\Delta h}{\Delta t} \Delta V
$$

where $Q_{i}$ is the flow rate into the cell, $S_{S}$ is the specific storage or the volume of water that can be injected per unit volume of aquifer material per unit change in head, $\Delta V$ is the volume of the cell and $\Delta h$ is the change in head over a time interval of length $\Delta t$. The MODFLOW-2005 flow chart is provided in Appendix B.

\subsection{Coupling surface water and groundwater models}

Two main factors must be taken in consideration for the coupling between two models, the mathematical compatibility and the compatibility of units (spatial and temporal).

In the case of the coupling between FLO-2D and MODFLOW-2005 this process was simplified by the fact that both programs source code was written in FORTRAN, and that both were developed using finite differences. In order to reinforce mathematical compatibility the coupling approach lead both programs to work with independent time steps, this allow each program to deal with numerical stability criteria independently.

Even if FLO-2D and MODFLOW-2005 allows users to determine the unit system to be used in a simulation (English or metric), in MODFLOW-2005 users can select the particular space and time units that are going to be used, FLO-2D only allows users to determine the unit system as units are already set in the code. For this reason, in order to achieve the compatibility of spatial units a series of procedures were incorporated in order to transform the predetermined units of FLO-2D into the same units used in MODFLOW-2005. A set of basic units used in FLO-2D can be seen in Table 3.1. 


\begin{tabular}{|c|c|c|}
\hline VARIABLE & ENGLISH & METRIC \\
\hline discharge & $\mathrm{cfs}$ & $\mathrm{m} / \mathrm{s}$ \\
\hline depth & $\mathrm{ft}$ & $\mathrm{mm} / \mathrm{hr}$ \\
\hline $\begin{array}{c}\text { infiltration } \\
\text { hydraulic conductivity }\end{array}$ & inches $/ \mathrm{hr}$ & $\mathrm{mm}$ \\
\hline $\begin{array}{c}\text { rainfall and abstraction } \\
\text { soil suction }\end{array}$ & inches & $\mathrm{mm}$ \\
\hline velocity & inches & $\mathrm{m} / \mathrm{s}$ \\
\hline volume & ft $/ \mathrm{s}$ & $\mathrm{m}$ \\
\hline viscosity & acre- $\mathrm{ft}$ & $\mathrm{poise}$ \\
\hline yield stress & poise $\left(\right.$ dynes-s/cm $\left.{ }^{3}\right)$ & dynes $/ \mathrm{cm}^{2}$ \\
\hline
\end{tabular}

Regarding the temporal coupling, the main factor that was taken in consideration was that FLO2-2D and MODFLOW-2005 models were developed using very different design principles. MODFLOW-2005 has three internal nested loops: the outermost is for stress periods that account for unsteady heads from rivers, channels or recharges; the intermediate loop is for time normally of the order of days or hours and the inner loop is for the iterative solver of the groundwater flow equations. MODFLOW-2005 calculation time steps are generally in the order of hours or days while FLO-2D uses variable time steps that are often in the order of a few seconds or less. For that reason and in order to avoid internal modification of the codes, a scheme was developed in which the intermediate loop of MODFLOW-2005 is responsible for controlling the transference of information between the models. Following this procedure a simulations will starts in 
FLO-2D at an initial time until it reach the time step set in MODFLOW-2005, at this time the simulation of the first time step using initial conditions is carried out in MODFLOW2005 and then information is transferred in both directions in order to start the following time step. This process will continue until the complete FLO-2D simulation time is reached. Several MODFLOW-2005 time stress periods can be included in one simulation time. Figure 3.4 shows the flow chart of this process.

Once this computational coupling was completely tested the physical process coupling was started.

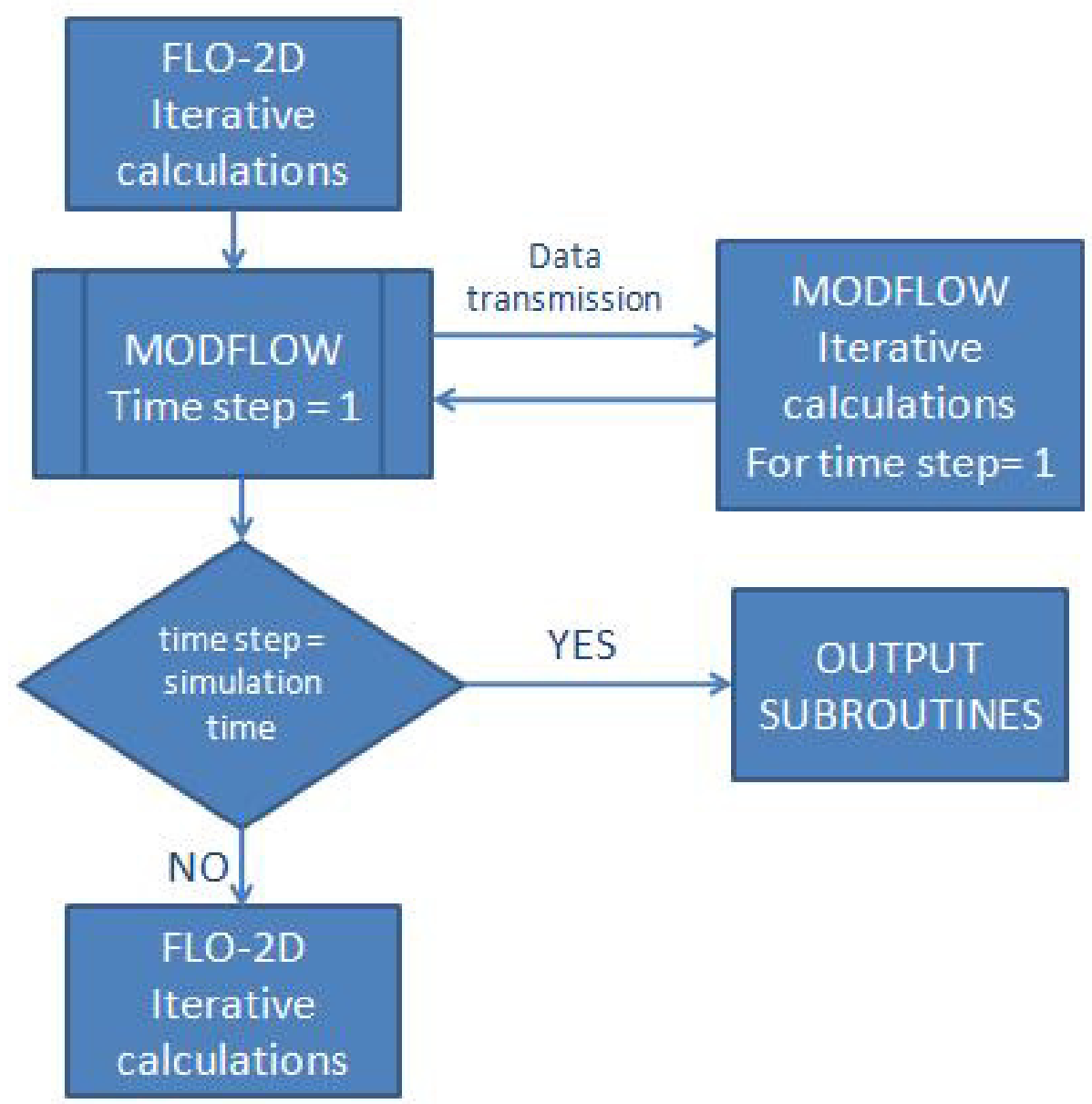

Figure 3.4 Flow Chart for Time Coupling 


\subsubsection{Coupling procedures for infiltration between surface and subsurface}

The coupling between surface and subsurface was divided in two phases, during the first phase the basic process of infiltration of water from surface into the subsurface was analyzed while the soil saturation was treated in the second phase.

Original methodology for the estimation of infiltration from FLO-2D was used to estimate the accumulated infiltrated volume for each time step. This methodology used the Green-Ampt method by using space variable parameters that allows having different infiltration rates for every cell, however, these parameters are uniforms for each cell. By using Green-Ampt methodology, an initial abstraction is first calculated in order to take in account all the water that becomes stagnant and therefore do not infiltrates, after this values is obtained the infiltration volume is calculated and then is accumulated over each FLO-2D time step. Details of the general formulation for the Green-Ampt method can be seen in the HEC-1 manual (USCOE, 1990).

After its calculation in FLO-2D, the accumulated infiltrated volume is transferred to MODFLOW-2005 every time a MODFLOW-2005 time step is reached. The accumulated infiltrated volume is then divided by the time step value in order to obtain a recharge rate, which is the original input data needed in MODFLOW-2005. Original MODFLOW-2005 recharge subroutines were modified in order to allow obtaining this value from a data transfer instead than from an input file.

The parameters necessary for the calculation of infiltration are hydraulic conductivity, the soil suction, the volumetric moisture deficiency, the percent of impervious area and the porosity, additionally FLO-2D need values for initial and final saturation. All these parameters are included in the INFIL.DAT file. 
The original FLO-2D code did not have the capacity to calculate the saturation of the soil in time, initial and final saturation were used to obtain a water moisture deficiency that will affect in a certain way, but not significantly, the infiltration volume, but in any case the infiltration will continue throughout the simulation period. In order to correct this issue a subroutine that compares the head obtained in MODFLOW-2005 with surface and free surface levels from FLO-2D in order to determine whether the soil is saturated or not was incorporated.

This process was developed by assuming that the concept of hydrostatic pressure can be used due to the low velocities that can be found normally in porous media and especially in zone with really small energy gradient like wetlands.

Following the concept of hydrostatic pressure, the piezometric head is:

$$
h=z+\frac{P}{\gamma}
$$

where $h$ is the piezometric head, $z$ is the datum elevation, $p$ is the pressure and $\gamma$ is the specific weight of the water.

And for unconfined aquifers, at the water table elevation can be approximated to:

$$
h \approx z
$$

By using this simplification, the head calculated by MODFLOF 2005 is compared whit the surface elevation, and if the head is higher than the surface elevation then saturation condition is reached and the NOINFIL switch is activated so no infiltration volume will be calculated. This condition will last until head level falls back bellow surface level in some of the followings time steps. Additionally, if this saturation condition is reached heads from groundwater are also compared with the free surface 
elevation. If the head is higher than the free surface elevation, then this additional volume is added to the overland flow in FLO-2D. These comparisons were made in a cell by cell basis.

To make possible this interaction between the models several modifications were carried out in both source codes. In FLO-2D the MODFLOW_GLOBAL module was created to contain all the variables needed for the transfer of the data. Additionally, the COMPUTE_INFILTRATED_VOLUME_FP was developed in order to receive the data that need to be transferred to MODFLOW-2005 and passed its value to the new transfer variable. The COMPUTE_SUP_RECHARGE_FP was created to solve the saturation condition.

In MODLOW the original recharge subroutine were partially modified in order to receive data from the trasnfer subroutines at each time step instead than from a data file. The rest of the functions and calculations were leaved as original so all the recharge options available for the original MODFLOW-2005 package were left fully operational. New developed source code can be seen at Appendix C. A flow chart with the infiltration procedures can be seen in Figure 3.5.

\subsubsection{Coupling procedures for interaction between channels and subsurface}

MODFLOW-2005 River Package was developed only with the purpose of dealing with the interaction between the aquifer and a river and do not solve flow routing. On the other hand, FLO-2D has the capability to route flow in a channel network. In this work, both characteristics were connected in order to achieve a better time variable approach of the behavior of the river-aquifer system. 


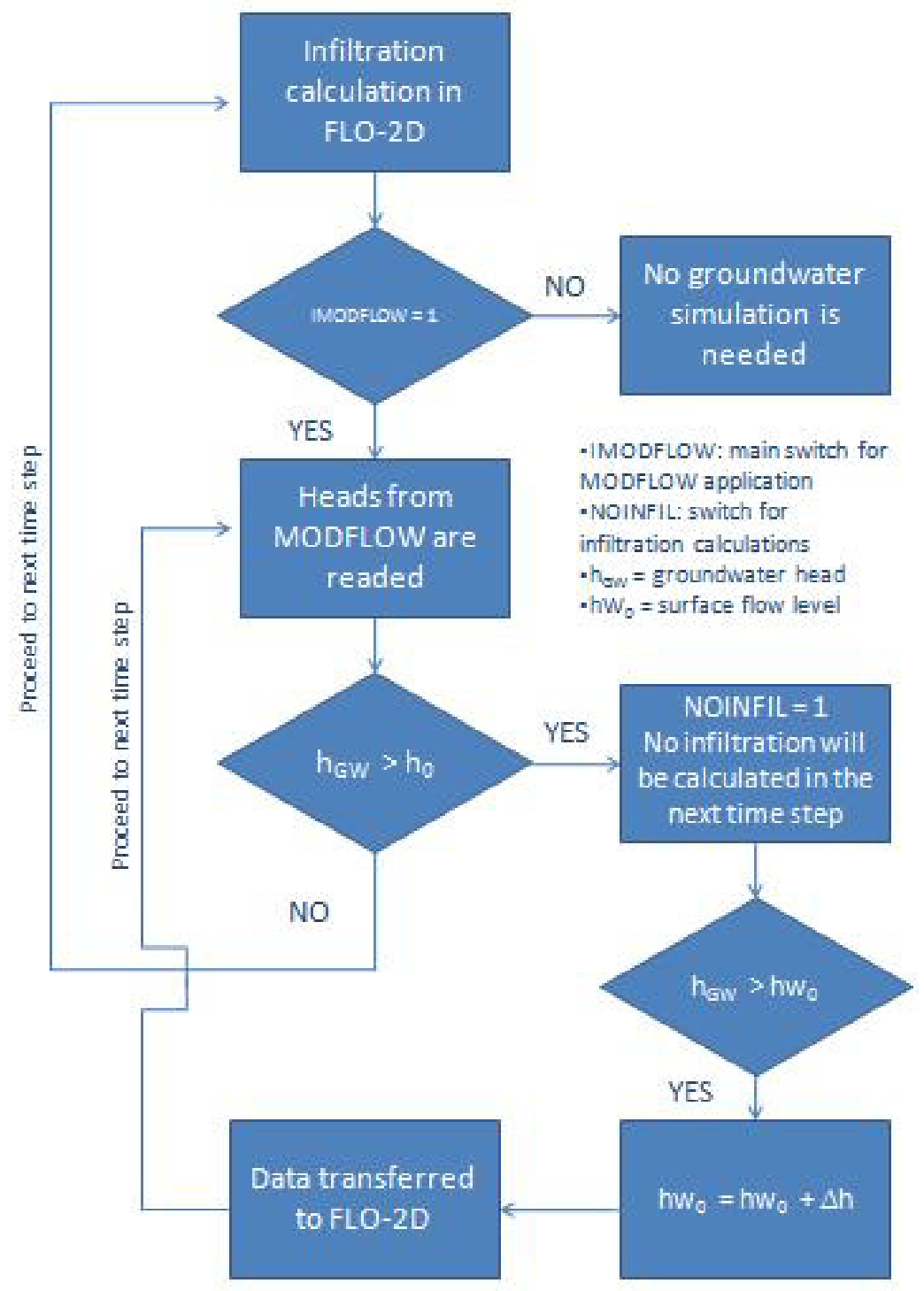

Figure 3.5 Flow Chart for Infiltration Methodology

There are three different ways in which channels and aquifers interact: first when groundwater head is bellow the bottom of the channel so all available water will infiltrate into the aquifer. Second, when groundwater heads are higher than the bottom of the channel but lower than the free surface, so only a portion of the available water will infiltrate and third when groundwater heads are also higher than the free surface so the aquifer actually flows to the channel. 
For the first case, when the bottom of the channel is higher than the groundwater heads, as can be seen in Figure 3.6, the volume of water that infiltrates from the channel to the aquifer is calculated in FLO-2D because of the more accurate methodology. While channels in MODFLOW-2005 only can have rectangular cross sectional areas FLO-2D can have rectangular, trapezoidal or irregular cross sectional areas and this ads more accuracy at the calculations of the volume of water available for infiltration.

The accumulated infiltrated volume is then calculated using the Green-Ampt method with a specific hydraulic conductivity value for the channel and that will be equivalent to the one used to obtain thee hydraulic conductance term needed in MODFLOW-2005. This volume of water is transferred to MODFLOW-2005 and then divided by the time step value in order to obtain the flow rate. This flow rate will be used instead of the original value that was normally obtained by the expression:

$$
\mathrm{QRIV}_{\mathrm{n}}=\mathrm{CRIV}_{\mathrm{n}}\left(\mathrm{HRIV}_{\mathrm{n}}-\mathrm{RBOT}_{\mathrm{n}}\right)
$$

where: $Q R I V$ is the flow rate; HRIV is the water level of the free surface of the river obtained from the FLO-2D; RBOT is the river bottom level and CRIV is the riverbed hydraulic conductance calculated as:

$$
C R I V=\frac{K_{n} L_{n} W_{n}}{M_{n}}
$$

where: $K$ is the hydraulic conductivity for the river bed; $L$ is the length of the reach inside the cell; $W$ is the river width and $M$ is the Thickness of the riverbed layer.

For the second and third case, when heads are higher than the channel bottom, as can be seen in Figure 3.7, calculations of volume of infiltration are done in MODFLOW2005 but using free surface water levels obtained from the FLO-2D simulation. 

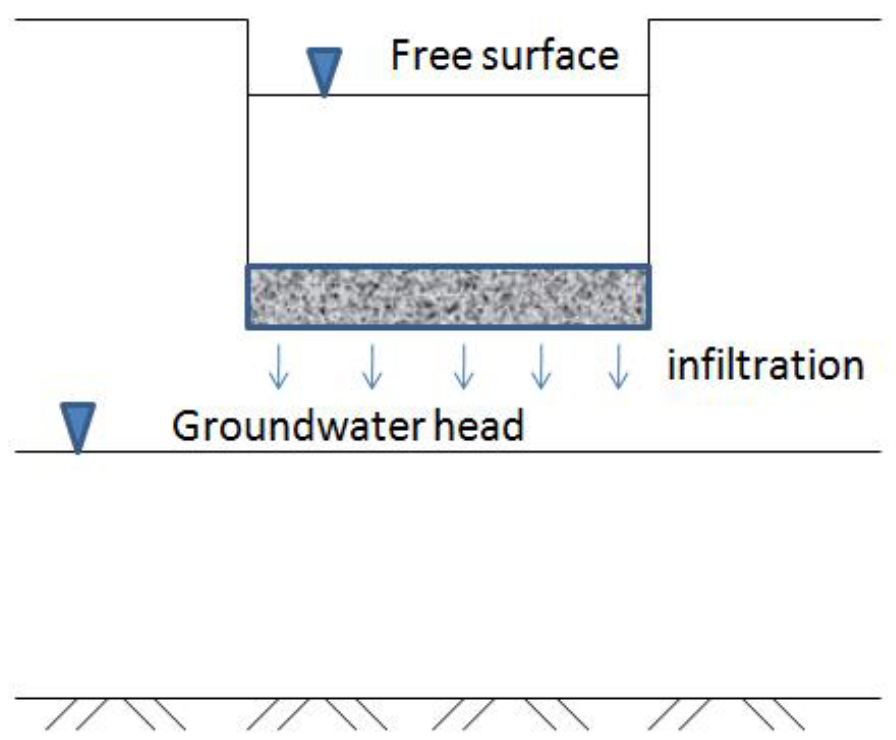

Figure 3.6 Scheme for Infiltration with Head Levels Bellow Channel Bed

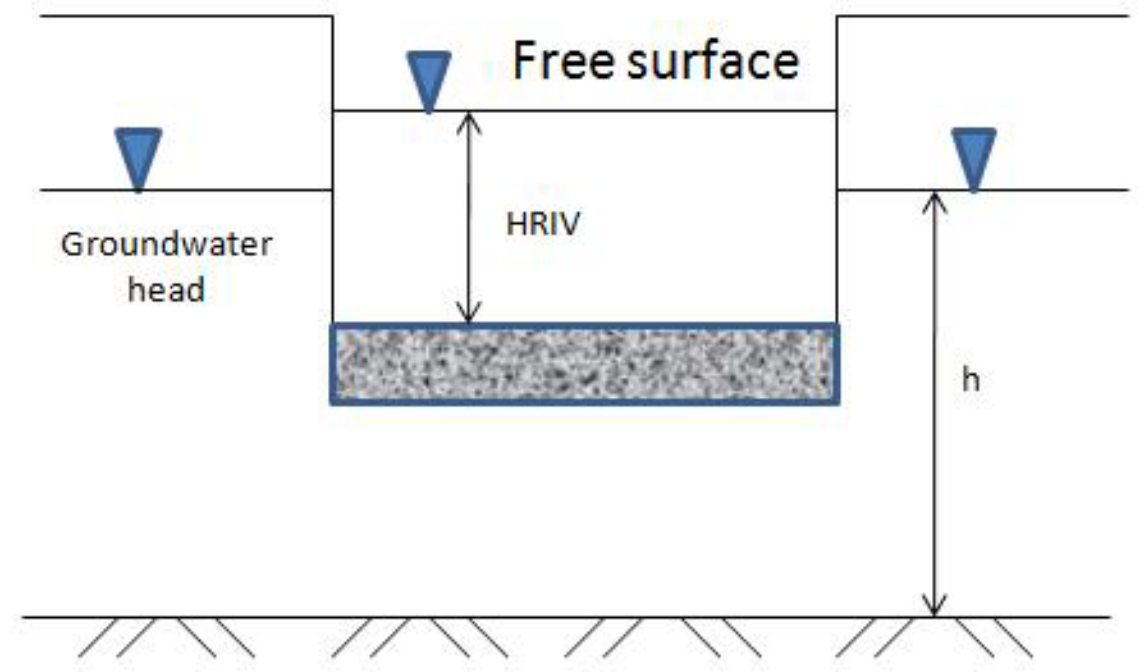

Figure 3.7 Scheme for Infiltration with Head Levels Above the Bottom of The Channel

For these two cases a simple formulation takes care for infiltration by calculating the rate of water that can flow in one direction or another as:

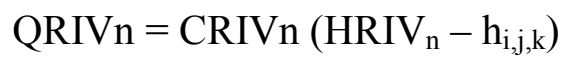


where: $Q R I V$ is the flow rate; $H R I V$ is the water level of the free surface of the river obtained from the FLO-2D; $\mathrm{h}$ is the groundwater head and $C R I V$ is the riverbed hydraulic conductance.

By using equation (9) and depending on the result of the relation between HRIV and $h$ is simple to obtain if the flow is going toward or coming from the river, while negative discharges will means that water is flowing into the river, positives values will mean that water is flowing into the aquifer. Details for the calculation of infiltration from channels can be seen at the MODFLOW-2005 user manual (Harbaugh, 2005).

To make possible this interaction between the models several modifications were carried out in both source codes. In FLO-2D the transfer variable ACCUMULATED_INF_VOLUME_CHAN was created in the MODFLOE_GLOBAL module. Additionally, the COMPUTE_INFILTRATED_VOLUME_CH was developed in order to receive the data that need to be transferred to MODFLOW-2005 and passed its value to the new transfer variable. Once in MODFLOW-2005 the transfer variable is divide by the time step value in order to obtain the recharge rate.

In MODFLOW-2005 the original river subroutine were partially modified in order to receive data from the trasnfer subroutines at each time step instead than from a data file. Only calcultations of the infitrated recharge when head levels are lower than the bottom of the channel were supressed and supplanted by the values obtained in the FLO2D simulation. The rest of the functions and calculations were leaved as original so all the river options available for the original MODFLOW-2005 package were left fully operational. New programed source code can be seen at Appendix C. 


\subsection{Vegetation Resistance}

The flow resistance due to vegetation is a fertile area of investigation in which one must not only differentiate between grasslike flexible vegetation and less flexible vegetation like bushes or trees, but also between totally submerged and partially submerged vegetation. However, most vegetation in wetlands is only partially submerged and previous research has demonstrated that once the vegetation is totally submerged and especially for flexible vegetation the resistance due to vegetation can be related to the bed resistance (Yen, B.C., 2002; Wu et al., 1999). Even if the main objective was to incorporate the effect of partially submerged vegetation the totally submerged was included in order to obtain a general formulation that could be used for modeling areas different than wetlands. Roughness in channels was continued to be treated as bed resistance only.

Three approaches were analyzed: The first approach included a source/sink term that represented the resistance due to submerged vegetation with a drag force expressed as (Fischer-Anzte et al., 2001):

$$
F_{D, i}=\rho \frac{U_{i}^{2}}{2} C_{D} \lambda
$$

where the vegetative coefficient $\lambda$ defined as:

$$
\lambda=\frac{\text { projected area of plant }}{\text { total volume }}=\frac{d}{S^{2}} \text { or } \lambda=\frac{d}{s \times l}
$$

where $\rho$ is the density, $U$ is the velocity averaged over time, $C_{D}$ is the drag coefficient, $d$ is the diameter of plants and $s$ and $l$ are the lengths of the control volume. 
The second approach was based on composite channel friction formulas like the presented by Yen, B.C. (2002) or the modification of the Darcy-Weisbach's formula (Armanini, 1999):

$$
\sqrt{\frac{1}{f}}=A_{1 v} \ln \frac{s}{S_{v}}+B_{1 w}
$$

where $A_{v}$ and $B_{v}$ are coefficient that depends on the type and state of the vegetation, $S$ is the wet area and $S_{v}$ is the vegetated area.

Finally the third approach was based on modified forms of the Manning equation based on the work of Petryk and Bosmajian (1975) like the Wu et al. expression (Wu et al., 1999):

$$
n_{b}=\left(\frac{D^{2 / 3}}{\sqrt{2 g}}\right) \sqrt{C_{D}^{\prime}}
$$

where $D$ is the depth of flow and $C^{\prime}{ }_{D}$ is the drag force for vegetation.

The first approach was discarded because the inclusion of the sink/source term would imply a major modification of several subroutines of FLO-2D, which could almost lead to a completely new surface water routing model.

Between the second and third approaches, the modified Manning approach was selected because these expressions included the physical effect of the effect of the vegetation by using the drag coefficient concept in the same way that the first analyzed approach did, also, as these coefficients were included to form a new modified expression of Manning coefficient this could be included more directly into the source code, and additionally this type of expressions are also extensively used by United State Agencies like the USGS (Arcement and Schneider, 1990). 
From these modified expressions of Manning's roughness coefficient, the Wu et al. (1999) expressions were selected. Wu et al. (1999) based their studies on the results of Petryk and Bosmajian (1975) were it was shown that the effect of vegetation in Manning's roughness coefficient could be estimated by using the vegetation density, the hydraulic radius and the boundary roughness, and that the boundary roughness could be neglected for heavily vegetated areas. The difference between Petryk and Bosmajian (1975) and the Wu et al. (1999) work was that the last one did not include the bottom roughness as the initial value, the expressions obtained in their work use only the effect of the vegetation, which is an appropriate approach because the effect of vegetation in the flow has been proven to be independent to the effect of the bottom, additionally, they also included separate expressions for submerged and unsubmerged vegetation.

The concept of drag force was used to deduce an expression to take in account the physical effect of vegetation, was obtained by applying force balance between gravitational, drag and boundary friction forces for a uniform flow in the direction of the vegetation. In this analysis friction forces resulted to be negligible in front of drag force, which was expressed for unsubmerged vegetation as

$$
F_{D}=C_{D}(\lambda A L) \frac{\rho V^{2}}{2}
$$

where $C_{D}$ is the drag coefficient; $\lambda$ is the vegetated area coefficient and depends on vegetation type, density and configuration; $\lambda A L$ is the frontal area of vegetation, $\rho$ is the mass density of water and $V$ is the mean flow velocity.

Drag coefficient was then obtained after solving the equilibrium of forces:

$$
C_{D}=\lambda \frac{2 g S_{0}}{V^{2}}
$$


where $S_{0}$ represent the longitudinal slope of the bed

In the same way, for submerged vegetation drag force was expressed as:

$$
F_{D}=C_{D}(\lambda T B L) \frac{\rho V^{2}}{2}
$$

where $T$ is the height of vegetation and $B$ is the channel width.

Drag coefficient for this expression had the following form:

$$
C_{D}=\lambda\left(\frac{D}{T}\right) \frac{2 g S}{V^{2}}
$$

where $D$ is the depth of flow.

The vegetation area coefficient $(\lambda)$ was obtained using the expression applied by Lee et al. (2004):

$$
\lambda=\frac{2 K_{0}}{s e}
$$

where $K_{0}$ is an areal coefficient of plant that will depend of vegetation type, and configuration and se is the separation between stems.

This coefficient expression was selected because all the values can be obtained by using data that can be collected in the field, and besides, other expressions only include a relation between total area and vegetated areas, and are not related with the type of vegetation.

The separation of the steam is obtained by the following expression:

$$
s e=\sqrt{\frac{1}{M}}
$$

where $M$ represents the vegetation density (plants $/ \mathrm{m}^{2}$ ). 
Finally, an expression for Manning's roughness coefficient was obtained for unsubmerged vegetation:

$$
n=\left(\frac{D^{2 / 3}}{\sqrt{2 g}}\right) \sqrt{C_{D}}
$$

And in the same way an expression was obtained for totally submerged vegetation:

$$
n=\left(\frac{D^{(1 / 6)} T^{(1 / 2)}}{\sqrt{2 g}}\right) \sqrt{C_{D}}
$$

The simulation of vegetation resistance was included as an option in the CONT.DAT the main input file that controls all the FLO-2D packages. In order to include these expressions in the source code, the first step was to include the number and identification of the heavily dense cell, the vegetation height, the coefficient of the plant and the separation of stems in the VEROUGH.DAT file a new FLO-2D data file created to manage resistance due to vegetation. The user has the capability to determine which cells are affected by vegetation and which cells are affected by bed shear.

A comparison between water flow levels and vegetation height was used to define which of the expressions had to be used to determine the roughness coefficient in a cell by cell basis.

Once the roughness coefficient is calculated, its value is compared with the initial bed roughness coefficient. If roughness due to vegetation is higher than the bed roughness then the value is used to simulate new velocities and depths. If bed roughness has a higher value, this would imply that there is no effect of vegetation in the simulated 
flow. This comparison is checked at each FLO-2D time step. New programed source code can be seen in Appendix C.

A flow chart with the infiltration procedures can be seen in Figure 3.8.

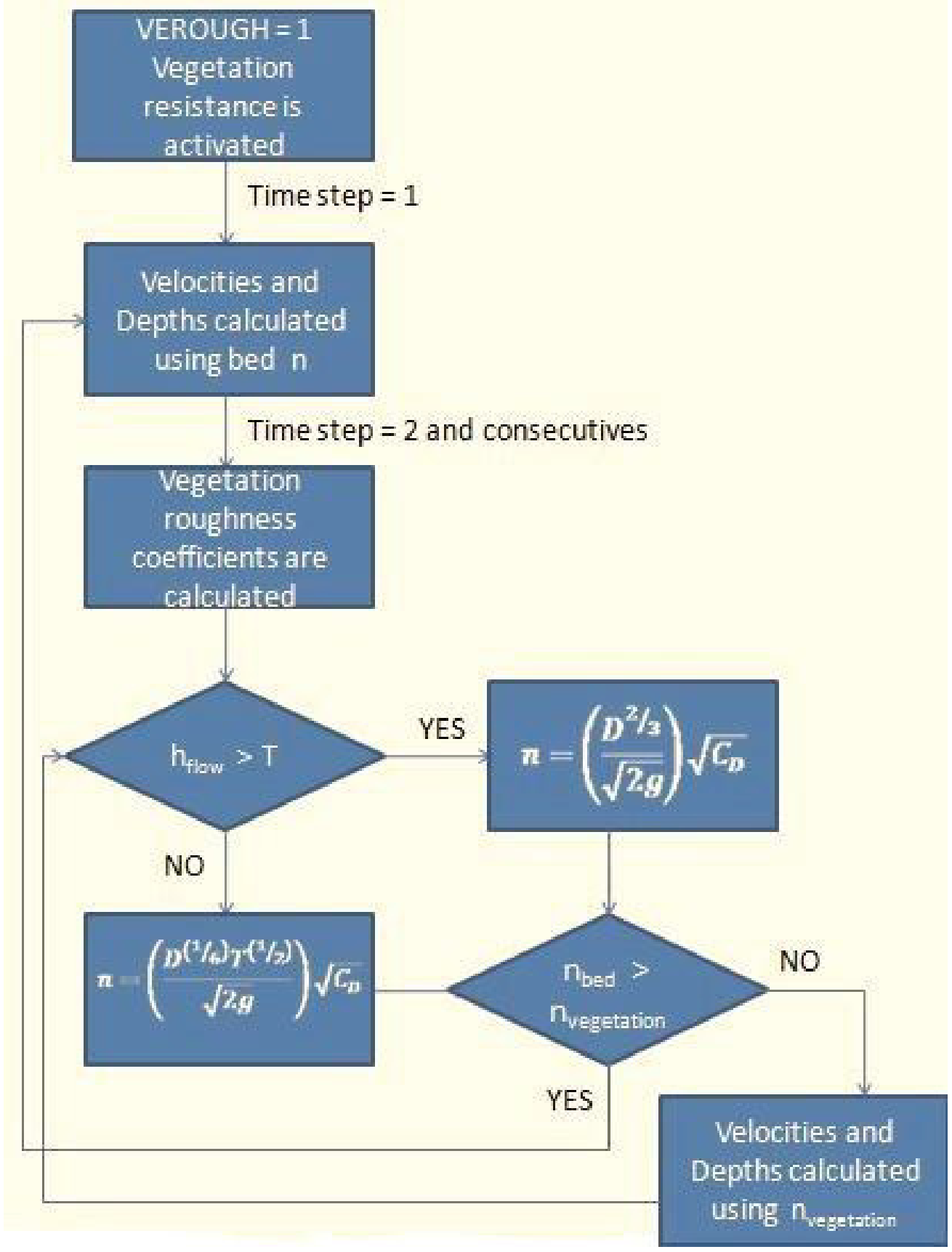

Figure 3.8 Flow Chart for the Vegetation Resistance Approach 


\subsection{Model Verification, Analysis and Discussion}

Before any change was applied to the original models, one single overland simulation was setup in order to test the capability of FLO-2D to simulate flow in zones with very low slopes. This simulation was based on the WCA-1 in the Everglades.

In order to model overland and canals flow through WCA-1 and try to recognize some of the hydrodynamics patterns of the refuge, the area was divided in rectangular cells of $200 \times 200 \mathrm{~m}$ (Figure 3.9).

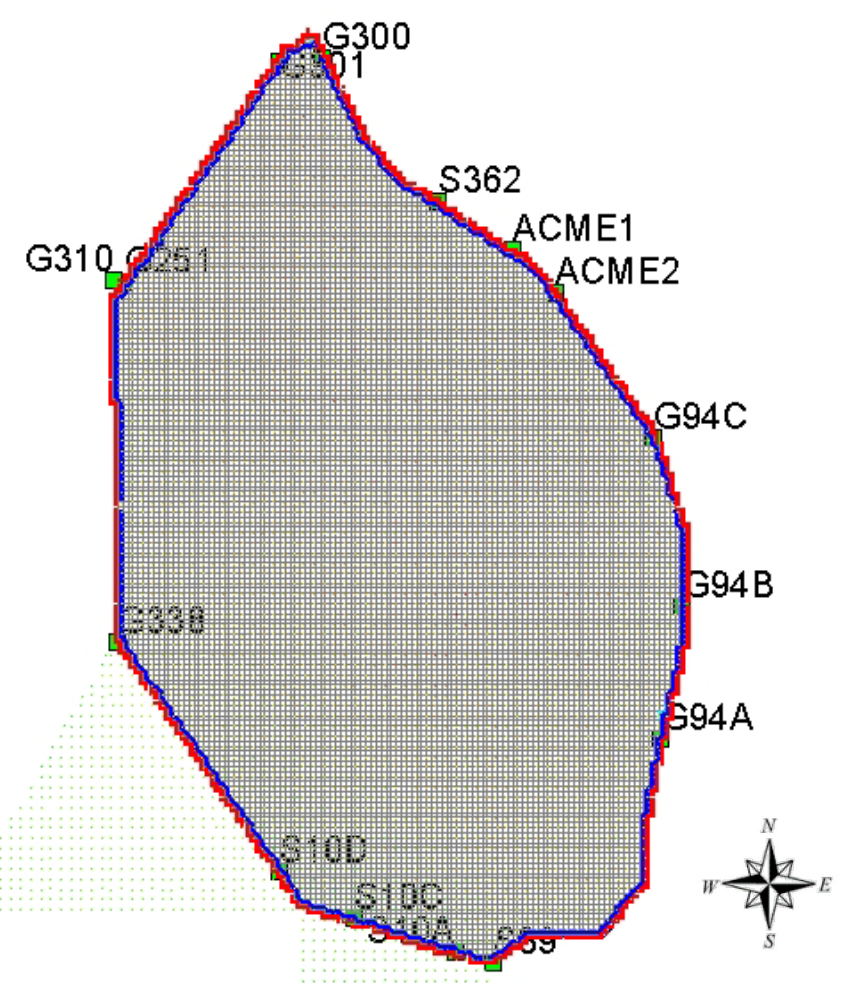

Figure 3.9 FLO-2D Grid for WCA-1

The elevation data was obtained from the SOFIA web site. The data is a high accuracy elevation data ( $+/-15 \mathrm{~cm}$ of vertical accuracy) obtained from surveys from 1995 to 2007 and using the North American Datum 1983 (NAD83) for horizontal positions and the North American Vertical Datum for the elevation. Data set is the same used for the 
Everglades Depth Estimation Network (EDEN) Digital Elevation Model. Topography was included by using an elevation point data file (Figure 3.10).

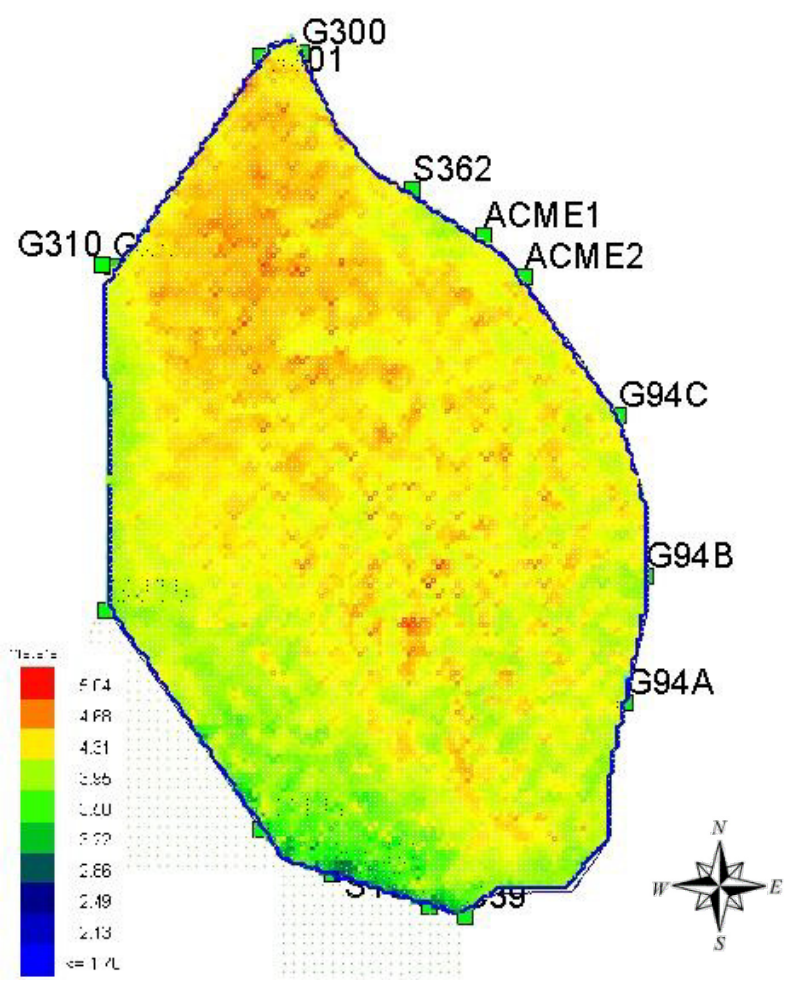

Figure 3.10 WCA-1 Elevation Data

The rim canals were included using rectangular cross section. An elevation of $5 \mathrm{~m}$ was used for all the canals while the cross section width was included using actual measured data (Mesehle et al., 2005) (Table 3.2). An initial depth of 4.5m was used as an initial condition for all the canals.

2003 Stage and Flow data from al the hydraulic structures were included in the simulation. Bidirectional Structures (G-300, G-301) were simulated by including two different structures, one as an inflow, and the other as a controlled outflow structure. The Hydrological data was obtained from the DBHYDRO webpage. 
Table 3.2 WCA 1 Cross Section Width

\begin{tabular}{|c|c|c|c|c|c|c|c|c|c|}
\hline Canal & Easting & Northing & $\begin{array}{l}\text { canal } \\
\text { mile }\end{array}$ & $\begin{array}{l}\text { Width } \\
\text { m }\end{array}$ & Canal & Easting & Northing & $\begin{array}{l}\text { canal } \\
\text { mile }\end{array}$ & $\begin{array}{c}\text { Width } \\
\mathrm{m}\end{array}$ \\
\hline L7-16 & 561525 & 2950503 & 0 & 0.00 & L40-28 & 563533 & 2950633 & 0 & 0.00 \\
\hline L7-15 & 560710 & 2949311 & 0.9 & 0.27 & L40-27 & 564165 & 2949288 & 0.92 & 0.28 \\
\hline L7-14 & 559806 & 2947996 & 1.89 & 0.58 & L40-26 & 564832 & 2947867 & 1.9 & 0.58 \\
\hline L7-13 & 558869 & 2946632 & 2.92 & 0.89 & L40-25 & 565882 & 2946594 & 2.92 & 0.89 \\
\hline L7-12 & 557955 & 2945304 & 3.92 & 1.19 & L40-24 & 567106 & 2945548 & 3.92 & 1.19 \\
\hline L7-11 & 557046 & 2943980 & 4.92 & 1.50 & L40-23 & 568472 & 2944658 & 4.94 & 1.51 \\
\hline L7-10 & 556140 & 2942659 & 5.91 & 1.80 & L40-22 & 569828 & 2943776 & 5.94 & 1.81 \\
\hline L7-01 & 555256 & 2941284 & 6.93 & 2.11 & L40-21 & 571184 & 2942902 & 6.95 & 2.12 \\
\hline L7-02 & 555256 & 2939521 & 8.02 & 2.44 & L40-20 & 572296 & 2941771 & 7.93 & 2.42 \\
\hline L7-03 & 555255 & 2937953 & 9 & 2.74 & L40-19 & 573252 & 2940467 & 8.94 & .72 \\
\hline L7-04 & 555262 & 2936357 & 9.99 & 3.04 & L40-18 & 574218 & 2939160 & 9.95 & 3.03 \\
\hline L7-05 & 555260 & 2934769 & 10.98 & 3.35 & L40-17 & 575159 & 2937830 & 10.96 & 3.34 \\
\hline L7-06 & 555259 & 2933103 & 12.01 & 3.66 & L40-16 & 576031 & 2936473 & 11.96 & 3.65 \\
\hline L7-07 & 555263 & 2931591 & & & & & & & 95 \\
\hline L7-08 & 555262 & 2930066 & 13.9 & 4.24 & L40-14 & 577228 & 2933471 & 13.97 & 4.26 \\
\hline L7-09 & 555315 & 2928408 & 14.93 & 4.55 & L40-13 & 577509 & 2931864 & 14.98 & 4.57 \\
\hline L39-01 & 556127 & 2926741 & 16.08 & 4.90 & L40-12 & 577535 & 2930277 & 15.97 & 4.87 \\
\hline L39-02 & 557056 & 2925424 & 17.08 & 5.21 & L40-11 & 577579 & 2928671 & 16.97 & 5.17 \\
\hline L39-03 & 557976 & 2924112 & 18.08 & 5.51 & L40-10 & 577443 & 2927070 & 17.97 & 5.48 \\
\hline L39-04 & 558916 & 2922783 & 19.09 & 5.82 & L40-09 & 577077 & 2925495 & 18.97 & 5.78 \\
\hline L39-05 & 559831 & 2921482 & 20.08 & 6.12 & L40-08 & 576718 & 2923953 & 19.96 & 6.08 \\
\hline L39-06 & 560773 & 2920146 & 21.09 & 6.43 & L40-07 & 576361 & 2922404 & 20.94 & 6.38 \\
\hline L39-07 & 561734 & 2918793 & 22.13 & 6.75 & L40-06 & 576090 & 2920841 & 21.93 & 6.68 \\
\hline L39-08 & 562717 & 2917596 & 23.09 & 7.04 & L40-05 & 576115 & 2919246 & 22.92 & 6.99 \\
\hline L39-09 & 564220 & 2917145 & 24.06 & 7.33 & L40-04 & 575529 & 2917746 & 23.92 & 7.29 \\
\hline L39-10 & 565732 & 2916662 & 25.05 & 7.64 & L40-03 & 574601 & 2916419 & 24.93 & 7.60 \\
\hline L39-11 & 567273 & 2916163 & 26.06 & 7.94 & L40-02 & 573007 & 2916279 & 25.92 & 7.90 \\
\hline L39-12 & 568804 & 2915664 & 27.06 & 8.25 & L40-01 & 571396 & 2916240 & 26.92 & 8.21 \\
\hline
\end{tabular}

Manning roughness coefficients for the canals was obtained using the USGS methodology (Arcement and Scheider, 1990):

$$
n=\left(n_{b}+n_{1}+n_{2}+n_{3}+n_{4}\right) m
$$


where $n_{b}$ is the base value depending on materials, $n_{l}$ is a correction factor that depends on surface irregularities, $n_{2}$ is a value for variations in shape and size of the cross section, $n_{3}$ is a value for obstructions, $n_{4}$ is a value for vegetation and flow conditions and $m$ is a correction factor for meandering of the channel.

For this case, the Manning roughness coefficient was $\mathrm{n}=0.032\left(\mathrm{n}_{\mathrm{b}}=0.028, \mathrm{n}_{1}=\right.$ smooth $=0.00, \mathrm{n}_{2}=$ gradual $=0.00, \mathrm{n}_{3}=$ negligible $=0.001, \mathrm{n}_{4}=$ small vegetation $=$ 0.003.). The canal's roughness coefficient was also used for the soil.

Results from this simplify preliminary test show some of the general flow patterns that occur inside the WCA-1.

The overall maximum elevation plot shows a banded flow pattern (Figure 3.11) that can also be seen in the InSAR imagery (Figure 3.12) (Wdowinski et al., 2004), this is evidence that even with very simplify conditions the model can capture the general hydrodynamic of the refuge.

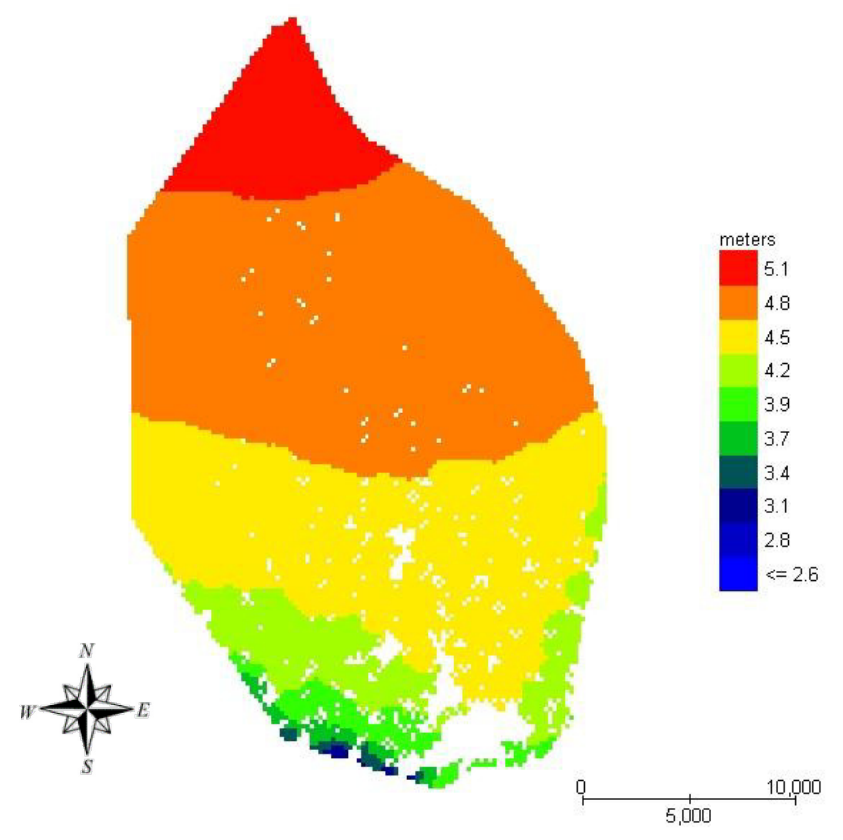

Figure 3.11 WCA-1 Model Maximum Elevations 


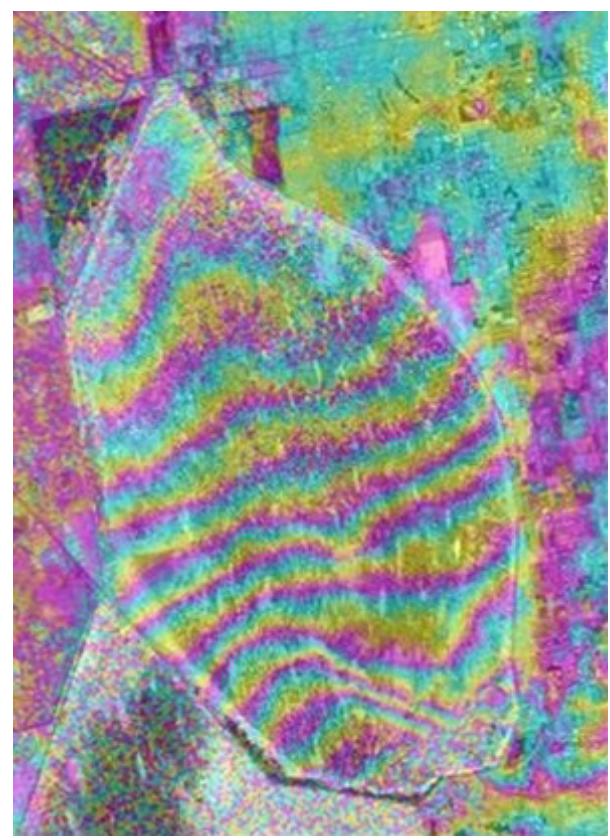

Figure 3.12 WCA-1 InSar Image (from Wdowinski et al., 2004)

Velocities also show to be comparable to the mean velocities of the refuge, with low velocities in almost all the area but in the canals, especially in the northern part of the refuge where cross sections are narrower.

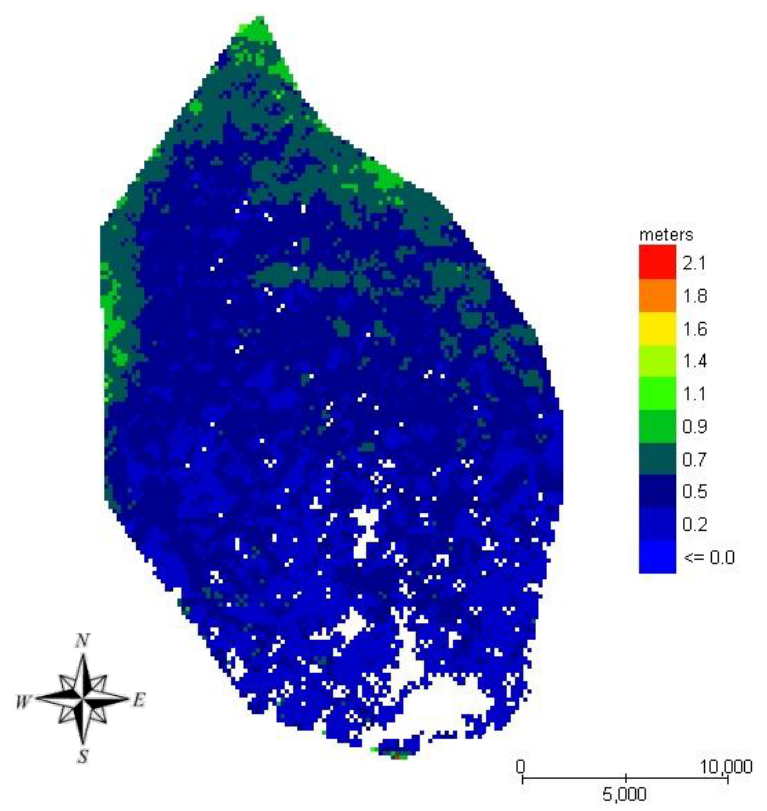

Figure 3.13 WCA-1 Maximum Modeled Velocities 
After the model was tested, three simulations were conducted to verify the proper functioning of the coupling routines between MODFLOW-2005 and FLO-2D models, starting from a simple case with one layer and recharge and ending with a multiple layer and stress period case that include a river reach. Cases were run first using MODFLOW2005 alone and then the same configuration was run again but using the coupled model. Simulations had the intention to verify that head variations were reasonable similar between the models and that there were any problem related with the water budgets. The first case was based on the original problem for the estimation of the recharge rate for a Long Island, New York (Jacob, 1943), the second case simulated a system of three aquifers separated by confining beds (Harbaugh, 2005) and the third case solved the case of an two aquifers separated by a confining bed that discharge in a river (McDonald et al., 1992).

\subsubsection{Island Recharge Simulation (Steady-State Simulation).}

This first verification test was used to verify the correct functioning of the first phase of the coupling, which implied the exchange of water between the surface and the subsurface and to test the mathematical accuracy of the couple model using a steady-state simulation. This was achieved by applying a constant recharge over a single layer for a period of a unique 24 hours MODFLOW-2005 stress period.

This simulation was based on Jacob's efforts to obtain the groundwater levels for Long Island, New York, by using the one dimensional form of Poisson's equation:

$$
\frac{d^{2} h}{d x^{2}}=-\frac{R}{T}
$$


where $R$ is the recharge rate and $T$ is the transmissivity.

In order to obtain his results Jacob worked based on three assumptions, in first place that the saturated thickness should be equal to the aquifer thickness, in second place that the water level is uniform at the boundaries were intersect the sea level and that the solution is symmetrical (Jacob, 1943). The simulated case took in account all the assumptions.

The conceptual model was build with a single layer $20 \mathrm{ft}$ depth with the top located at an elevation of $0 \mathrm{ft}$. The island is $23,500 \mathrm{ft}$ long and 11,500 $\mathrm{ft}$ wide and was discretized using $500 \mathrm{ft}$ square cells. A scheme of the system is shown in Figure 3.14. No flow condition at the boundaries and a constant head of $0 \mathrm{ft}$ at the center of the island were set. The main objective was to estimate the value of the recharge rate needed to obtain a steady state solution. The complete set of data files is presented in Appendix F.

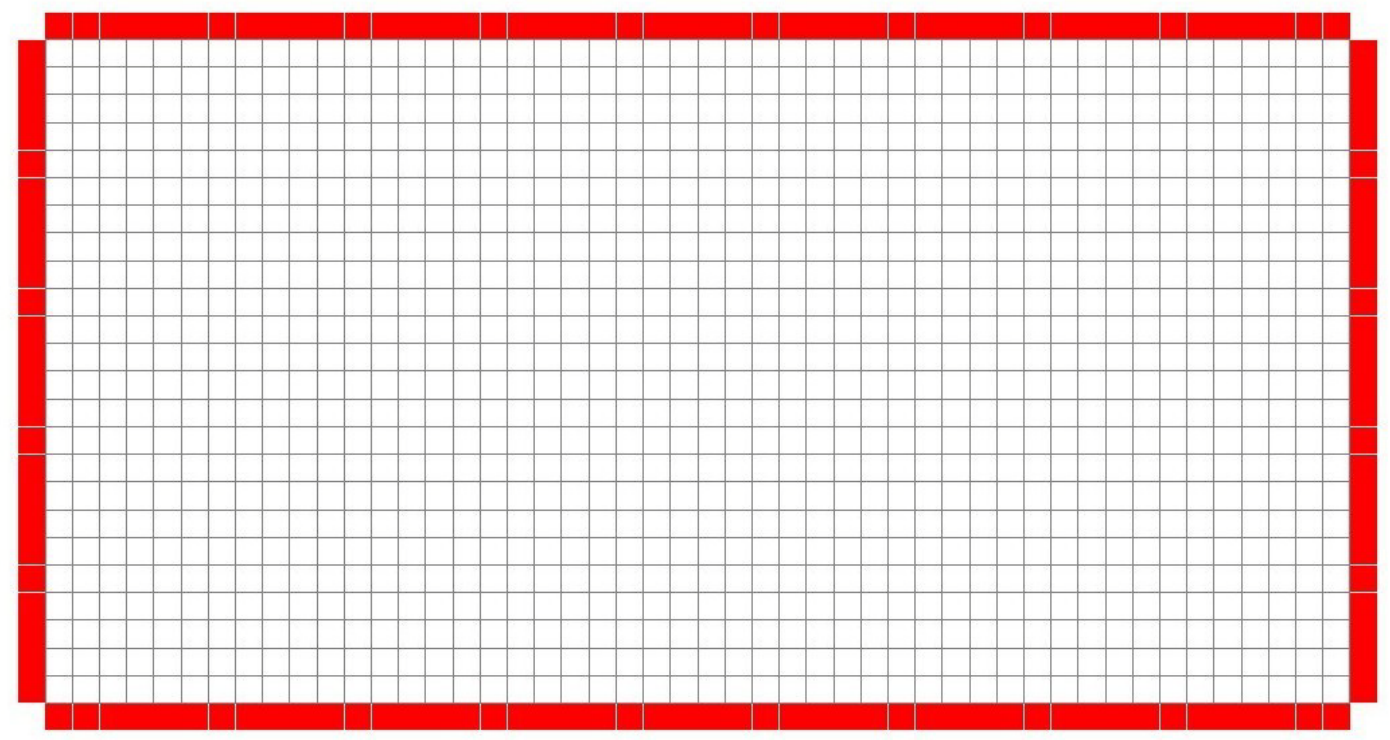

Figure 3.14 Conceptual Model Discretization 
The simulation was tested in MODFLOW-2005 and in WHIMFLO-2D in order to compare the results and the analytical solution was added to have a valid range of values for comparison. Analytical solution was obtained from the double integration of the one dimensional Poisson's equation:

$$
h(x)=-\frac{R}{2 T} \frac{X^{2}}{2}+A x+B
$$

In order to obtain the specific solution, a no flow condition $(d h / d x=0)$ was set at the center of the island along with $\mathrm{h}(\mathrm{x})=0$ at the extremes. This analytical solution was implemented at the center and for the short side of the island from $\mathrm{x}=0 \mathrm{ft}$ to $\mathrm{x}=$ $5,500 \mathrm{ft}$ and from $\mathrm{x}=6,000 \mathrm{ft}$ to $\mathrm{x}=11,500 \mathrm{ft}$.

During the simulation process, the values of the recharge rates were modified until the best approximation to a convergence between all the solutions was achieved, these values were then compared with the recharge rate obtained from the analytical solution.

Optimal recharge rate values for WHIMFLO-2D were obtained after calibrate the percent of impervious flooding area and the surface detention parameter. For this simulation values for $10 \%$ of impervious area and $0.0001 \mathrm{ft}$ of surface detention were obtained. With these calibrated values recharge obtained using WHIMFLO-2D model matched, as expected, the recharge obtained using MODFLOW-2005 and have shown a good fit with the recharge rate obtained using the analytical solution. Recharge rate values for both models and for the analytical solution can be seen in Table 3.3.

Head values also shown a good fit with an overall maximum difference of 0,348 inches. Longitudinal profile for the center of the island can be seen in Figures 3.14 and 3.15. Comparison with the analytical solution is included in Figure 3.16. 


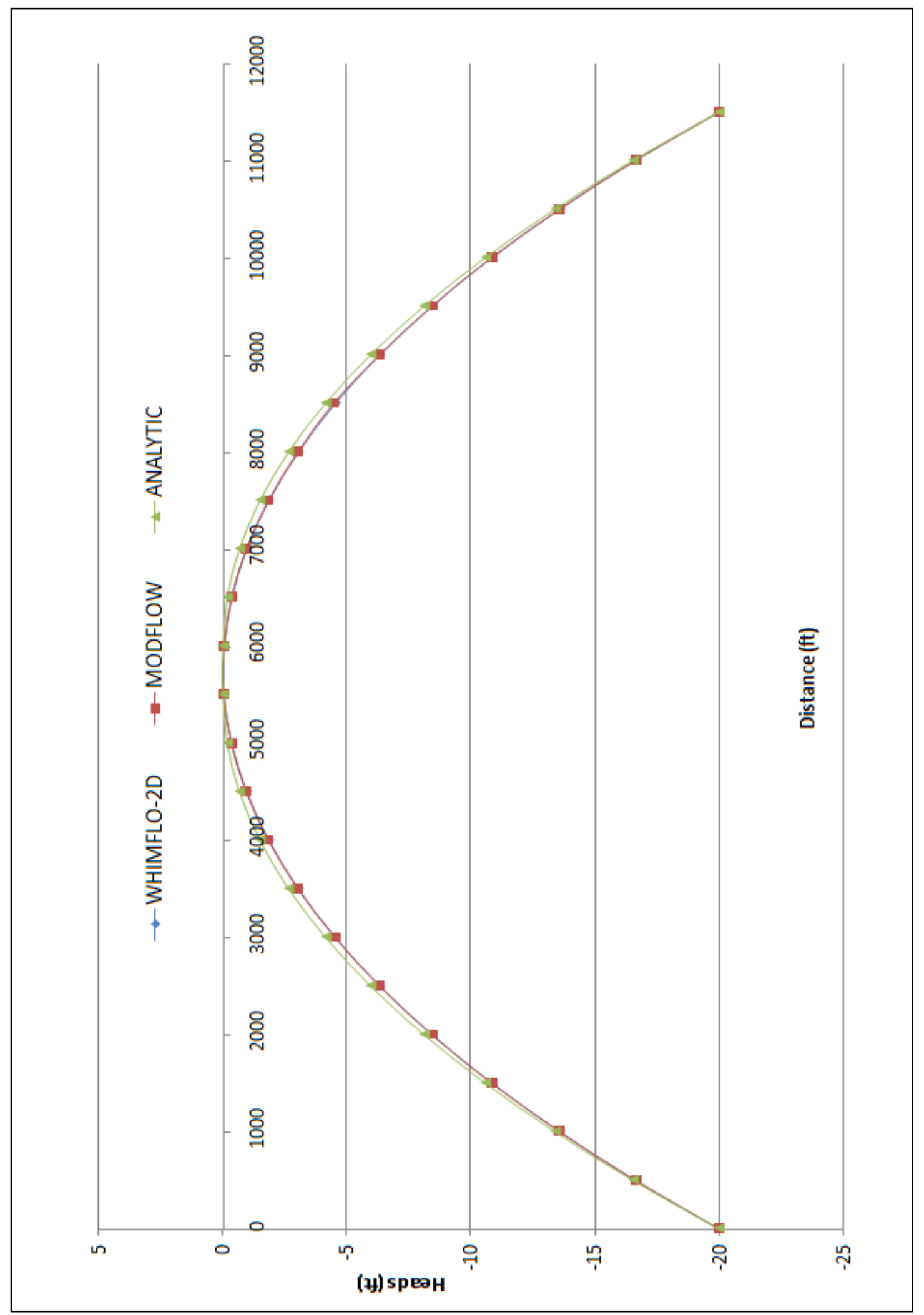

Figure 3.15 Head Comparison for Cross Section at the Center of the Island - Short Side 


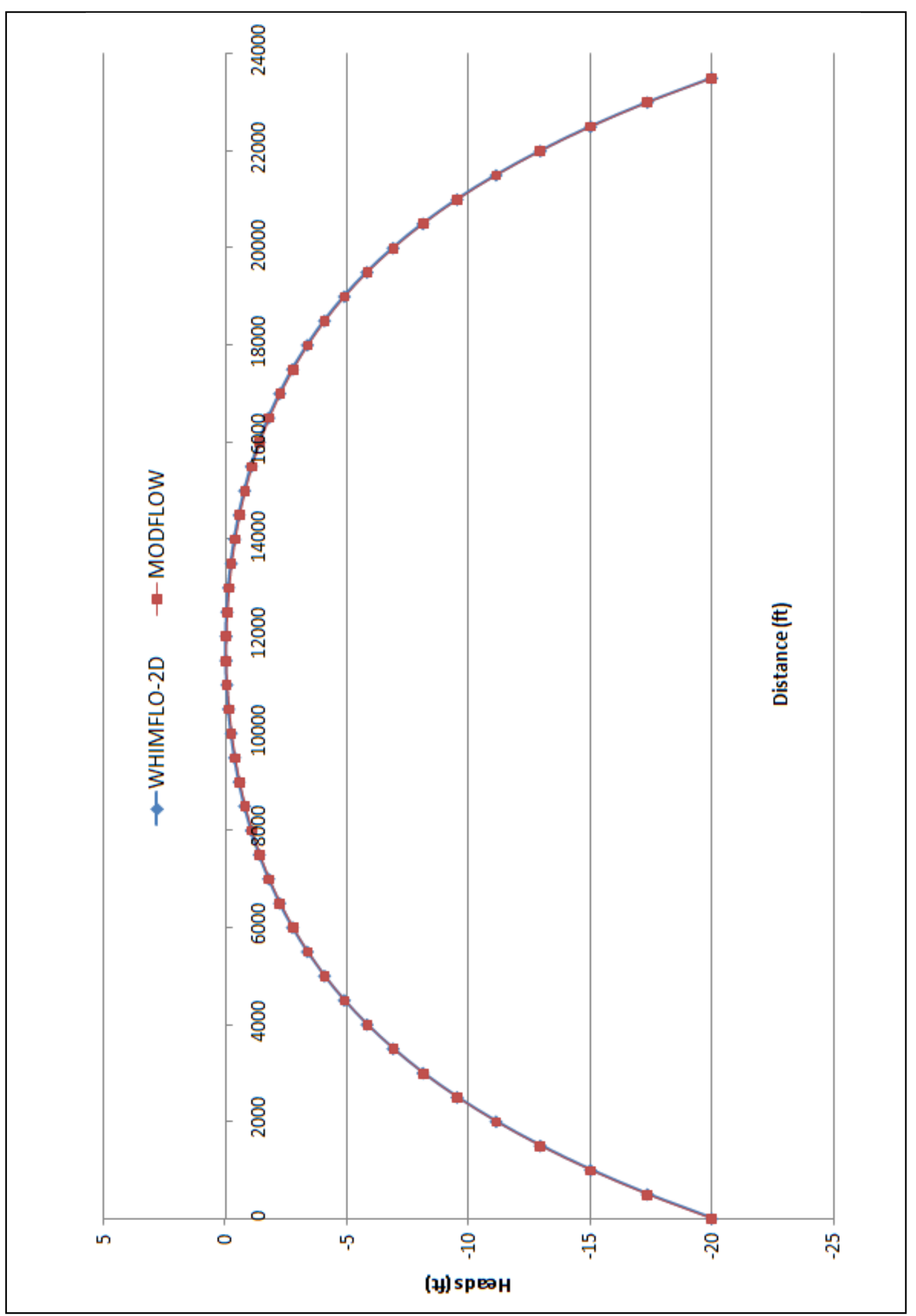

Figure 3.16 Head Comparison for Cross Section at the Center of the Island - Long Side 
Table 3.3 Estimated Recharge Rate Values

\begin{tabular}{|c|c|}
\hline MODEL & Recharge Rate (ft/day) \\
\hline MODFLOW-2005 & 0.01320 \\
\hline WHIMFLO-2D & 0.01320 \\
\hline ANALYTICAL & 0.01322 \\
\hline
\end{tabular}

The comparison between the budgets showed an overall error of $0.167 \%$. Values for the final budget can be seen in Table 3.4. Results from this simulation imply that the coupling between surface and subsurface is working properly for a simple layer case. The complete set of output files is presented in Appendix D.

Table 3.4 Final Cumulative Volumes and Final Rates Comparison

\begin{tabular}{|c|c|c|c|c|}
\cline { 3 - 5 } \multicolumn{2}{c|}{} & $\begin{array}{c}\text { MODFLOW- } \\
2005\end{array}$ & WHIMFLO-2D & $\Delta(\%)$ \\
\hline \multirow{2}{*}{$\begin{array}{c}\text { Cumulative } \\
\text { Volume (cuf) }\end{array}$} & Total Vol. IN & 3340237 & 3345824 & 0.167 \\
\cline { 2 - 5 } & Total Vol. OUT & 3340270 & 3345856 & 0.167 \\
\hline \multirow{2}{*}{ Rates (cfs) } & Total Q IN & 3340239 & 3345824 & 0.167 \\
\cline { 2 - 5 } & Total Q OUT & 3340260 & 3345856 & 0.167 \\
\hline
\end{tabular}

\subsubsection{Multiple Layer Test (Steady-State Simulation)}

The second numerical simulation test was implemented to test the coupling approach for a multiple layer case and to verify that additional MODFLOW-2005 features can be normally used in WHIMFLO-2D without compromising the mathematical accuracy. This simulation is a MODFLOW-2005 benchmark originally developed for the USGS by MacDonald and Harbaugh in 1988 (MacDonald and Harbaugh, 1988) and modified by Harbaugh (Harbaugh, 2005). 
The computational domain was a $75,000 \times 75,000 \mathrm{ft}$ area, discretized in 225 , $5,000 \mathrm{ft}$ square cells. The groundwater domain was formed by 3 aquifers separated by 2 confining beds. The first layer was an unconfined aquifer of $350 \mathrm{ft}$ depth, while the second and third layer represented confined aquifers of $100 \mathrm{ft}$ and $50 \mathrm{ft}$ respectively. The confining beds had a thickness of $50 \mathrm{ft}$ each. The aquifer had a constant recharge of $3 \times 10^{-8}$ $\mathrm{ft} / \mathrm{s}, 15$ wells and 1 drain were also included. No flow boundary conditions were set for layers 1 and 2 at the first column. A scheme of the system is shown in Figure 3.17.

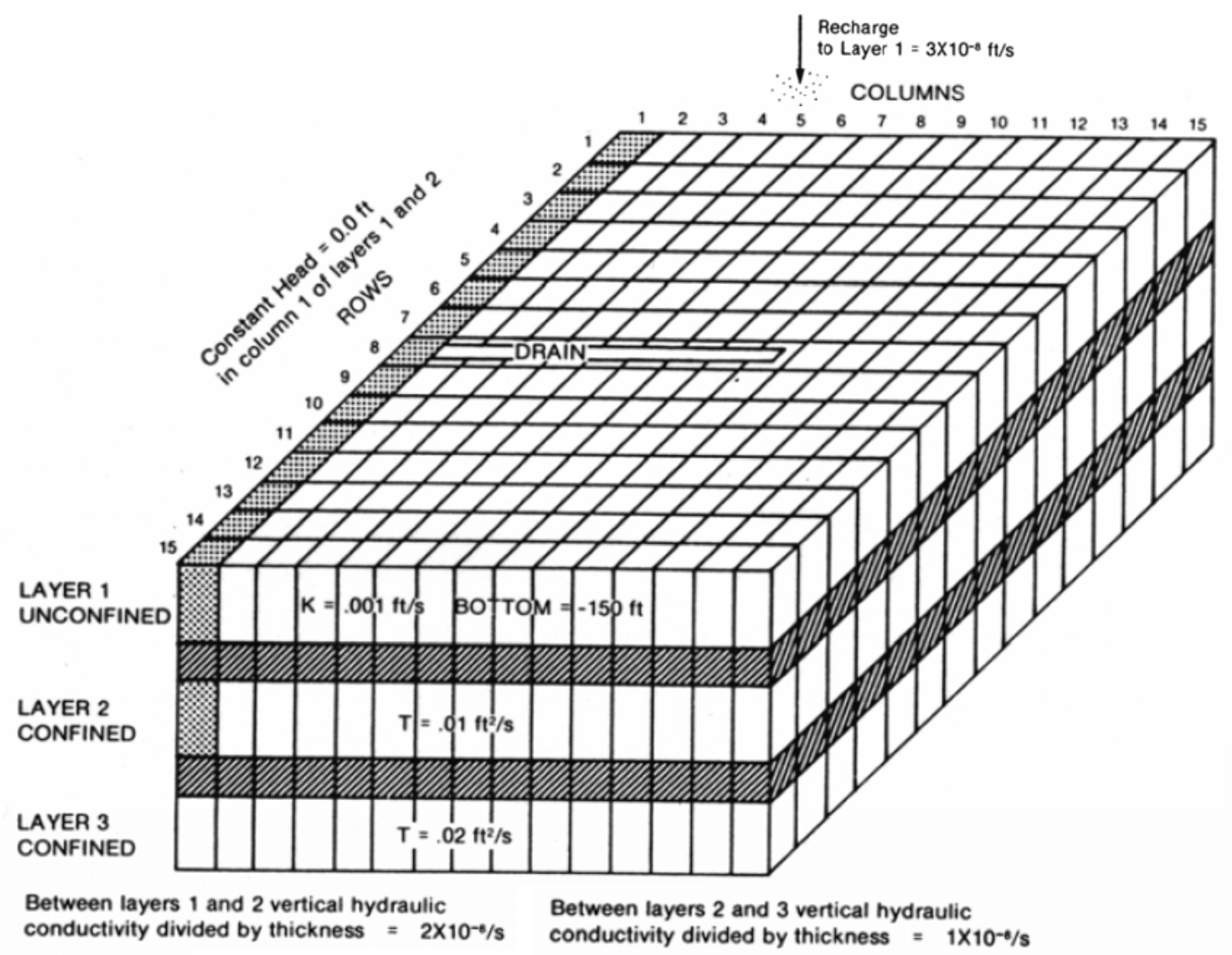

Figure 3.17 Conceptual Model Scheme (Harbaugh, 2005)

In order to set up the simulation in MODFLO-2D, the constant recharge used in MODFLOW-2005 was replaced by an equivalent total rainfall of 0.0311 inches in order 
to satisfy FLO-2D unit requirements and soil porosity was set to a standard value of 0.4 . The complete set of data files is presented in Appendix E.

As all the values needed for the simulation were available, calibration was realized only by modifying the values of percent of impervious flooding area, that will depend on the type and use of the land and the surface detention parameter that depend on the intensity of the rain and the initial saturation. The optimal values obtained were $25 \%$ for the impervious area and $0.0000015 \mathrm{ft}$ for the surface detention parameter.

At the end of the simulation, solution from WHIMFLO-2D showed a very good fit when compared with the solution obtained from Harbaugh using MODFLOW-2005 with differences in head in the order of few inches.

The maximum head difference between the models in all the layers was 1.32 inches. Final head comparison at each layer for rows 1, 7 and 15 can be seen in Figures 3.18a, 3.18b, 3.19a, 3.19b, 3.20a and 3.20b.

It is important to emphasize that the differences in heads were negligible and the small differences between the volumetric budgets are due to the amount of water that is retained in the surface when using the WHIMFLO-2D.

Comparative volumetric budget and rates can be seen at Table 3.5. The complete set of output files is presented in Appendix F.

Table 3.5 Final Cumulative Volumes and Final Rates Comparison

\begin{tabular}{|c|c|c|c|c|}
\cline { 3 - 5 } \multicolumn{2}{c|}{} & $\begin{array}{c}\text { MODFLOW- } \\
2005\end{array}$ & WHIMFLO-2D & $\Delta(\%)$ \\
\hline Cumulative & Total Vol. IN & 13608000 & 13600769 & 0.0531 \\
\cline { 2 - 5 } Volume (cuf) & Total Vol. OUT & 13607603 & 13600371 & 0.0531 \\
\hline \multirow{2}{*}{ Rates (cfs) } & Total Q IN & 157.50 & 157.416 & 0.0533 \\
\cline { 2 - 5 } & Total Q OUT & 157.4954 & 157.4117 & 0.0531 \\
\hline
\end{tabular}




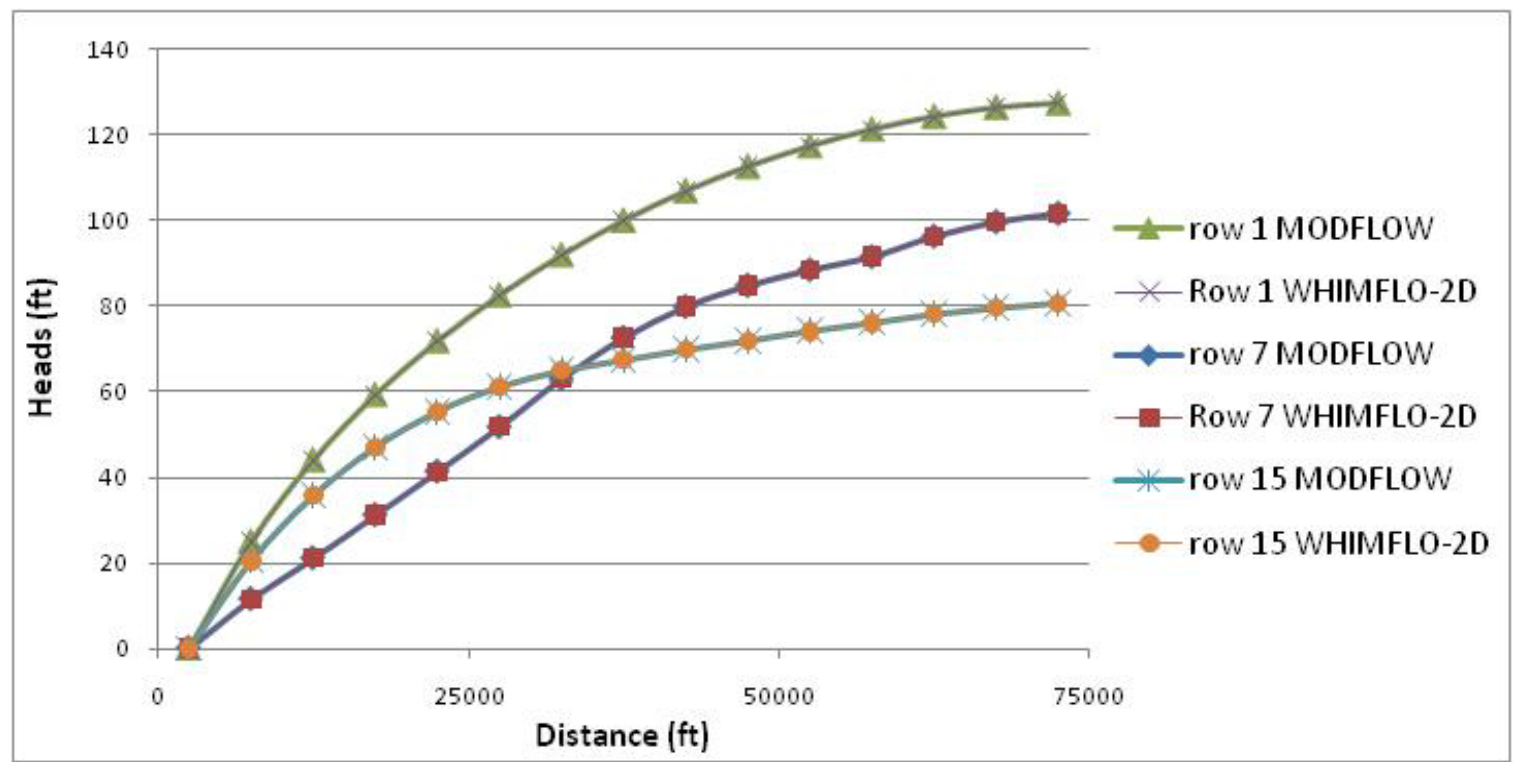

(a)

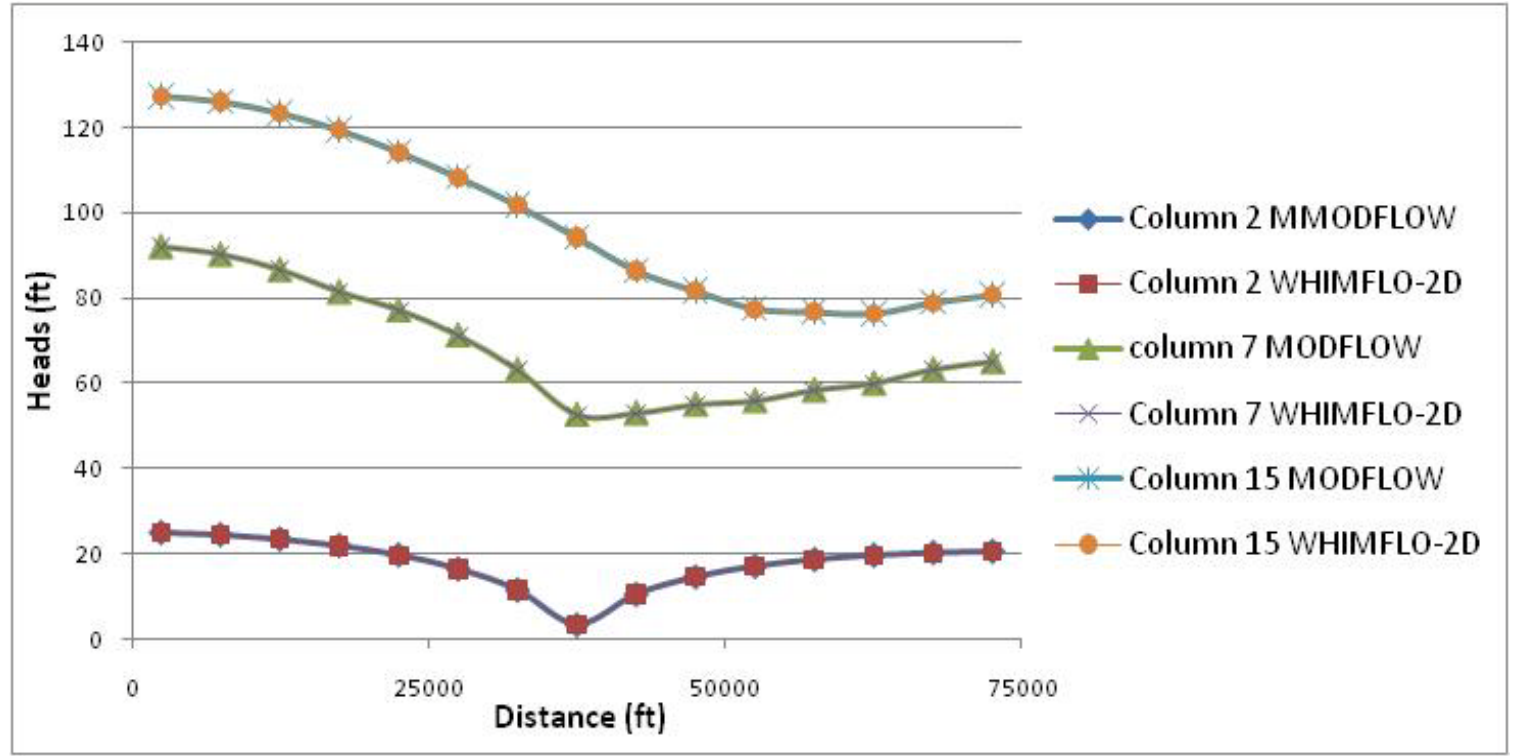

(b)

Figure 3.18 Heads Comparison for Layer 1 


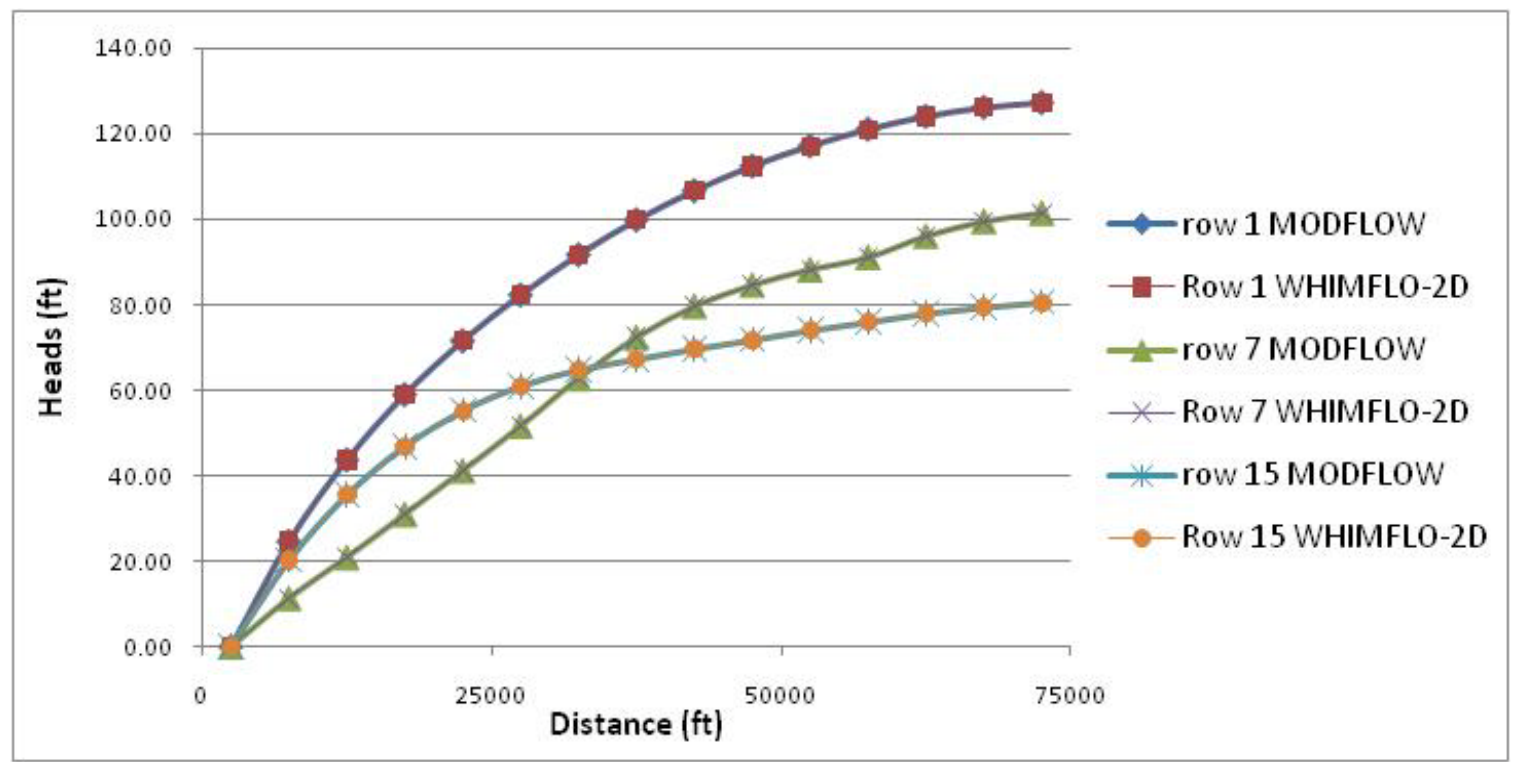

(a)

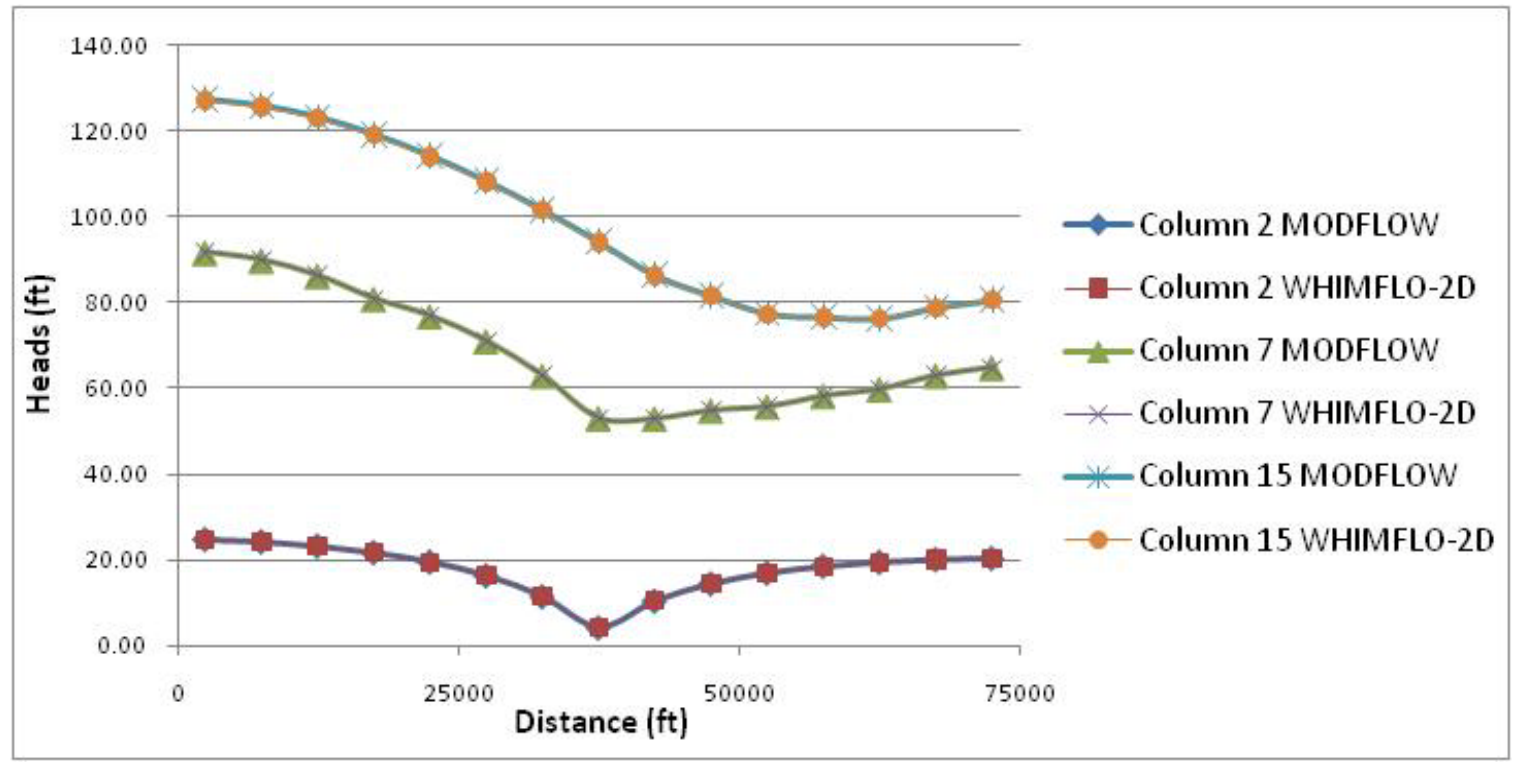

(b)

Figure 3.19 Heads Comparison for Layer 2 


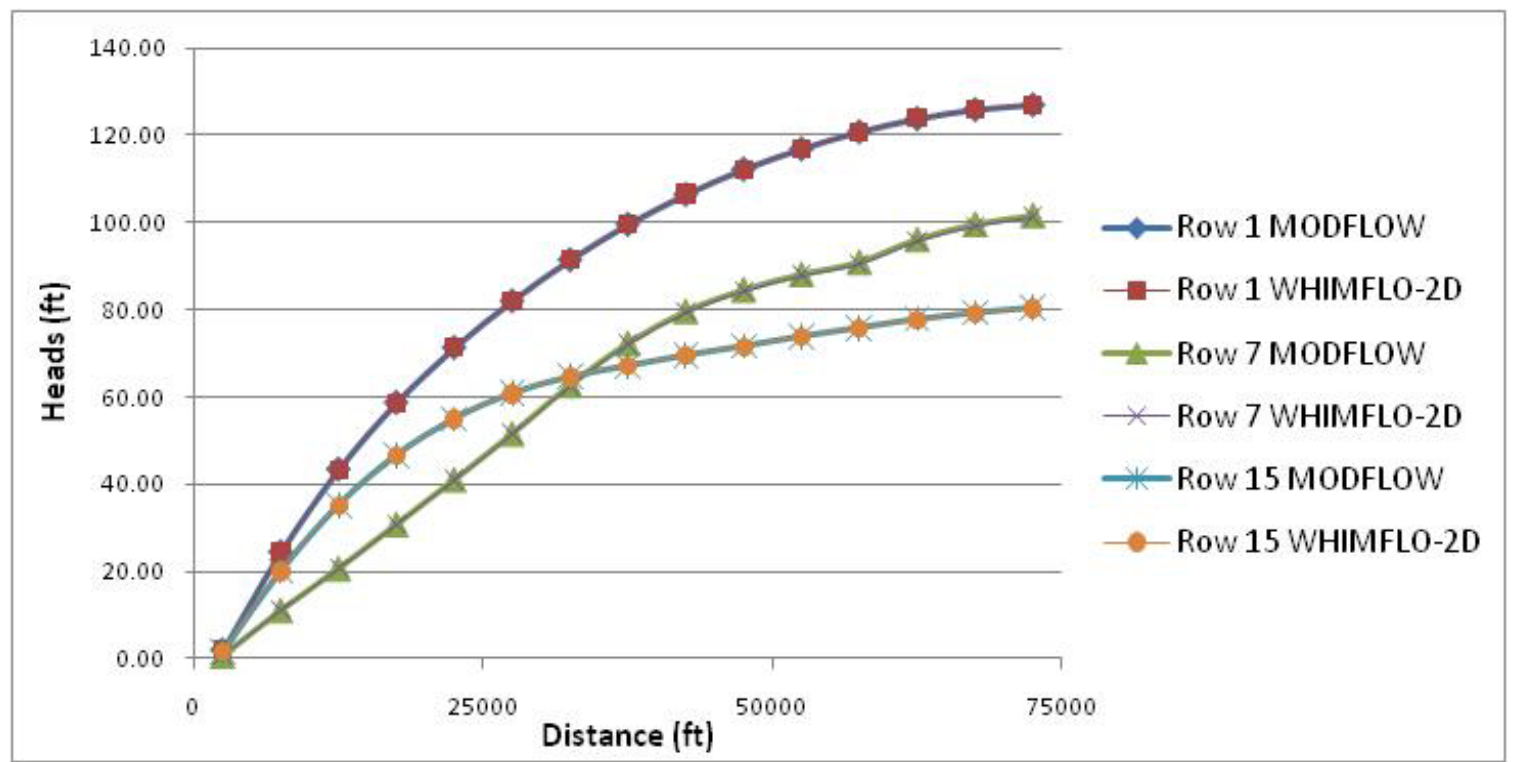

(a)

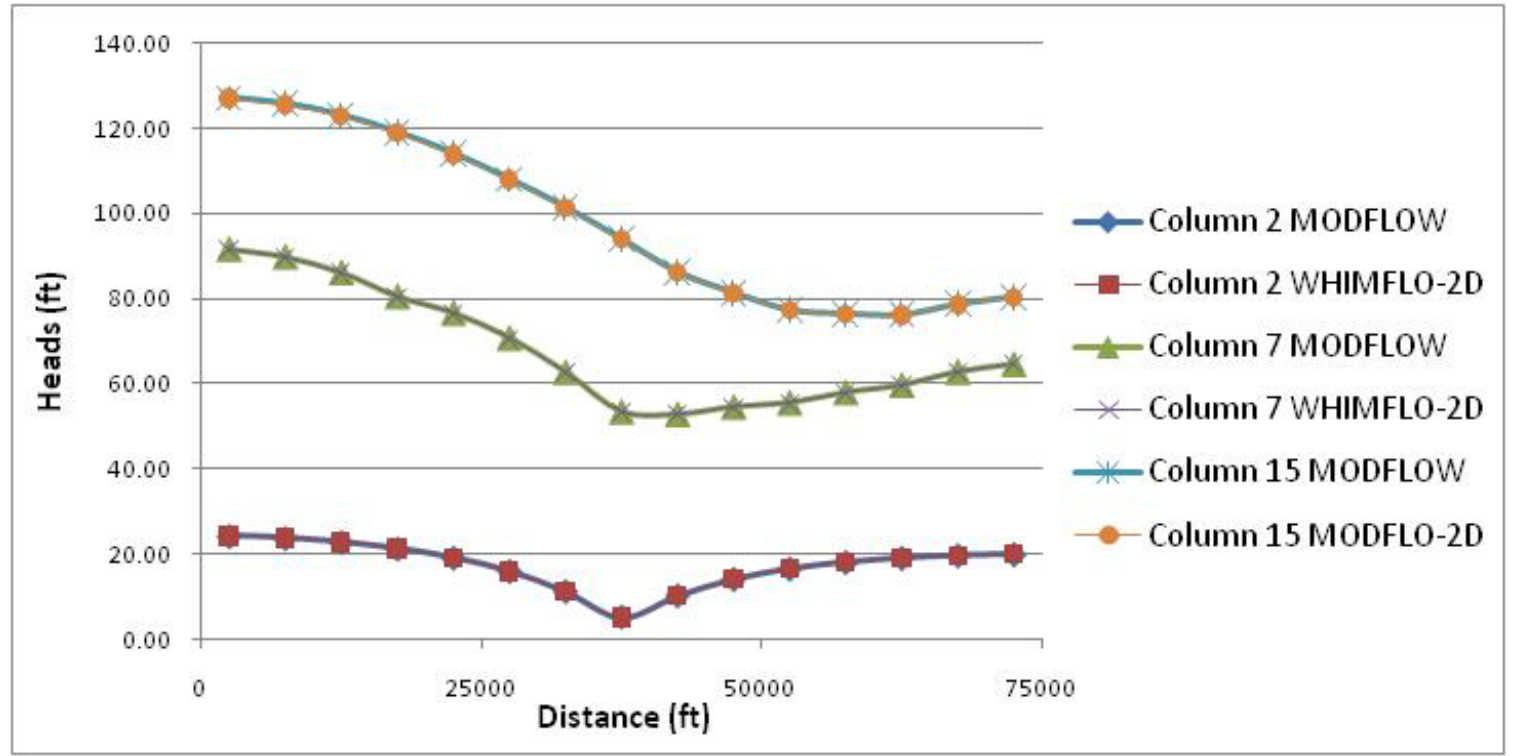

(b)

Figure 3.20 Heads Comparison for Layer 3 


\subsubsection{Comprehensive Scenario (Transient-State Simulation)}

This numerical simulation test had the purpose to test the time coupling between FlO-2D and MODFLOW-2005 for the complete coupling routine that included river infiltration using a transient-state simulation. Additional features were added in order to test multiple stress period simulation and to verifying that modified subroutines did not affect MODFLOW-2005's wetting and drying procedures or the mathematical accuracy. This simulation is a MODFLOW-2005 benchmark originally developed for the USGS by MacDonald in 1992 (MacDonald and others, 1992) in order to test the saturation desaturation process in variable head cells.

The system was composed by two aquifers that discharge into a river whose bottom was located adjacent to the second layer. Aquifers were separated by a confining layer. Upper layer was set as initially dry and a recharge of 0.004 feet per day was applied to the second layer in order to saturate the system. For the second stress period two wells were implemented to withdraw water in order to dry the system. The complete set of data files is presented in Appendix I. Discretized system was a 5,000 ft x 7,500 ft area divided in 10 rows and 15 columns with $500 \mathrm{ft}$ square cells. The top of the system was located at an elevation of $150 \mathrm{ft}$ and was $100 \mathrm{ft}$ thick, the confining bed and the second layer had a thickness of $50 \mathrm{ft}$ each. The bottom of the system was located at an elevation of $-50 \mathrm{ft}$ while the river bottom was located at an elevation of $-5 \mathrm{ft}$. A scheme of the system is shown in Figure 3.21.

In order to obtain the optimal steady state solution, the constant recharge used in MODFLOW-2005 was replaced by equivalent total rainfall of 0.048 inches in order to satisfy FLO-2D unit requirements and soil porosity was set to a standard value of 0.4. 
Additionally, the percent of impervious flooding area and the surface detention parameter were calibrated. The optimal values obtained were $30 \%$ for the impervious area and $0.0001 \mathrm{ft}$ for the surface detention parameter.

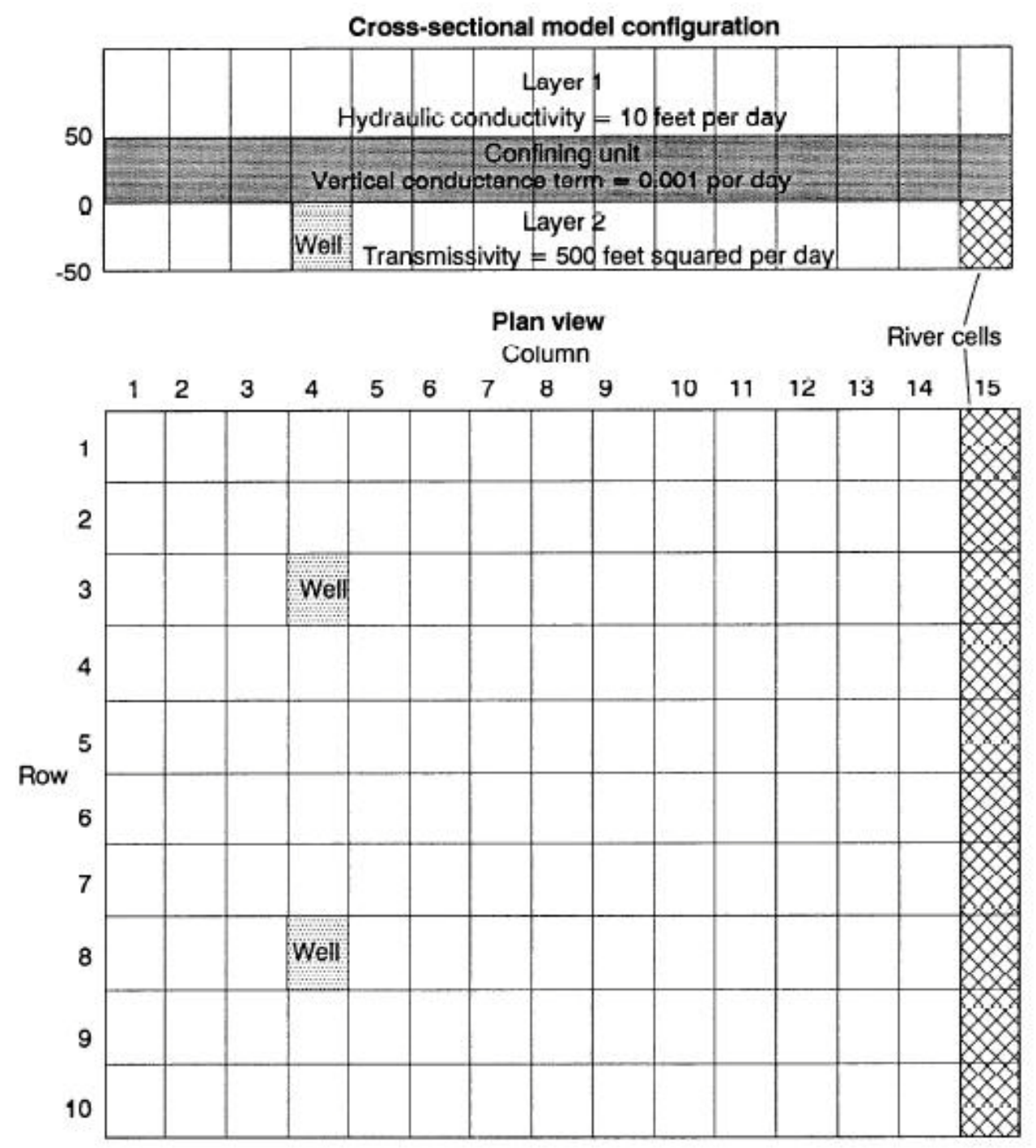

Figure 3.21 Discretized Model (MacDonald et al., 1992)

At the end of the simulation, solution from WHIMFLO-2D had shown once more a very good fit with the solution obtained by McDonald using MODFLOW-2005. This imply that WHIMFLO-2D coupling routines work properly also in the presence of multiple stress times and with wet and dry conditions in the upper underground layer. It's 
also important that new coupling routine for rivers properly simulate the infiltration process even with the bottom located at the second layer of the system.

For the first stress period when recharge was applied directly to the second layer and the first layer was became active as cells became wet, result show a good fit for both layers when compared with original values from MODFLOW-2005 with a maximum difference in head of 2.4 inches. Figure 3.22 shows the surface for layer 1 at the end of stress time one while comparison between heads can be seen in Figure 3.23. As head values are uniform along columns results, only results for the longitudinal center of the domain were plotted.

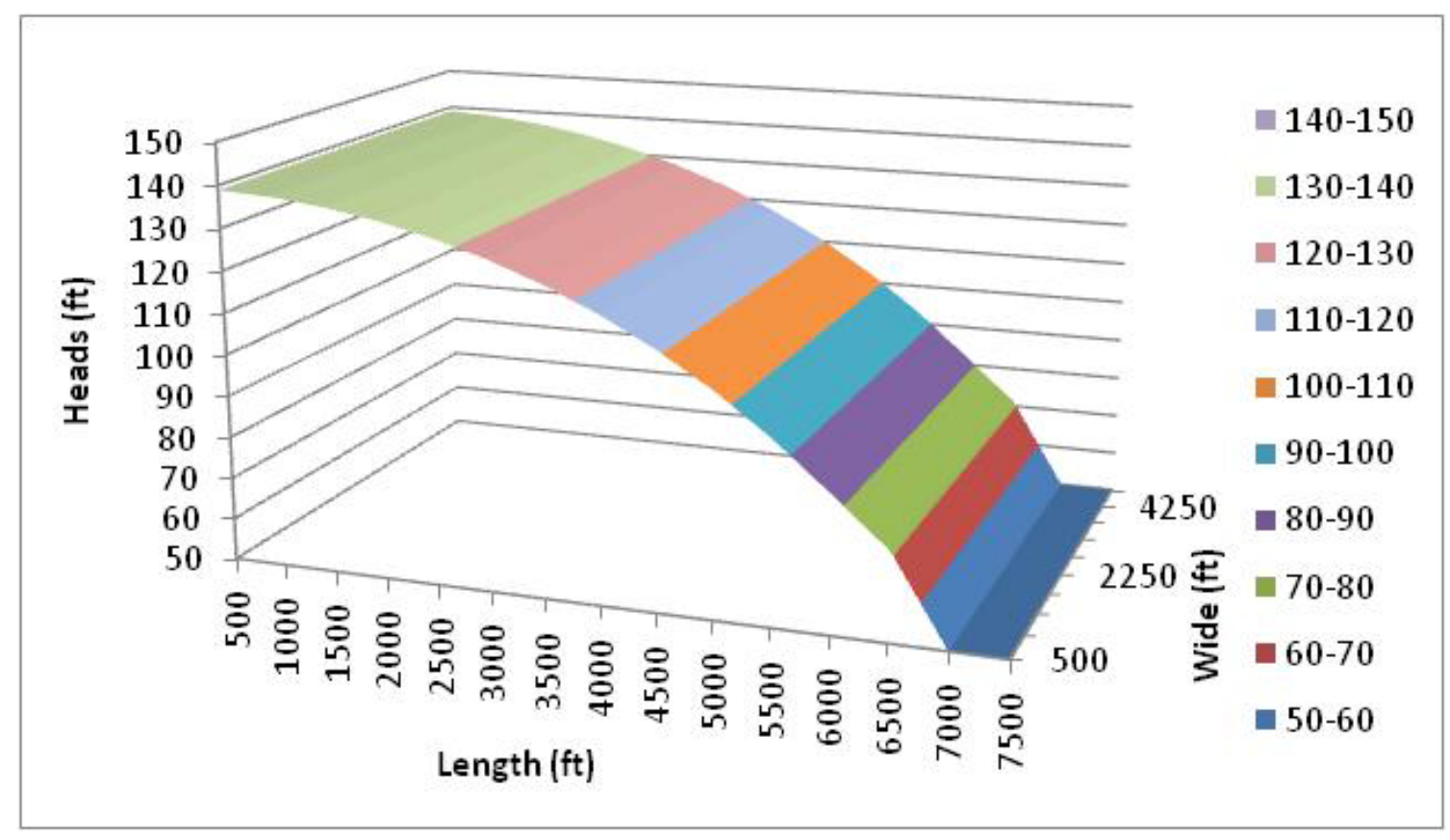

Figure 3.22 Surface Plot - Layer 1 - Stress Period 1

Figure 3.24 shows the surface for heads in layer 2 at the end of stress time one while comparison between heads can be seen in Figure 3.25. As head values are 
uniform along columns results, only results for the longitudinal center of the domain were plotted.

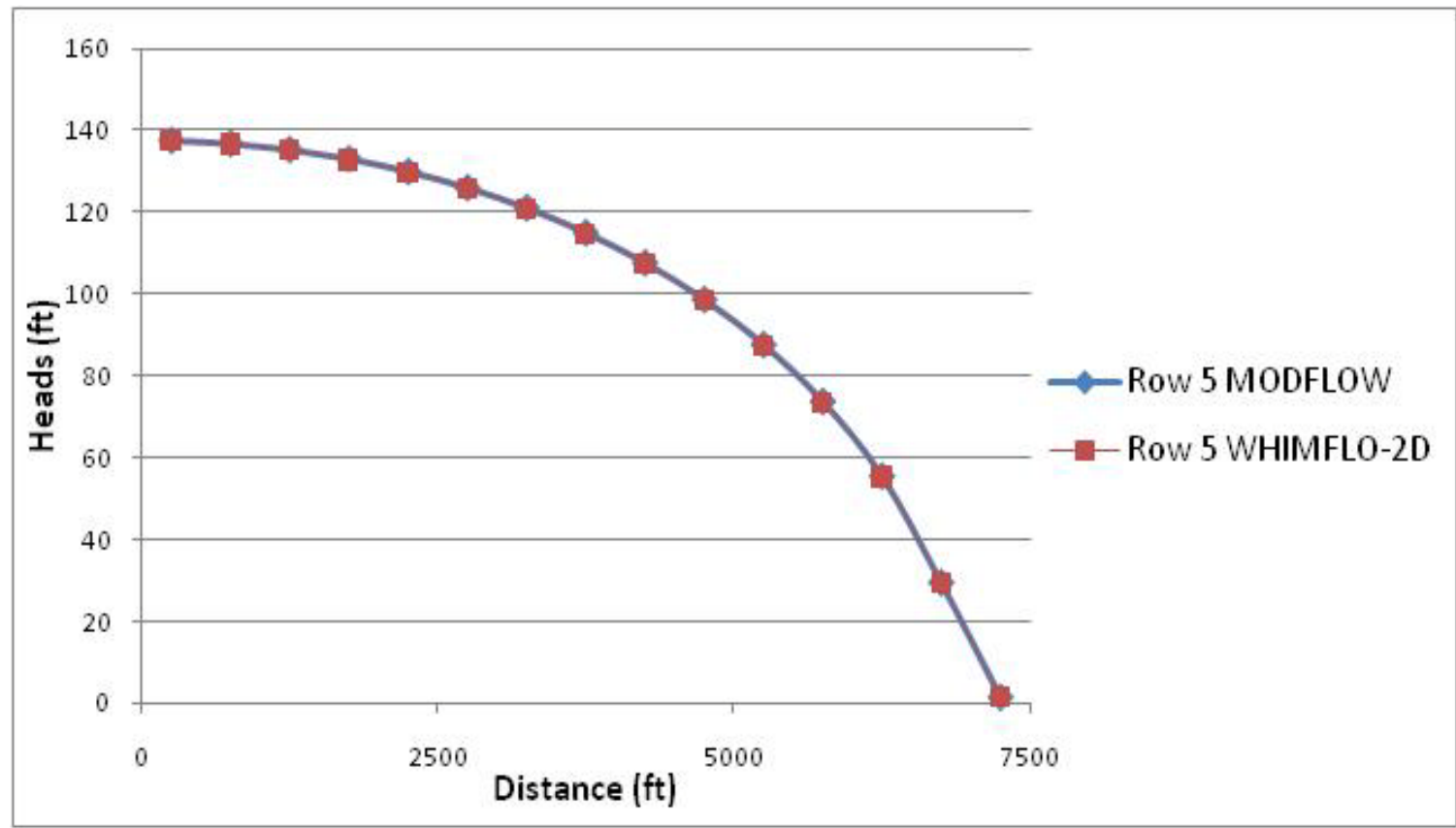

Figure 3.23 Longitudinal Profile - Layer 1 - Stress Period 1

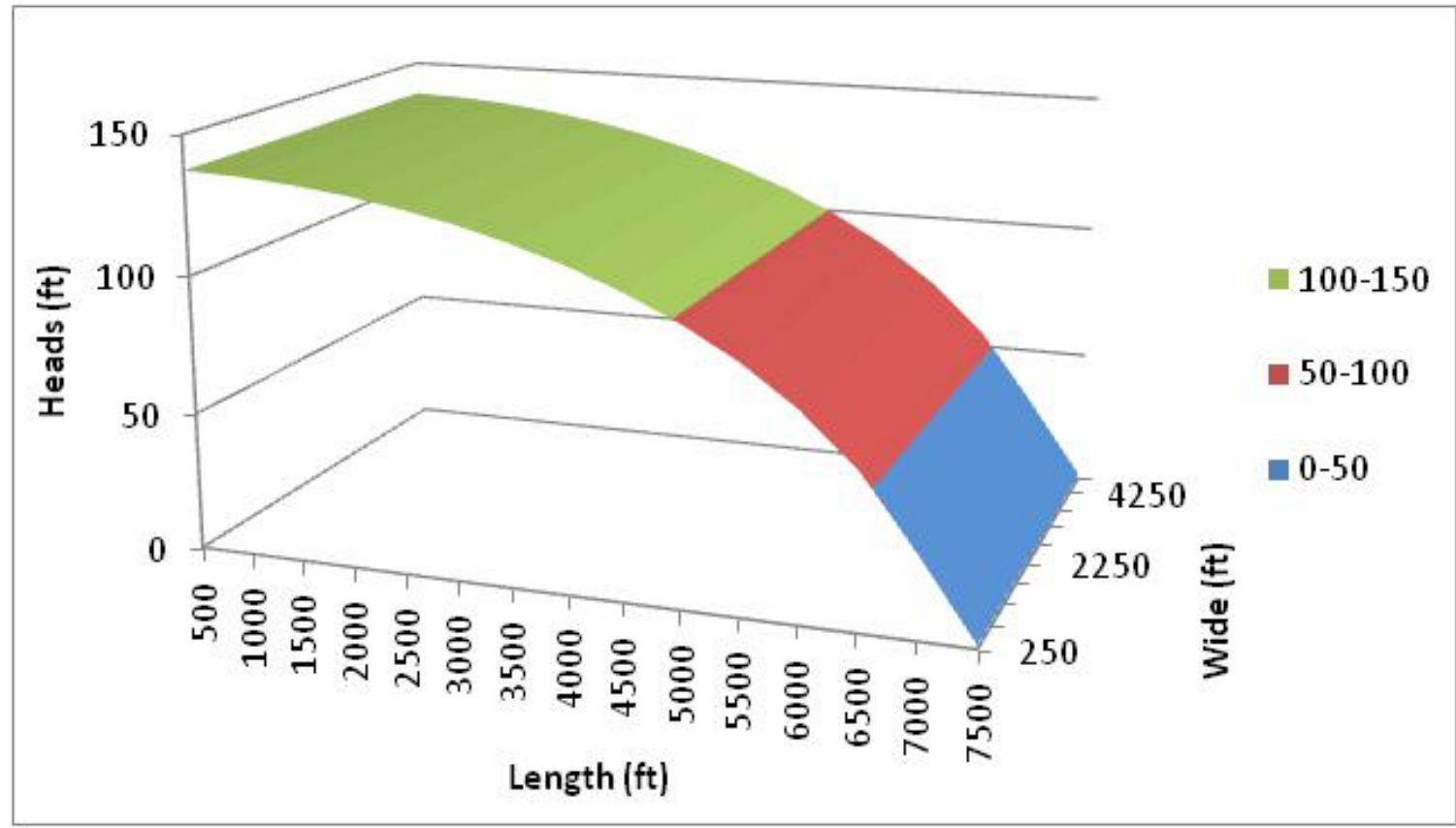

Figure 3.24 Surface Plot - Layer 2 - Stress Period 1 


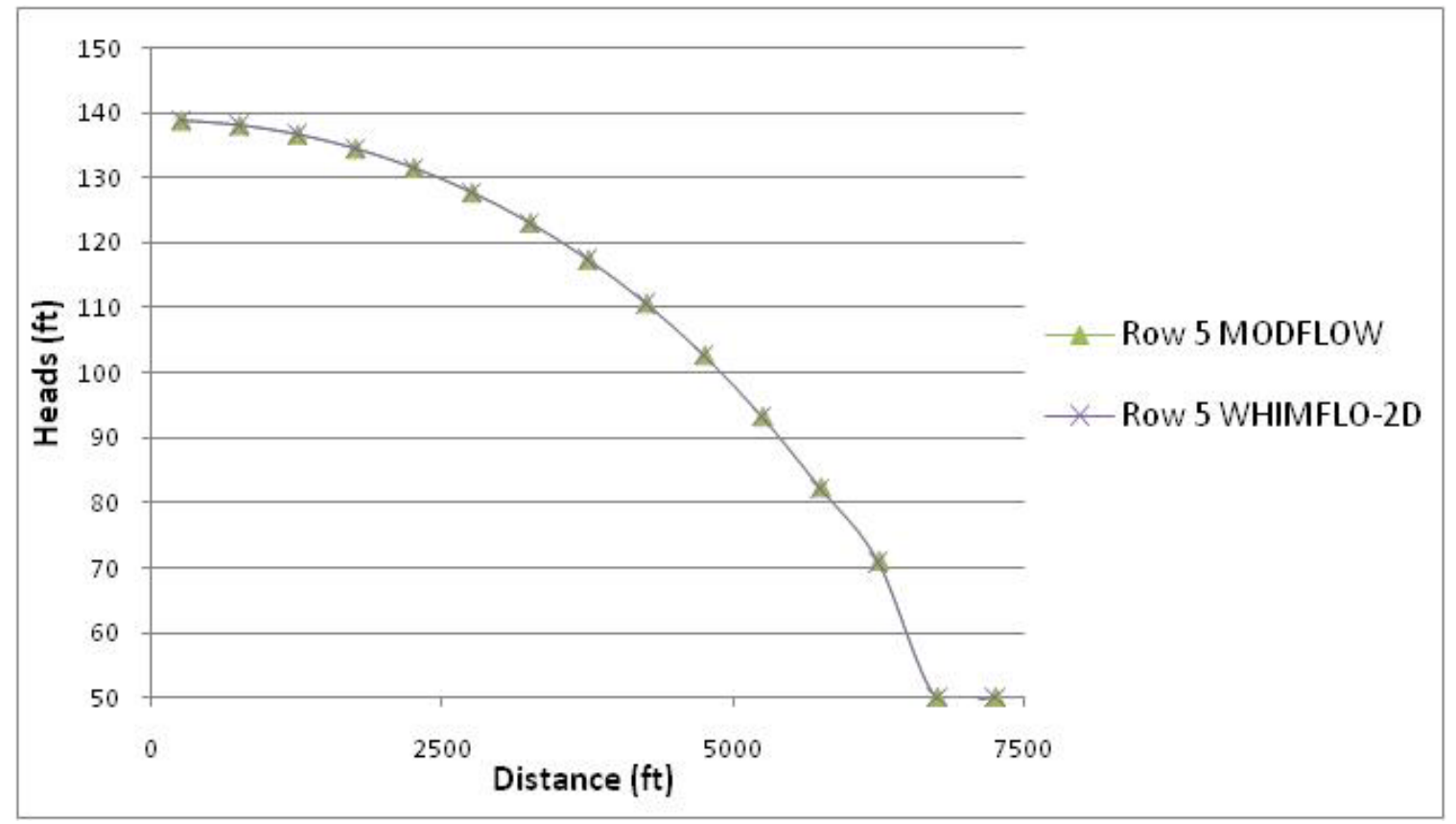

Figure 3.25 Longitudinal Profile - Layer 2 - Stress Period 1

The difference between the volumetric budgets obtained from WHIMFLO-2D and MODFLOW-2005 for the first stress period was 5.45\%. Comparative volumetric budget and rates can be seen at Table 3.6

Table 3.6 Final Cumulative Volumes and Final Rates Comparison for Stress Period 1

\begin{tabular}{|c|c|c|c|c|}
\cline { 3 - 5 } \multicolumn{2}{c|}{} & $\begin{array}{c}\text { MODFLOW- } \\
2005\end{array}$ & $\begin{array}{c}\text { WHIMFLO- } \\
\text { 2D }\end{array}$ & $\Delta(\%)$ \\
\hline \multirow{2}{*}{$\begin{array}{c}\text { Cumulative } \\
\text { Volume (cuf) }\end{array}$} & Total Vol. IN & 150000.0156 & 141818.1094 & 5.45 \\
\cline { 2 - 5 } & Total Vol. OUT & 150000.0156 & 141818.1094 & 5.45 \\
\hline \multirow{2}{*}{ Rates (cfs) } & Total Q IN & 150000.0156 & 141818.1094 & 5.45 \\
\cline { 2 - 5 } & Total Q OUT & 150000.0156 & 141818.1094 & 5.45 \\
\hline
\end{tabular}

Results from the second stress period that include the effect of wells pumping out water from the system shown that coupling routines can handle the effects of wetting and drying without any problem. Maximum head differences for stress period number two are 
in the order of 4.9 inches. Figure 3.26 shows the surface for layer 1 at the end of stress time number two, while comparison between heads can be seen in Figure 3.27. As head values are uniform along columns results, only results for one of the profiles that include wells were plotted.

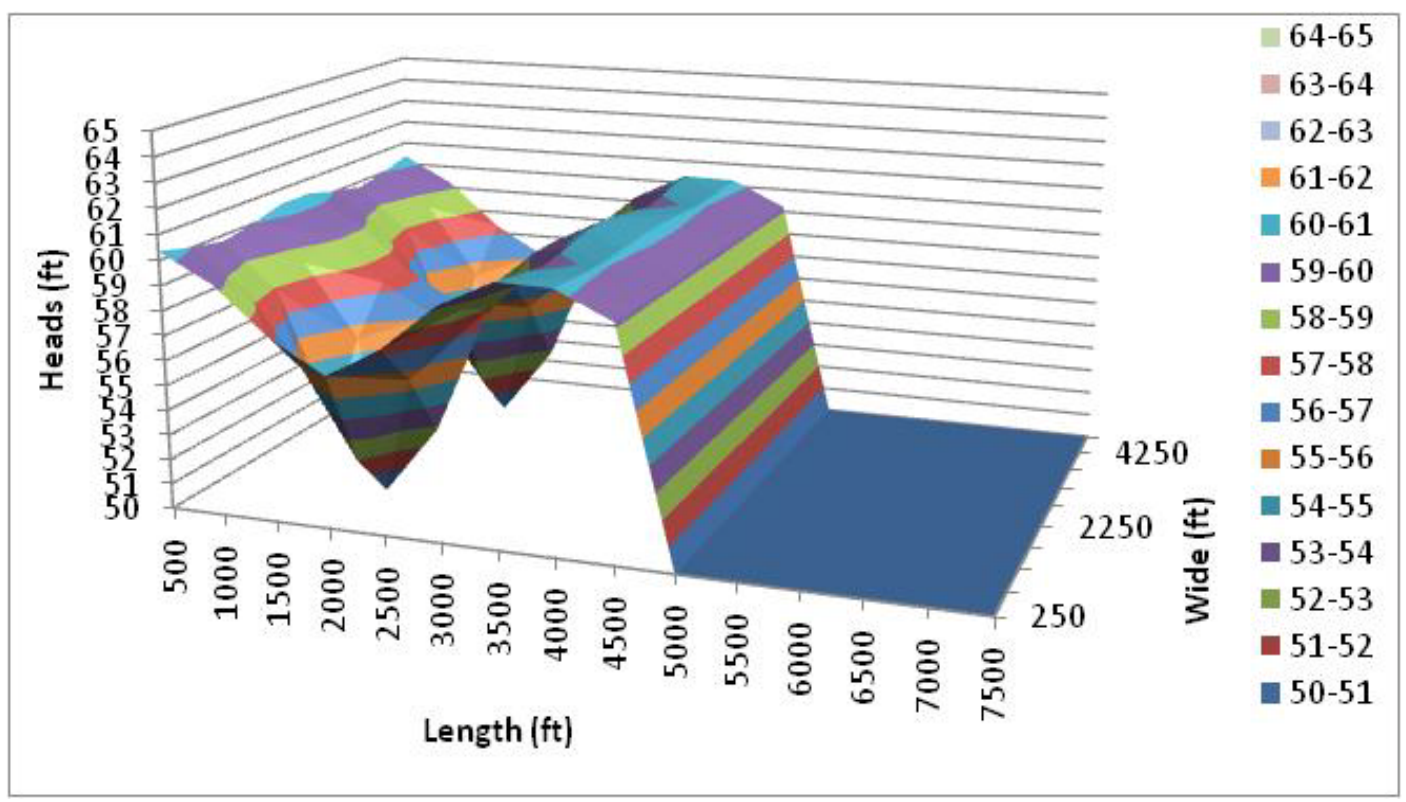

Figure 3.26 Surface Plot - Layer 1 - Stress Period 2

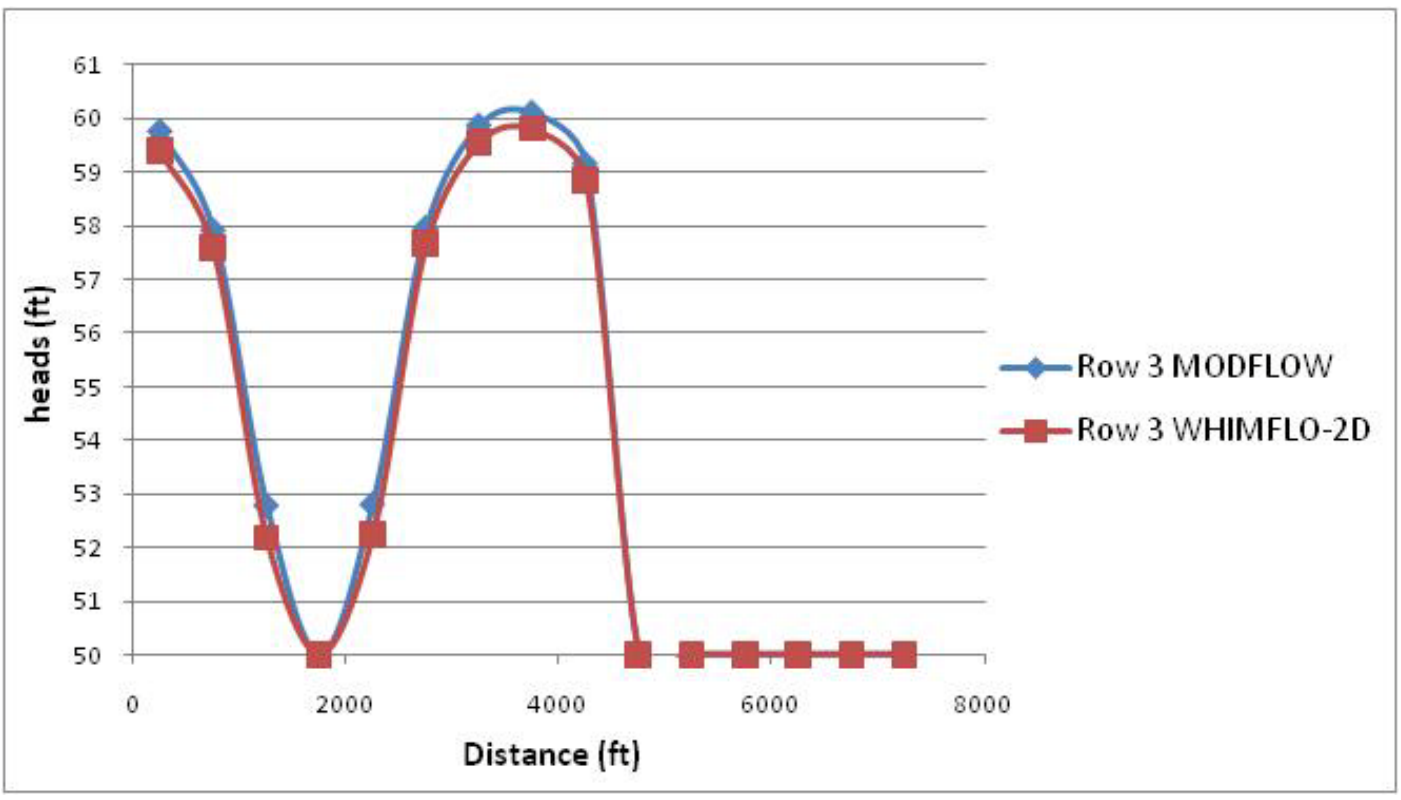

Figure 3.27 Longitudinal Profile - Layer 1 - Stress Period 2 
Figure 3.28 shows the surface for heads in layer 2 at the end of stress time one while comparison between heads can be seen in Figure 3.29. As head values are uniform along columns results, only results for one of the profiles that include wells were plotted.

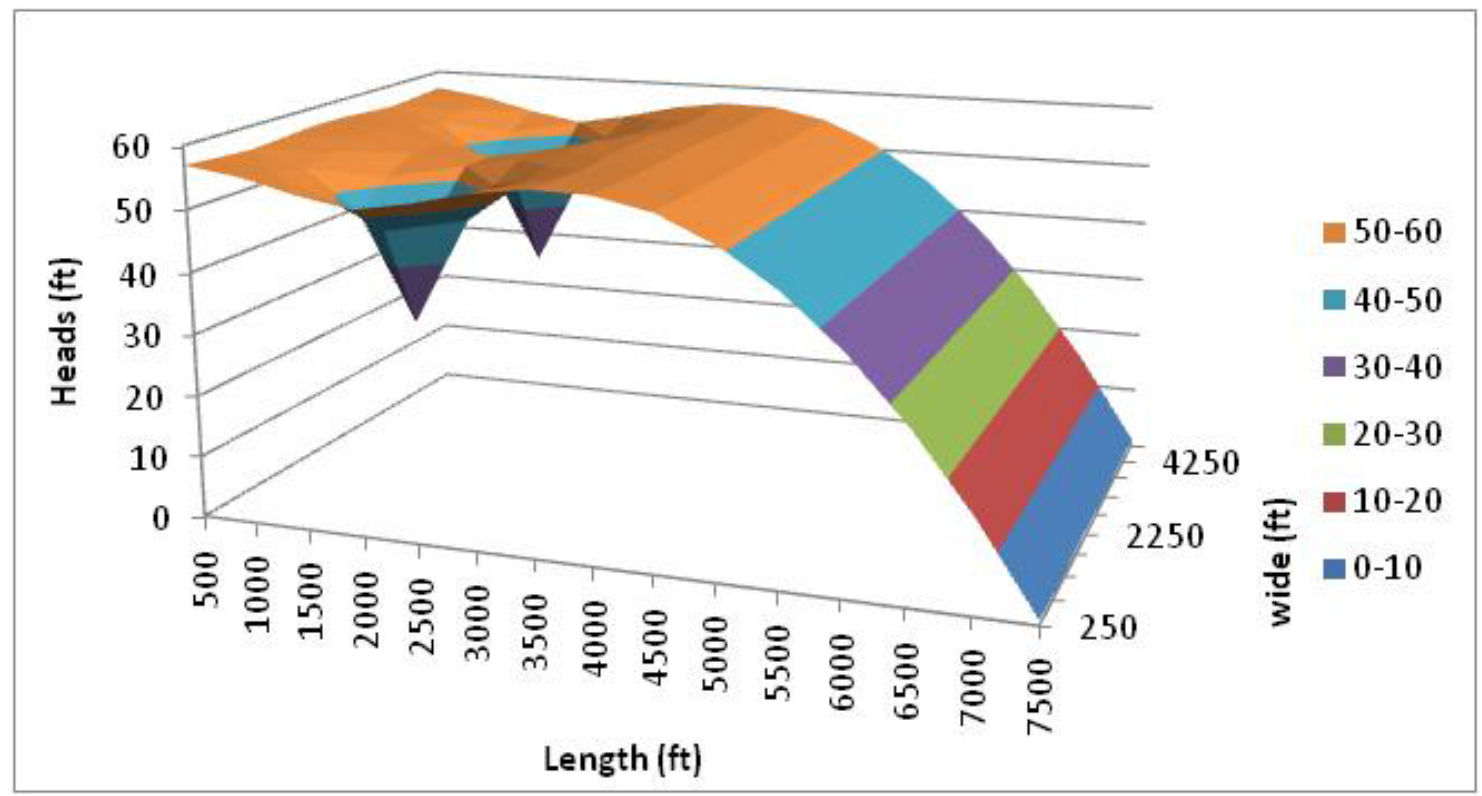

Figure 3.28 Surface Plot - Layer 1 - Stress Period 2

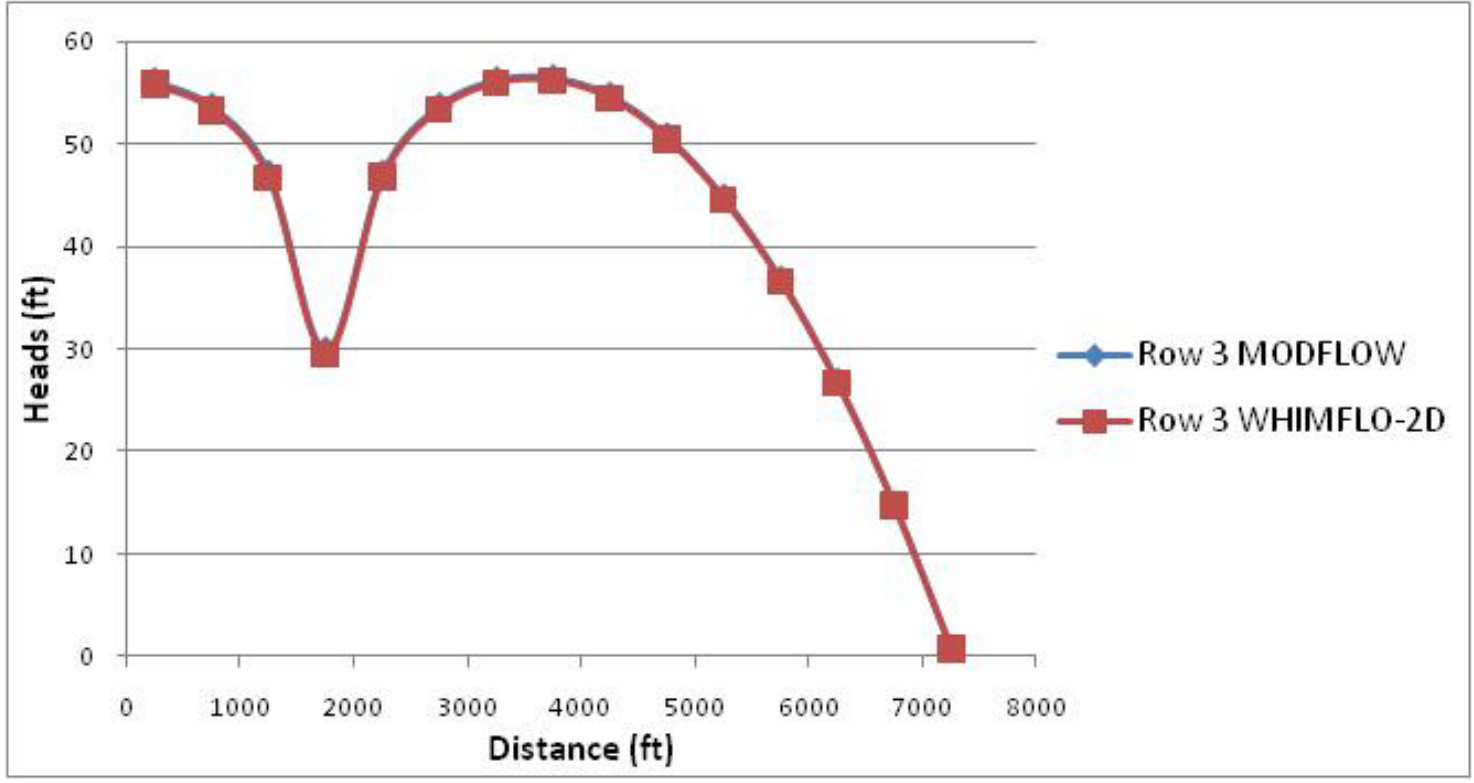

Figure 3.29 Longitudinal Profile - Layer 1 - Stress Period 2 
The difference between the volumetric budgets obtained from WHIMFLO-2D and MODFLOW-2005 for the second stress period was also 5.45\%. Comparative volumetric budget and rates can be seen at Table 3.7. The complete set of output files is presented in Appendix G.

Table 3.7 Final Cumulative Volumes and Final Rates Comparison for Stress Period 2

\begin{tabular}{|c|c|c|c|c|}
\cline { 3 - 5 } \multicolumn{2}{c|}{} & $\begin{array}{c}\text { MODFLOW- } \\
2005\end{array}$ & $\begin{array}{c}\text { WHIMFLO- } \\
\text { 2D }\end{array}$ & $\Delta(\%)$ \\
\hline \multirow{2}{*}{$\begin{array}{c}\text { Cumulative } \\
\text { Volume (cuf) }\end{array}$} & Total Vol. IN & 300000.0312 & 283636.2188 & 5.45 \\
\cline { 2 - 5 } & Total Vol. OUT & 300000.0312 & 283636.2188 & 5.45 \\
\hline \multirow{2}{*}{ Rates (cfs) } & Total Q IN & 150000.0156 & 141818.1094 & 5.45 \\
\cline { 2 - 5 } & Total Q OUT & 150000 & 141818.125 & 5.45 \\
\hline
\end{tabular}

\subsubsection{Vegetation Resistance Approach.}

Data from the experiments of Velasco et al. (2003) was used to test the approach used to simulate the effect of the resistance of vegetation in the surface flow. This data was obtained from an experiment developed in a $20 \mathrm{~m}$ long, $1 \mathrm{~m}$ wide and $0.91 \mathrm{~m}$ deep experimental flume. Plastic plants were setup along the flume and gravel particles were deposited in the bottom. Discharge rates from 20 lps to 160 lps were used in order to obtain an wide range of conditions. Flume bed friction was set to 0.025 .

Values from these experiments were used as an input to test the proposed methodology. Three different plant densities were used 156, 100 and 70 plants $/ \mathrm{m}^{2}$.

For the first series the value of $\mathrm{K}_{0}$ was calibrated, this value was then maintained for the rest of the simulations. The obtained calibrated value was $\mathrm{K}_{0}=0.9$. 
In order to compare the calculated and simulated values, the Manning's coefficient was transformed to friction factor by using the expression (Panday and Huyakorn, 2004):

$$
f=8 \frac{g n^{2}}{h^{1 / 3}}
$$

where $n$ is the Manning's roughness coefficient, $h$ is the water depth and $g$ is the acceleration of gravity.

Calculated values showed a good fit with values form the flume for the lowest Reynolds numbers, for higher Reynolds numbers the calculated values by using the proposed methodology were lower than those measured in the flume and all felled almost bellow the bed roughness value. The reason is that in this deep limited flume higher Reynolds numbers were related with high flows velocities and this methodology is not intended to deal with those conditions, but in any case, it is important to remember that for these conditions bending vegetation could probably have no influence in the flow so the resistance will be only due to bed friction.

For the less dense conditions results do not show a very good fit for most of the values. Comparison of results can be seen at Figures 3.30, 3.31 and 3.32.

Figure 3.33 shows how the calculated Manning's roughness coefficients behave as expected. By increasing the Reynolds number the value of the coefficients start to decay until they all tend to converge to the same values, which is approximate to the initial bed roughness coefficient value and showing the direct dependency to the flow depth and velocity. 


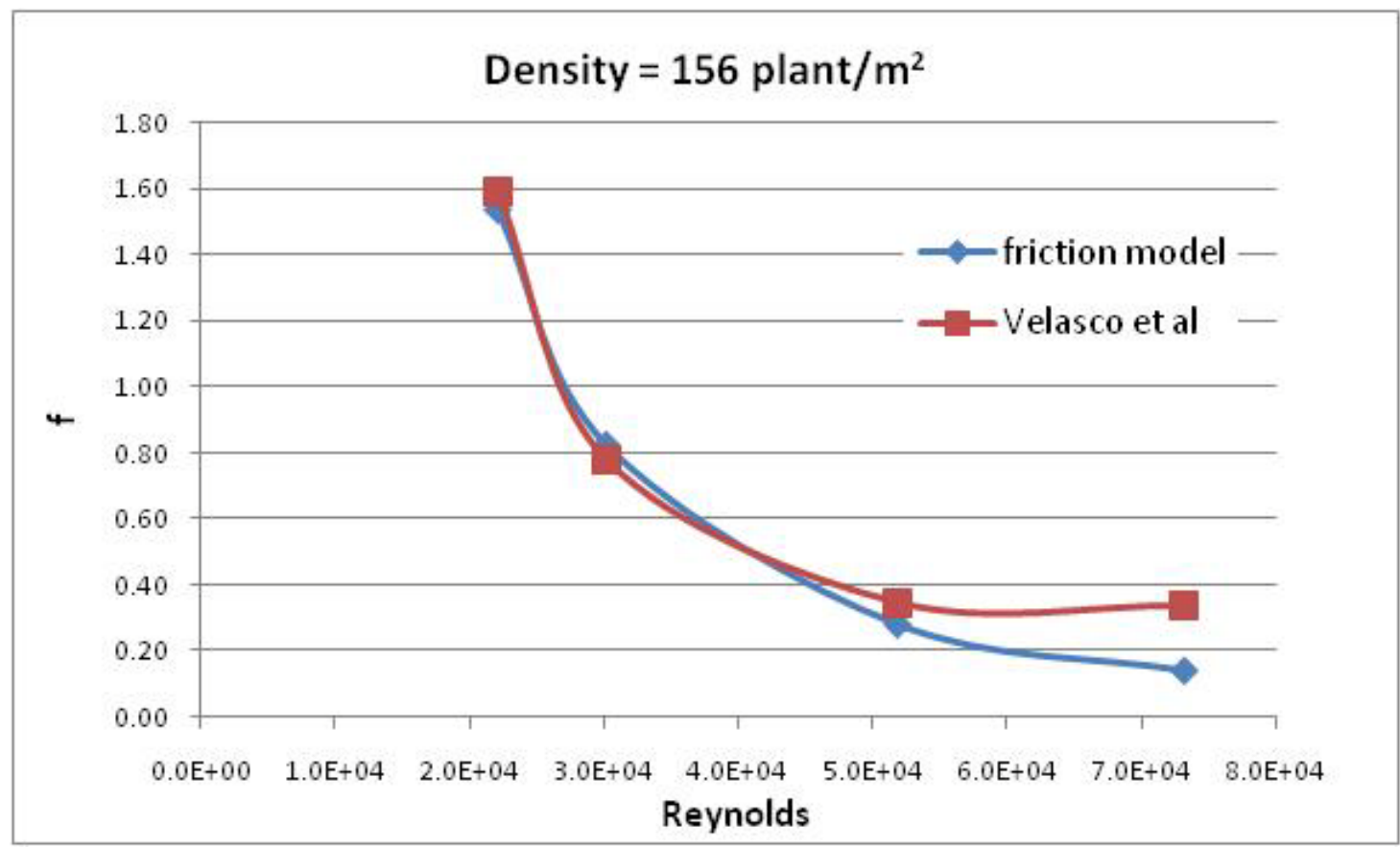

Figure 3.30 Calculated $f$ vs. Measured $f$ for $D=156$

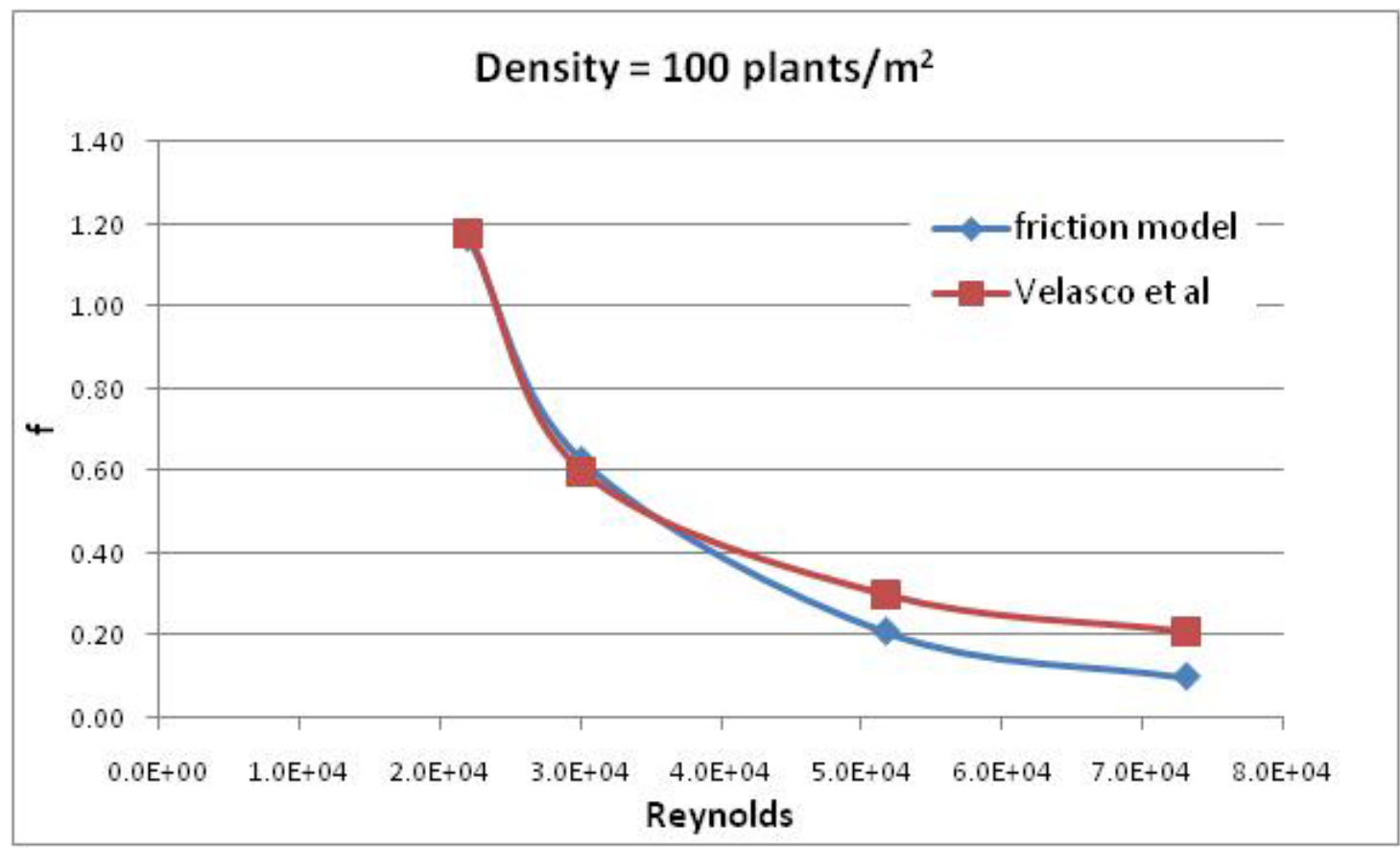

Figure 3.31 Calculated $f$ vs. Measured $f$ for $D=100$ 


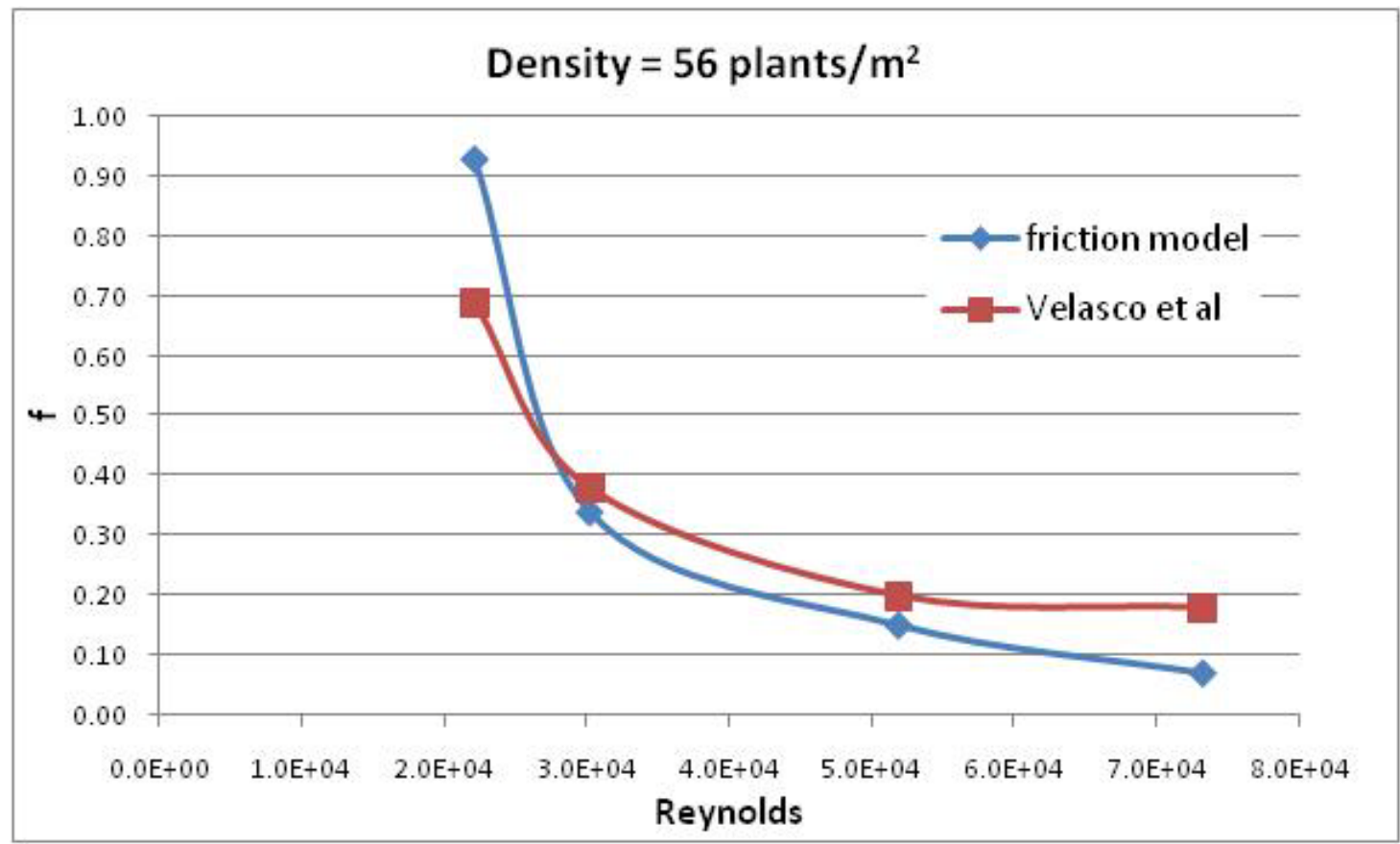

Figure 3.32 Calculated $\mathrm{f}$ vs. Measured $\mathrm{f}$ for $\mathrm{D}=\mathbf{5 6}$

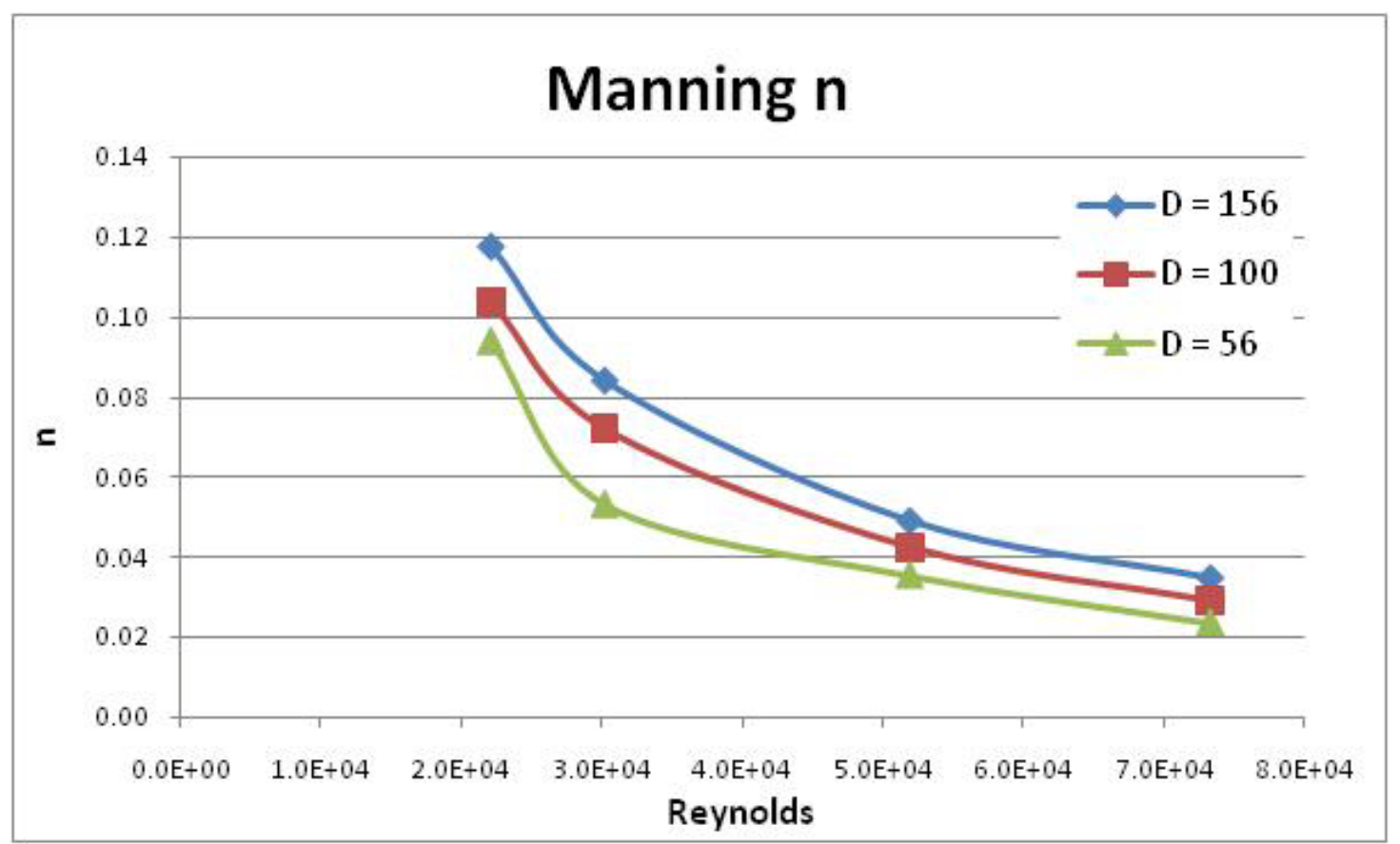

Figure 3.33 Manning's n vs. Reynolds for Calculated Values 


\section{MODEL ILLUSTRATIVE APPLICATION}

Data from the Loxahatchee Impoundment Landscape Assessment (LILA) was used In order to test the potential of the model to simulate the hydrology of a real wetland.

\subsection{Study Area and Data}

LILA is an 80 acre area located at the Arthur R. Marshall Loxahatchee National Wild Life Refuge in Boynton Beach, Florida, created in 2003 in order to help the studies of landscapes similar to the Everglades but under completely controlled conditions (Figure 4.1).

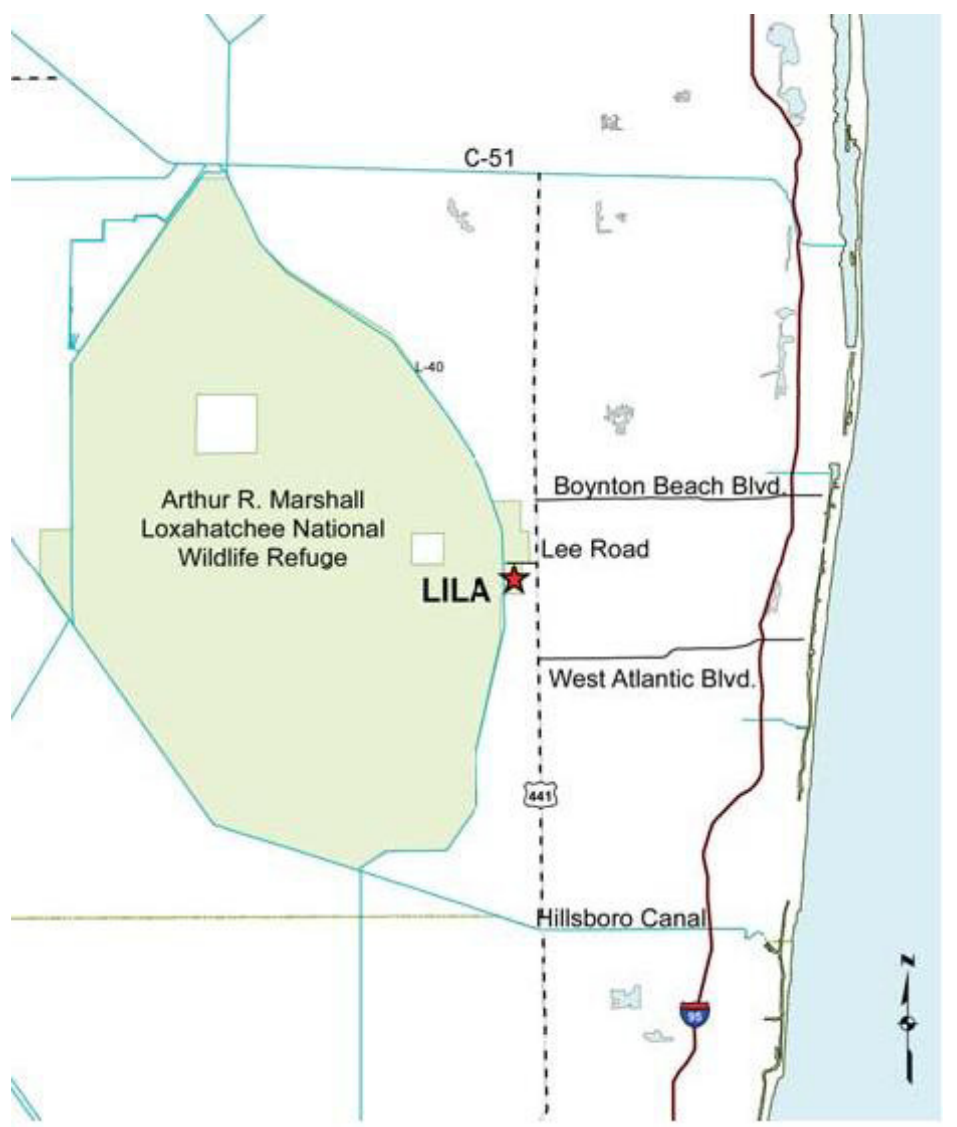

Figure 4.1 Loxahatchee Impoundment Landscape Assessment (LILA) location (SFWMD) 
The area is divided in four 20 -acre sub-areas, called macrocosms that are a miniaturized representation of the Everglade's original ridge and slough configuration. Each macrocosm is formed by a main ridge, one shallow slough and one deep slough that contain two tree islands, as can be seen in Figure 4.2
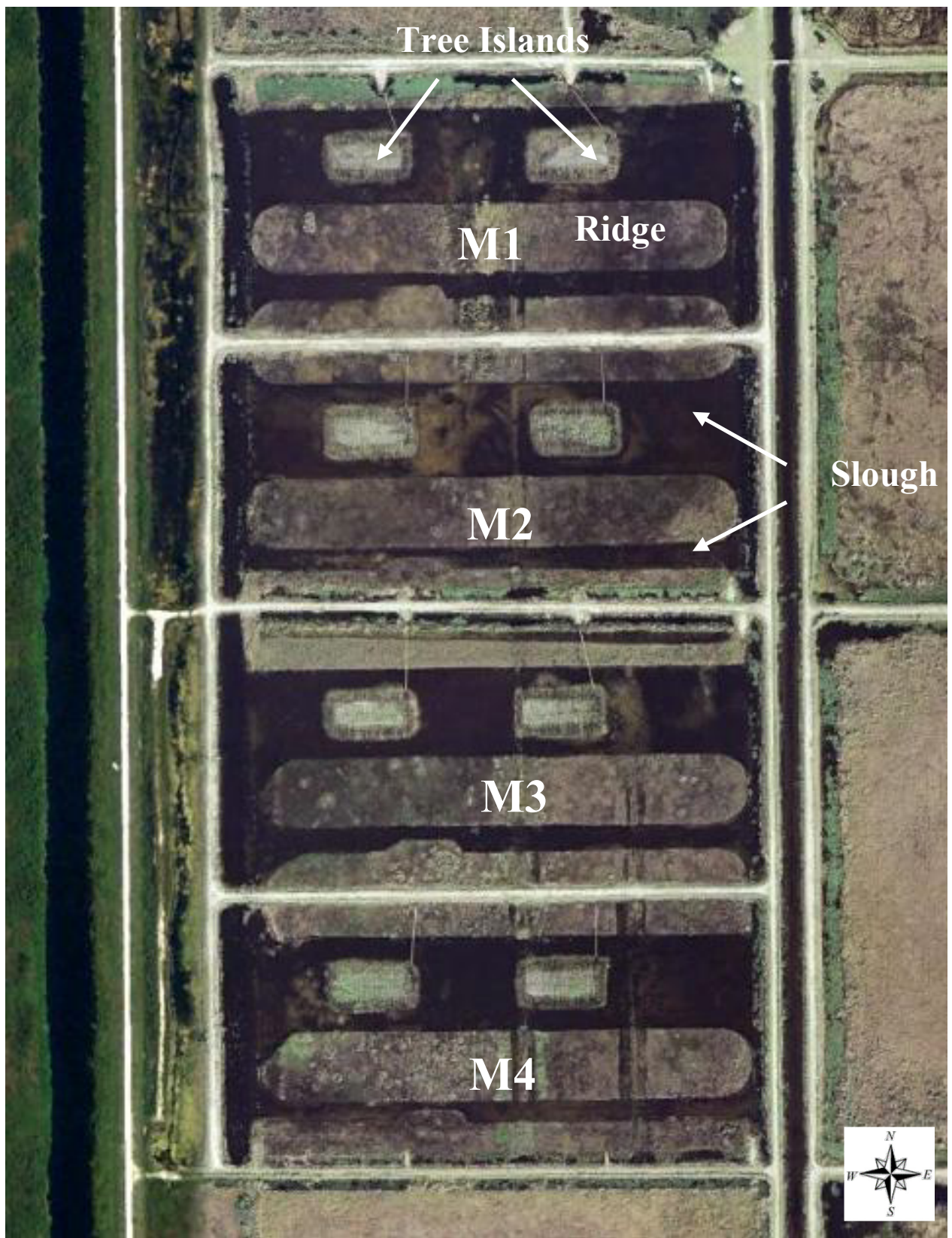

Figure 4.2 LILA - Macrocosms detail (Google Earth) 
There are nine wells at each tree island, one at each quadrant vertex.

Hydraulic conditions are controlled at each macrocosm by two culverts, one controlling the inflow and other one in the opposite side controlling the outflows. Each tree island is divided in four quadrants in which trees were planted using different densities. Density locations at each tree island were random, what means that every tree island has a different configuration.

Because hydrological and geological conditions are similar between all the macrocosms, only macrocosm M1 was used for simulation purposes.

Hydrological and meteorological data was obtained from the South Florida Water Management District Environmental Data Base (DBHYDRO) website (www.sfwmd.gov/org/ema/dbhydro/).

Daily stage data was obtained from gauging stations LILA1I and LILA1O. Rainfall and evapotranspiration was obtained from station LXWS which is the nearest meteorological station to LILA. The information of the hydrological and meteorological data can be seen in Appendix G.

GIS data was provided by Peter Harlem from CERP and was obtained from field data and from the original LILA blueprints. This data included elevation, vegetation density quadrants location and wells location.

The GIS data used the North American Datum 1983 (NAD83) for horizontal positions and the North American Vertical Datum for the elevation. Information of these geographical files can be seen at Appendix $\mathrm{H}$.

Data from wells located in the tree islands was also available. 
Hydrogeological data is scarce, for this reason, initial values for hydraulic conductivity, storage coefficient and porosity were assumed to be the mean values obtained from the aquifer information.

In order to define de computational domain, the M1 macrocosm was approximated to a $400 \mathrm{~m}$ x $200 \mathrm{~m}$ rectangle. Rectangular cells of $10 \mathrm{~m}$ x $10 \mathrm{~m}$ were selected because this is the minimum cell size that conformed to the density of elevation points. The discretized domain can be seen in Figure 4.3.

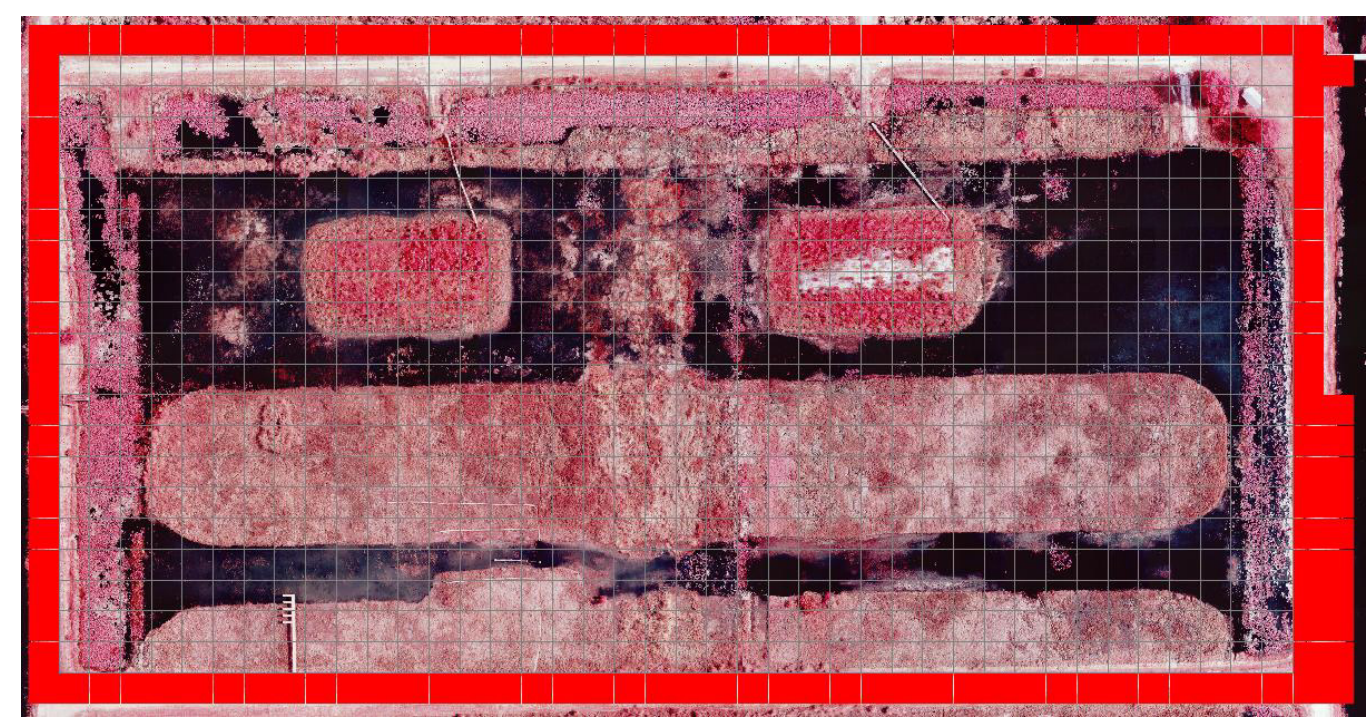

Figure 4.3 LILA - M1 Computational Domain

Elevations were interpolated by the FLO-2D Grid Developer System based on the data available and the final interpolated surface can be seen in Figure 4.4

Initial Manning coefficients for the bed was obtained from the classical Manning coefficient table and based on soil type present; a value of 0.022 was used for the slough, 0.035 was used for the ridges, 0.014 was used for the tree islands and 0.04 was used for the levees. Manning's coefficient distribution can be seen in Figure 4.5. The value of the coefficient for the tree islands was set to a low value in order to ensure that in case of 
flow through the island the coefficient is calculated using the proposed methodology for resistance due to presence of vegetation.

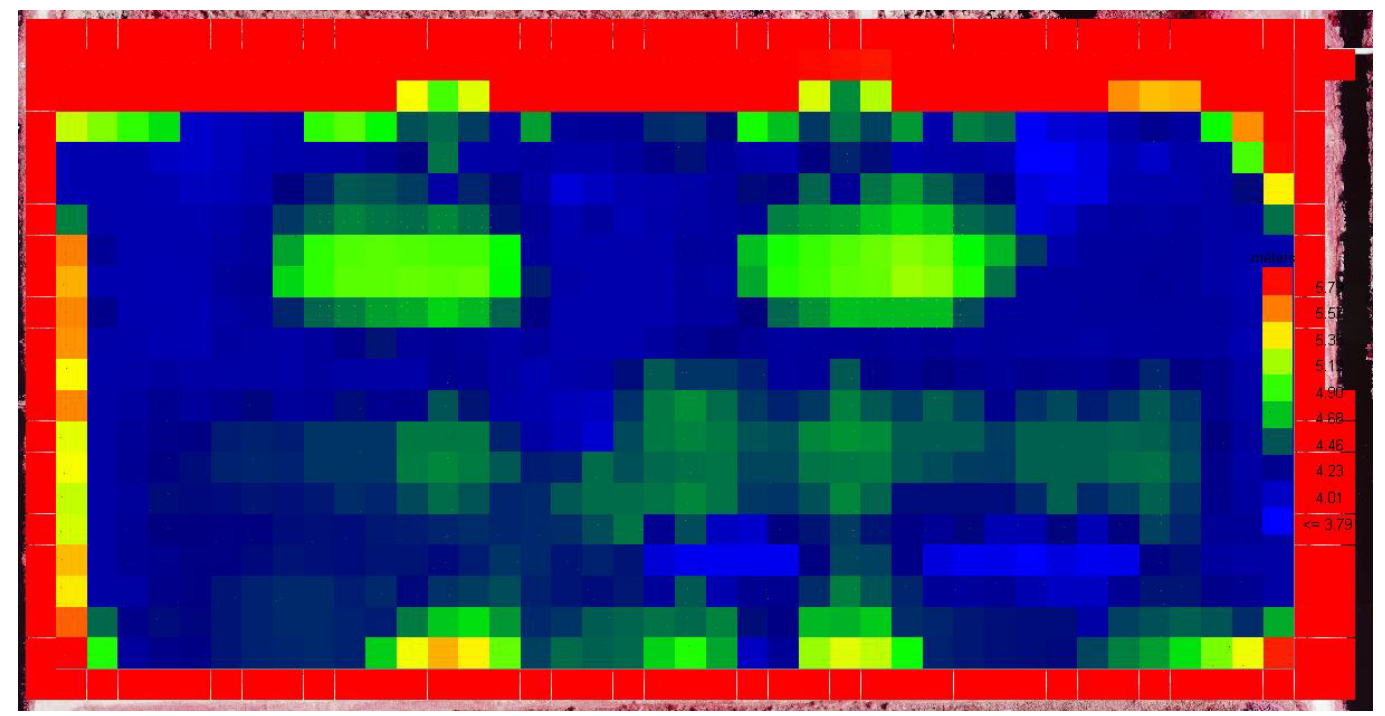

Figure 4.4 LILA - M1 Surface Elevations

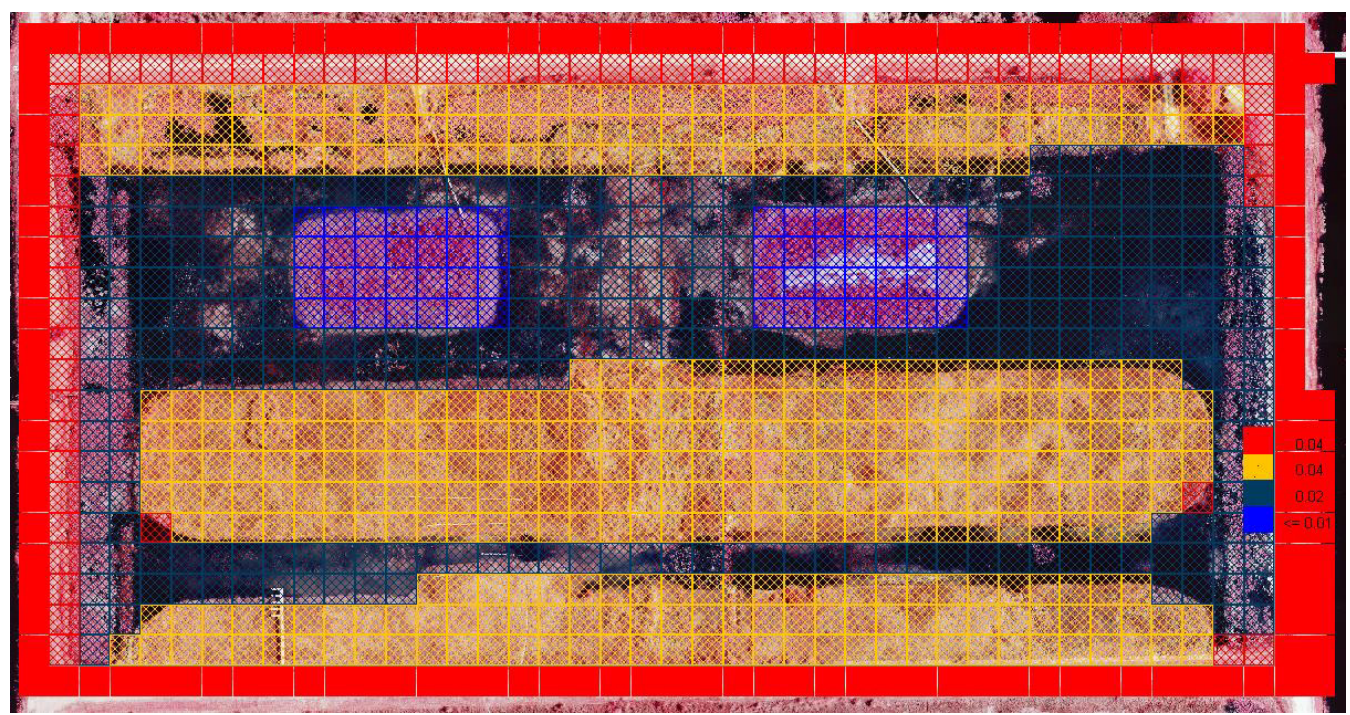

Figure 4.5 LILA - M1 Bed Manning’s Coefficient Distribution

The available information for both tree islands includes most of the parameters needed for the simulation of the vegetation resistance. Vegetation data includes plants high and density. 
In order to include this information inside the computational domain, all the data from each quadrant was averaged and then included in the data files. A scheme for the quadrant division can be seen in Figure 4.6

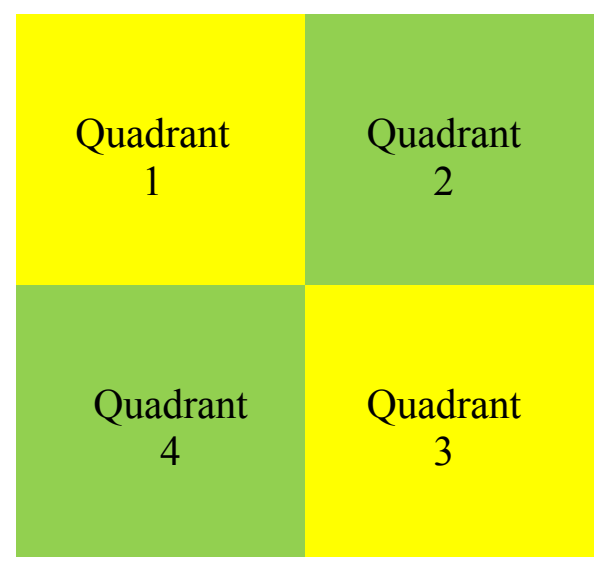

Figure 4.6 Scheme for the Tree Island quadrants division

The characteristics for each tree island quadrant in the M1 zone can be seen at Table 4.1.

Table 4.1 Tree Island Vegetation Characteristics by Island Quadrant

\begin{tabular}{|c|c|c|c|}
\hline & & & \\
\hline & Location & West & East \\
\hline & Core Material & Limestone & Peat \\
\hline & 1 & 2.33 & 1 \\
\hline 㯊 & 2 & 1 & 3 \\
\hline$\infty$ & 3 & 3 & 2.33 \\
\hline & 4 & 1.67 & 1.67 \\
\hline & 1 & 2.33 & 1.94 \\
\hline & 2 & 2.91 & 1.72 \\
\hline & 3 & 2.05 & 2.33 \\
\hline & 4 & 2.08 & 1.67 \\
\hline
\end{tabular}


Additionally, in order to take in account the water that is lost due to tree absorption a percentage of impervious area relative to each density was included as an initial abstraction, so, the area with the higher density will have a higher percentage of impervious area en the area with less vegetation density will have a lower percentage. These values were not changed during the calibration process. A scheme of the proposed initial values for the percentage of impervious area can be seen in Figure 4.7.

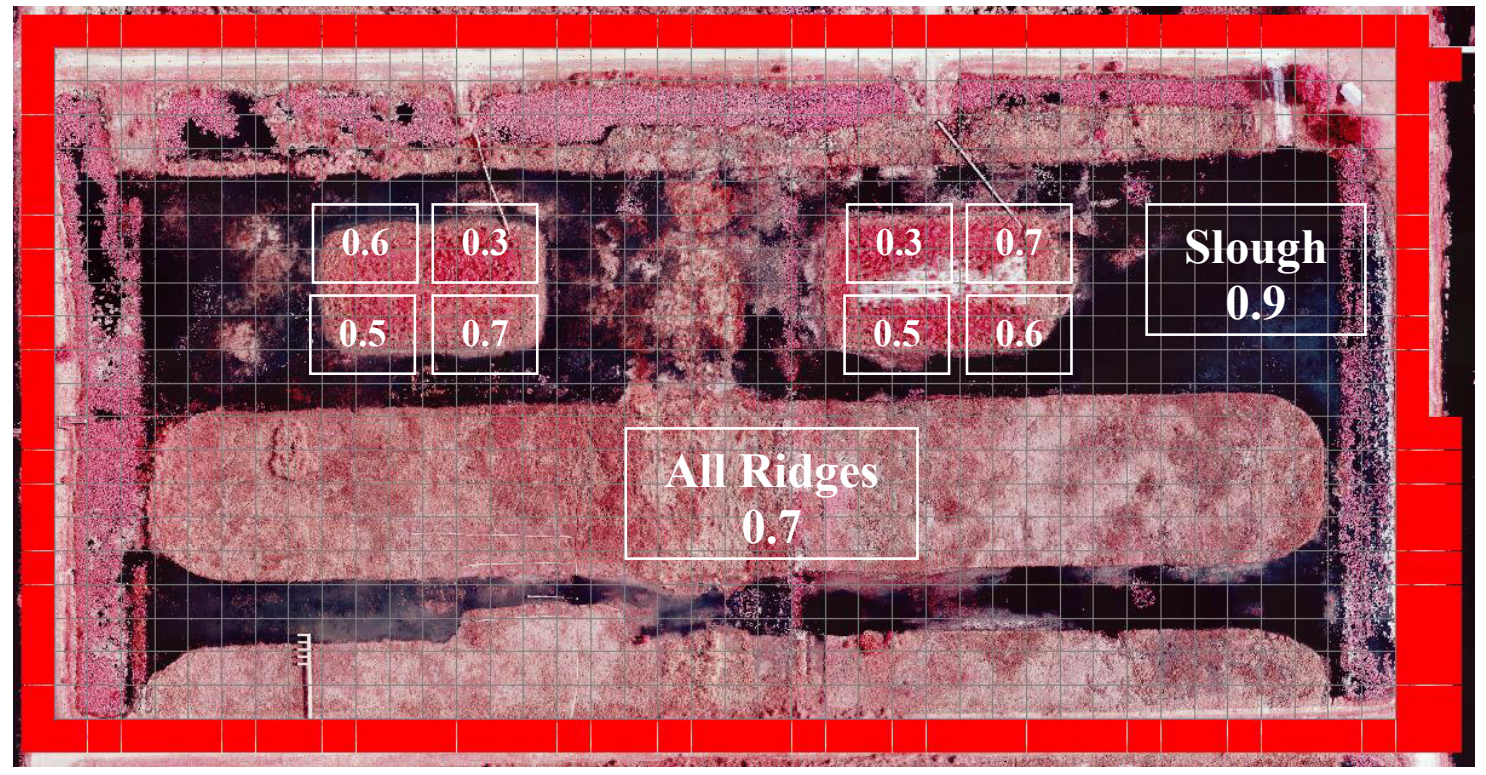

Figure 4.7 Scheme for the estimated \% of Impervious Area

Initial values for the simulation of the infiltration were assumed from the soil conditions and characteristics. For the slough, that is always flooded, infiltration conditions were set to minimum (there was a possibility to disable the infiltration simulation for this zone, but was leaved free in order to allow the new subroutines to be able to stop the process in a presence of complete saturation of the cell). Infiltration conditions from the Ridges and the Tree Islands were based on the material and additionally, it was also assumed that these zones were initially dry. 
Hydraulic conductivities used in both models were estimated from the values founded in the literature, especially in studies related to the everglades like Harvey et al. (2000, 2002, 2004 and 2005). Initial estimated values of hydraulic conductivity can be seen in Table 4.2.

Table 4.2 Estimated and Calibrated Hydraulic Conductivity Values

\begin{tabular}{|c|c|}
\hline Core Material / Location & $\begin{array}{c}\text { Hydraulic Conductivity } \\
(\mathrm{mm} / \mathrm{h})\end{array}$ \\
\hline Peat / M1E & 9.0 \\
\hline Limestone / M1W & 52.07 \\
\hline Limestone very Sandy/Ridges & 381 \\
\hline Limestone, Mud and Sand/ Slough & 2.54 \\
\hline
\end{tabular}

\subsection{Preliminary Calibration}

Daily data sets from July 2007 to June of 2008 were used to pre-calibrate the model. This specific period was used because in addition to the hydrology data, the complete sets of meteorological data (rainfall and evapotranspiration) were available.

The simulation was carried out by imposing stage-time data at the inlet near the south west corner and setting a free outlet which is located at the south east corner. Stage data was obtained from station LILA1I and the data from the station at the outlet was used to compare the results.

For the groundwater model, the north, south and west boundaries of the computational domain were assumed to have constant heads, and additionally, three wells located at the west tree island (M1W) and three wells located at the east tree island (M1E) were used as time variant head boundary conditions, finally, and in order to accomplish this, MODFLOW-2005 simulation time was divided in nine stressed periods, 
each one including initial and final head levels. A scheme for the location of wells at the tree islands can be seen in Figure 4.8.

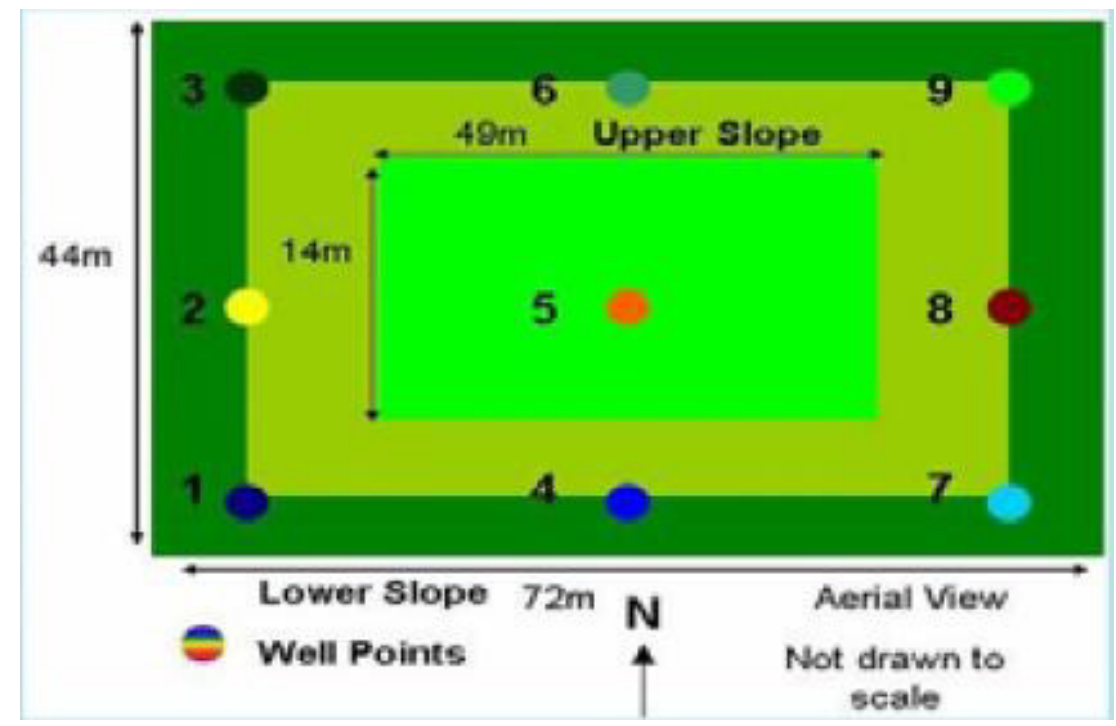

Figure 4.8 Scheme for the Well Location at Each Tree Island

In order to simplify the pre-calibration it was assumed that for the infiltration processes the hydraulic conductivity was the driven factor, and for this reason, the rest of the parameters included in the Green-Ampt methodology were not modified during the pre-calibration process. The parameters modified in order to achieve agreement between measured and simulated values were the roughness coefficient, the abstractions coefficients, the hydraulic conductivities and the vegetation parameter.

Due to de simplicity and relative small size of the simulated area, the precalibration process was developed manually. As a first step, manning roughness coefficients and vegetation coefficient and initial abstraction coefficients were modified and stages values were compared at the control station (LILAIO) in order to obtain an acceptable fitting. No velocity data sets were available in order to be used for precalibration purposes. Once surface water was initially calibrated, the hydraulic 
conductivity values were tested and obtained results were compared with the available data. Final values were compared with values from the available literature in order to guaranty that were located in an acceptable range for that specific location.

As a result of the pre-calibration process some initial values were modified. The hydraulic conductivity for the ridges was changed from $381 \mathrm{~mm} / \mathrm{h}$ to $52.07 \mathrm{~mm} / \mathrm{h}$, this match the value that was used for Limestone core material and is an acceptable value for the site (Harvey et al., 2000, 2002, 2004 and 2005); the Manning coefficient for the sloughs was modified from 0.022 to 0.025 . The vegetation parameter $\left(K_{0}\right)$ was finally set to a value of 0.0005 . These changes have introduced improvements in velocities and stages, however, there are no velocities data sets to compare with the simulated values in order to better adjust this parameter. The transmissivity of the ground layer for MODFLOW-2005 was changed from $79 \mathrm{~m}^{2} / \mathrm{h}$ to $28 \mathrm{~m}^{2} / \mathrm{h}$, this is an acceptable value for the site and is similar to the values that can be found in the literature (Harvey et al., 2000, 2002, 2004 and 2005). Data for the pre-calibration simulation can be seen in Appendix I.

Measured and simulated values were compared by using the concepts of mean absolute and mean relative errors. The mean absolute error (MAE) was obtained by using the expression:

$$
M A E=\frac{1}{n} \sum_{i=1}^{n}\left(f_{i}-x_{i}\right)
$$

where $n$ is the number of tested values, $f_{i}$ is the prediction and $x_{i}$ is the measured value.

The mean relative error (MRE) was calculated by using the expression:

$$
M R E=\frac{1}{n} \sum_{i=1}^{n}\left(\frac{e_{i}}{x_{i}}\right)
$$

where $e_{i}$ is the absolute error. 
Final results from the pre-calibration simulation showed a general good fit for the results in the overland flow as can be seen in Figure 4.9, with some differences that can be seen in the latest stages of the simulation. The MAE for the pre-calibration was $0.04 \mathrm{~m}$ with a maximum local value of $0.38 \mathrm{~m}$. The MRE obtained for these values was $1.00 \%$ with a maximum local error of $8.82 \%$.

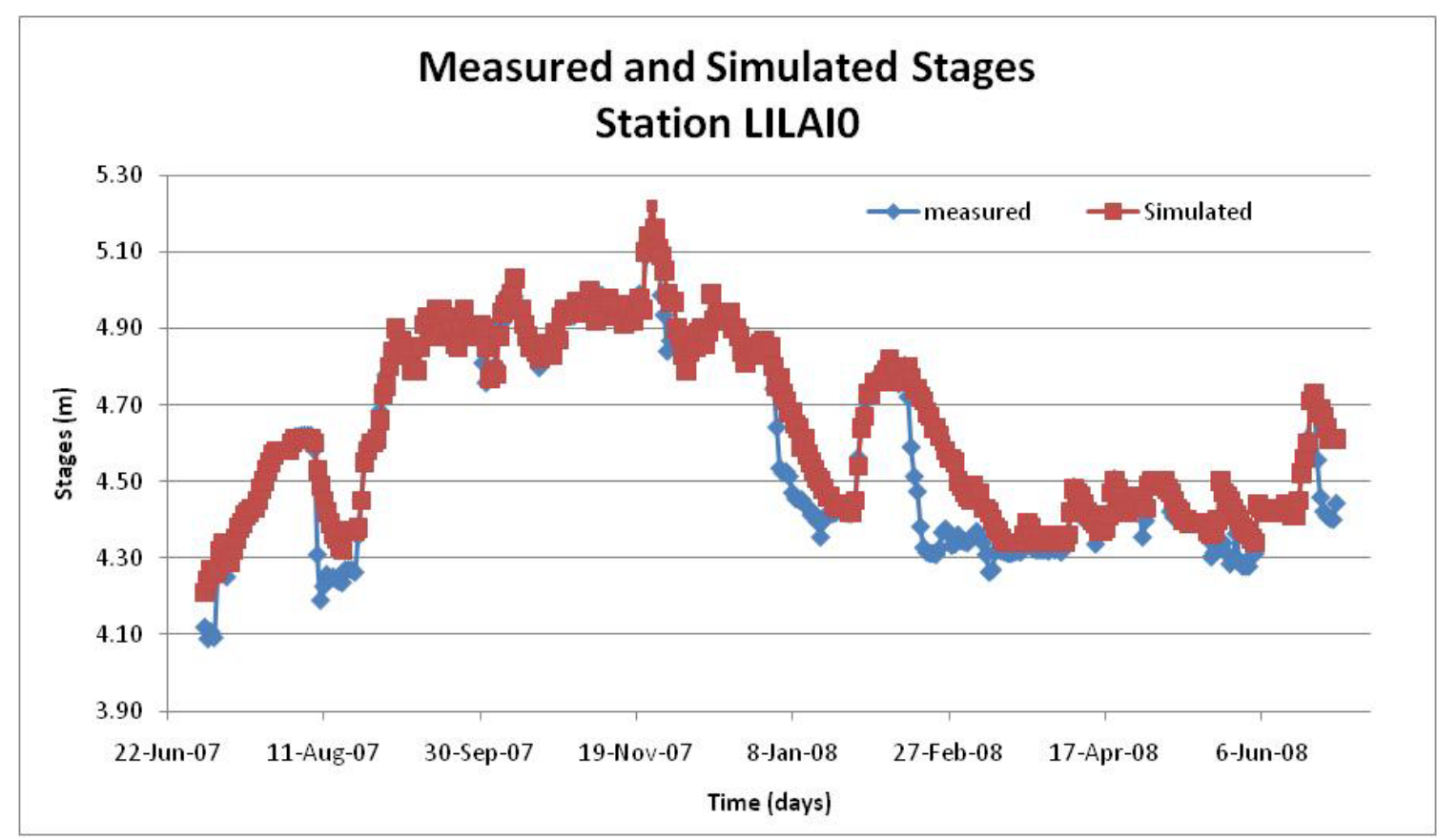

Figure 4.9 Comparisons between Measured and Simulated Stages from the PreCalibration at Station LILA1O (System Outlet)

Roughness coefficient from vegetation were calculated when tree island were partially or totally submerged and these values seems to be reasonable even if there is no actual way to do a comparison. Values which were active can be seen in Table 4.3.

None of the center cell of the tree Islands had a value in the VROUGHMAX file; this happens either when the cell is not wet or when the effect is no strong enough to supersede the bed friction coefficient. 
Table 4.3 Calculated Vegetation Roughness Coefficients

\begin{tabular}{|c|c|c|c|}
\hline FLO-2D Cell & Location at M1 & Original $\mathrm{n}$ & Modified $\mathrm{n}$ \\
\hline 172 & S.W. corner of M1W & 0.014 & 0.319 \\
\hline 175 & N.W. corner of M1W & 0.014 & 0.290 \\
\hline 215 & N of M1W & 0.014 & 0.045 \\
\hline 235 & N of M1W & 0.014 & 0.146 \\
\hline 255 & N of M1W & 0.014 & 0.004 \\
\hline 292 & S.E. corner of M1W & 0.014 & 0.055 \\
\hline 295 & N.E. corner of M1W & 0.014 & 0.457 \\
\hline 472 & S.W. corner of M1E & 0.014 & 0.08 \\
\hline 592 & S.E. corner of M1E & 0.014 & 0.268 \\
\hline 595 & N.E. corner of M1E & 0.014 & 0.130 \\
\hline
\end{tabular}

Velocity seems to be inside the acceptable values for LILA where velocities tend to have an estimate average velocity of $2 \mathrm{~cm} / \mathrm{s}$ at normal conditions (Price and Sullivan, 2008). Figure 4.10 showed the velocity field at time $=1488$ at one of the pikes of the hydrograph and as it can be seen even at this moment higher velocities never goes beyond $0.3 \mathrm{~m} / \mathrm{s}$. In Figure 4.10 can also be seen that for high water levels the ridges are flooded but center of the tree island for this case are dry. Non colored cells may indicate dry zones or no flow conditions.

As clearly shows by Figure 4.11, final infiltration values obtained at the end of the simulations demonstrates how the infiltration in cells of the slough is lower even if these cells have a permanently volume of water. This suggests that the infiltration has stopped at the first stages of the modeling due to saturation of the terrain. Higher values were found at the ridges that were partially flooded during the simulation tine and the boundaries of tree islands while the center had received water mostly from rainfall. 


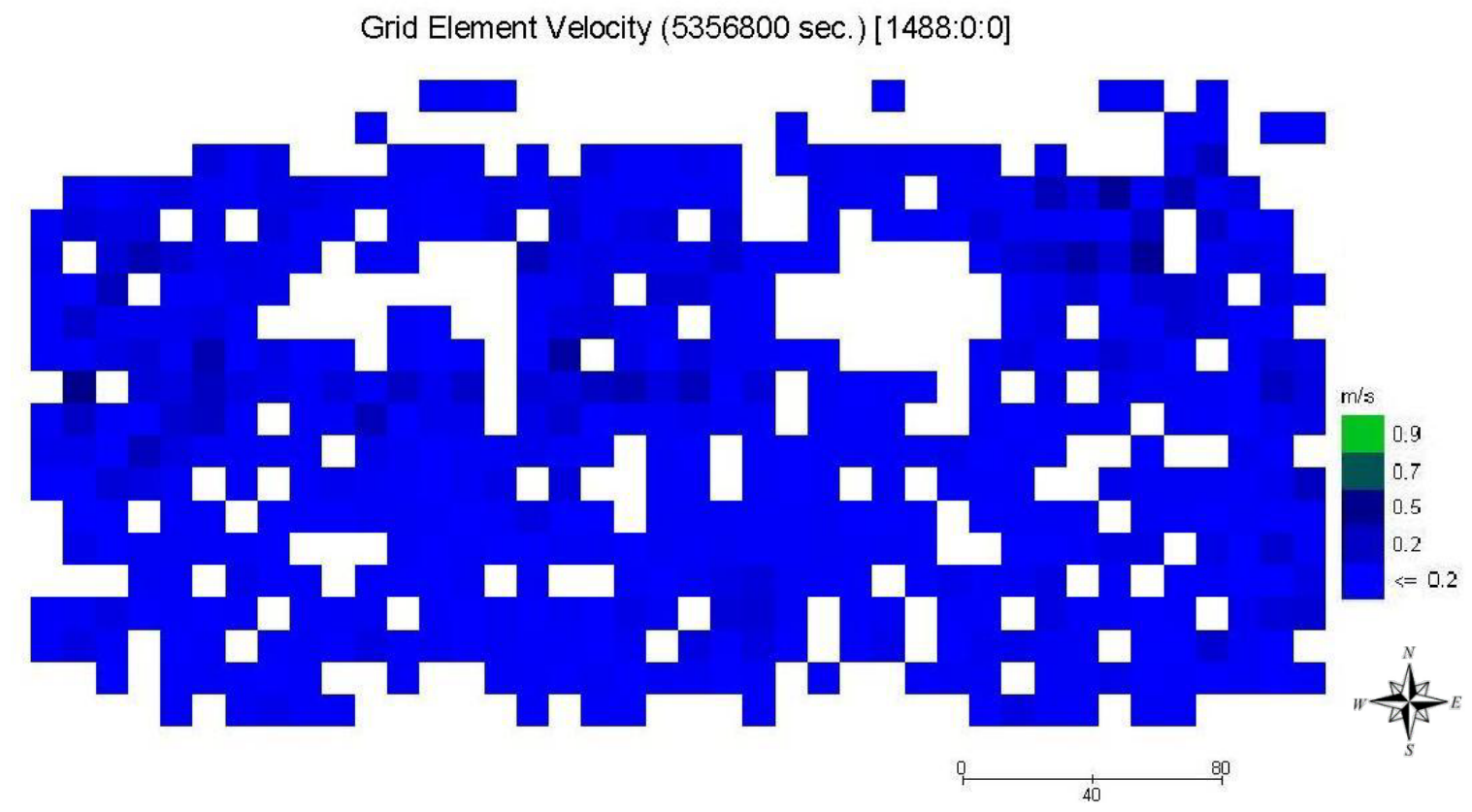

Figure 4.10 Velocity values from Pre-Calibration Simulation at time=1488 hours

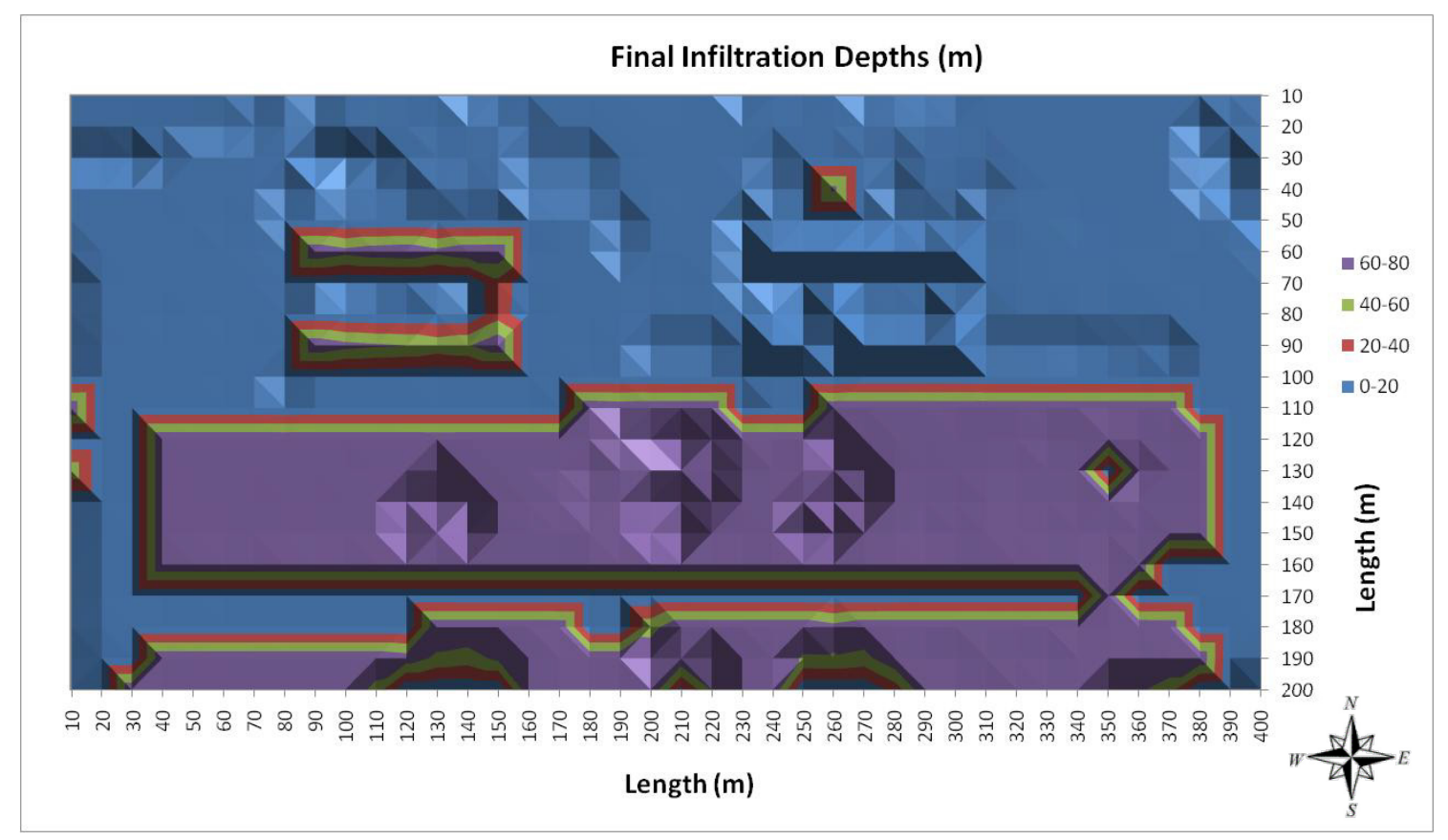

Figure 4.11 Final Infiltration depths for the Pre-Calibration (m)

Groundwater heads distribution could only be monitored for the well 8 at M1W.

Heads at the slough are leveled which was expected since there was almost no 
infiltration. General groundwater head distributions can be seen in Figure 4.12. In this case because of the use of the monitoring wells as a time variant boundary condition the trend of the behavior of groundwater heads was the expected. The higher values for the west island were also expected because this Island was flooded for longer time and also because it's hydraulic conductivity values are higher than the East Island. A comparison between measured values and simulated values at the M1W8P well, in Figure 4.13, shows a good fit between the heads.

The MAE for the ground water heads was $0.02 \mathrm{~m}$ with a maximum local error of $0.31 \mathrm{~m}$. the MRE found from these values for the heads was $0.36 \%$ with a maximum local error value of $6.77 \%$. Unfortunately there were no wells in the ridges so these values will remain as uncertain.

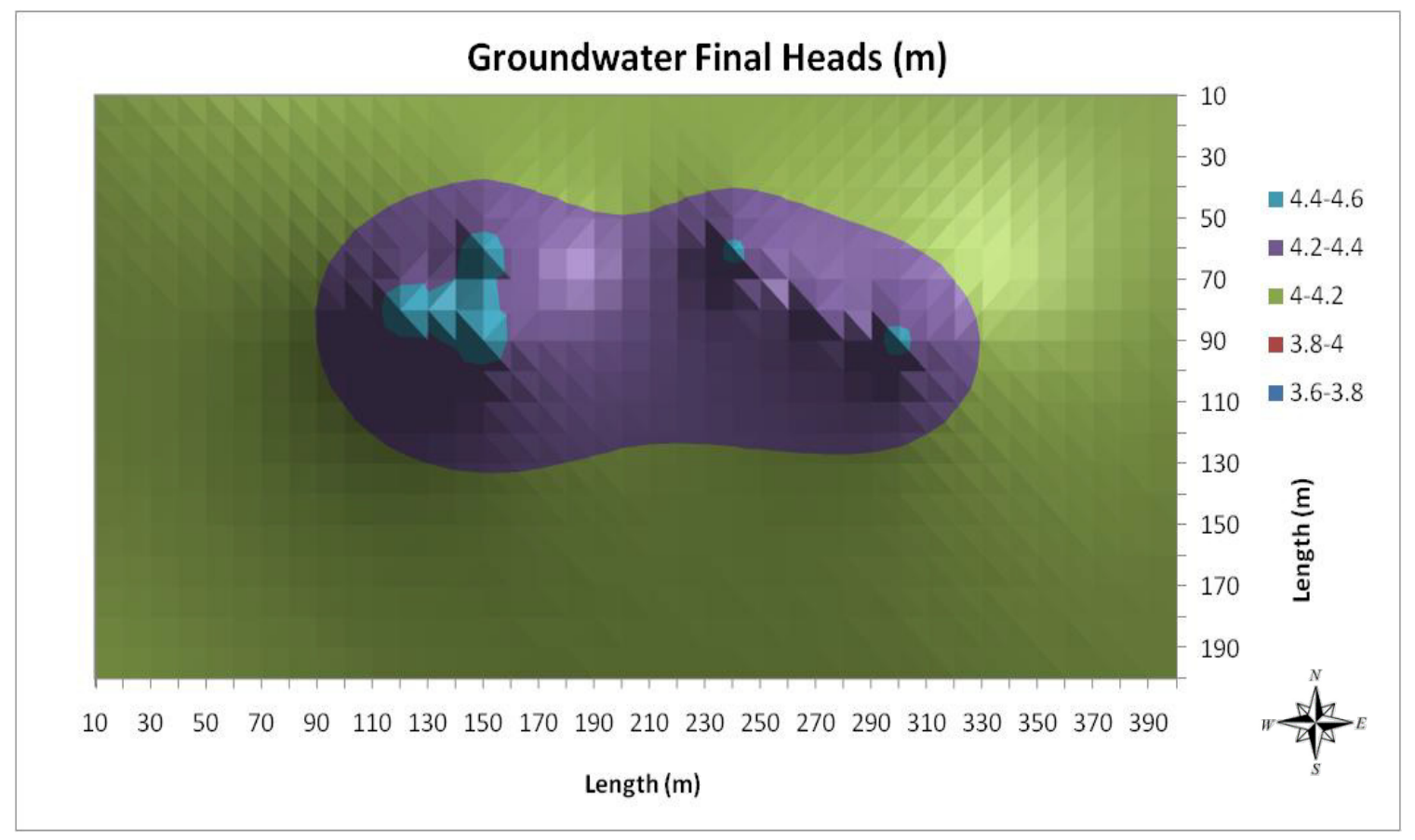

Figure 4.12 Final Groundwater Head Distribution (m) 


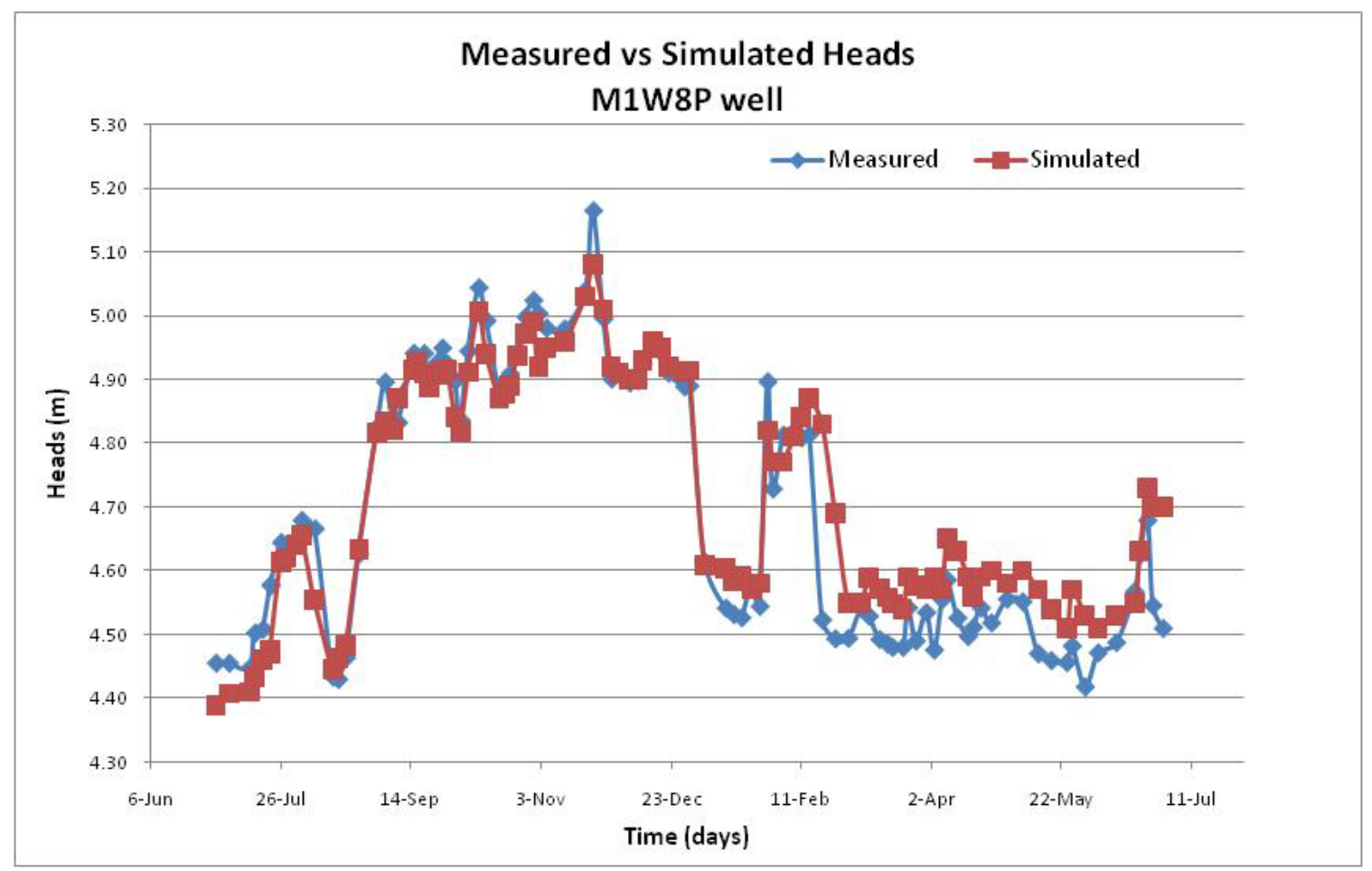

Figure 4.13 Comparison for Groundwater Head at M1W8P Well

\subsection{Verification Simulation}

Data from July 2008 to March of 2009 was used in order to run the verification simulation. This specific period was used because as in the pre-calibration data, additionally to the hydrology data, the complete set of meteorological data (rainfall and evapotranspiration) was available.

In the same way as in pre-calibration, the verification simulation was carried out by including stage-time data at the inlet near the south west corner and setting a free outlet which is located at the south east corner. Stage data was obtained from station LILA1I and the data from the station at the outlet was used to compare the results. Boundary conditions for the north, south and west subsurface boundaries were 
maintained as well as the parameter values obtained in the calibration. Data for the verification simulation can be seen in Appendix $\mathrm{J}$.

Final results from the verification simulation showed a good fit for the results in the overland flow as can be seen in Figure 4.14. For this simulation the MAE for the stages compared at the system outlet was $0.01 \mathrm{~m}$ whit a maximum local absolute error of $0.26 \mathrm{~m}$. The MRE for the verification simulation was $0.14 \%$ with a maximum local error value of $6.03 \%$.

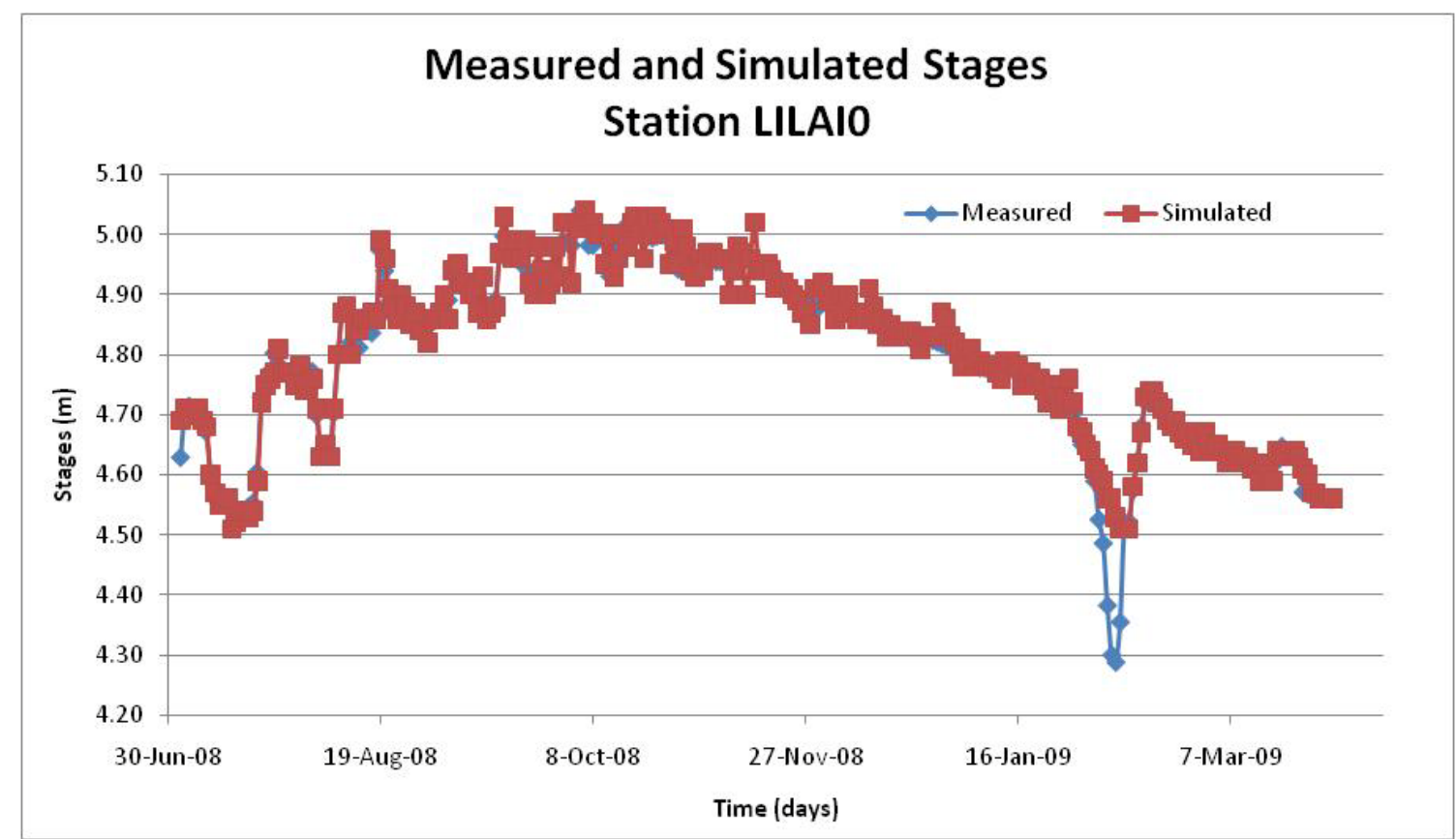

Figure 4.14 Comparisons between Measured and Simulated Stages at Station LILA1O (System Outlet)

Maximum values for the roughness coefficient from vegetation obtained for the partially or totally submerged areas of M1W and M1E can be seen in Table 4.4. Once again as in the calibration simulations the center of the tree islands was not flooded so no coefficients for vegetation resistance were calculated. 
Table 4.4 Calculated Vegetation Roughness Coefficients

\begin{tabular}{|c|c|c|c|}
\hline FLO-2D Cell & Location at M1 & Original $\mathrm{n}$ & Modified $\mathrm{n}$ \\
\hline 172 & S.W. corner of M1W & 0.014 & 0.319 \\
\hline 175 & N.W. corner of M1W & 0.014 & 0.290 \\
\hline 215 & N of M1W & 0.014 & 0.045 \\
\hline 235 & N of M1W & 0.014 & 0.146 \\
\hline 255 & N of M1W & 0.014 & 0.004 \\
\hline 292 & S.E. corner of M1W & 0.014 & 0.055 \\
\hline 295 & N.E. corner of M1W & 0.014 & 0.457 \\
\hline 472 & S.W. corner of M1E & 0.014 & 0.08 \\
\hline 592 & S.E. corner of M1E & 0.014 & 0.268 \\
\hline 595 & N.E. corner of M1E & 0.014 & 0.130 \\
\hline
\end{tabular}

Velocity seems to be inside the acceptable values for LILA. Figure 4.15 obtained for the one of the stage peak at time $=1224$ show that also in this case for the expected maximum flow conditions, velocity values seems to be reasonable and with an average bellow $0.1 \mathrm{mps}$. Flow patterns for this simulation are also in this case consistent with the known flow pattern inside LILA.

The groundwater values have a good fit with the values that were found for wells in the tree islands, unfortunately data recordings are missing from July 16 until September 08 , so for this specific period of time there is a lack of information in order to compare the heads at the wells for that period, in any case, measurements starting on September 09 and until the end of the simulation time are complete. Values available were compared and can be seen in Figure 4.16. The MAE obtained for the verification simulation was $0.08 \mathrm{~m}$ with a maximum local absolute error of $0.12 \mathrm{~m}$. For these values, an MRE of $1.64 \%$ was obtained with a maximum local error value of $2.47 \%$. 


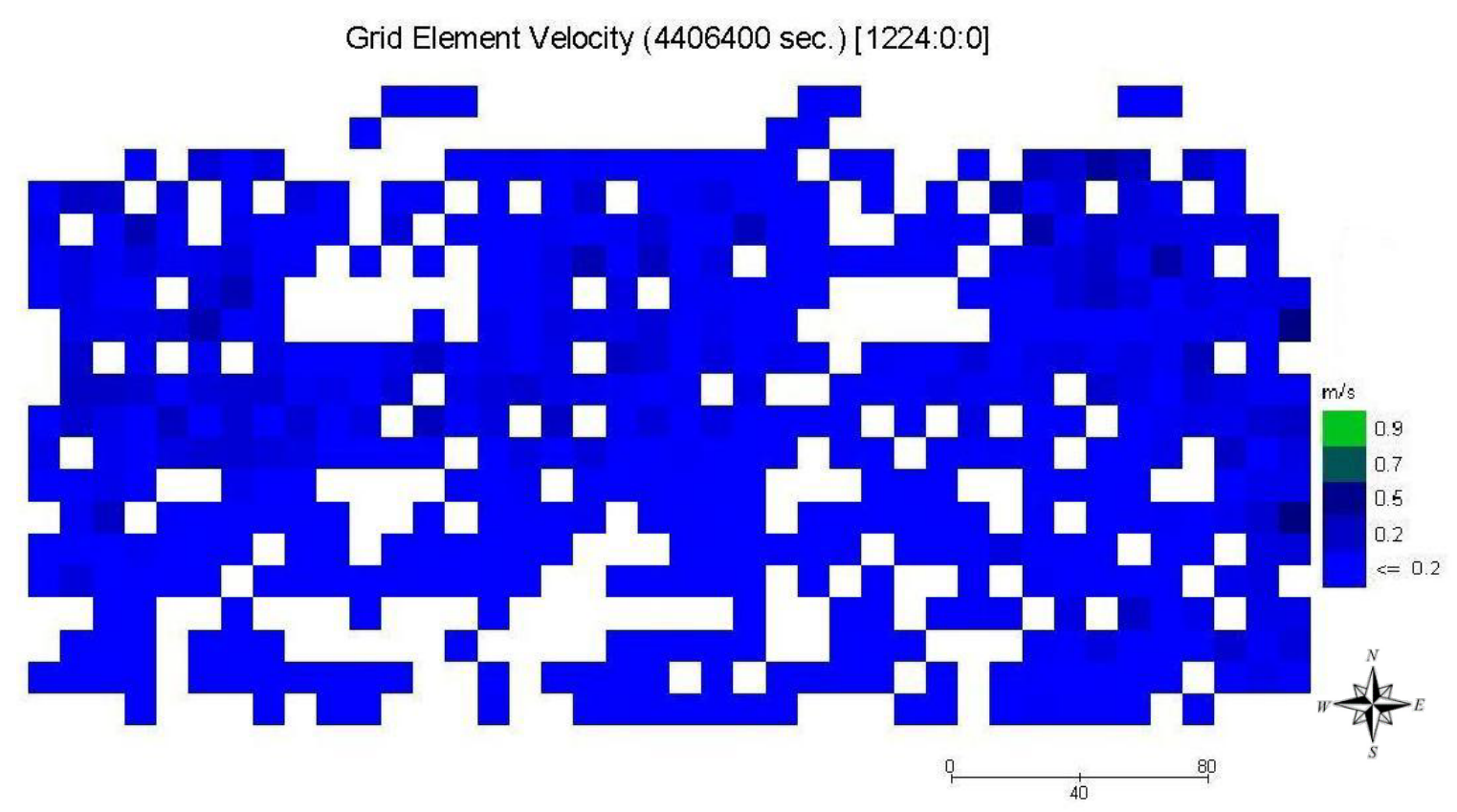

Figure 4.15 Velocity ranges from Calibration Simulation at time $=1224$

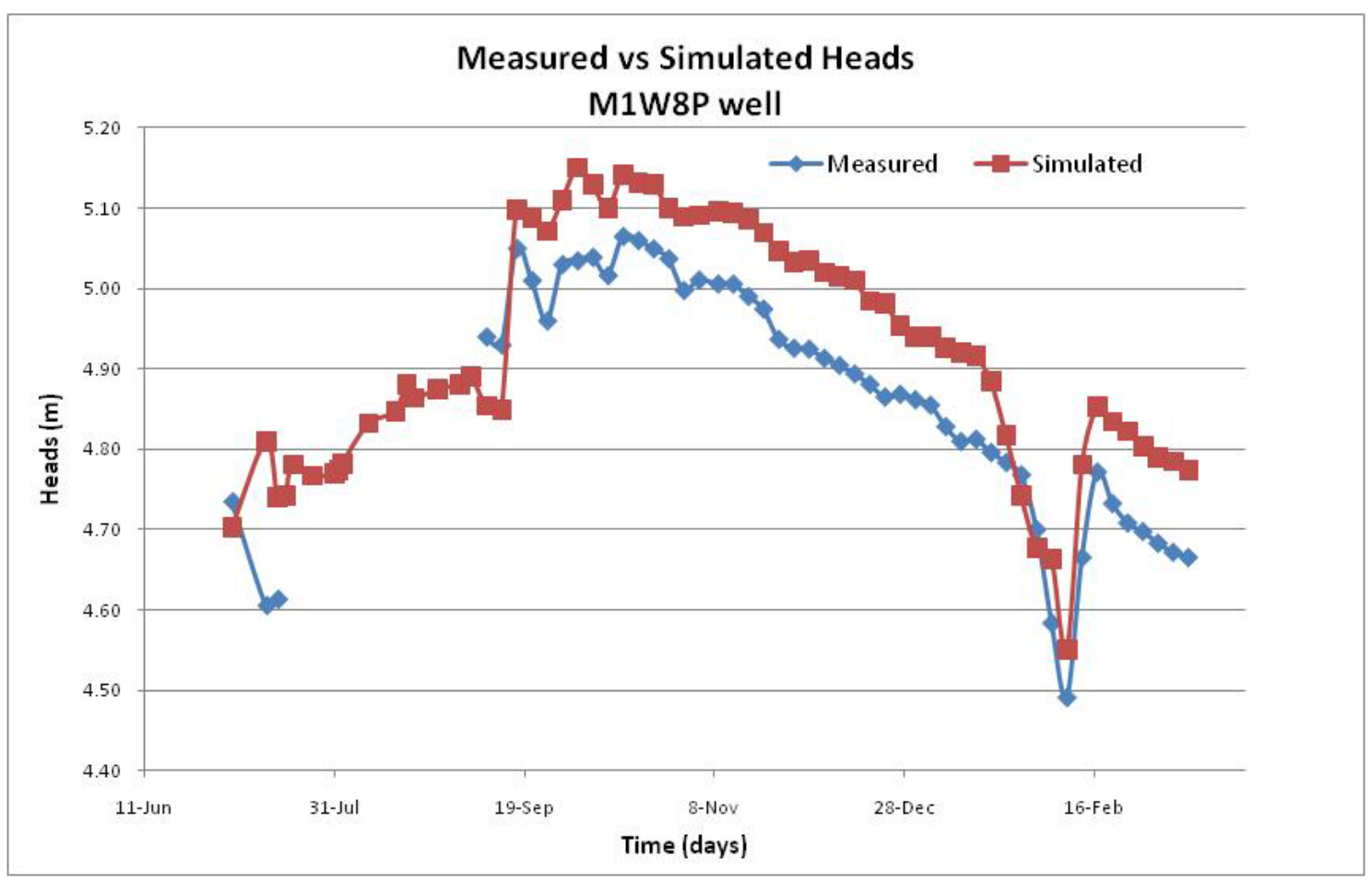

Figure 4.16 Comparisons for Groundwater Head at M1W8P Well 
The general plot of groundwater heads for $t=1824$ (September 21) is available in Figure 4.17. High values in the Figure 4.18 were founded in the tree island and in the ridges that are located at a higher elevation than the bottom of the sloughs and which lower level are limited by the water elevation.

\section{Groundwater Heads (m) at $\mathrm{T}=1824$ hours}

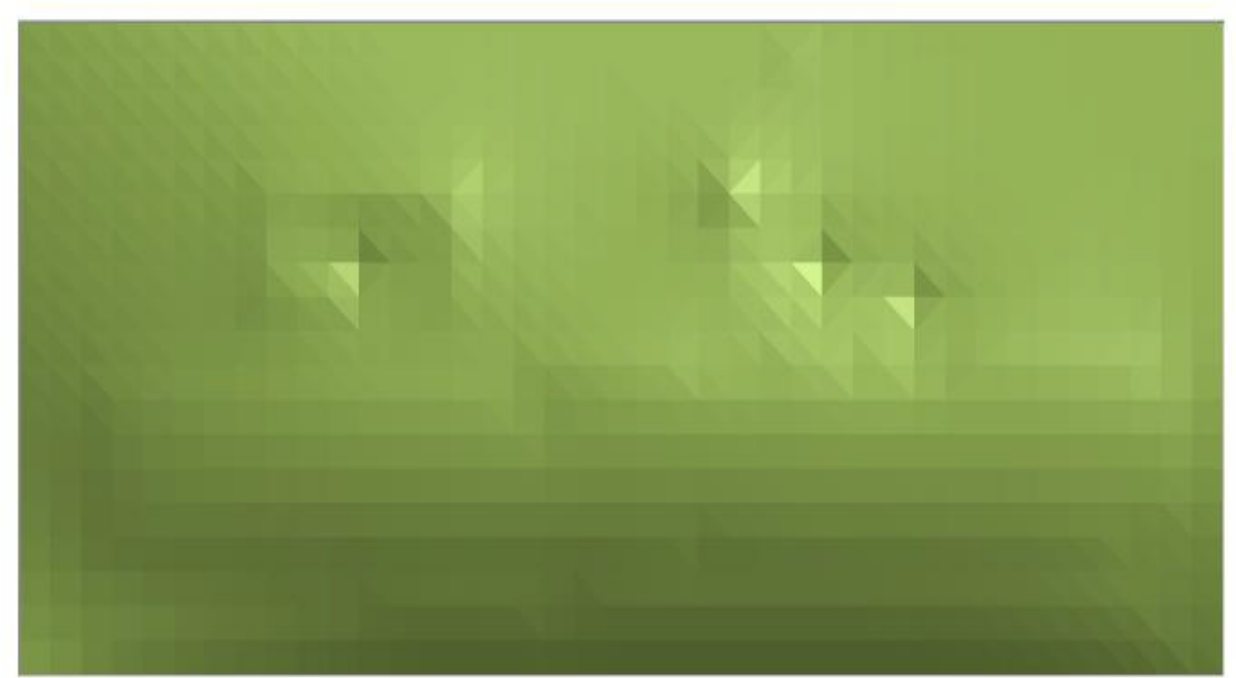

10

$30=4-6$

$50 \quad 2-4$

$70 \quad 0-2$

90

110 छ

130

$150 \stackrel{\frac{1}{\lrcorner}}{1}$

170

190

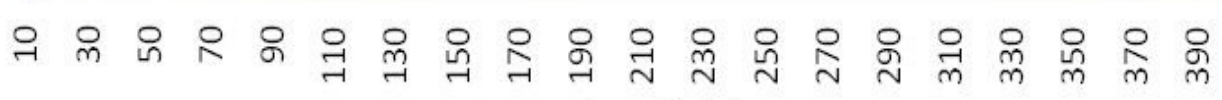

$$
\text { Length }(\mathrm{m})
$$

Figure 4.17 Final Groundwater Head Distribution (m) 


\section{CONCLUSIONS}

The numerical simulation of flow through wetlands includes several factors as complex flow patterns, the interaction between surface and subsurface, and the influence of vegetation in the flow that have been only partially cover by other numerical models. In order to incorporate these factors involved in a flow through wetlands, the development, testing and application of a numerical model that is able to simulate in a more realistic way the flow of water through vegetation and the interactions between surface and subsurface flow was achieved during this research

The following conclusions can be derived by the research documented in this dissertation:

1. The coupling between surface and subsurface subroutines using dynamical transfer of data based on time stepping was developed and allowed MODFLOW2005 to solve groundwater flow without the necessity of incorporate time stresses.

2. Three cases were setup to assess the numerical verification of the coupling procedures: two steady-state cases for the testing of the mathematical correctness and one transient-state case for the testing of the additional time coupling. Comparisons between simulated values obtained by using MODFLOW-2005 and WHIMFLO-2D showed small differences in head (always below 5 inches) as well as in volume conservation for all the simulated scenarios. With only requiring the calibration of the initial abstraction coefficients in the original FLO-2D data files, results showed that the coupling approach did not affect the internal subroutines of MODFLOW-2005. 
3. A methodology to simulate the dynamic effect of submerged and unsubmerged vegetation in flow resistance was incorporated. This methodology was created by unifying several existing expressions into one new expression for an equivalent Manning's roughness coefficient. A specific vegetation factor expression was selected by following the principle that this factor must take in account the density and type of vegetation. This vegetation factor was then added to a drag coefficient that includes the effect of depth and flow velocity.

4. Numerical simulations based on the laboratory experiences of Velasco et al. (2003) showed that the model was capable to adjust the resistance factor in the presence of vegetated area but maintaining an acceptable range of values.

5. The illustrative application of the model in the LILA site showed that WHIMFLO-2D is capable of simulating the dynamics involved in the flow through wetlands with mean relative errors for surface water levels below $1 \%$ and mean relative errors for ground water heads below $2 \%$.

6. Additionally to the direct objectives of this research, the coupling of these two modeling tools has resulted in some additional benefits to each model by obtaining a direct improvement that enhances its individual performance, independently if the study is coupled, surface or subsurface based. These improvements are, specifically:

a. By adding the possibility of bidirectional exchange of data between both models, now the FLO-2D model has the capability to completely stop infiltration if the soil is saturated. This is an important improvement even 
for some flood simulations. This feature was not available in the original code.

b. Before the coupling, the MODFLOW-2005 model used the evapotranspiration package and the loss coefficient Sf1 to deal with the water losses from the saturated flow, now this factor plus additional water retention and losses can be directly treated by using the FLO-2D's INFIL.DAT file. In this way, FLO-2D surface can work as a root zone effect that is just indirectly included in the original MODFLOW-2005 code.

c. By using evapotranspiration and/or rainfall directly from the FLO-2D, now the MODFLOW-2005 user will have the possibility to model time and space variant recharge and loses conditions only using the simulation time, so Stress Times are not longer needed. Stress Times will still being necessary in order to work with other factors like well operation or timevariable head cells. 


\section{RECOMMENDATIONS}

The coupling of FLO-2D model with MODFLOW-2005 model and the incorporation of the dynamic effect of flow resistance due to submerged and unsubmerged vegetation has become an important contribution to the field of numerical modeling of hydrologic flow in wetlands. This contribution could be enhanced by the following recommendations that are intended to lead into more research topics and therefore to more knowledge and advancement in this field. These recommendations include:

1. The actual FLO-2D Guided User Interface needs to be modified in order to include the MODFLOW-2005 simulation parameters. This would simplify the coupled simulation processes.

2. FLO-2D post processing packages must be modified in order to include the visualization of the MODFLOW-2005 results over time.

3. To improve the complete saturation procedure, MODFLOW-2005 should be modified in order to be able to receive the surface elevation data from FLO-2D and set that value as the head elevation from MODFLOW-2005 for the next time step.

4. A graphical subroutine should be developed in order to allow the user to observe the changes in groundwater head in real time.

5. A detailed experimental study on the Vegetation Parameter used in the drag coefficient formulation should be conducted. This study must try to understand the effective role of the type and characteristic of vegetation in order to obtain a 
quantifiable physical expression. It's important that this study includes a wide variety of flow conditions and vegetation.

6. Is highly recommended to develop a simulation of a larger scale real case wetland like the WCA-1.

7. In order to realize efficient simulations that help to understand the behavior of the flow in South Florida wetlands, it is important to improve the quality and quantity of the data available for the ENP. Controlled environments like LILA are important in order to improve the knowledge about the flow behavior in wetlands. The LILA site has an important and valuable amount of data but some efforts should be made to have better topographic and hydrogeological information. To have the most reliable elevation values as possible is a key factor to simulate flow in zones with very low gradients. 


\section{REFERENCES}

Arcement, G.J., and Schneider, V.R. (1990). Guide for Selecting Manning's Roughness Coefficients for Natural Channels and Flood Plains. United States Geological Survey Water-supply Paper 2339.

Armanini, A. (1999). Principi di Idraulica Fluviale, Editoriale BIOS, Cosenza.

Bolster, C.H., and Saiers, J.E. (2002). "Development and Evaluation of a Mathematical Model for Surface-Water Flow Within the Shark River Slough of the Florida Everglades." Journal of Hydrology, Vol. 259(1), 221-235.

Carollo, F.G., Ferro, V., and Termini, D. (2005). "Flow Resistance Law in Channels with Flexible Submerged Vegetation.” Journal of Hydraulic Engineering, Vol. 10, 554-564.

Cowardin, L.M., Carter, V., Golet, F.C., and LaRoe, E. T. (1979). Classification of. Wetlands and Deepwater Habitats of the United States, Office of Biological Sciences, Fish and Wildlife Service. U. S. Department of Interior. FWS/OBS-79/31. 103 p.

Environmental Protection Agency of the United States. www.epa.gov

Fathi-Maghadam, M., and Kouwen, N. (1997). "Nonrigid, Unsubmerge, Vegetative Roughness on Floodplains." Journal of Hydraulic Engineering, Vol. 123(1), 51-57.

Fischer-Antze, T., Stoesser,T., Bates, P., and Olsen, N.R.B. (2001). "3D Numerical Modeling of Open Channel Flow with Submerged Vegetation." Journal of Hydraulic Research, Vol. 39(3), 303-310.

Garcia Diaz, R. (2005). "Analysis of Manning coefficient for small-depth flows on vegetated beds." Hydrological Processes, Vol. 19(16), 3221-3223.

Harbaugh, A.W. (2005). MODFLOW-2005. The U.S. Geological Survey Modular Ground-Water Model. The Ground-Water Flow Process. United States Geological Survey, $253 \mathrm{p}$.

Harvey, J.W., Jackson, J.M., Mooney, R.H., and Choi, J. (2000). Interactions Between Ground Water and Surface Water in Taylor Slough and Vicinity, Everglades National Park, south Florida: study Methods and Appendixes. U.S. Geological Survey Open-File Report 00-483. 67 p.

Harvey, J.W., Krupa, S.L., Gefvert, C., Mooney, R.H., Choi, J., King, S.A. and Giddings, J.B. (2002). Interactions between Surface Water and Ground Water and Effects on Mercury Transport in the North-central Everglades. USGS Water Resources Report 024050. $91 \mathrm{p}$. 
Harvey, J.W., Krupa, S.L., and Krest, J.M. (2004). "Ground Water Recharge and Discharge in the Central Everglades." Ground Water, Vol. 2(7), 1090-1102.

Harvey, J.W., Newlin, J.T., Krest, J.M., Choi, J., Nemeth, E.A., and Krupa, S.L. (2005). Surface Water and Ground Water Interactions in Water Conservation Area 2A, Central Everglades. United States Geological Survey Scientific Investigations Report 2004-5069. $88 \mathrm{p}$.

Helmio, T. (2005). "Unsteady 1D Flow Model of a River With Partly Vegetated Floodplains - Application to the River Rhine." Environmental Modeling \& Software, Vol. 20, 361-375.

Jacob, C.E. (1943). "Correlation of Ground-Water Levels and Precipitation on Long Island, New York." Trans. Amer. Geophysical Union, 564-573.

James, C.S., Birkhead, A.L., Jordanova, A.A., and O'Sullivan, J.J. (2004). "Flow Resistance of Emergent Vegetation." Journal of Hydraulic Research, Vol. 42(4), 390398.

Jarvela, J. (2004). Flow Resistance in Environmental Channels: Focus on Vegetation. Helsinki University of Technology Water Resources Publications. Ph.D Dissertation. 54 p.

Lal, A.M.W., Belnap, M., and Van Zee, R. (1998). "Simulation of Overland and Groundwater Flow in the Everglades National Park." Proceedings of the International Water Resources Eng. Conference, Aug. 3-7, Memphis, TN, 610-615.

Langevin, C., Swain, E., and Wolfert, M. (2005). "Simulation of Integrated SurfaceWater/Ground-Water Flow and Salinity for a Coastal Wetland and Adjacent Estuary." Journal of Hydrology, Vol. 312(1-4), 212-234.

Lee, J.K., Roig, L.C., Jenter, H.L., and Visser, H.M. (2004). "Drag Coefficients for Modeling Flow Through Emergent Vegetation in the Florida Everglades." Ecological Engineering. Vol. 22, 237-248.

Lightbody, A.F., and Nepf, H.M. (2006). "Prediction of Near-Field Shear Dispersion in an Emergent Canopy with Heterogeneous Morphology." Environmental Fluid Mechanics. Vol. 6(5)477-488.

Lin S.T., and Shih S.F. (1979). "Modified Water Quantity Receiving Model for Florida Conservation Areas." Journal of the American Water Resources Association, Vol. 15(1), $155-166$.

Markstrom, S.T., Niswonger, R.G., Regan, R.S., Prudic, D.E., and Barlow, P.M. (2008). GSFLOW-Coupled Ground-Water and Surface-Water Flow Model Based on the 
Integration of the Precipitation-Runoff Modeling System (PRMS) and the Modular Ground-Water Flow Model (MODFLOW-2005). U.S. Geological Survey. Chapter 1 of Section D, Ground-Water/Surface-Water, Book 6, Modeling Techniques, 254 p.

MacVicar, T., Van Lent, T., and Castro, A. (1984). South Florida Water Management Model Documentation Report. Technical Publication 84-3, South Florida Water Management District, West Palm Beach, Florida.

Maxwell, R.M., and Miller, N.L. (2004). "Development of a Coupled Land Surface and Groundwater Model." Journal of Hydrometeorology, vol. 6(3), p. 233.

McDonald, M.G., and Harbaugh, A.W. (1988). A Modular Three-Dimensional FiniteDifference Ground-Water Flow Model. U.S. Geological Survey Techniques of WaterResources Investigations, book 6, chap. A1, 586 p.

McDonald, M.G., Harbaugh, A.W., Orr, B.R., and Ackerman, D.J. (1992). A Method of Converting No-Flow Cells to Variable-Head Cells for the U.S. Geological Survey Modular Finite-Difference Ground-Water Flow Model. U.S. Geological Survey OpenFile Report 91-536, 99 p.

Meselhe, E., Griborio, A.G., and Gautam, S. (2005). Hydrodinamic and Water Quality Modeling for the A.R.M. Loxahatchee National Wildlife Refuge - Phase 1: Preparation of Data - Task 1: Data Acquisition and Processing. Report \#LOXA05-014. United States Fish and Wildlife Service, Department of the Interior.

Moustafa, M.Z. (2000). "Calibration of the Wetland Hydrodynamic Model to the Everglades Nutrient Removal Project." Water Quality and Ecosystem Modeling, Vol. 1, $141-167$.

Musleh, F.A., and Cruise, J.F. (2006). "Functional Relationships of Resistance in Wide Flood Plains with Rigid Unsubmerged Vegetation." Journal of Hydraulic Engineering, Vol. 132(2), 163-171.

Nepf, H.M., Ghisalberti, White, B., and Murphy, W. (2007). "Retention Time and Dispersion Associated with Submerged Aquatic Canopies." Water Resources Research, Vol. 43, W04422, doi:10.1029/2006WR005362

O'Brien, J.S., Julien, P.Y., and Fullerton, W.T. (1993). "Two-Dimensional Water Flood and Mudflow Simulation." Journal of Hydraulic Engineering, Vol. 119(2), 244-259. O'Brien, J. (2009). FLO-2D User's Manual, 2009. Version 2007.06, Nutrioso, AZ, USA.

Panday, S., and Huyakorn, P.S. (2004). "A Fully Coupled Physically-Based SpatiallyDistributed Model for Evaluating Surface/Subsurface Flow." Advances in Water Resources. N 27, 361-382. 
Petryk, S., and Bosmajian III, G. (1975). "Analysis of Flow Through Vegetation." Journal of the Hydraulic Division, ASCE, Vol. 101(7), 871-884.

Price, R., and Sullivan, P. (2008). A Physical Investigation of Groundwater-Surface water Interaction at Loxahatchee Impound Landscape Assessment (LILA). South Florida Water Management District Annual Report for PO\#4500013487. 21 p.

Reid, R.O., and Whitaker, R.E. (1976). "Wind-Driven Flow of Water Influenced by a Canopy."' Journal Waterways, Harbors, Coastal Engr. Div. Vol. 102, p. 61.

Schaffranek, R.W., Riscassi, A.L., and Nowacki, D.J. (2006). "Flow Simulation in Everglades National Park." Third Federal Interagency Hydrologic Modeling Conference, April 2-6, 2006, Reno, NV, p. 8.

Kucukali, S., and Cokgor, S. (2006). "Discussion of 'Open Channel Flow through Different Forms of Submerged Flexible Vegetation' by Wilson, C. A. M. E., Stoesser, T., Bates, P. D., and Batemann Pinzen, A." Journal of Hydraulic Engineering, Vol. 132, p. 748

South Florida Water Management District (2005). Documentation of the South Florida Water Management Model Version 5.5. South Florida Water Management District.

South Florida Information Acces (SOFIA) http://sofia.usgs.gov/title.php

Stoesser, T, Neary, V., and Wilson, C.A.M.E. (2004). "Modeling Vegetated Channel Flows: Challenges \& Opportunities." WSEAS Conference, Corfu, August 2004.

Richardson, J.R., Bryant, W.L., Kitchens, W.M., Mattson, J.E., and Pope, K.R. (1990). An Evaluation of Refuge Habitats and Relationships to Water Quality, Quantity, and Hydroperiod: A Synreport Report. Florida Cooperative Fish and Wildlife Research Unit. University of Florida, Gainesville, FL.

Velazco, D., Bateman, A., Redondo, J.M., and De Medina, V. (2003). “An Open Channel Flow Experimental and Theoretical Study of Resistance and Turbulent Characterization over Flexible Vegetated Linings." Flow, Turbulence and Combustion, Vol. 70, 69-88

Wang, F.E., and Anderson, M.P. (1982). Introduction to Groundwater Modeling. California. Academic Press. 237 p.

Welter, D. (2002). Loxahatchee National Wildlife Refuge HSE Model. South Florida Water Management District, West Palm Beach, FL.

Wdowinski, S., Amelung, F., Miralles-Wilhelm, F., and Dixon, T. (2004). "Space-Based Measurements of Sheet Flow Characteristics in the Everglades Wetland FL." Geophysical Research Letters, 31, L15503. 
Wdowinski, S., Kim, S., Amelung, F., Dixon, T., Miralles-Wilhelm, F., and Sonenshein, R., (2007). "Space-Based Detection of Wetlands Surface Water Level Changes from Lband SAR Interferometry." Remote Sensing of Environment, in press, doi:10.1016/j.rse.2007.06.008.

Wilson, C.A.M.E., Stoesser, T., Bates, P.D., and Batemann Pinzen, A. (2003). "Open Channel Flow Through Different Forms of Submerged Flexible Vegetation." Journal of Hydraulic Engineering, Vol. 129, p. 847

Wilson, C.A.M.E., Stoesser, T., Bates, P.D., and Batemann Pinzen, A. (2006). "Closure to 'Open Channel Flow through Different Forms of Submerged Flexible Vegetation' by C.A.M.E. Wilson, T. Stoesser, P. D. Bates, and Batemann Pinzen, A." Journal of Hydraulic Engineering, Vol. 132, p. 750

Wilson, C.A.M.E., Yaggi, O., Rauch, H.P., and Stoesser, T. (2006). "Application of the Drag Force Approach to Model the Flow Interaction of Natural Vegetation." International Journal of River Basin Management, Vol. 4(2), 137-146

Wu, F., Shen, W.H., and Chou, Y. (1999). "Variation of Roughness Coefficients for Unsubmerged and Submerged Vegetation." Journal of Hydraulic Engineering, Vol. 125(9), 934-942.

Yen, B.C. (2002). "Open channel flow resistance". Journal of Hydraulic Engineering, Vol. 128(1), 20-39.

Zhiguo, E., Weiming, W., and Sam, S.Y.W. (2008). "Coupled Finite-Volume Model for 2D Surface and 3D Subsurface Flows." Journal of Hydrologic Engineering, Vol. 13(9), 835-845.

U.S. Army Corps of Engineers, (1990). HEC-1, Flood Hydrograph Package User's Manual, Hydrologic Engineering Center, Davis, CA. 
FLO-2D FLOW CHART (From FLO-2D User Manual)

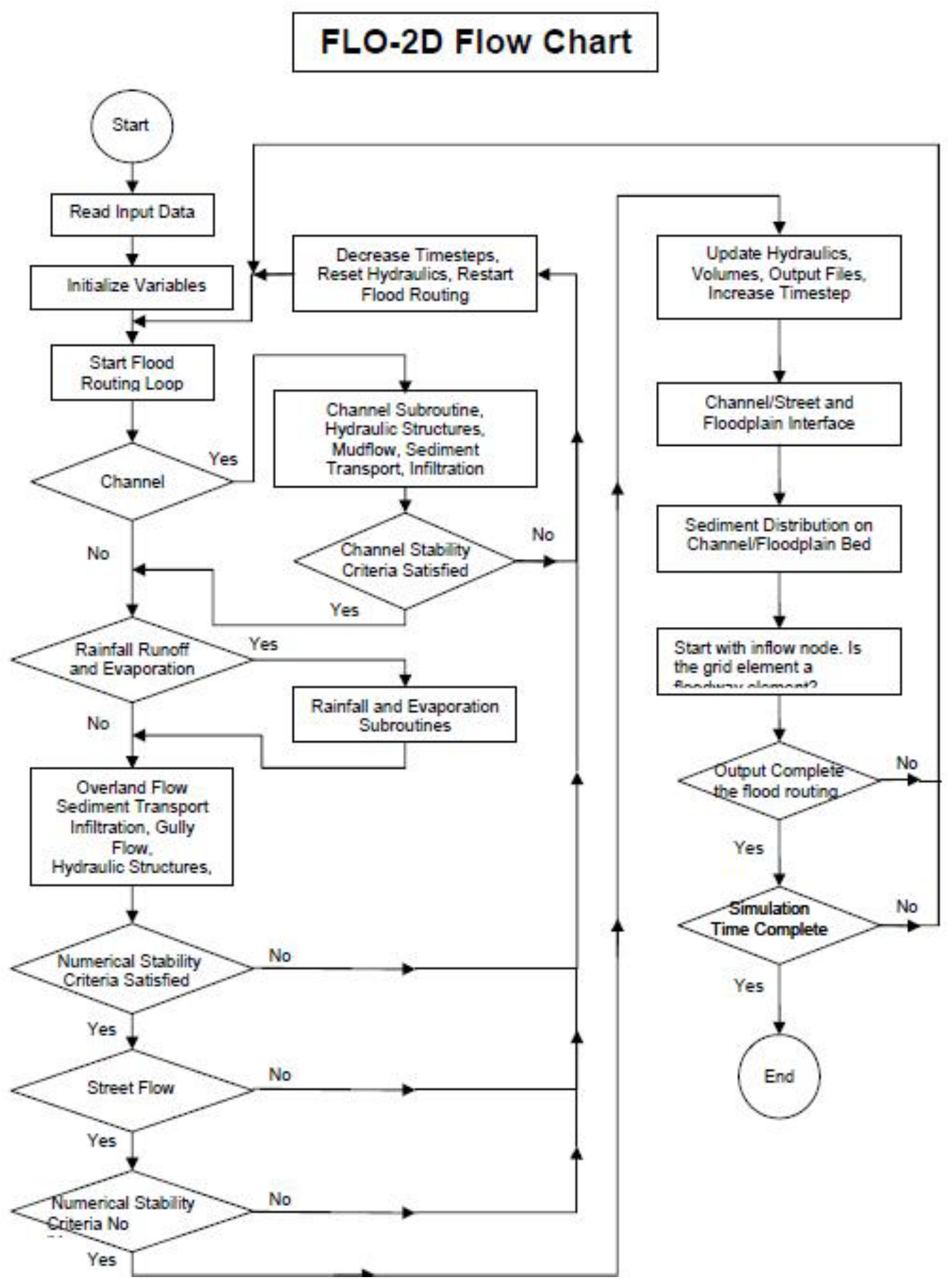




\section{APPENDIX B}

MODFLOW-2005 FLOW CHART (From MODFLOW-2005 User Manual)

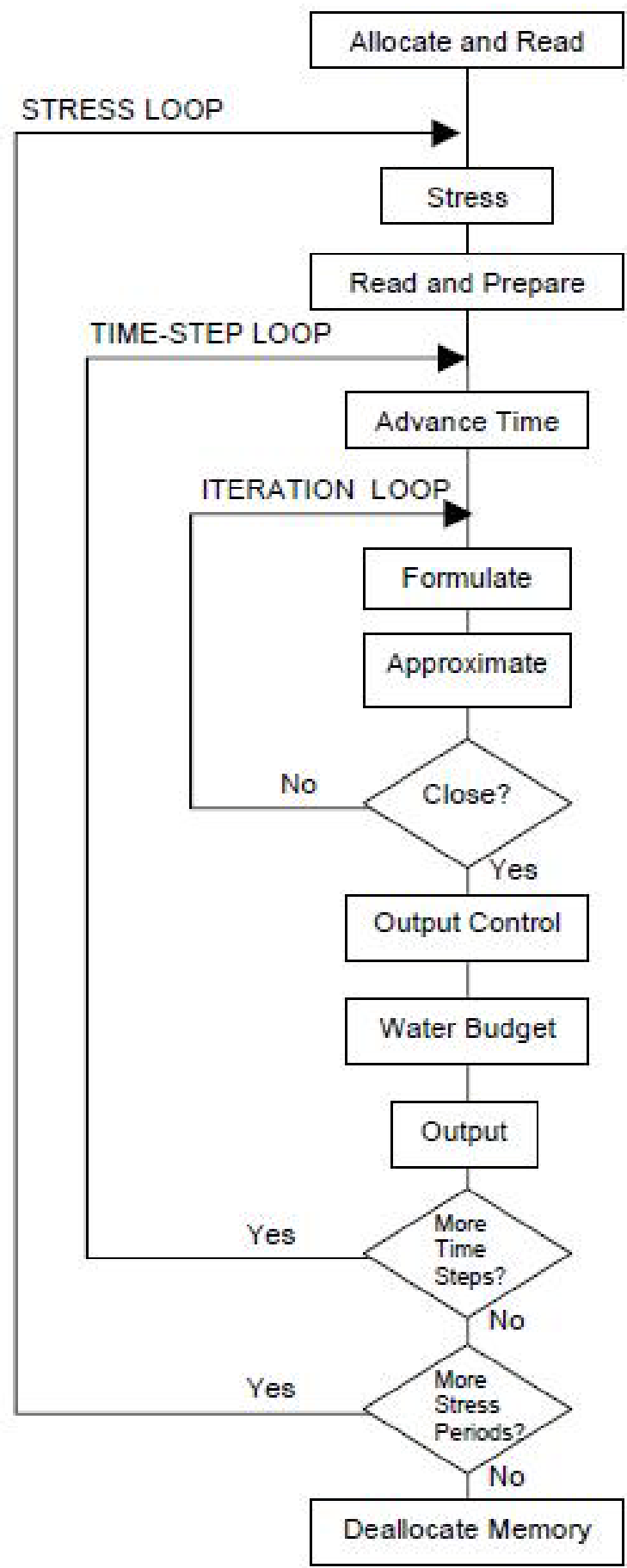




\section{APPENDIX C}

\section{NEW AND MODIFIED SOURCE CODE LINES}

\section{FLO-2D CODE}

\section{FILE: COMMON.F90}

CHANGES: multiple source code changes

Lines 270 to 274 new variables added

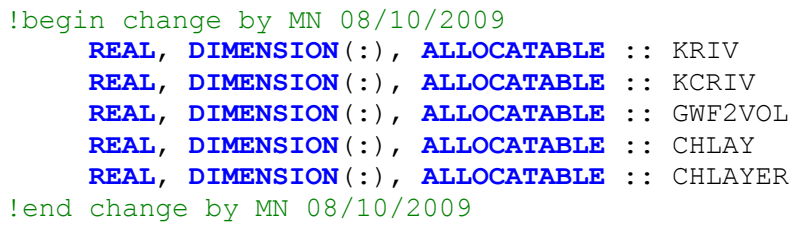

Lines 1126 to 1136 new variable added

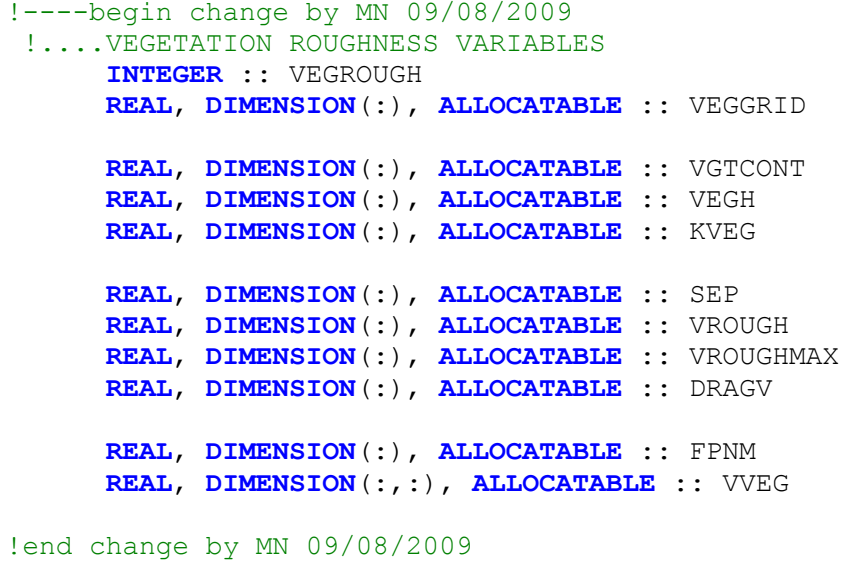

\section{FILE: ALLOCHAN.F90}

CHANGE: new variable allocation

Lines 84 to 88 new variables allocated

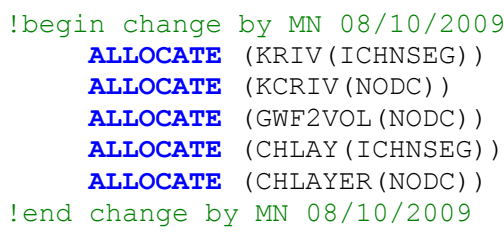




\section{FILE: MODFLOW.F90}

CHANGE: new subroutine

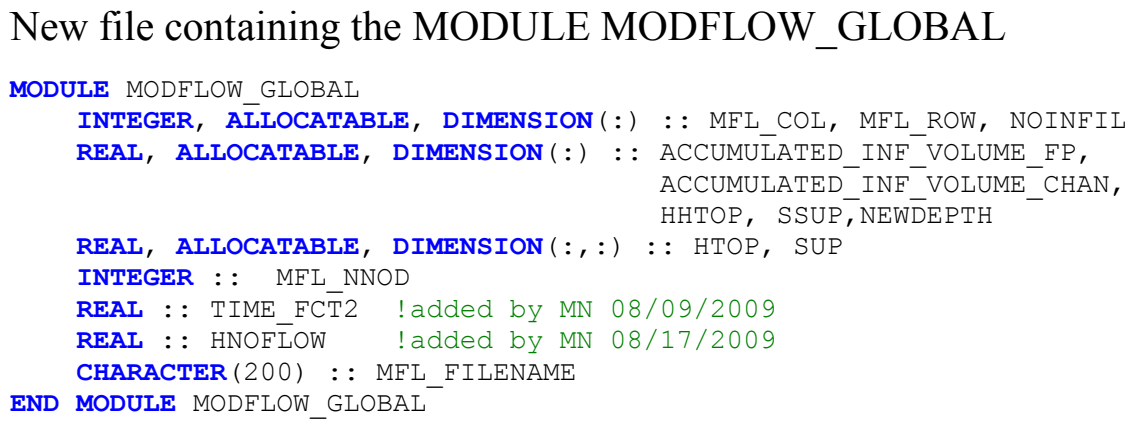

\section{FILE: FLOMAIN.F90}

CHANGE: multiple source code changes

Line 22 to 23 new lines added:

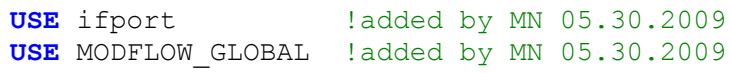

Line 122: dummy variable initialization

FIRST_STEP $=1 \quad$ ! Added by MN 05.30.2009

Lines 1289 to 1303: New lines added

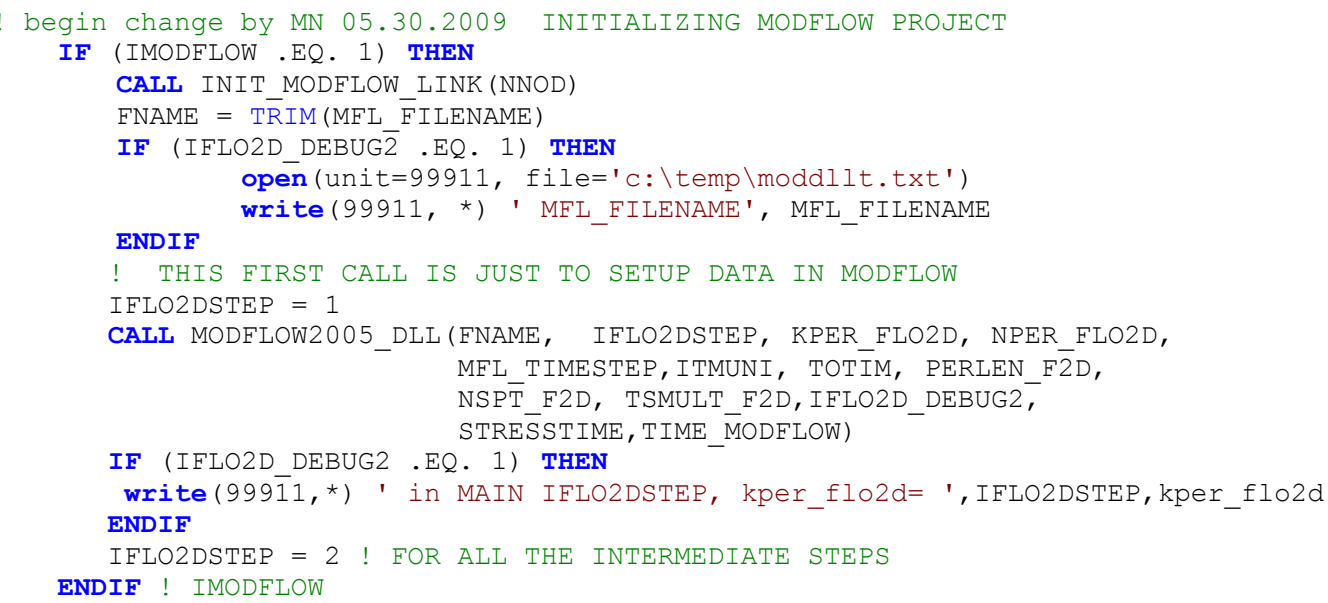




\section{Lines 1305 to 1311: dummy variable initialization}

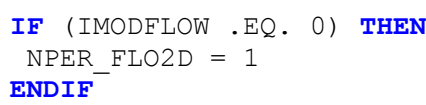

Lines 1309 to 1326: time unit transformation and control writing

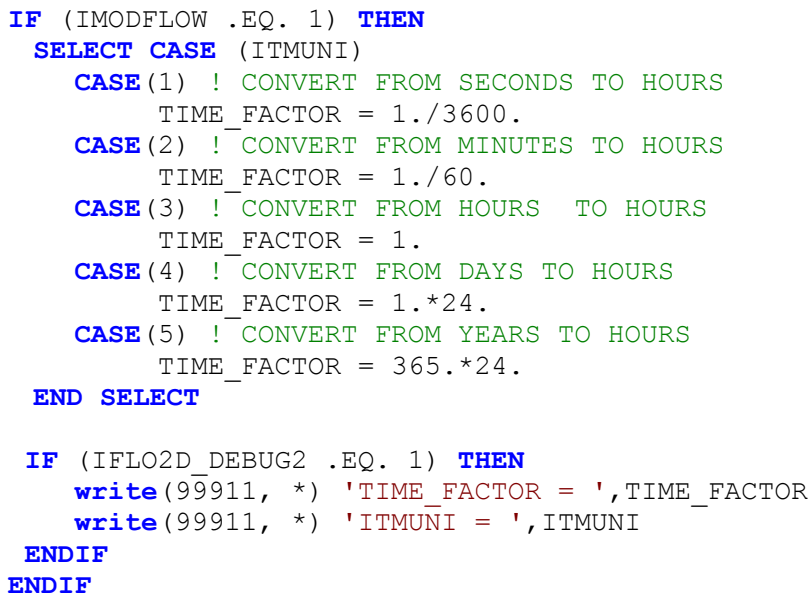

\section{Lines 1328 to 1331: variable initialization}

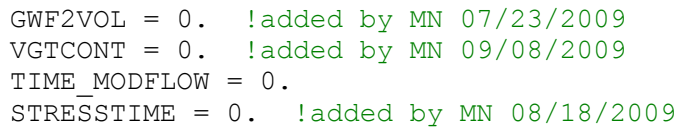

\section{Lines 1333 to 1353: new lines added}

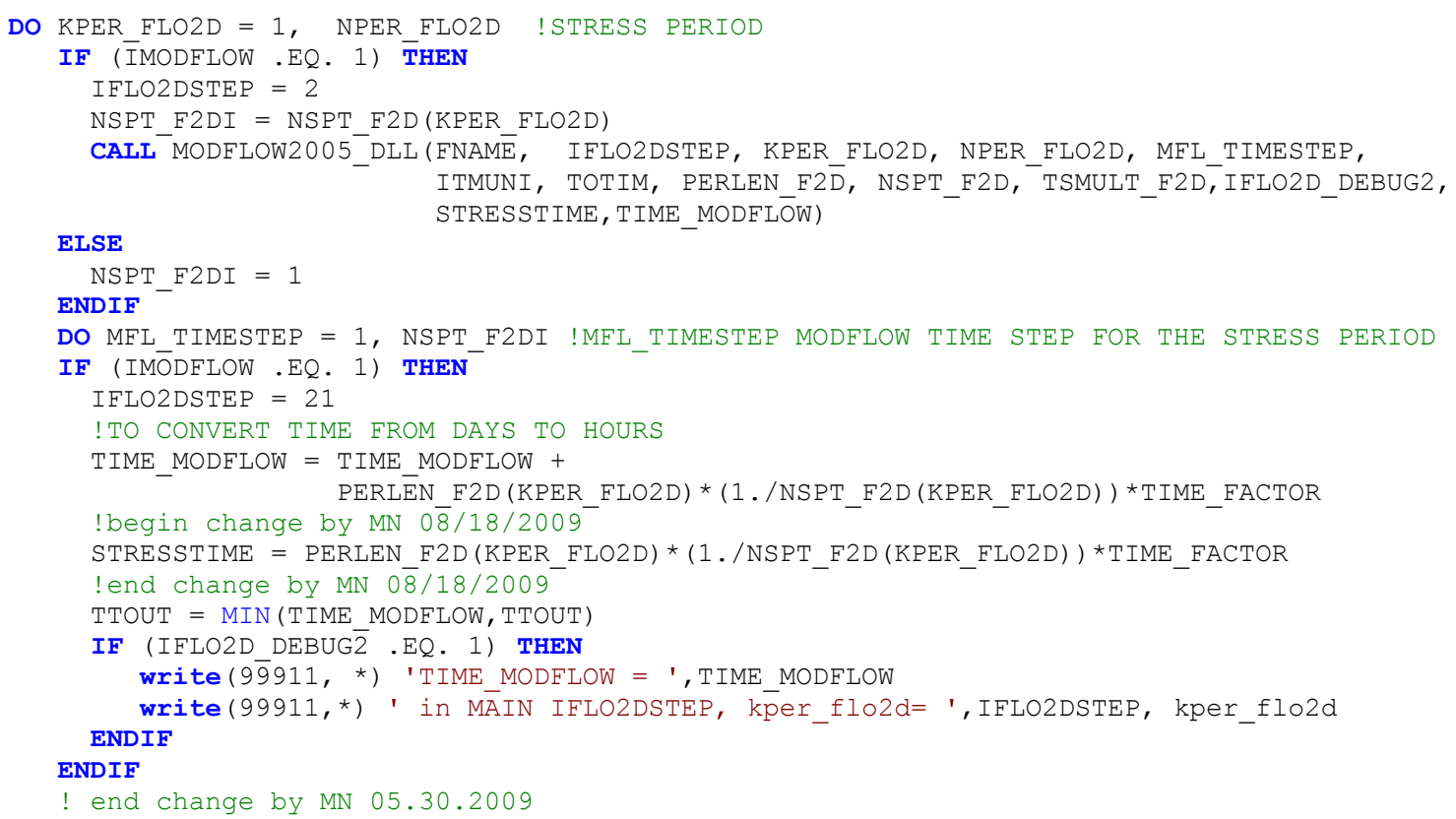


Lines 2087 to 2091 and 2100 to 2104: new lines added

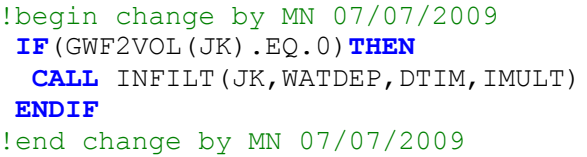

\section{Lines 2108 to 2111: lines modified}

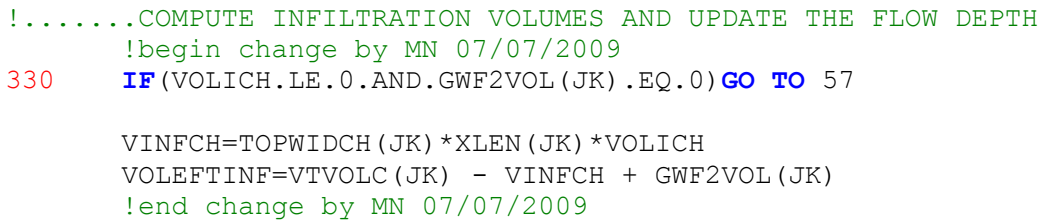

\section{Lines 4041 to 4047: new lines added}

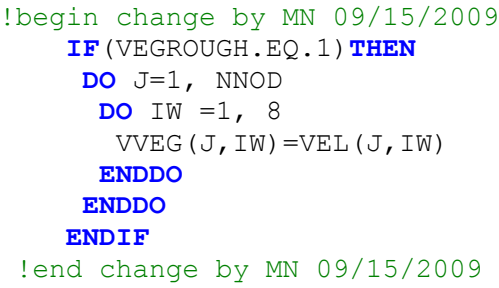

Lines 4051 to 4069: new lines added

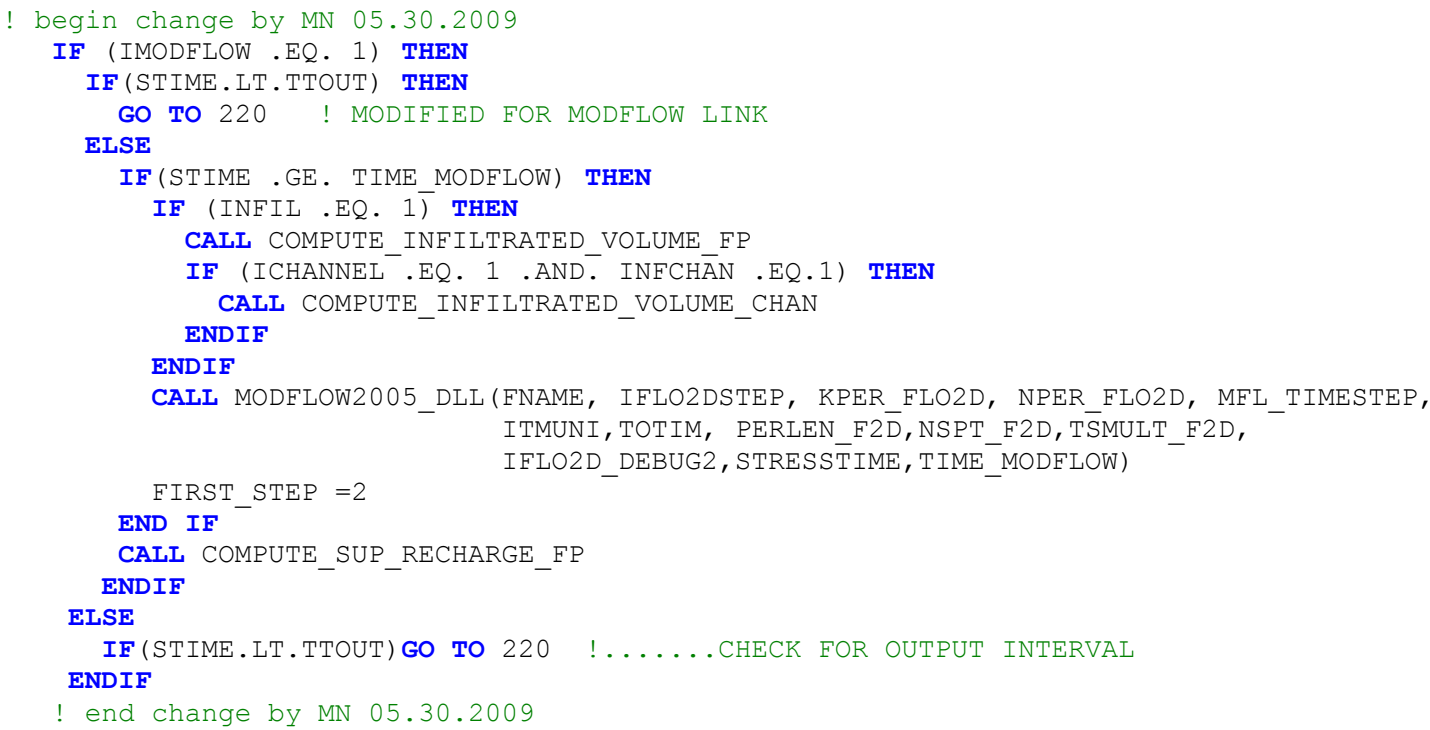


Lines 4559 to 4563: new lines added

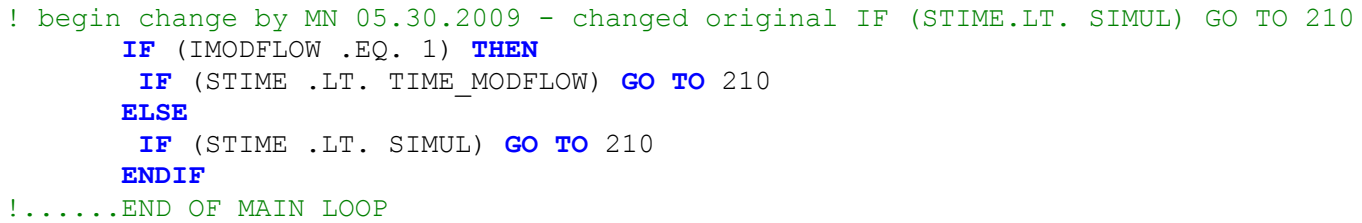

Lines 4572 to 4575: new lines added

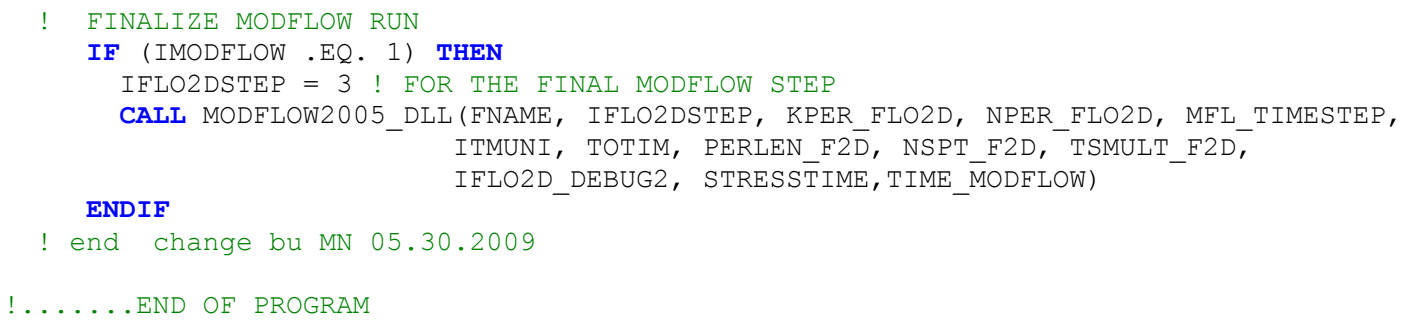

\section{FILE: INPUTD.F90}

\section{CHANGE: multiple source code changes}

\section{Line 107 to 108: lines modified, options IMODFLOW and VEROUGH added}

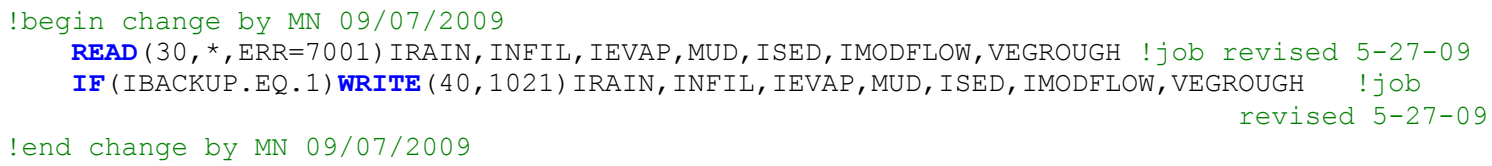

Line 271 to 274 : new lines added

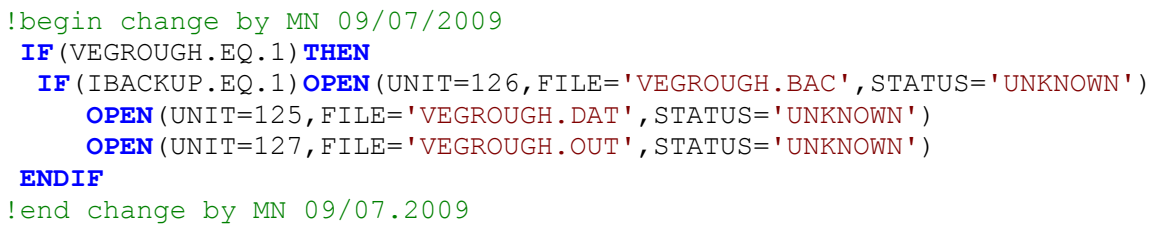


Line 917 to 946: new lines added

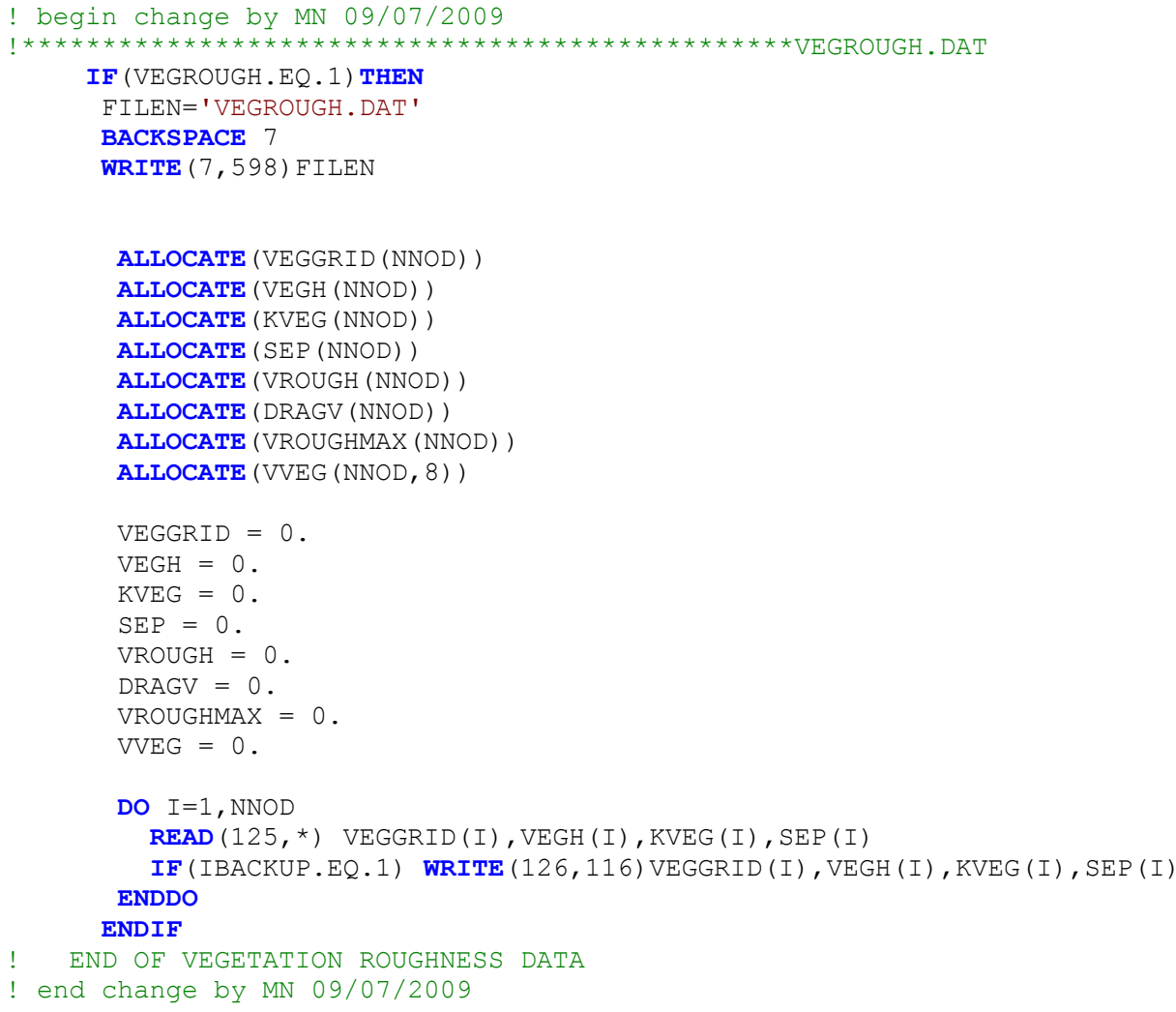

\section{FILE: OUTPUT.F90}

CHANGE: new source code added

\section{Line 330 to 332 : new lines added}

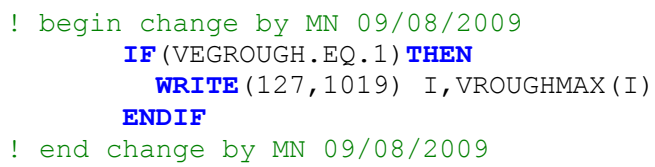




\section{FILE: MODFLOW_2.F90}

CHANGE: a group of new subroutines related with the coupling of the models are included in this file.

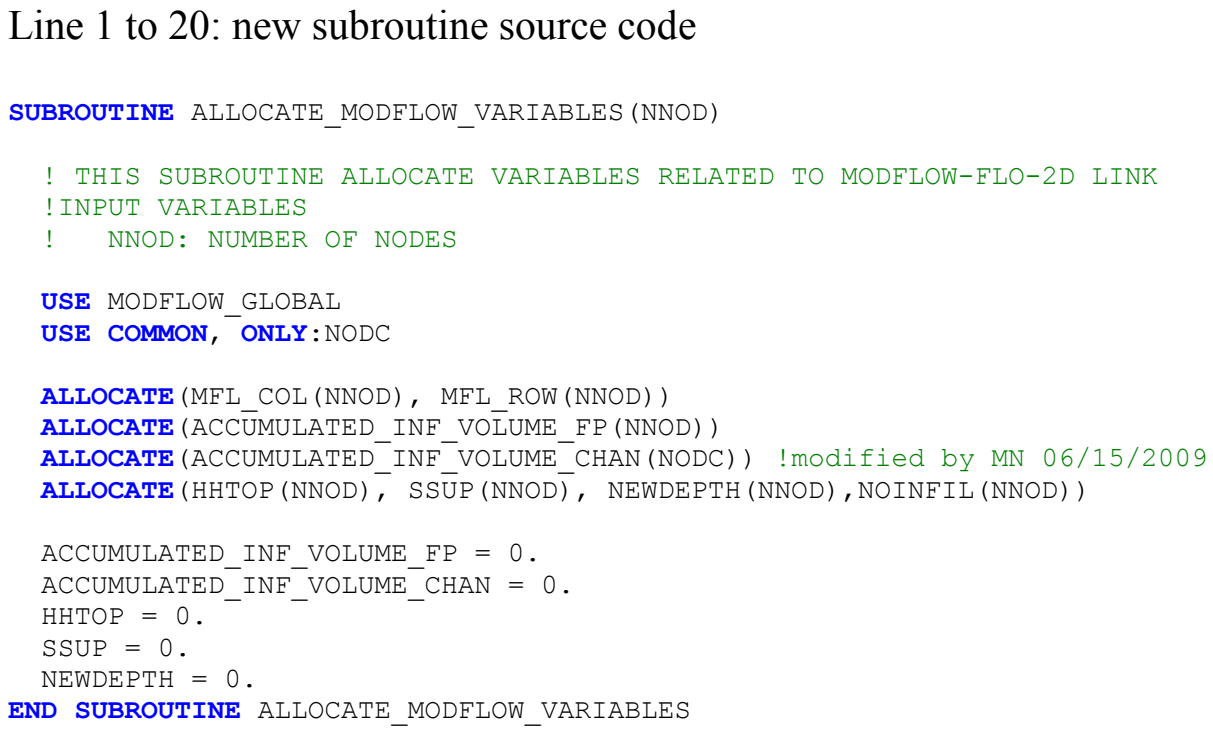

Line 23 to 36: new subroutine source code

SUBROUTINE INIT_MODFLOW_LINK(NNOD)

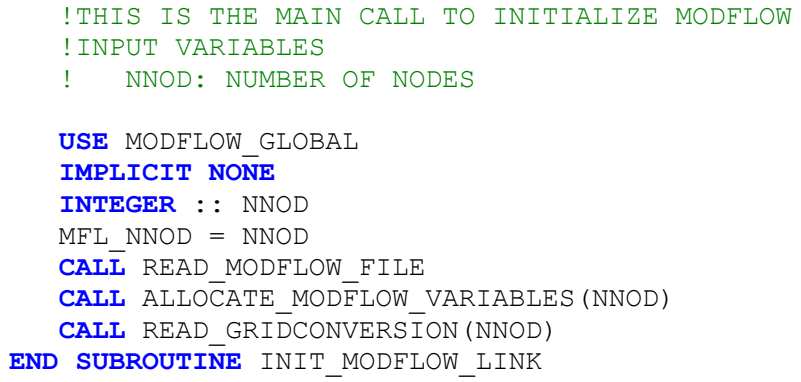

Line 23 to 36 : new subroutine source code

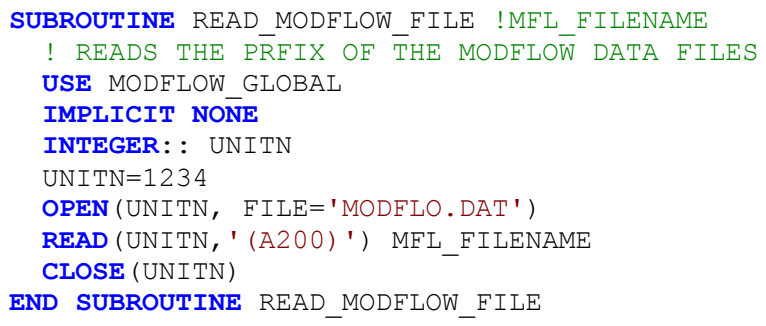




\section{Line 51 to 63: new subroutine source code}

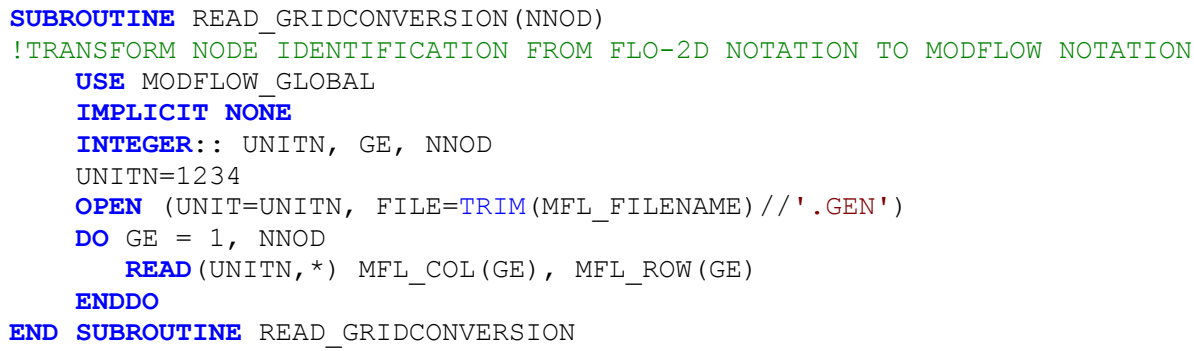

Line 66 to 86 : new subroutine source code

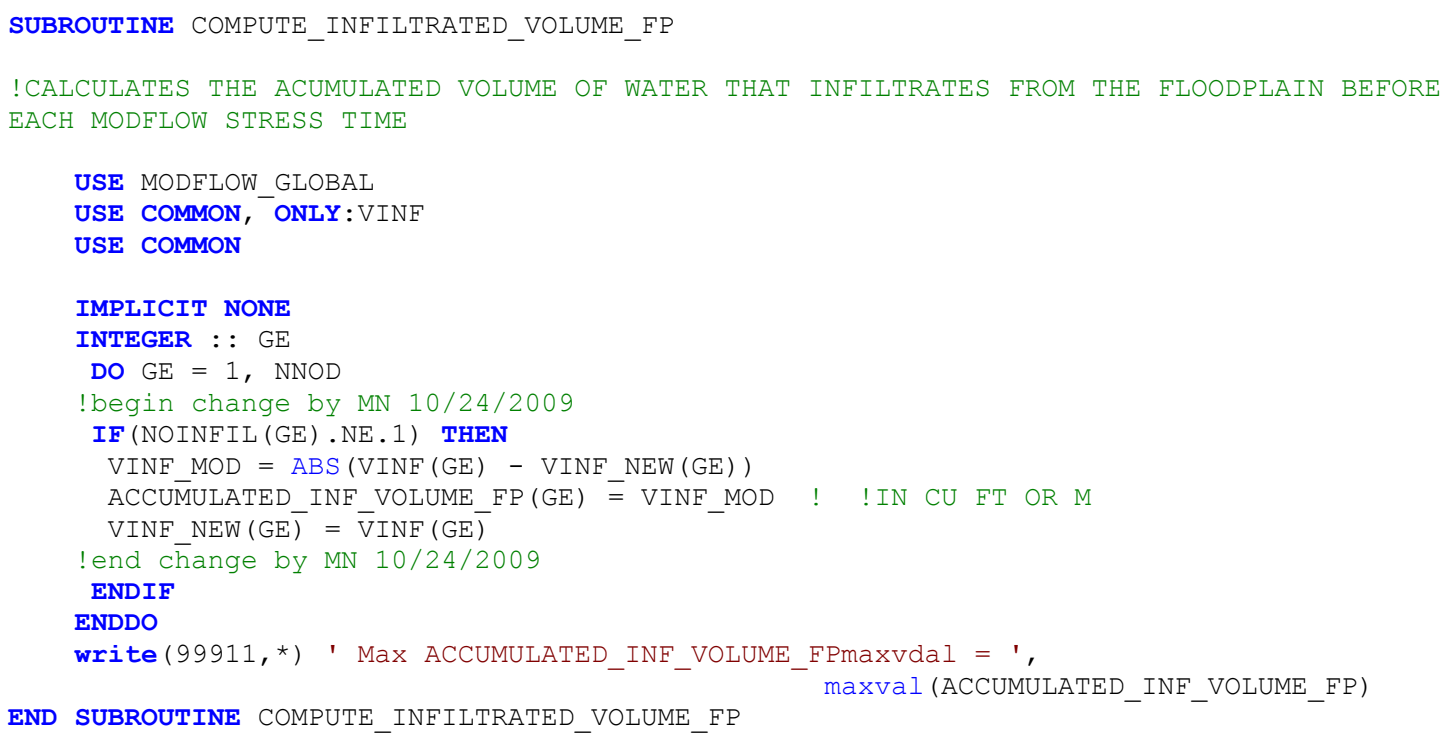

\section{Line 89 to 105: new subroutine source code}

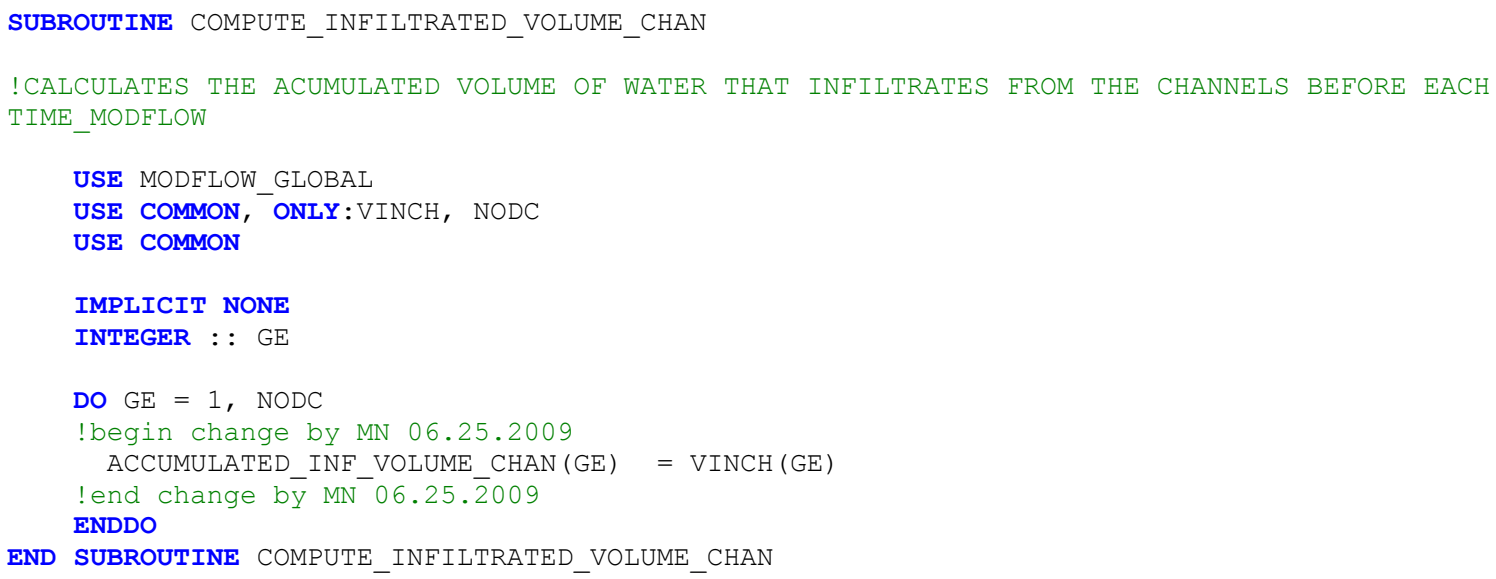




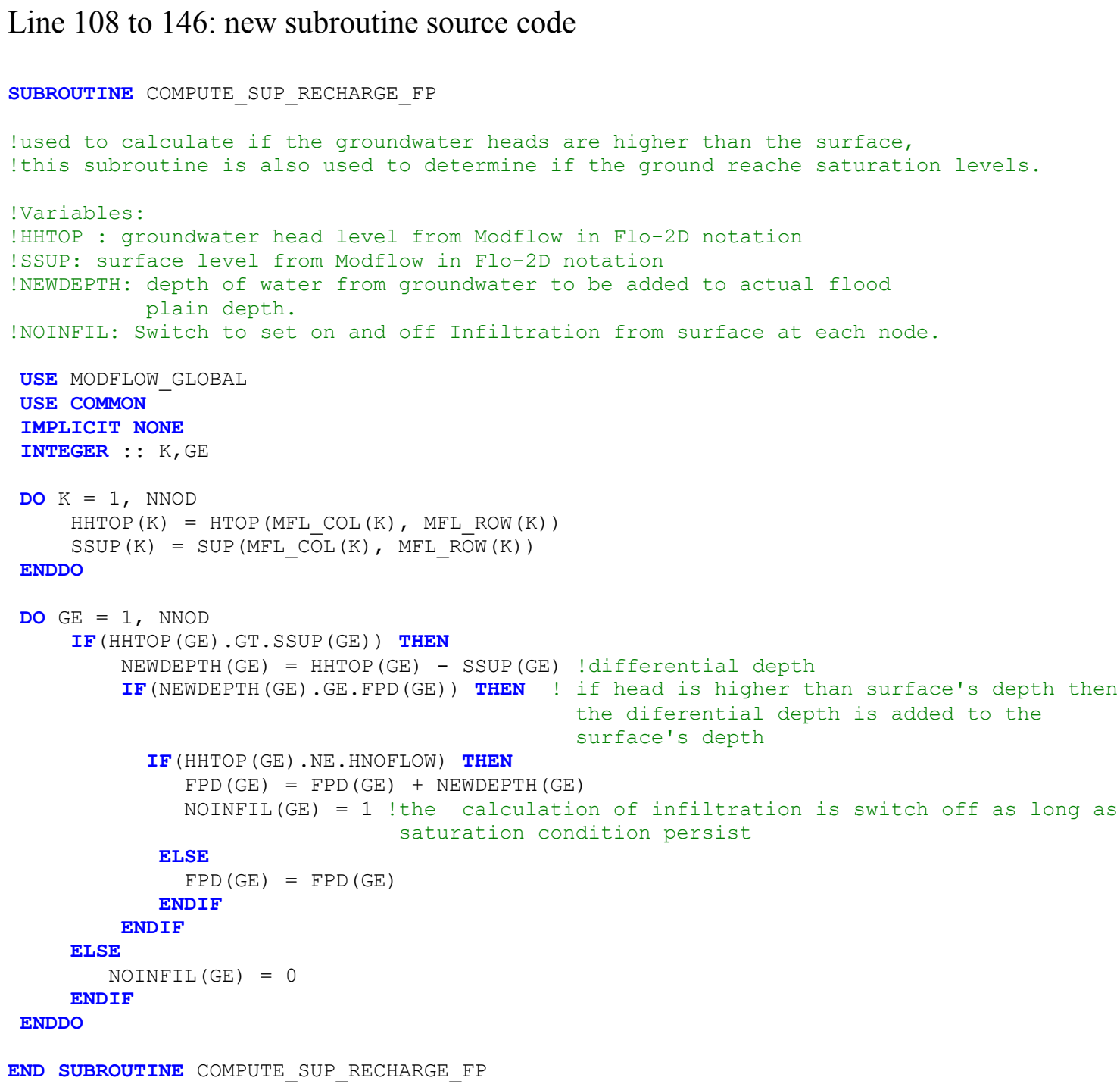

\section{FILE: OVRLAND.F90}

\section{CHANGE: multiple source code changes}

\section{Line 10: new line added}

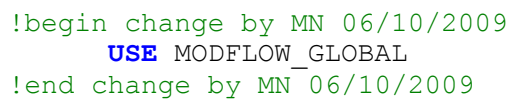




\section{Lines 547 to 549: new lines added}

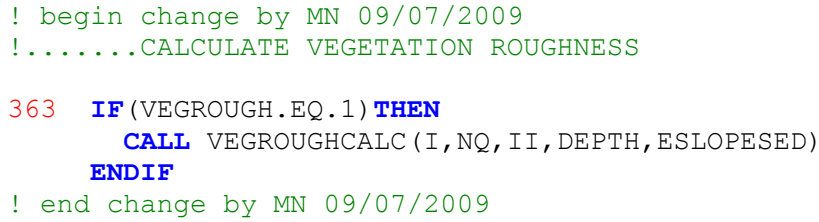

\section{Line 1276: line modified}

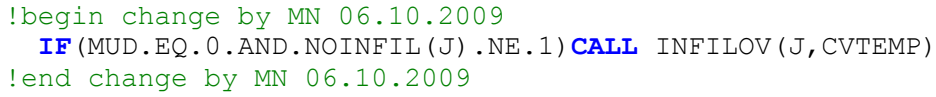

\section{Line 1301: line modified}

!begin change by MN 06.10.2009

568 IF (CVTEMP.LT.0.15.AND.NOINFIL (J).NE.1) CALL INFILOV (J, CVTEMP)

!end change by MN 06.10.2009

\section{FILE: VEGROUGH.F90}

CHANGE: new subroutine for the calculation of resistance due to vegetation

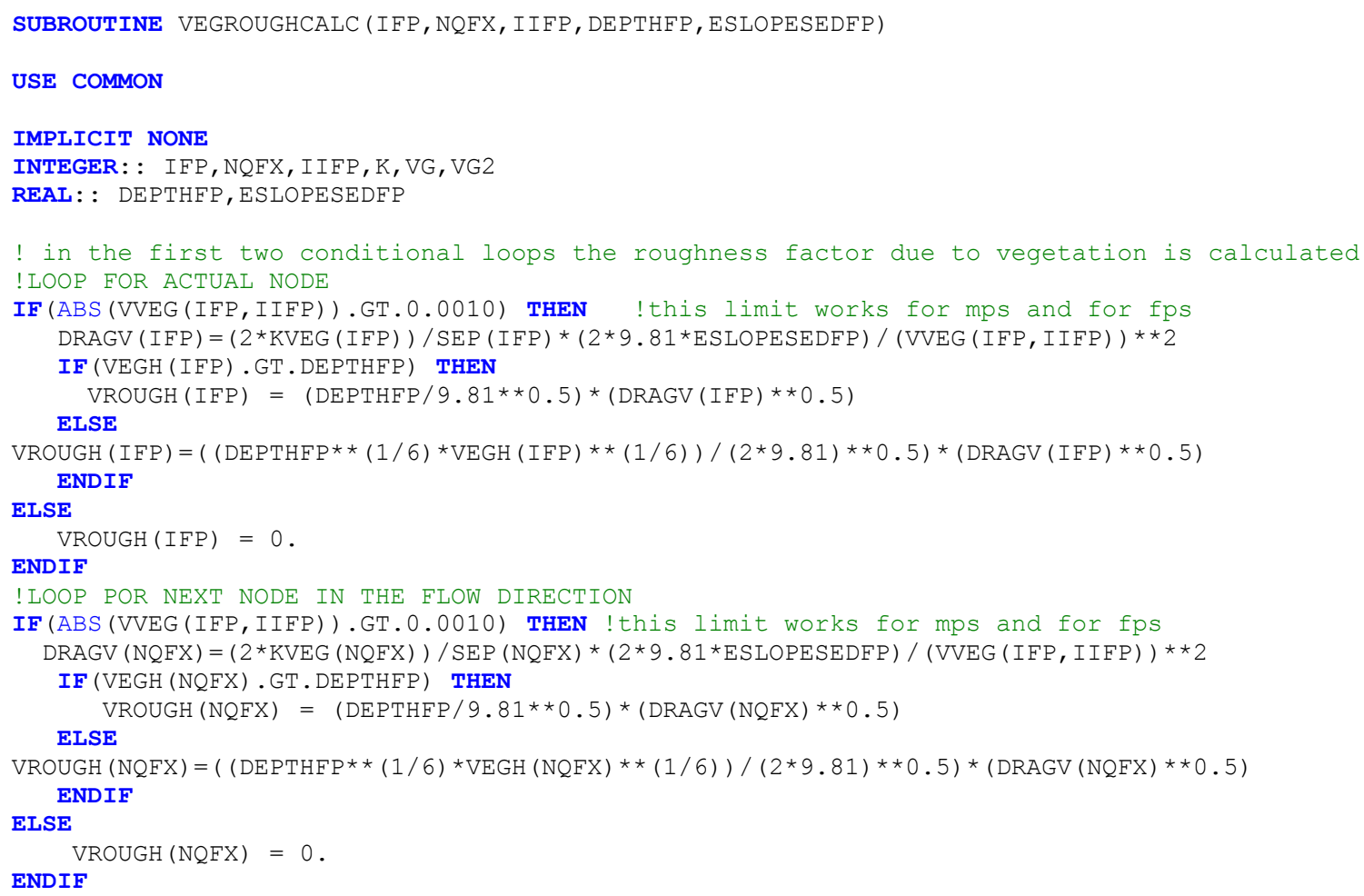




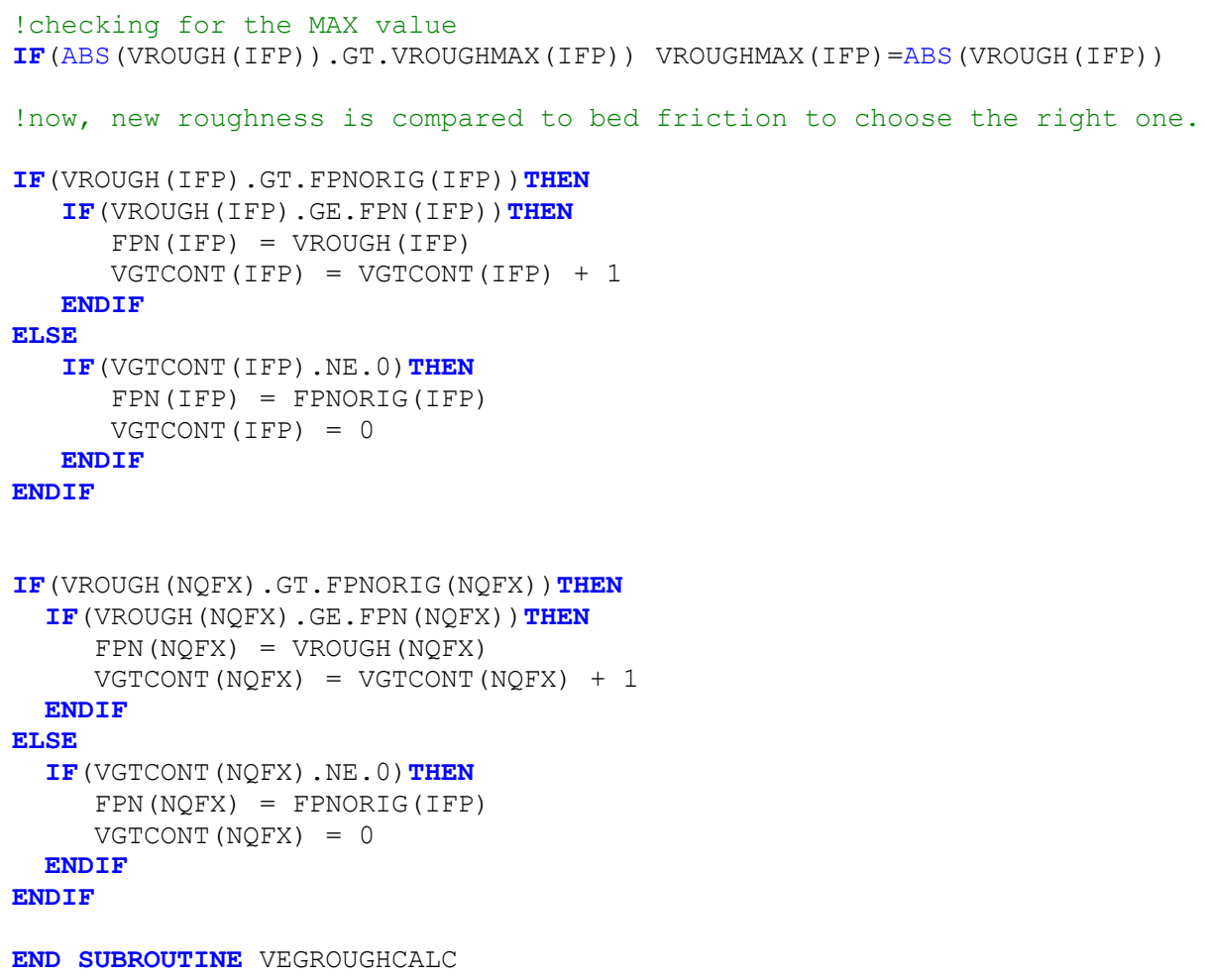

END SUBROUTINE VEGROUGHCALC

\section{FILE: Qfp.F90}

CHANGE: new line added

Line 121: new line added, new conditional loop end at line 153

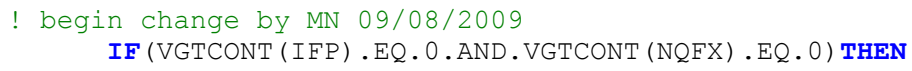




\section{MODFLOW SOURCE CODE}

\section{FILE: MODFLOW_SUBS.f}

CHANGE: this new file supersedes the original GWF2RCH7.f from MODFLOW

Line 51: line modified, only NRCHOP and IRCHCB are read from file

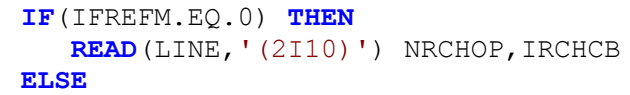

Lines 159 to $161 ; 178$ to $180 ; 198$ to 200 : lines modified to use FLO-2D data in MODFLOW notation

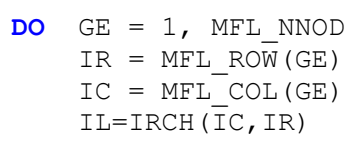

Lines 167; 187 and 210: Lines modified to receive recharge from FLO-2D

C begin change by MN 08/09/2009

RECH $($ IC, IR) =ACCUMULATED_INF_VOLUME_FP (GE) / (STRESSTIME*TIME_FCT2)

$\mathrm{C}$ end change by MN 08/09/2009

FILE: MODFLOW_SUBS2.f

CHANGE: this new file supersedes the original GWF2RIV7.f from MODFLOW

Lines 236 to 253 and 335 to 352: lines modified to use FLO-2D data in MODFLOW notation

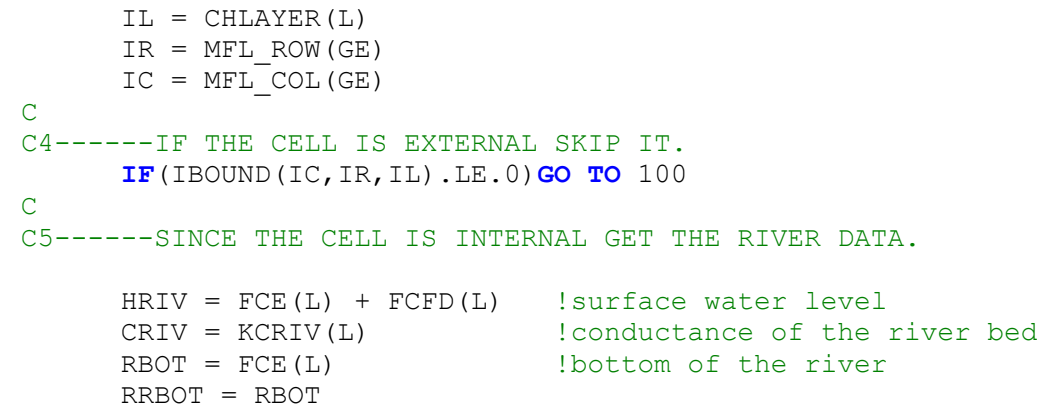


Line 264: line modified to receive data from FLO-2D

C8-1 INFILTRATION FROM THE RIVER IS CALCULATED IN FLO-2D

96 RHS (IC, IR, IL) = RHS (IC,IR, IL)-ACCUMULATED_INF_VOLUME_CHAN (L) / (STRESSTIME*TIME_FCT2)

Line 366: line modified to calculate rate using data from FLO-2D

RATE=ACCUMULATED_INF_VOLUME_CHAN (L) / (STRESSTIME*TIME_FCT2)

FILE: mf2005_dll.f

CHANGE: multiple source code changes

Line 19: new line added

USE MODFLOW_GLOBAL

Lines 40 to 42 : new lines added for variable initialization

REAL, ALLOCATABLE : : PERLEN_F2D (:), TSMULT_F2D (:)

INTEGER, ALLOCATABLE :: NSPT_F2D(:)

INTEGER : : IFLO2D_DEBUG

Lines 75 to 76 : new lines added

REAL:: STRESSTIME, TIME MODFLOW

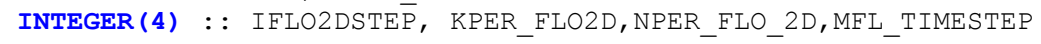

Line 130: new line added

! begin change by MN 07/07/2009

CALL GWF2RIVFLO2D7AR (IN, IGRID)

! end change by MN 07/07/2009

Line 137: line modified

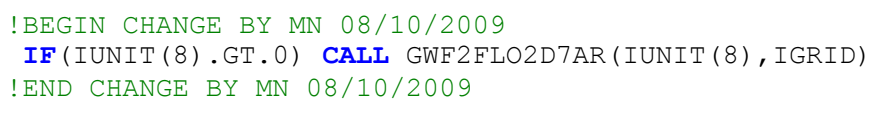




\section{Lines 187 to 198: new lines added}

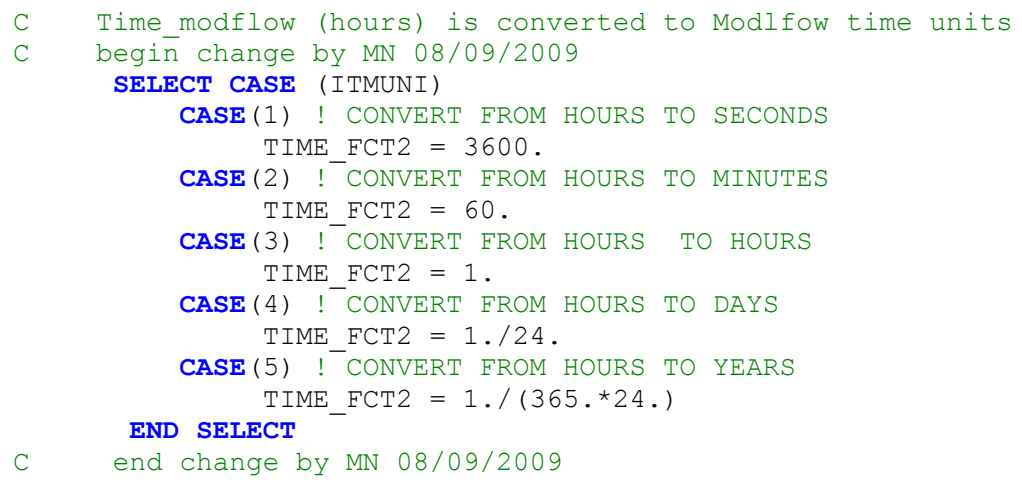

\section{Line 230: line modified}

C begin change by MN 08/12/2009

IF (IUNIT (8) .GT.0) CALL GWF2FLO2D7RP (IUNIT (8), IGRID)

C end change by MN 08/12/2009

Line 304: line modified

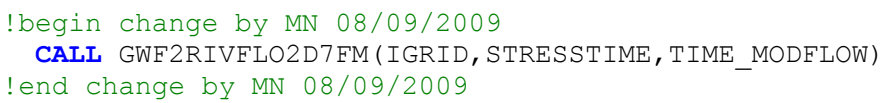

Line 319: line modified
C begin change by MN 08/10/2009
CALI GWF2FLO2D7FM(IGRID, STRESSTIME, TIME_MODFLOW)
C end change by MN 08/10/2009

\section{Lines 390 to 395: new lines added}

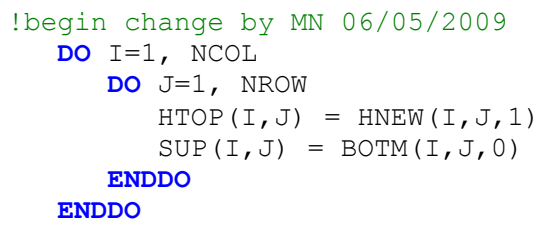

\section{Line 452: line modified}

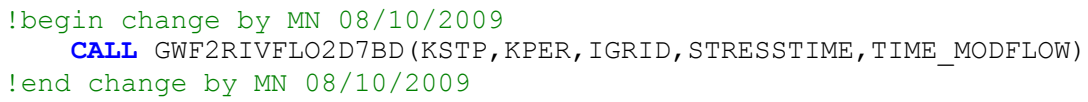


Line 471: line modified

C

begin change by MN 08/07/2009

CALL GWF2FLO2D7BD (KKSTP, KKPER, IGRID)

C

end change by MN 08/07/2009

Line 558: line modified

!BEGIN CHANGE BY MN 03/03/2009

CALL GWF2FLO2D7DA (IGRID)

! END CHANGE BY MN 03/03/2009 


\section{APPENDIX D}

\section{ISLAND RECHARGE OUTPUT FILES}

\section{FLO-2D}

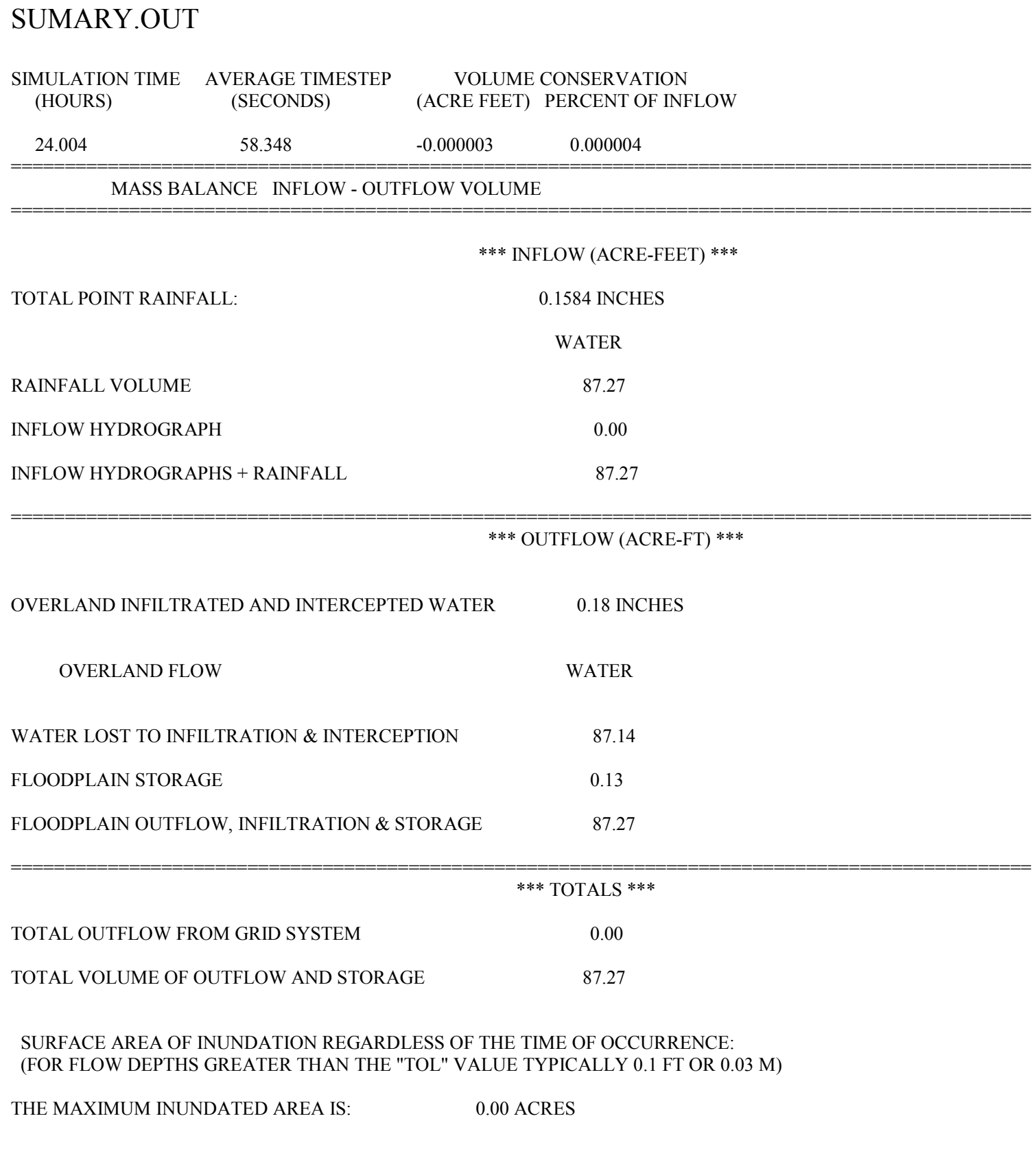

COMPUTER RUN TIME IS: 0.00057 HRS

THIS OUTPUT FILE WAS TERMINATED ON: 9/ 8/2009 AT: 15:58: 2 


\section{MODFLOW}

\section{TRWI.LST}

MODFLOW-2005

U.S. GEOLOGICAL SURVEY MODULAR FINITE-DIFFERENCE GROUND-WATER FLOW MODEL VERSION 1.4.00 11/2/2007

LIST FILE: C: PPROYECTOS $\backslash F L O-2 D-M O D F L O W \backslash I S L A N D R E C H \backslash$ twri.lst UNIT 201

OPENING C:|PROYECTOS\FLO-2D-MODFLOW\ISLANDRECH\twri.dis FILE TYPE:DIS UNIT 202 STATUS:OLD

FORMAT:FORMATTED ACCESS:SEQUENTIAL

OPENING C:IPROYECTOS\FLO-2D-MODFLOW $\backslash$ ISLANDRECH \twri.ba6 FILE TYPE:BAS6 UNIT 203 STATUS:OLD

FORMAT:FORMATTED ACCESS:SEQUENTIAL

OPENING C:IPROYECTOS\FLO-2D-MODFLOW $\backslash$ ISLANDRECH $\backslash$ twri.chd FILE TYPE:CHD UNIT 204 STATUS:OLD

FORMAT:FORMATTED ACCESS:SEQUENTIAL

OPENING C:|PROYECTOS\FLO-2D-MODFLOW $\backslash$ ISLANDRECH $\backslash$ twri.bc6 FILE TYPE:BCF6 UNIT 205 STATUS:OLD

FORMAT:FORMATTED ACCESS:SEQUENTIAL

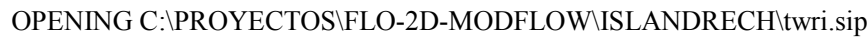
FILE TYPE:SIP UNIT 206 STATUS:OLD

FORMAT:FORMATTED ACCESS:SEQUENTIAL

OPENING C:IPROYECTOS\FLO-2D-MODFLOW $\backslash I S L A N D R E C H \backslash$ twri.rch FILE TYPE:RCH UNIT 218 STATUS:OLD

FORMAT:FORMATTED ACCESS:SEQUENTIAL

BAS -- BASIC PACKAGE, VERSION 7, 5/2/2005 INPUT READ FROM UNIT 203

DISCRETIZATION INPUT DATA READ FROM UNIT 202

1 LAYERS 24 ROWS 48 COLUMNS

1 STRESS PERIOD(S) IN SIMULATION

MODEL TIME UNIT IS DAYS

MODEL LENGTH UNIT IS FEET

Confining bed flag for each layer=

0

$$
\begin{aligned}
& \text { DELR }=500.000 \\
& \text { DELC }=500.000
\end{aligned}
$$

TOP ELEVATION OF LAYER $1=0.00000$

MODEL LAYER BOTTOM EL. $=-20.0000 \quad$ FOR LAYER 1

STRESS PERIOD LENGTH TIME STEPS MULTIPLIER FOR DELT SS FLAG

$\begin{array}{llll} & 1.000000 & 1 & 1.000\end{array}$

STEADY-STATE SIMULATION

THE FREE FORMAT OPTION HAS BEEN SELECTED

BOUNDARY ARRAY FOR LAYER 1 READING ON UNIT 203 WITH FORMAT: (FREE) 
$\begin{array}{llllllllllllllllllllllllllllll}1 & 2 & 3 & 4 & 5 & 6 & 7 & 8 & 9 & 10 & 11 & 12 & 13 & 14 & 15 & 16 & 17 & 18 & 19 & 20 & 21 & 22 & 23 & 24 & 25 & 26 & 27 & 28 & 29 & 30\end{array}$ $\begin{array}{llllllllllllllllll}31 & 32 & 33 & 34 & 35 & 36 & 37 & 38 & 39 & 40 & 41 & 42 & 43 & 44 & 45 & 46 & 47 & 48\end{array}$

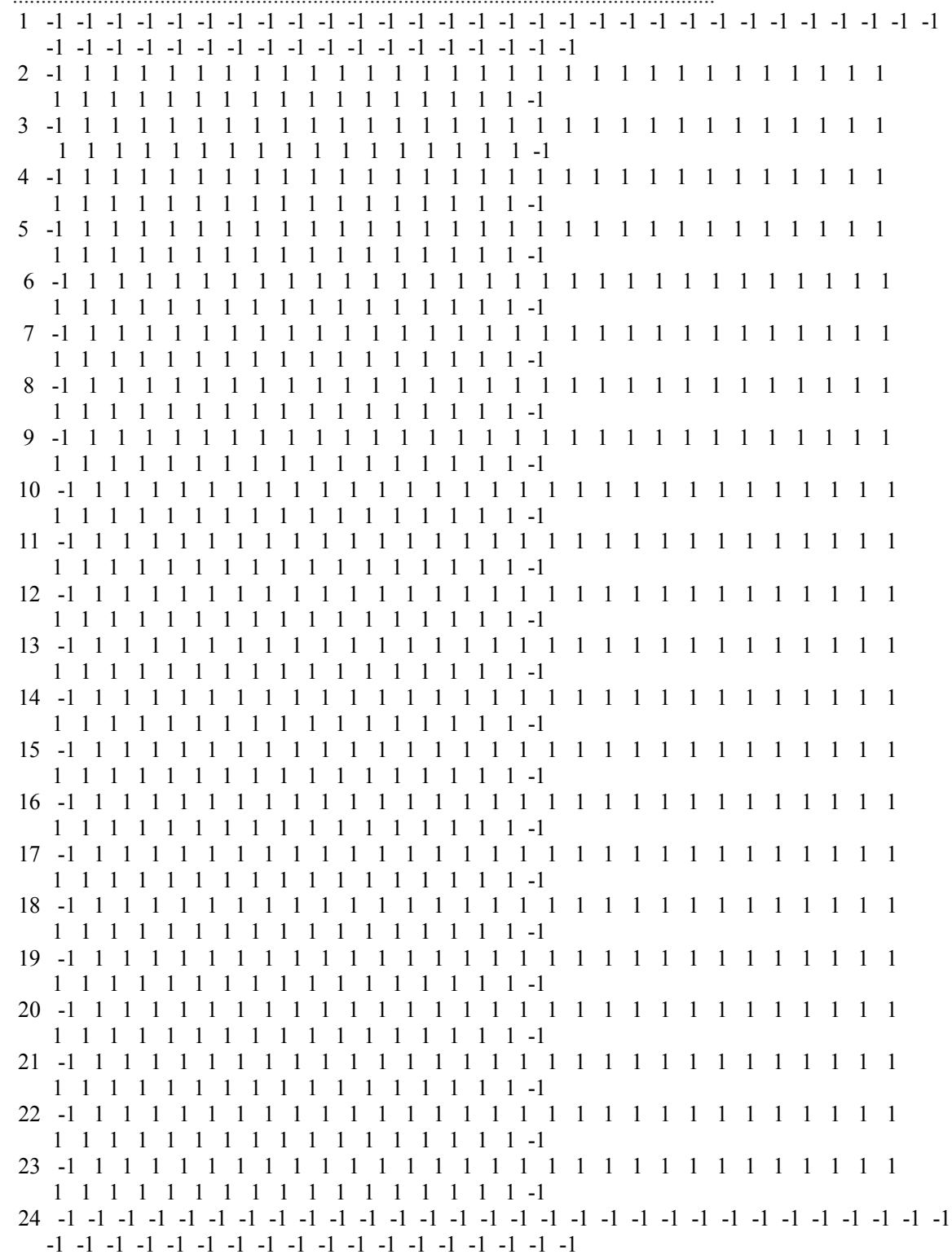

AQUIFER HEAD WILL BE SET TO 999.99 AT ALL NO-FLOW NODES (IBOUND=0).

INITIAL HEAD $=-20.0000 \quad$ FOR LAYER 1

DEFAULT OUTPUT CONTROL

THE FOLLOWING OUTPUT COMES AT THE END OF EACH STRESS PERIOD:

TOTAL VOLUMETRIC BUDGET HEAD

BCF -- BLOCK-CENTERED FLOW PACKAGE, VERSION 7, 5/2/2005

INPUT READ FROM UNIT205

STEADY-STATE SIMULATION

HEAD AT CELLS THAT CONVERT TO DRY $=0.10000 \mathrm{E}+31$

WETTING CAPABILITY IS NOT ACTIVE

LAYER LAYER-TYPE CODE INTERBLOCK T 


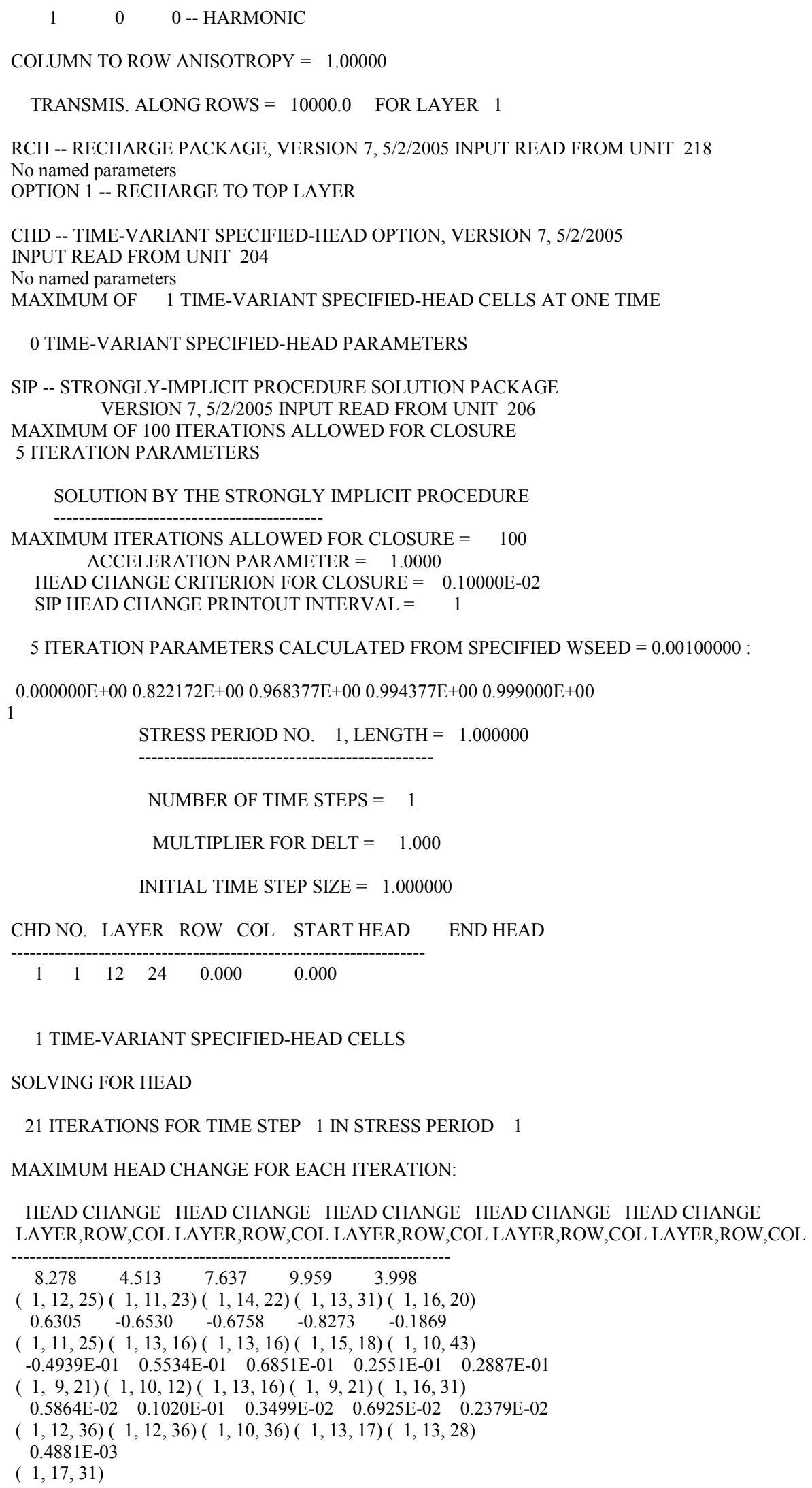




\begin{tabular}{|c|c|c|c|c|c|c|c|c|c|c|}
\hline & 1 & 2 & 3 & 4 & 5 & 6 & 7 & 8 & 9 & 10 \\
\hline & 11 & 12 & 13 & 14 & 15 & 16 & 17 & 18 & 19 & 20 \\
\hline & 21 & 22 & 23 & 24 & 25 & 26 & 27 & 28 & 29 & 30 \\
\hline & 31 & 32 & 33 & 34 & 35 & 36 & 37 & 38 & 39 & 40 \\
\hline & 41 & 42 & 43 & 44 & 45 & 46 & 47 & 48 & & \\
\hline \multirow[t]{5}{*}{1} & -20.00 & -20.00 & -20.00 & -20.00 & -20.00 & -20.00 & -20.00 & -20.00 & -20.00 & -20.00 \\
\hline & -20.00 & -20.00 & -20.00 & -20.00 & -20.00 & -20.00 & -20.00 & -20.00 & -20.00 & -20.00 \\
\hline & -20.00 & -20.00 & -20.00 & -20.00 & -20.00 & -20.00 & -20.00 & -20.00 & -20.00 & -20.00 \\
\hline & -20.00 & -20.00 & -20.00 & -20.00 & -20.00 & -20.00 & -20.00 & -20.00 & -20.00 & -20.00 \\
\hline & -20.00 & -20.00 & -20.00 & -20.00 & -20.00 & -20.00 & -20.00 & -20.00 & & \\
\hline \multirow[t]{5}{*}{2} & -20.00 & -19.37 & -18.90 & -18.53 & -18.23 & -17.98 & -17.77 & -17.59 & -17.43 & -17.30 \\
\hline & -17.18 & -17.08 & -17.00 & -16.92 & -16.86 & -16.81 & -16.76 & -16.73 & -16.69 & -16.67 \\
\hline & -16.65 & -16.64 & -16.63 & -16.62 & -16.62 & -16.63 & -16.64 & -16.65 & -16.67 & -16.69 \\
\hline & -16.73 & -16.76 & -16.81 & -16.86 & -16.92 & -17.00 & -17.08 & -17.18 & -17.30 & -17.43 \\
\hline & -17.59 & -17.77 & -17.98 & -18.23 & -18.53 & -18.90 & -19.37 & -20.00 & & \\
\hline \multirow[t]{5}{*}{3} & -20.00 & -18.90 & -18.03 & -17.33 & -16.74 & -16.25 & -15.83 & -15.47 & -15.17 & -14.90 \\
\hline & -14.68 & -14.48 & -14.31 & -14.17 & -14.04 & -13.94 & -13.85 & -13.78 & -13.71 & -13.66 \\
\hline & -13.62 & -13.60 & -13.58 & -13.57 & -13.57 & -13.58 & -13.60 & -13.62 & -13.66 & -13.71 \\
\hline & -13.77 & -13.85 & -13.94 & -14.04 & -14.17 & -14.31 & -14.48 & -14.68 & -14.90 & -15.17 \\
\hline & -15.48 & -15.83 & -16.25 & -16.74 & -17.33 & -18.03 & -18.90 & -20.00 & & \\
\hline \multirow[t]{5}{*}{4} & -20.00 & -18.54 & -17.33 & -16.33 & -15.49 & -14.78 & -14.17 & -13.64 & -13.19 & -12.80 \\
\hline & -12.47 & -12.18 & -11.93 & -11.72 & -11.54 & -11.38 & -11.25 & -11.14 & -11.05 & -10.98 \\
\hline & -10.92 & -10.88 & -10.85 & -10.83 & -10.83 & -10.85 & -10.88 & -10.92 & -10.98 & -11.05 \\
\hline & -11.14 & -11.25 & -11.38 & -11.54 & -11.72 & -11.93 & -12.18 & -12.47 & -12.81 & -13.19 \\
\hline & -13.64 & -14.17 & -14.78 & -15.49 & -16.33 & -17.33 & -18.54 & -20.00 & & \\
\hline \multirow[t]{5}{*}{5} & -20.00 & -18.24 & -16.76 & -15.51 & -14.44 & -13.53 & -12.74 & -12.07 & -11.48 & -10.98 \\
\hline & -10.55 & -10.17 & -9.850 & -9.572 & -9.334 & -9.131 & -8.960 & -8.816 & -8.697 & -8.601 \\
\hline & -8.526 & -8.471 & -8.435 & -8.417 & -8.417 & -8.435 & -8.471 & -8.526 & -8.601 & -8.697 \\
\hline & -8.816 & -8.960 & -9.132 & -9.335 & -9.573 & -9.851 & -10.17 & -10.55 & -10.98 & -11.49 \\
\hline & -12.07 & -12.74 & -13.53 & -14.44 & -15.51 & -16.76 & -18.24 & -20.00 & & \\
\hline \multirow[t]{5}{*}{6} & -20.00 & -18.00 & -16.29 & -14.83 & -13.56 & -12.48 & -11.54 & -10.73 & -10.03 & -9.419 \\
\hline & -8.895 & -8.441 & -8.050 & -7.714 & -7.425 & -7.179 & -6.970 & -6.795 & -6.651 & -6.534 \\
\hline & -6.443 & -6.377 & -6.333 & -6.311 & -6.311 & -6.333 & -6.377 & -6.444 & -6.535 & -6.651 \\
\hline & -6.796 & -6.970 & -7.179 & -7.425 & -7.714 & -8.051 & -8.442 & -8.896 & -9.420 & -10.03 \\
\hline & -10.73 & -11.54 & -12.48 & -13.56 & -14.83 & -16.29 & -18.01 & -20.00 & & \\
\hline \multirow[t]{5}{*}{7} & -20.00 & -17.81 & -15.91 & -14.27 & -12.84 & -11.61 & -10.54 & -9.608 & -8.803 & -8.105 \\
\hline & -7.500 & -6.977 & -6.525 & -6.136 & -5.803 & -5.518 & -5.277 & -5.074 & -4.907 & -4.772 \\
\hline & -4.666 & -4.589 & -4.537 & -4.512 & -4.512 & -4.538 & -4.589 & -4.667 & -4.773 & -4.908 \\
\hline & -5.075 & -5.277 & -5.518 & -5.803 & -6.137 & -6.526 & -6.978 & -7.501 & -8.106 & -8.804 \\
\hline & -9.609 & -10.54 & -11.61 & -12.84 & -14.27 & -15.91 & -17.81 & -20.00 & & \\
\hline \multirow[t]{5}{*}{8} & -20.00 & -17.66 & -15.61 & -13.82 & -12.26 & -10.90 & -9.722 & -8.694 & -7.802 & -7.026 \\
\hline & -6.353 & -5.771 & -5.267 & -4.833 & -4.461 & -4.143 & -3.873 & -3.647 & -3.460 & -3.309 \\
\hline & -3.191 & -3.103 & -3.046 & -3.018 & -3.018 & -3.047 & -3.105 & -3.192 & -3.310 & -3.461 \\
\hline & -3.648 & -3.874 & -4.144 & -4.462 & -4.834 & -5.268 & -5.772 & -6.355 & -7.027 & -7.803 \\
\hline & -8.696 & -9.723 & -10.90 & -12.26 & -13.82 & -15.61 & -17.66 & -20.00 & & \\
\hline \multirow[t]{5}{*}{9} & -20.00 & -17.54 & -15.37 & -13.47 & -11.81 & -10.35 & -9.083 & -7.976 & -7.013 & -6.175 \\
\hline & -5.446 & -4.815 & -4.269 & -3.799 & -3.394 & -3.049 & -2.756 & -2.510 & -2.307 & -2.142 \\
\hline & -2.013 & -1.918 & -1.855 & -1.824 & -1.825 & -1.857 & -1.921 & -2.016 & -2.145 & -2.309 \\
\hline & -2.512 & -2.758 & -3.050 & -3.396 & -3.800 & -4.271 & -4.816 & -5.448 & -6.176 & -7.014 \\
\hline & -7.977 & -9.084 & -10.35 & -11.81 & -13.47 & -15.37 & -17.54 & -20.00 & & \\
\hline & $0-20.00$ & -17.45 & -15.20 & -13.21 & -11.47 & -9.946 & -8.611 & -7.445 & -6.428 & -5.542 \\
\hline & -4.772 & -4.104 & -3.526 & -3.027 & -2.598 & -2.232 & -1.921 & -1.660 & -1.444 & -1.269 \\
\hline & -1.132 & -1.030 & -0.9612 & -0.9269 & -0.9295 & -0.9656 & -1.034 & -1.136 & -1.273 & -1.448 \\
\hline & -1.663 & -1.924 & -2.234 & -2.600 & -3.029 & -3.527 & -4.105 & -4.773 & -5.543 & -6.429 \\
\hline & -7.446 & -8.612 & -9.947 & -11.47 & -13.21 & -15.20 & -17.45 & -20.00 & & \\
\hline & $1-20.00$ & -17.39 & -15.08 & -13.05 & -11.25 & -9.679 & -8.300 & -7.094 & -6.042 & -5.124 \\
\hline & -4.326 & -3.633 & -3.033 & -2.515 & -2.070 & -1.689 & -1.366 & -1.095 & -0.8706 & -0.6884 \\
\hline & -0.5449 & -0.4372 & -0.3630 & -0.3227 & -0.3301 & -0.3708 & -0.4436 & -0.5503 & -0.6929 & -0.8745 \\
\hline & -1.099 & -1.369 & -1.692 & -2.072 & -2.517 & -3.034 & -3.634 & -4.327 & -5.125 & -6.042 \\
\hline & -7.095 & -8.300 & -9.679 & -11.25 & -13.04 & -15.08 & -17.39 & -20.00 & & \\
\hline & $2-20.00$ & -17.36 & -15.03 & -12.96 & -11.14 & -9.546 & -8.146 & -6.920 & -5.849 & -4.916 \\
\hline & -4.103 & -3.398 & -2.787 & -2.259 & -1.806 & -1.418 & -1.089 & -0.8130 & -0.5841 & -0.3983 \\
\hline
\end{tabular}




\begin{tabular}{|c|c|c|c|c|c|c|c|c|c|}
\hline-0.2517 & -0.1407 & $-6.0429 \mathrm{E}-0$ & $20.00-2$. & 6996E-02 & $-7.3137 \mathrm{E}-\mathrm{C}$ & $02-0.148$ & -0.2579 & -0.4035 & -0.5887 \\
\hline-0.8170 & -1.093 & -1.421 & -1.808 & -2.261 & -2.788 & -3.399 & -4.104 & -4.916 & -5.849 \\
\hline-6.920 & -8.146 & -9.546 & -11.14 & -12.96 & -15.03 & -17.36 & -20.00 & & \\
\hline $13-20.00$ & -17.36 & -15.03 & -12.96 & -11.14 & -9.547 & -8.146 & -6.920 & -5.850 & -4.916 \\
\hline-4.104 & -3.398 & -2.787 & -2.260 & -1.806 & -1.418 & -1.089 & -0.8131 & -0.5843 & -0.3987 \\
\hline-0.2526 & $-0.143-6$ & $.7521 \mathrm{E}-02$ & $-2.6562 \mathrm{E}-$ & $02-3.4100$ & E-02-7.54 & $55 \mathrm{E}-02-0$ & $0.1497 \quad-0.2$ & $2585-0.4$ & $4040 \quad-0.589$ \\
\hline-0.8174 & -1.093 & -1.422 & -1.809 & -2.262 & -2.788 & -3.399 & -4.104 & -4.916 & -5.849 \\
\hline-6.920 & -8.145 & -9.546 & -11.14 & -12.96 & -15.03 & -17.36 & -20.00 & & \\
\hline $14-20.00$ & -17.39 & -15.08 & -13.05 & -11.25 & -9.679 & -8.301 & -7.095 & -6.042 & -5.125 \\
\hline-4.326 & -3.633 & -3.033 & -2.515 & -2.070 & -1.689 & -1.366 & -1.095 & -0.8710 & -0.6892 \\
\hline-0.5466 & -0.4406 & -0.3697 & -0.3341 & -0.3368 & -0.3743 & $\begin{array}{ll}3-0.445 \\
\end{array}$ & $57 \quad-0.551$ & $17 \quad-0.694$ & $42 \quad-0.8758$ \\
\hline-1.100 & -1.370 & -1.693 & -2.073 & -2.517 & -3.035 & -3.634 & -4.326 & -5.124 & -6.041 \\
\hline-7.094 & -8.300 & -9.679 & -11.25 & -13.04 & -15.08 & -17.39 & -20.00 & & \\
\hline $15-20.00$ & -17.45 & -15.20 & -13.21 & -11.47 & -9.947 & -8.612 & -7.446 & -6.429 & -5.543 \\
\hline-4.773 & -4.105 & -3.527 & -3.028 & -2.599 & -2.232 & -1.921 & -1.661 & -1.445 & -1.270 \\
\hline-1.134 & -1.033 & -0.9659 & -0.9330 & -0.9343 & -0.9689 & -1.037 & -1.138 & -1.275 & -1.449 \\
\hline-1.665 & -1.925 & -2.236 & -2.602 & -3.030 & -3.528 & -4.106 & -4.773 & -5.543 & -6.428 \\
\hline-7.445 & -8.611 & -9.946 & -11.47 & -13.21 & -15.20 & -17.45 & -20.00 & & \\
\hline $16-20.00$ & -17.54 & -15.37 & -13.47 & -11.81 & -10.35 & -9.084 & -7.977 & -7.014 & -6.176 \\
\hline-5.448 & -4.816 & -4.270 & -3.799 & -3.395 & -3.049 & -2.756 & -2.510 & -2.307 & -2.143 \\
\hline-2.015 & -1.920 & -1.858 & -1.827 & -1.828 & -1.860 & -1.923 & -2.018 & -2.147 & -2.311 \\
\hline-2.514 & -2.760 & -3.052 & -3.397 & -3.801 & -4.271 & -4.817 & -5.447 & -6.175 & -7.013 \\
\hline-7.976 & -9.083 & -10.35 & -11.81 & -13.47 & -15.37 & -17.54 & -20.00 & & \\
\hline $\begin{array}{ll}17 & -20.00\end{array}$ & -17.66 & -15.61 & -13.82 & -12.26 & -10.90 & -9.723 & -8.696 & -7.803 & -7.027 \\
\hline-6.355 & -5.772 & -5.268 & -4.834 & -4.461 & -4.143 & -3.873 & -3.647 & -3.460 & -3.309 \\
\hline-3.191 & -3.105 & -3.048 & -3.020 & -3.020 & -3.049 & -3.107 & -3.194 & -3.313 & -3.464 \\
\hline-3.651 & -3.877 & -4.146 & -4.464 & -4.836 & -5.269 & -5.772 & -6.355 & -7.027 & -7.802 \\
\hline-8.695 & -9.722 & -10.90 & -12.26 & -13.82 & -15.61 & -17.66 & -20.00 & & \\
\hline $\begin{array}{ll}18 & -20.00\end{array}$ & -17.81 & -15.91 & -14.27 & -12.84 & -11.61 & -10.54 & -9.609 & -8.804 & -8.106 \\
\hline-7.501 & -6.978 & -6.526 & -6.137 & -5.803 & -5.518 & -5.277 & -5.074 & -4.907 & -4.772 \\
\hline-4.667 & -4.589 & -4.538 & -4.513 & -4.514 & -4.540 & -4.591 & -4.669 & -4.775 & -4.910 \\
\hline-5.077 & -5.279 & -5.521 & -5.805 & -6.139 & -6.527 & -6.978 & -7.501 & -8.105 & -8.803 \\
\hline-9.608 & -10.54 & -11.61 & -12.84 & -14.27 & -15.91 & -17.81 & -20.00 & & \\
\hline $19-20.00$ & -18.00 & -16.29 & -14.83 & -13.56 & -12.48 & -11.54 & -10.73 & -10.03 & -9.420 \\
\hline-8.896 & -8.442 & -8.051 & -7.714 & -7.425 & -7.179 & -6.970 & -6.795 & -6.651 & -6.534 \\
\hline-6.443 & -6.377 & -6.333 & -6.311 & -6.312 & -6.334 & -6.378 & -6.445 & -6.537 & -6.653 \\
\hline-6.798 & -6.973 & -7.181 & -7.427 & -7.715 & -8.052 & -8.443 & -8.896 & -9.420 & -10.03 \\
\hline-10.73 & -11.54 & -12.48 & -13.56 & -14.83 & -16.29 & -18.00 & -20.00 & & \\
\hline $20-20.00$ & -18.24 & -16.76 & -15.51 & -14.44 & -13.53 & -12.74 & -12.07 & -11.49 & -10.98 \\
\hline-10.55 & -10.17 & -9.851 & -9.573 & -9.335 & -9.132 & -8.960 & -8.816 & -8.697 & -8.601 \\
\hline-8.526 & -8.471 & -8.435 & -8.417 & -8.418 & -8.436 & -8.472 & -8.527 & -8.602 & -8.698 \\
\hline-8.817 & -8.961 & -9.133 & -9.336 & -9.574 & -9.851 & -10.17 & -10.55 & -10.98 & -11.48 \\
\hline-12.07 & -12.74 & -13.53 & -14.44 & -15.51 & -16.76 & -18.24 & -20.00 & & \\
\hline $21-20.00$ & -18.54 & -17.33 & -16.33 & -15.49 & -14.78 & -14.17 & -13.64 & -13.19 & -12.81 \\
\hline-12.47 & -12.18 & -11.93 & -11.72 & -11.54 & -11.38 & -11.25 & -11.14 & -11.05 & -10.98 \\
\hline-10.92 & -10.88 & -10.85 & -10.83 & -10.83 & -10.85 & -10.88 & -10.92 & -10.98 & -11.05 \\
\hline-11.14 & -11.25 & -11.38 & -11.54 & -11.72 & -11.94 & -12.18 & -12.47 & -12.81 & -13.19 \\
\hline-13.64 & -14.17 & -14.78 & -15.49 & -16.33 & -17.33 & -18.54 & -20.00 & & \\
\hline $22-20.00$ & -18.90 & -18.03 & -17.33 & -16.74 & -16.25 & -15.83 & -15.47 & -15.17 & -14.90 \\
\hline-14.68 & -14.48 & -14.31 & -14.17 & -14.04 & -13.94 & -13.85 & -13.77 & -13.71 & -13.66 \\
\hline-13.62 & -13.60 & -13.58 & -13.57 & -13.57 & -13.58 & -13.60 & -13.63 & -13.66 & -13.71 \\
\hline-13.78 & -13.85 & -13.94 & -14.05 & -14.17 & -14.31 & -14.48 & -14.68 & -14.90 & -15.17 \\
\hline-15.47 & -15.83 & -16.25 & -16.74 & -17.33 & -18.03 & -18.90 & -20.00 & & \\
\hline $23-20.00$ & -19.37 & -18.90 & -18.53 & -18.23 & -17.98 & -17.77 & -17.59 & -17.43 & -17.30 \\
\hline-17.18 & -17.08 & -17.00 & -16.92 & -16.86 & -16.81 & -16.76 & -16.73 & -16.69 & -16.67 \\
\hline-16.65 & -16.64 & -16.63 & -16.62 & -16.62 & -16.63 & -16.64 & -16.65 & -16.67 & -16.70 \\
\hline-16.73 & -16.76 & -16.81 & -16.86 & -16.93 & -17.00 & -17.08 & -17.18 & -17.30 & -17.43 \\
\hline-17.59 & -17.77 & -17.98 & -18.23 & -18.53 & -18.90 & -19.37 & -20.00 & & \\
\hline $24-20.00$ & -20.00 & -20.00 & -20.00 & -20.00 & -20.00 & -20.00 & -20.00 & -20.00 & -20.00 \\
\hline-20.00 & -20.00 & -20.00 & -20.00 & -20.00 & -20.00 & -20.00 & -20.00 & -20.00 & -20.00 \\
\hline-20.00 & -20.00 & -20.00 & -20.00 & -20.00 & -20.00 & -20.00 & -20.00 & -20.00 & -20.00 \\
\hline-20.00 & -20.00 & -20.00 & -20.00 & -20.00 & -20.00 & -20.00 & -20.00 & -20.00 & -20.00 \\
\hline-20.00 & -20.00 & -20.00 & -20.00 & -20.00 & -20.00 & -20.00 & -20.00 & & \\
\hline
\end{tabular}


VOLUMETRIC BUDGET FOR ENTIRE MODEL AT END OF TIME STEP 1 IN STRESS PERIOD 1

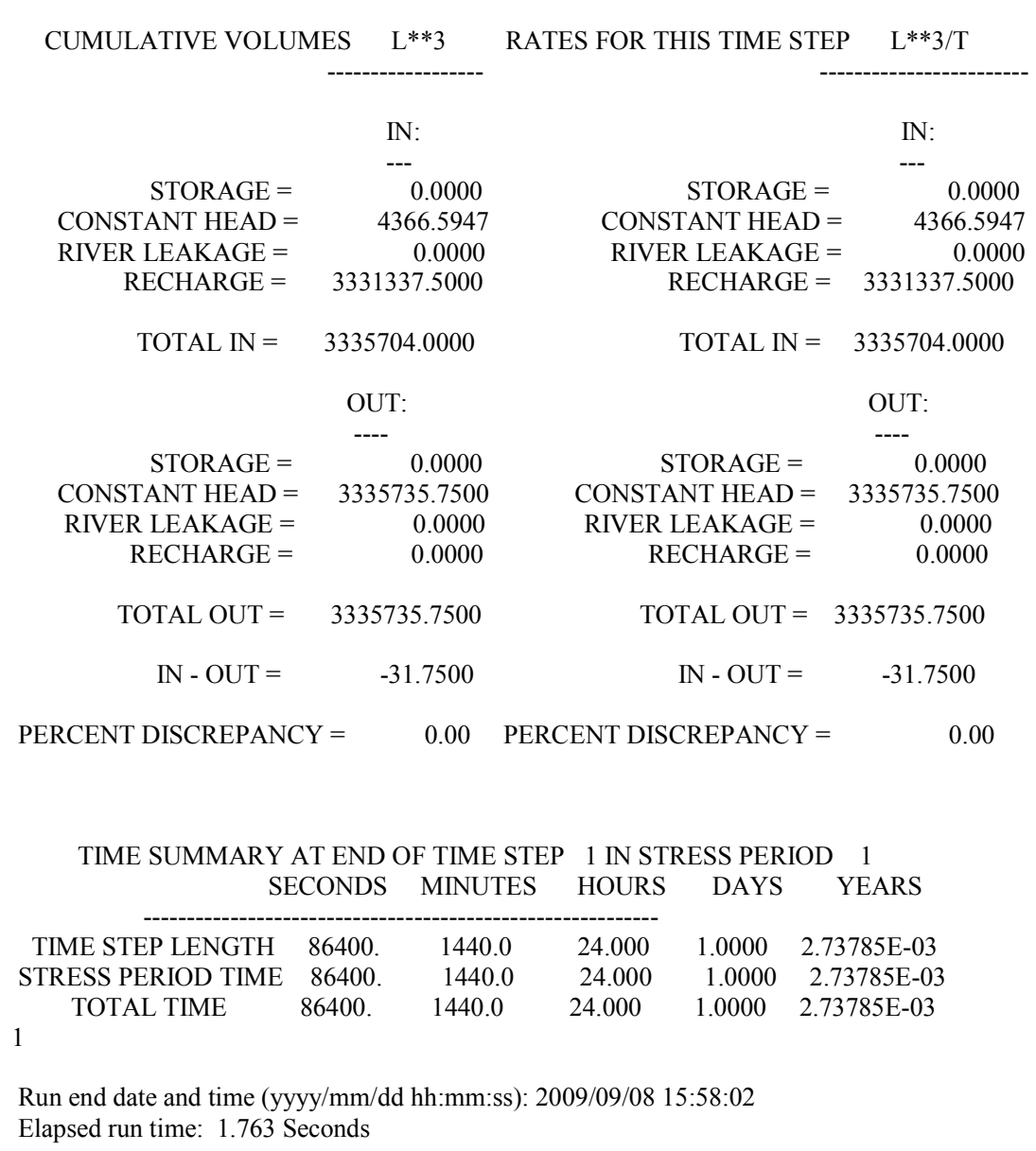




\section{APPENDIX E}

\section{MULTIPLE LAYER SIMULATION OUTPUT FILES}

\section{FLO-2D}

\section{SUMARY.OUT}

SUMMARY.OUT FILE CREATED WITH VERSION: 0.00

NEGATIVE VOLUME CONSERVATION (ACRE FEET) INDICATES EXCESS VOLUME (OUTFLOW + STORAGE > INFLOW)

SIMULATION TIME AVERAGE TIMESTEP VOLUME CONSERVATION (HOURS) (SECONDS) (ACRE FEET) PERCENT OF INFLOW

$\begin{array}{rrrr}1.000 & 4.303 & -0.000004 & 0.000001 \\ 2.001 & 5.956 & -0.000004 & 0.000001 \\ 3.001 & 6.804 & -0.000004 & 0.000001 \\ 4.001 & 7.256 & -0.000004 & 0.000001 \\ 5.002 & 7.571 & -0.000004 & 0.000001 \\ 6.000 & 7.814 & -0.000004 & 0.000001 \\ 7.002 & 8.012 & -0.000004 & 0.000001 \\ 8.002 & 8.179 & -0.000004 & 0.000001 \\ 9.001 & 8.324 & -0.000004 & 0.000001 \\ 10.001 & 8.451 & -0.000004 & 0.000001 \\ 11.002 & 8.566 & -0.000004 & 0.000001 \\ 12.002 & 8.669 & -0.000004 & 0.000001 \\ 13.002 & 8.764 & -0.000004 & 0.000001 \\ 14.000 & 8.850 & -0.000004 & 0.000001 \\ 15.000 & 8.931 & -0.000004 & 0.000001 \\ 16.001 & 9.006 & -0.000004 & 0.000001 \\ 17.002 & 9.076 & -0.000004 & 0.000001 \\ 18.002 & 9.142 & -0.000004 & 0.000001 \\ 19.002 & 9.205 & -0.000004 & 0.000001 \\ 20.000 & 9.263 & -0.000004 & 0.000001 \\ 21.002 & 9.319 & -0.000004 & 0.000001 \\ 22.002 & 9.373 & -0.000004 & 0.000001 \\ 23.002 & 9.423 & -0.000004 & 0.000001 \\ 24.002 & 9.472 & -0.000004 & 0.000001\end{array}$

MASS BALANCE INFLOW - OUTFLOW VOLUME

*** INFLOW (ACRE-FEET) ***

TOTAL POINT RAINFALL: $\quad 0.0311$ INCHES

WATER

RAINFALL VOLUME

334.67

INFLOW HYDROGRAPH $\quad 0.00$

INFLOW HYDROGRAPHS + RAINFALL $\quad 334.67$ 


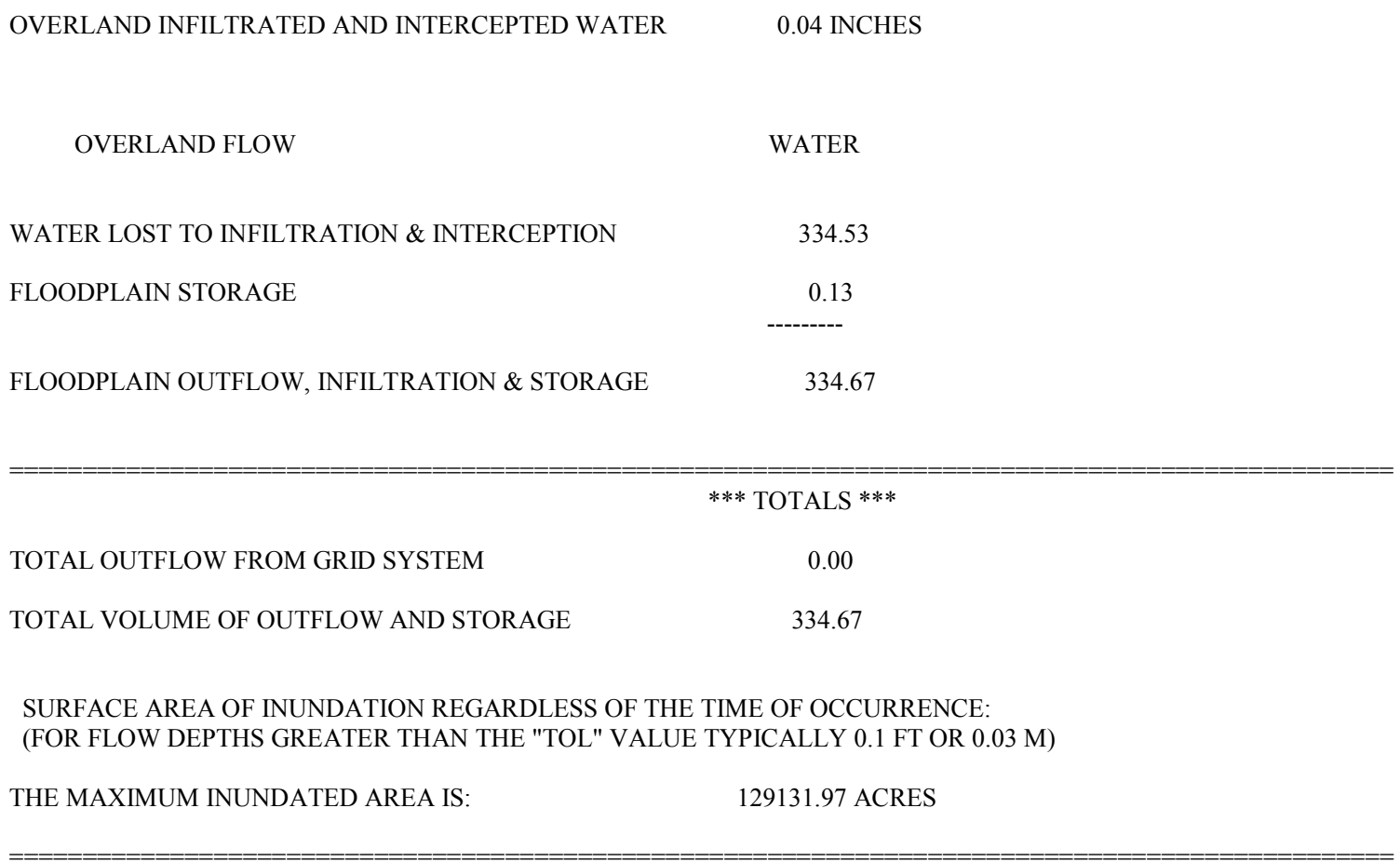

COMPUTER RUN TIME IS : 0.00101 HRS

THIS OUTPUT FILE WAS TERMINATED ON: 8/20/2009 AT: 17:33:23

\section{MODFLOW}

\section{TWRI.LST}

MODFLOW-2005

U.S. GEOLOGICAL SURVEY MODULAR FINITE-DIFFERENCE GROUND-WATER FLOW MODEL VERSION 1.4.00 11/2/2007

LIST FILE: twri.lst

UNIT 201

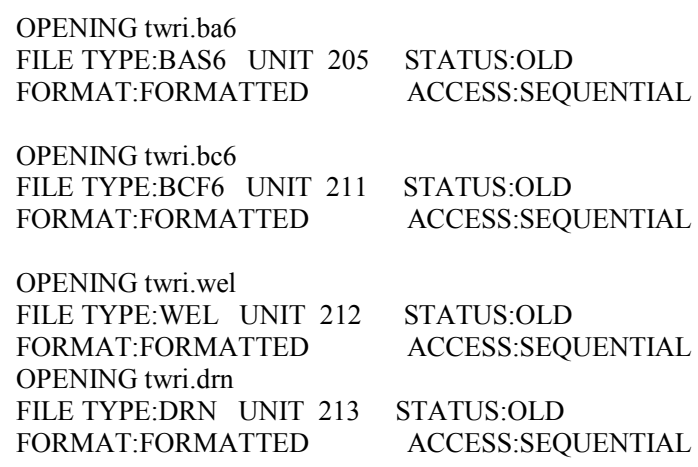




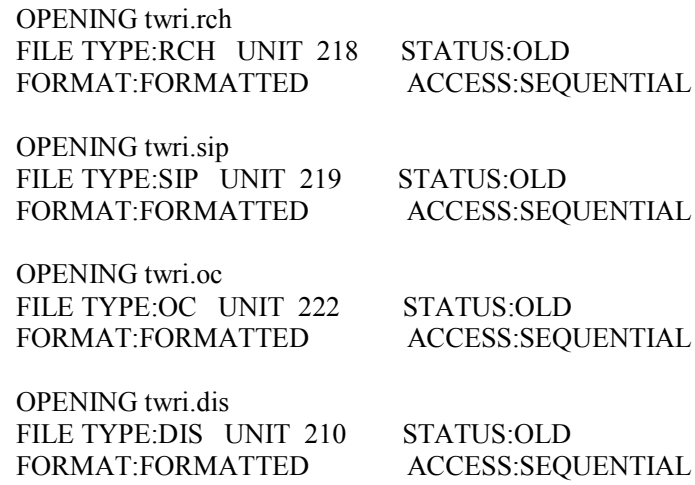

STEADY-STATE SIMULATION

\#SAMPLE----3 LAYERS, 15 ROWS, 15 COLUMNS; STEADY STATE; CONSTANT HEADS COLUMN \#LAYERS 1 AND 2; RECHARGE, WELLS AND DRAINS 
BOUNDARY ARRAY FOR LAYER 1

READING ON UNIT 205 WITH FORMAT: (20I4)

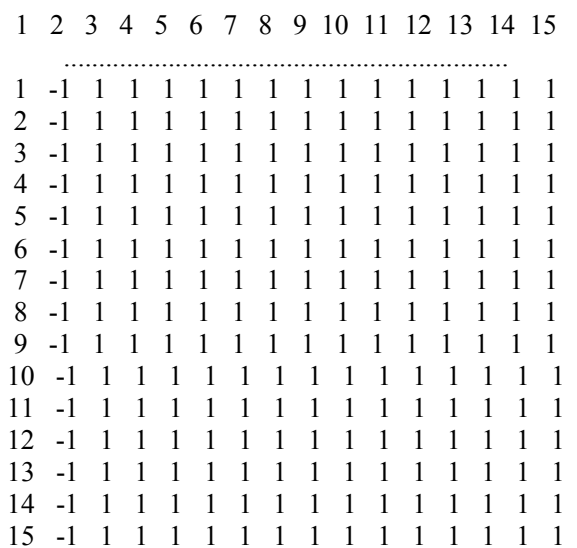

BOUNDARY ARRAY FOR LAYER 2 READING ON UNIT 205 WITH FORMAT: (20I4)

$\begin{array}{lllllllllllllll}1 & 2 & 3 & 4 & 5 & 6 & 7 & 8 & 9 & 10 & 11 & 12 & 13 & 14 & 15\end{array}$

$\begin{array}{llllllllllllllll}1 & -1 & 1 & 1 & 1 & 1 & 1 & 1 & 1 & 1 & 1 & 1 & 1 & 1 & 1 & 1\end{array}$ $\begin{array}{lllllllllllllllllllllllllll}2 & -1 & 1 & 1 & 1 & 1 & 1 & 1 & 1 & 1 & 1 & 1 & 1 & 1 & 1 & 1\end{array}$ $\begin{array}{llllllllllllllll}3 & -1 & 1 & 1 & 1 & 1 & 1 & 1 & 1 & 1 & 1 & 1 & 1 & 1 & 1 & 1\end{array}$ $\begin{array}{llllllllllllllll}4 & -1 & 1 & 1 & 1 & 1 & 1 & 1 & 1 & 1 & 1 & 1 & 1 & 1 & 1 & 1\end{array}$ $\begin{array}{cccccccccccccccc}5 & -1 & 1 & 1 & 1 & 1 & 1 & 1 & 1 & 1 & 1 & 1 & 1 & 1 & 1 & 1\end{array}$ $\begin{array}{llllllllllllllll}6 & -1 & 1 & 1 & 1 & 1 & 1 & 1 & 1 & 1 & 1 & 1 & 1 & 1 & 1 & 1\end{array}$ $\begin{array}{cccccccccccccccc}7 & -1 & 1 & 1 & 1 & 1 & 1 & 1 & 1 & 1 & 1 & 1 & 1 & 1 & 1 & 1\end{array}$ $\begin{array}{cccccccccccccccc}8 & -1 & 1 & 1 & 1 & 1 & 1 & 1 & 1 & 1 & 1 & 1 & 1 & 1 & 1 & 1\end{array}$ $\begin{array}{cccccccccccccccc}9 & -1 & 1 & 1 & 1 & 1 & 1 & 1 & 1 & 1 & 1 & 1 & 1 & 1 & 1 & 1\end{array}$ $\begin{array}{llllllllllllllll}10 & -1 & 1 & 1 & 1 & 1 & 1 & 1 & 1 & 1 & 1 & 1 & 1 & 1 & 1 & 1\end{array}$ $\begin{array}{llllllllllllllll}11 & -1 & 1 & 1 & 1 & 1 & 1 & 1 & 1 & 1 & 1 & 1 & 1 & 1 & 1 & 1\end{array}$ $\begin{array}{llllllllllllllll}12 & -1 & 1 & 1 & 1 & 1 & 1 & 1 & 1 & 1 & 1 & 1 & 1 & 1 & 1 & 1\end{array}$ $\begin{array}{llllllllllllllll}13 & -1 & 1 & 1 & 1 & 1 & 1 & 1 & 1 & 1 & 1 & 1 & 1 & 1 & 1 & 1\end{array}$ $\begin{array}{llllllllllllllll}14 & -1 & 1 & 1 & 1 & 1 & 1 & 1 & 1 & 1 & 1 & 1 & 1 & 1 & 1 & 1\end{array}$ $\begin{array}{llllllllllllllll}15 & -1 & 1 & 1 & 1 & 1 & 1 & 1 & 1 & 1 & 1 & 1 & 1 & 1 & 1 & 1\end{array}$

BOUNDARY ARRAY $=\quad 1$ FOR LAYER 3

AQUIFER HEAD WILL BE SET TO 999.99 AT ALL NO-FLOW NODES (IBOUND=0).

$$
\begin{array}{lll}
\text { INITIAL HEAD }=0.00000 & \text { FOR LAYER } & 1 \\
\text { INITIAL HEAD }=0.00000 & \text { FOR LAYER } & 2 \\
\text { INITIAL HEAD }=0.00000 & \text { FOR LAYER } & 3
\end{array}
$$

OUTPUT CONTROL IS SPECIFIED ONLY AT TIME STEPS FOR WHICH OUTPUT IS DESIRED HEAD PRINT FORMAT CODE IS 20 DRAWDOWN PRINT FORMAT CODE IS 0 HEADS WILL BE SAVED ON UNIT 0 DRAWDOWNS WILL BE SAVED ON UNIT 0

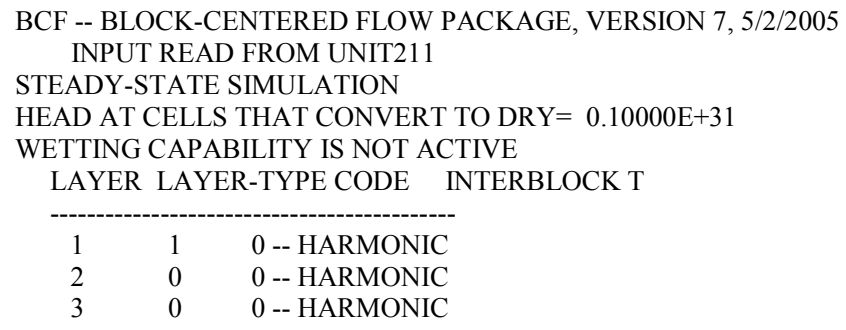




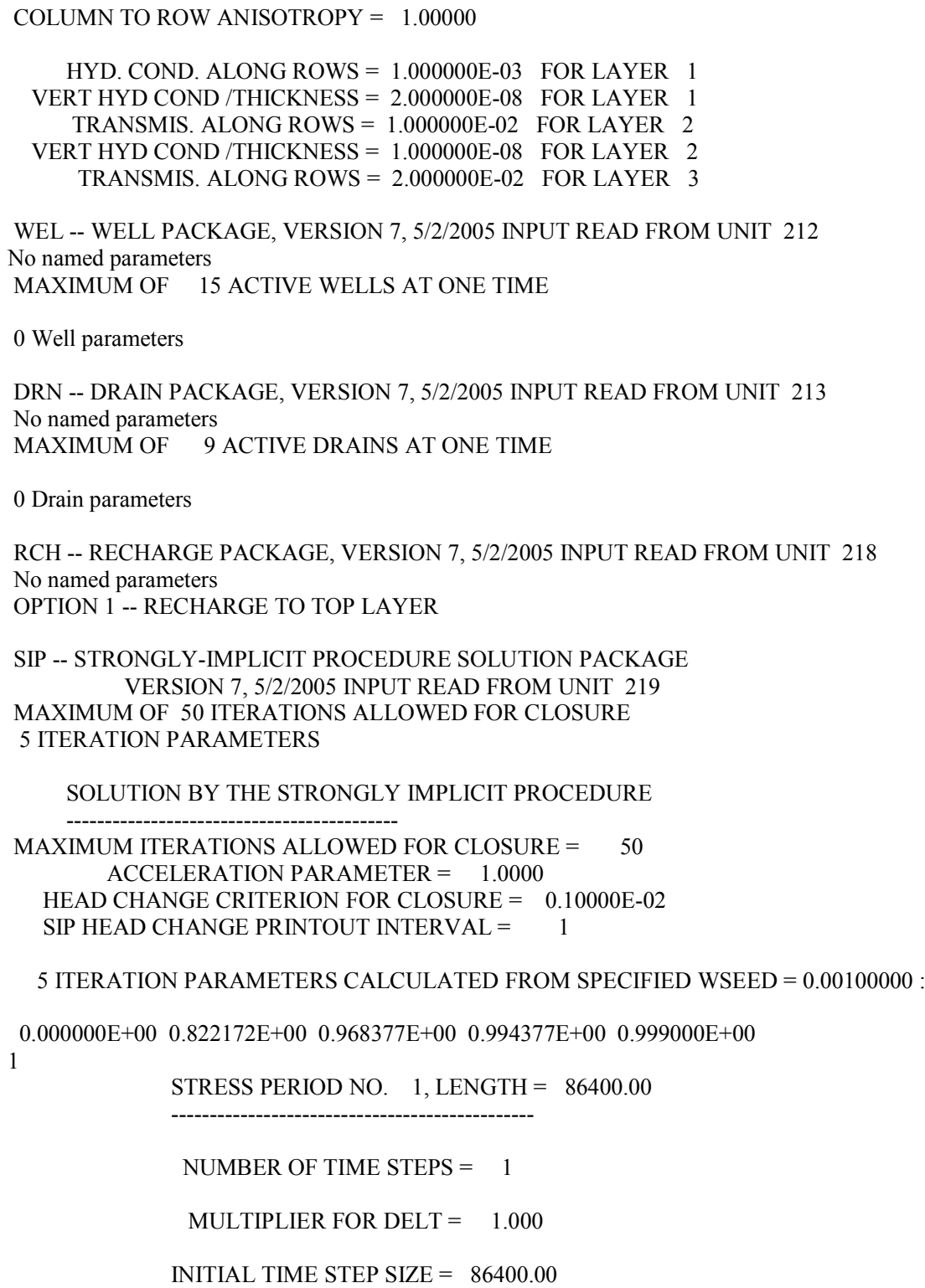

WEL -- WELL PACKAGE, VERSION 7, 5/2/2005 INPUT READ FROM UNIT 212

No named parameters

MAXIMUM OF 15 ACTIVE WELLS AT ONE TIME

0 Well parameters

DRN -- DRAIN PACKAGE, VERSION 7, 5/2/2005 INPUT READ FROM UNIT 213

No named parameters

MAXIMUM OF 9 ACTIVE DRAINS AT ONE TIME

0 Drain parameters

RCH -- RECHARGE PACKAGE, VERSION 7, 5/2/2005 INPUT READ FROM UNIT 218

No named parameters

OPTION 1 -- RECHARGE TO TOP LAYER
SIP -- STRONGLY-IMPLICIT PROCEDURE SOLUTION PACKAGE VERSION 7, 5/2/2005 INPUT READ FROM UNIT 219
MAXIMUM OF 50 ITERATIONS ALLOWED FOR CLOSURE 5 ITERATION PARAMETERS

SOLUTION BY THE STRONGLY IMPLICIT PROCEDURE

WELL NO. LAYER ROW COL STRESS RATE

$\begin{array}{ccccc}1 & 3 & 5 & 11 & -5.000 \\ 2 & 2 & 4 & 6 & -5.000 \\ 3 & 2 & 6 & 12 & -5.000 \\ 4 & 1 & 9 & 8 & -5.000 \\ 5 & 1 & 9 & 10 & -5.000 \\ 6 & 1 & 9 & 12 & -5.000 \\ 7 & 1 & 9 & 14 & -5.000 \\ 8 & 1 & 11 & 8 & -5.000 \\ 9 & 1 & 11 & 10 & -5.000 \\ 10 & 1 & 11 & 12 & -5.000 \\ 11 & 1 & 11 & 14 & -5.000 \\ 12 & 1 & 13 & 8 & -5.000 \\ 13 & 1 & 13 & 10 & -5.000 \\ 14 & 1 & 13 & 12 & -5.000 \\ 15 & 1 & 13 & 14 & -5.000\end{array}$


15 WELLS

DRAIN NO. LAYER ROW COL DRAIN EL. CONDUCTANCE

$\begin{array}{lrrrrr}1 & 1 & 8 & 2 & 0.000 & 1.000 \\ 2 & 1 & 8 & 3 & 0.000 & 1.000 \\ 3 & 1 & 8 & 4 & 10.00 & 1.000 \\ 4 & 1 & 8 & 5 & 20.00 & 1.000 \\ 5 & 1 & 8 & 6 & 30.00 & 1.000 \\ 6 & 1 & 8 & 7 & 50.00 & 1.000 \\ 7 & 1 & 8 & 8 & 70.00 & 1.000 \\ 8 & 1 & 8 & 9 & 90.00 & 1.000 \\ 9 & 1 & 8 & 10 & 100.0 & 1.000\end{array}$

9 DRAINS

SOLVING FOR HEAD

31 ITERATIONS FOR TIME STEP 1 IN STRESS PERIOD 1

MAXIMUM HEAD CHANGE FOR EACH ITERATION:

HEAD CHANGE HEAD CHANGE HEAD CHANGE HEAD CHANGE HEAD CHANGE

LAYER,ROW,COL LAYER,ROW,COL LAYER,ROW,COL LAYER,ROW,COL LAYER,ROW,COL

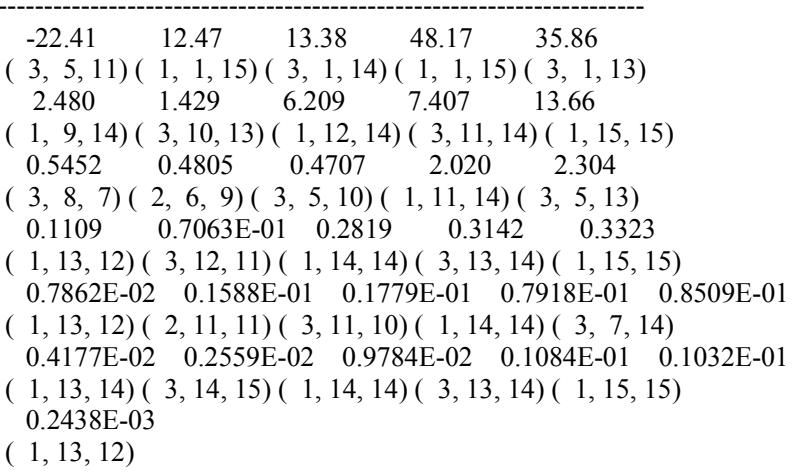

OUTPUT CONTROL FOR STRESS PERIOD 1 TIME STEP 1 PRINT HEAD FOR ALL LAYERS

HEAD IN LAYER 1 AT END OF TIME STEP 1 IN STRESS PERIOD 1

\begin{tabular}{rrrrrrrrrrrrrr} 
& 1 & 2 & 3 & 4 & 5 & 6 & 7 & 8 & 9 & 10 & 11 & 12 \\
\cline { 1 - 1 } & 13 & 14 & 15 & & & & & & & & & \\
\hline 1 & 0.000 & 24.93 & 43.98 & 59.22 & 71.78 & 82.46 & 91.84 & 99.97 & 106.8 & 112.6 & 117.3 & 121.2 \\
& 124.2 & 126.3 & 127.4 & & & & & & & & & \\
2 & 0.000 & 24.43 & 43.08 & 57.94 & 70.12 & 80.52 & 90.06 & 98.33 & 105.2 & 110.9 & 115.6 & 119.5 \\
& 122.7 & 124.8 & 126.0 & & & & & & & & & \\
3 & 0.000 & 23.43 & 41.27 & 55.40 & 66.73 & 76.16 & 86.45 & 95.14 & 102.1 & 107.5 & 111.9 & 116.1 \\
& 119.5 & 122.0 & 123.3 & & & & & & & & & \\
4 & 0.000 & 21.90 & 38.58 & 51.72 & 61.75 & 67.98 & 81.28 & 90.69 & 97.57 & 102.5 & 106.0 & 110.6 \\
& 114.8 & 117.8 & 119.3 & & & & & & & & & \\
5 & 0.000 & 19.72 & 34.89 & 47.29 & 57.65 & 66.69 & 77.03 & 85.70 & 92.15 & 96.07 & 97.20 & 103.0 \\
& 108.7 & 112.4 & 114.2 & & & & & & & & & \\
6 & 0.000 & 16.50 & 29.48 & 40.87 & 51.27 & 61.17 & 71.14 & 79.79 & 86.40 & 90.74 & 92.94 & 94.13 \\
& 102.0 & 106.3 & 108.3 & & & & & & & & & \\
7 & 0.000 & 11.54 & 21.09 & 31.19 & 41.38 & 51.82 & 63.04 & 72.62 & 79.89 & 84.84 & 88.51 & 91.57 \\
& 96.33 & 99.72 & 101.7 & & & & & & & & & \\
8 & 0.000 & 3.480 & 6.828 & 16.25 & 26.29 & 36.96 & 52.57 & 64.26 & 72.45 & 77.17 & 81.90 & 84.91 \\
& 89.17 & 91.62 & 94.23 & & & & & & & & & \\
9 & 0.000 & 10.54 & 19.09 & 28.10 & 36.89 & 45.24 & 52.91 & 55.32 & 65.08 & 65.99 & 73.84 & 73.69 \\
& 80.73 & 80.06 & 86.39 & & & & & & & & &
\end{tabular}




\begin{tabular}{|c|c|c|c|c|c|c|c|c|c|c|c|c|}
\hline \multirow[t]{2}{*}{10} & 0.000 & 14.61 & 25.84 & 35.36 & 43.45 & 50.07 & 54.88 & 57.48 & 62.87 & 65.46 & 70.29 & 72.34 \\
\hline & 76.61 & 78.15 & 81.69 & & & & & & & & & \\
\hline \multirow[t]{2}{*}{11} & 0.000 & 17.10 & 29.93 & 39.98 & 47.74 & 53.19 & 55.75 & 53.26 & 60.18 & 59.20 & 66.34 & 65.35 \\
\hline & 72.12 & 70.93 & 77.51 & & & & & & & & & \\
\hline \multirow[t]{2}{*}{12} & 0.000 & 18.66 & 32.53 & 43.04 & 50.77 & 55.87 & 58.27 & 58.40 & 61.85 & 63.09 & 67.03 & 68.40 \\
\hline & 72.19 & 73.35 & 76.74 & & & & & & & & & \\
\hline \multirow[t]{2}{*}{13} & 0.000 & 19.66 & 34.21 & 45.10 & 52.96 & 57.98 & 59.84 & 56.67 & 62.50 & 60.82 & 67.12 & 65.65 \\
\hline & 71.79 & 70.24 & 76.37 & & & & & & & & & \\
\hline \multirow[t]{2}{*}{14} & 0.000 & 20.25 & 35.24 & 46.44 & 54.56 & 60.02 & 63.10 & 64.44 & 67.16 & 68.70 & 71.54 & 73.07 \\
\hline & 75.73 & 76.92 & 78.98 & & & & & & & & & \\
\hline \multirow[t]{2}{*}{15} & 0.000 & 20.54 & 35.75 & 47.12 & 55.43 & 61.20 & 64.95 & 67.45 & 69.86 & 71.92 & 74.19 & 76.11 \\
\hline & 78.11 & 79.55 & 80.71 & & & & & & & & & \\
\hline
\end{tabular}

1

HEAD IN LAYER 2 AT END OF TIME STEP 1 IN STRESS PERIOD 1

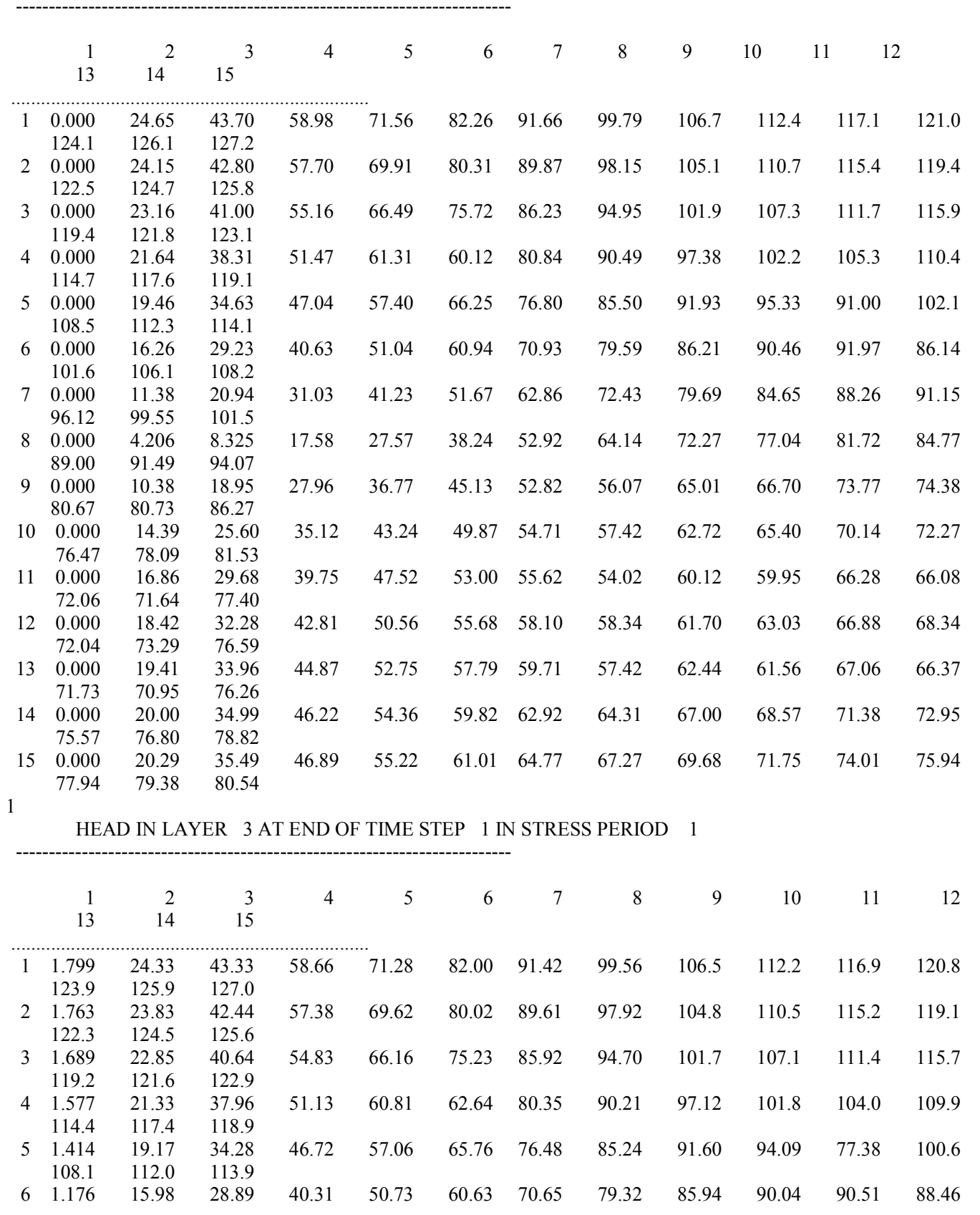




\begin{tabular}{|c|c|c|c|c|c|c|c|c|c|c|c|c|}
\hline & 101.1 & 105.9 & 107.9 & & & & & & & & & \\
\hline \multirow[t]{2}{*}{7} & 0.8268 & 11.21 & 20.78 & 30.87 & 41.07 & 51.52 & 62.63 & 72.17 & 79.44 & 84.38 & 87.90 & 90.68 \\
\hline & 95.84 & 99.32 & 101.3 & & & & & & & & & \\
\hline \multirow[t]{2}{*}{8} & 0.4328 & 5.128 & 10.18 & 19.26 & 29.18 & 39.82 & 53.38 & 64.02 & 72.04 & 76.87 & 81.49 & 84.59 \\
\hline & 88.78 & 91.34 & 93.85 & & & & & & & & & \\
\hline \multirow[t]{2}{*}{9} & 0.7538 & 10.21 & 18.81 & 27.82 & 36.64 & 45.03 & 52.74 & 56.97 & 64.95 & 67.56 & 73.72 & 75.21 \\
\hline & 80.61 & 81.53 & 86.14 & & & & & & & & & \\
\hline \multirow[t]{2}{*}{10} & 1.038 & 14.12 & 25.28 & 34.82 & 42.96 & 49.61 & 54.49 & 57.37 & 62.53 & 65.36 & 69.96 & 72.23 \\
\hline & 76.29 & 78.05 & 81.33 & & & & & & & & & \\
\hline \multirow[t]{2}{*}{11} & 1.223 & 16.58 & 29.35 & 39.44 & 47.24 & 52.74 & 55.47 & 54.94 & 60.08 & 60.85 & 66.24 & 66.96 \\
\hline & 72.02 & 72.49 & 77.27 & & & & & & & & & \\
\hline \multirow[t]{2}{*}{12} & 1.340 & 18.14 & 31.95 & 42.51 & 50.28 & 55.42 & 57.88 & 58.29 & 61.52 & 62.99 & 66.70 & 68.30 \\
\hline & 71.87 & 73.25 & 76.38 & & & & & & & & & \\
\hline \multirow[t]{2}{*}{13} & 1.414 & 19.12 & 33.62 & 44.57 & 52.48 & 57.54 & 59.57 & 58.31 & 62.40 & 62.44 & 67.02 & 67.24 \\
\hline & 71.69 & 71.79 & 76.13 & & & & & & & & & \\
\hline \multirow[t]{2}{*}{14} & 1.458 & 19.71 & 34.65 & 45.92 & 54.08 & 59.57 & 62.69 & 64.17 & 66.78 & 68.43 & 71.17 & 72.81 \\
\hline & 75.36 & 76.66 & 78.60 & & & & & & & & & \\
\hline \multirow[t]{2}{*}{15} & 1.480 & 20.00 & 35.15 & 46.59 & 54.95 & 60.75 & 64.52 & 67.03 & 69.44 & 71.51 & 73.78 & 75.71 \\
\hline & 77.71 & 79.16 & 80.31 & & & & & & & & & \\
\hline
\end{tabular}

VOLUMETRIC BUDGET FOR ENTIRE MODEL AT END OF TIME STEP 1 IN STRESS PERIOD 1

\begin{tabular}{|c|c|c|c|}
\hline CUMULATIVE VOI & LUMES $\quad \mathrm{L}^{* * 3}$ & RATES FOR THIS TIME & $L^{* * 3 / T}$ \\
\hline \multicolumn{3}{|c|}{$\mathrm{IN}:$} & IN: \\
\hline STORAGE $=$ & 0.0000 & STORAGE $=$ & 0.0000 \\
\hline CONSTANT HEAD = & 0.0000 & CONSTANT HEAD $=$ & 0.0000 \\
\hline WELLS = & 0.0000 & WELLS = & 0.0000 \\
\hline DRAINS $=$ & 0.0000 & DRAINS $=$ & 0.0000 \\
\hline RIVER LEAKAGE = & 0.0000 & RIVER LEAKAGE = & 0.0000 \\
\hline RECHARGE = & 13600769.0000 & RECHARGE $=$ & 157.4163 \\
\hline \multirow[t]{2}{*}{ TOTAL IN = } & 13600769.0000 & TOTAL IN = & 157.4163 \\
\hline & OUT: & & OUT: \\
\hline STORAGE $=$ & 0.0000 & STORAGE $=$ & 0.0000 \\
\hline CONSTANT HEAD $=$ & 4323250.5000 & CONSTANT HEAD $=$ & 50.0376 \\
\hline WELLS $=$ & 6480000.0000 & WELLS = & 75.0000 \\
\hline DRAINS $=$ & 2797121.2500 & DRAINS $=$ & 32.3741 \\
\hline RIVER LEAKAGE = & 0.0000 & RIVER LEAKAGE = & 0.0000 \\
\hline RECHARGE $=$ & 0.0000 & RECHARGE $=$ & 0.0000 \\
\hline TOTAL OUT $=$ & 13600371.0000 & TOTAL OUT $=$ & 157.4117 \\
\hline $\mathrm{IN}-\mathrm{OUT}=$ & 398.0000 & $\mathrm{IN}-\mathrm{OUT}=$ & $4.5929 \mathrm{E}-03$ \\
\hline
\end{tabular}

PERCENT DISCREPANCY $=\quad 0.00 \quad$ PERCENT DISCREPANCY $=\quad 0.00$

\footnotetext{
TIME SUMMARY AT END OF TIME STEP 1 IN STRESS PERIOD 1 SECONDS MINUTES HOURS DAYS YEARS

$\begin{array}{llllll}\text { TIME STEP LENGTH } & 86400 . & 1440.0 & 24.000 & 1.0000 & 2.73785 \mathrm{E}-03\end{array}$

STRESS PERIOD TIME 86400. $\quad 1440.0 \quad 24.000 \quad 1.0000 \quad 2.73785 \mathrm{E}-03$

$\begin{array}{lllll}\text { TOTAL TIME } 86400 . & 1440.0 & 24.000 & 1.0000 & 2.73785 \mathrm{E}-03\end{array}$

Run end date and time (yyyy/mm/dd hh:mm:ss): 2009/08/20 17:33:23

Elapsed run time: 6.922 Seconds
} 


\section{APPENDIX F}

\section{MULTIPLE LAYERS AND MULTIPLE TIME STRESS OUTPUT FILE}

\section{FLO-2D}

\section{SUMARY.OUT}

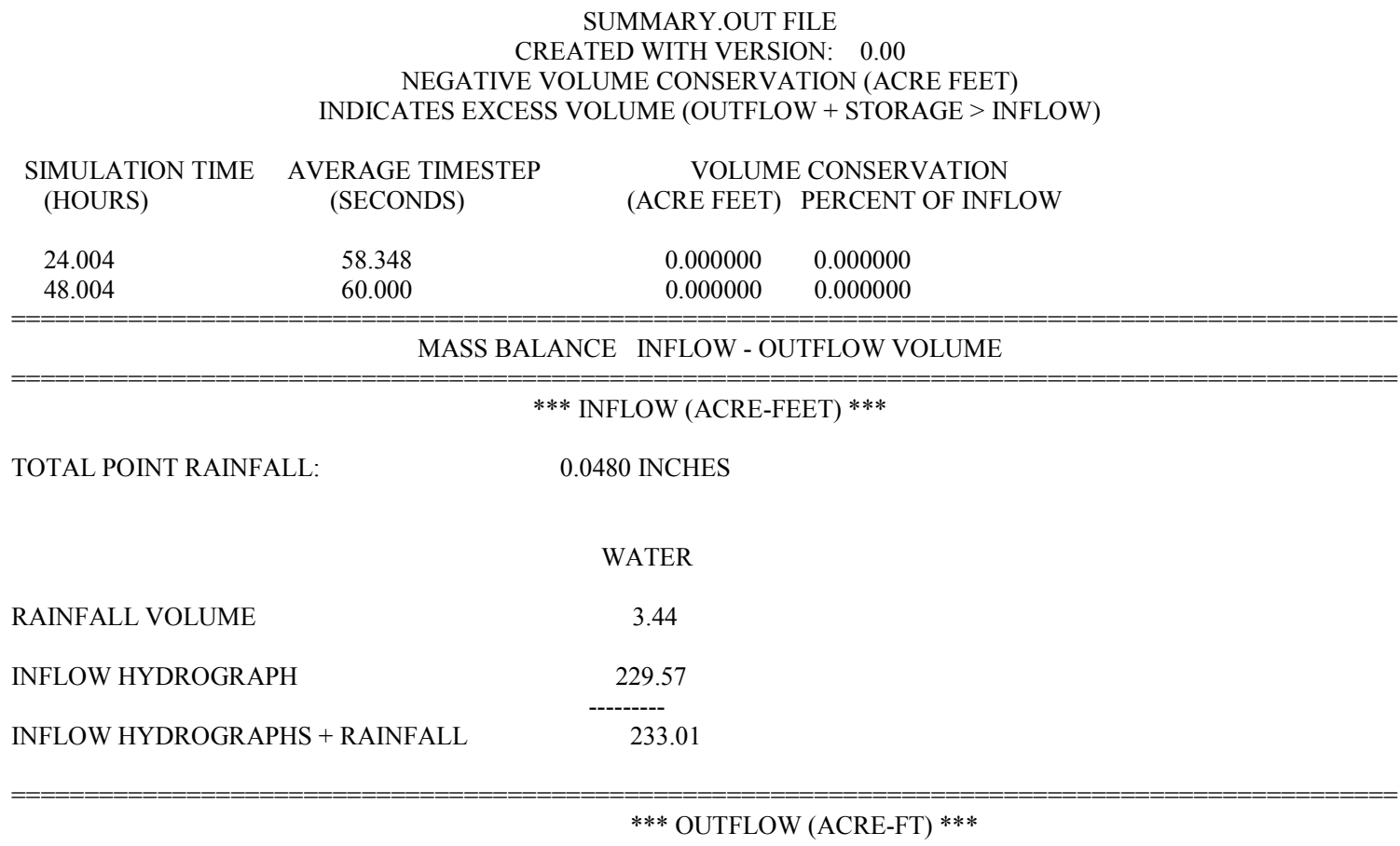

OVERLAND INFILTRATED AND INTERCEPTED WATER $\quad$ 0.07 INCHES

OVERLAND FLOW WATER

WATER LOST TO INFILTRATION \& INTERCEPTION 3.19

$\begin{array}{ll}\text { FLOODPLAIN STORAGE } & 208968.50\end{array}$

FLOODPLAIN OUTFLOW, INFILTRATION \& STORAGE 208971.69

CHANNEL FLOW

$\begin{array}{ll}\text { CHANNEL INFILTRATION } & 0.18\end{array}$

CHANNEL STORAGE 229.57

$\begin{array}{ll}\text { CHANNEL OUTFLOW } & 0.00\end{array}$

CHANNEL OUTFLOW AND STORAGE 229.75 


$\begin{array}{lc} & * * * \text { TOTALS } * * * \\ \text { TOTAL OUTFLOW FROM GRID SYSTEM } & 0.00 \\ \text { TOTAL VOLUME OF OUTFLOW AND STORAGE } & 209201.44 \\ & \\ \text { SURFACE AREA OF INUNDATION REGARDLESS OF THE TIME OF OCCURRENCE: } & \\ \text { (FOR FLOW DEPTHS GREATER THAN THE "TOL" VALUE TYPICALLY 0.1 FT OR 0.03 M) } & 45.91 \text { ACRES } \\ \text { THE MAXIMUM INUNDATED AREA IS: } & 0.00 \text { ACRES } \\ \text { THE MAXIMUM WETTED FLOODPLAIN AREA IS: } & 45.91 \text { ACRES } \\ \text { THE MAXIMUM WETTED CHANNEL AREA IS: } & \end{array}$

COMPUTER RUN TIME IS : 0.00020 HRS

THIS OUTPUT FILE WAS TERMINATED ON: 8/18/2009 AT: 16:25: 8

\section{MODFLOW}

\section{BCF2SS.LST}

MODFLOW-2005

U.S. GEOLOGICAL SURVEY MODULAR FINITE-DIFFERENCE GROUND-WATER FLOW MODEL VERSION 1.4.00 11/2/2007

LIST FILE: bcf2ss.1st

UNIT 201

OPENING bcf2ss.ba6

FILE TYPE:BAS6 UNIT 205 STATUS:OLD

FORMAT:FORMATTED ACCESS:SEQUENTIAL

OPENING bcf2ss.bc6

FILE TYPE:BCF6 UNIT 211 STATUS:OLD

FORMAT:FORMATTED ACCESS:SEQUENTIAL

OPENING bcf2ss.wel

FILE TYPE:WEL UNIT 212 STATUS:OLD

FORMAT:FORMATTED ACCESS:SEQUENTIAL

OPENING bcf2ss.rch

FILE TYPE:RCH UNIT 218 STATUS:OLD

FORMAT:FORMATTED ACCESS:SEQUENTIAL

OPENING bcf2ss.pcg

FILE TYPE:PCG UNIT 219 STATUS:OLD

FORMAT:FORMATTED ACCESS:SEQUENTIAL

OPENING bcf2ss.oc

FILE TYPE:OC UNIT 222 STATUS:OLD

FORMAT:FORMATTED ACCESS:SEQUENTIAL

OPENING bcf2ss.dis

FILE TYPE:DIS UNIT 210 STATUS:OLD

FORMAT:FORMATTED ACCESS:SEQUENTIAL 
BAS -- BASIC PACKAGE, VERSION 7, 5/2/2005 INPUT READ FROM UNIT 205

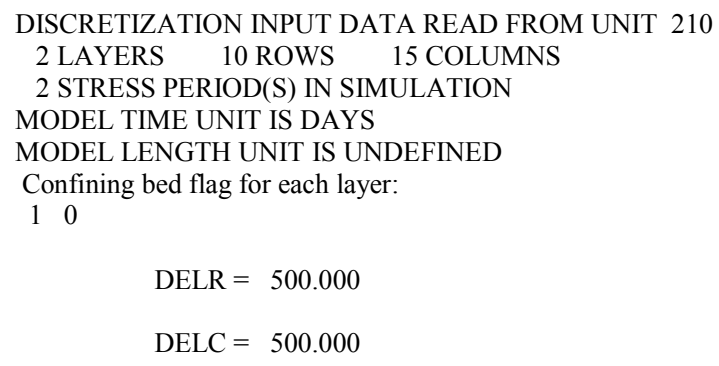

TOP ELEVATION OF LAYER $1=150.000$

MODEL LAYER BOTTOM EL. $=50.0000 \quad$ FOR LAYER 1

BOT. EL. OF QUASI-3D BED $=0.00000 \quad$ FOR LAYER 1

MODEL LAYER BOTTOM EL. $=-50.0000 \quad$ FOR LAYER 2

STRESS PERIOD LENGTH TIME STEPS MULTIPLIER FOR DELT SS FLAG

$\begin{array}{lllll}1 & 1.000000 & 1 & 1.000 & \text { SS } \\ 2 & 1.000000 & 1 & 1.000 & \text { SS }\end{array}$

STEADY-STATE SIMULATION

\#Valley aquifer with 2 sand layers separated by silt. Stress period 1 is natur \# conditions. Stress period 2 adds wells.

$$
\begin{array}{lll}
\text { BOUNDARY ARRAY }= & \text { 0 FOR LAYER } & 1 \\
\text { BOUNDARY ARRAY }= & \text { 1 FOR LAYER } & 2
\end{array}
$$

AQUIFER HEAD WILL BE SET TO 999.99 AT ALL NO-FLOW NODES (IBOUND=0).

$$
\begin{array}{lll}
\text { INITIAL HEAD }=0.00000 & \text { FOR LAYER } & 1 \\
\text { INITIAL HEAD }=0.00000 & \text { FOR LAYER } & 2
\end{array}
$$

OUTPUT CONTROL IS SPECIFIED EVERY TIME STEP

HEAD PRINT FORMAT CODE IS -4 DRAWDOWN PRINT FORMAT CODE IS -4 HEADS WILL BE SAVED ON UNIT 50 DRAWDOWNS WILL BE SAVED ON UNIT 50

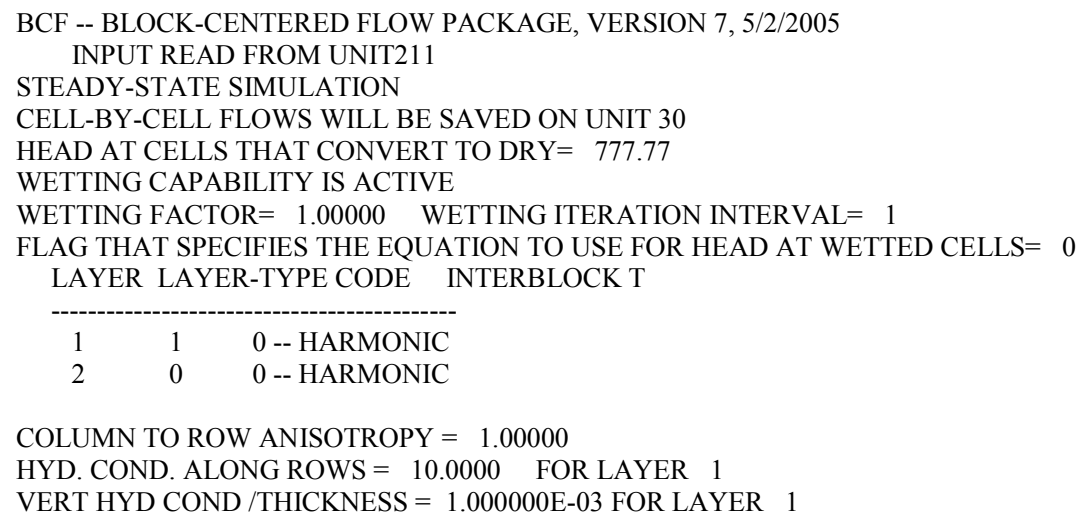




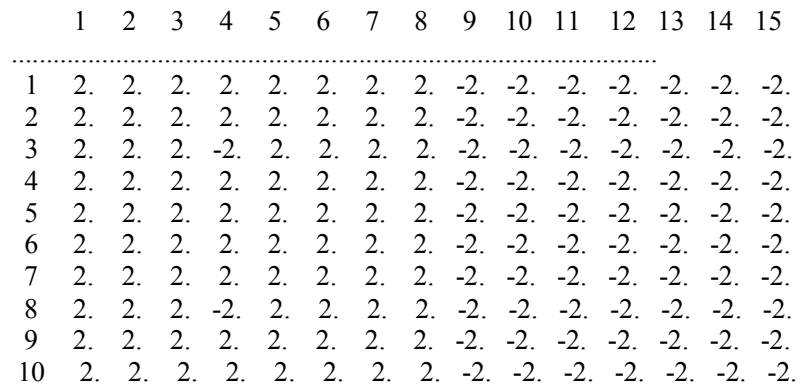

TRANSMIS. ALONG ROWS $=500.000 \quad$ FOR LAYER 2

WEL -- WELL PACKAGE, VERSION 7, 5/2/2005 INPUT READ FROM UNIT 212

No named parameters

MAXIMUM OF 2 ACTIVE WELLS AT ONE TIME

CELL-BY-CELL FLOWS WILL BE SAVED ON UNIT 30

0 Well parameters

RCH -- RECHARGE PACKAGE, VERSION 7, 5/2/2005 INPUT READ FROM UNIT 218

No named parameters

OPTION 3 -- RECHARGE TO HIGHEST ACTIVE NODE IN EACH VERTICAL COLUMN

PCG -- CONJUGATE-GRADIENT SOLUTION PACKAGE, VERSION 7, 5/2/2005

MAXIMUM OF 40 CALLS OF SOLUTION ROUTINE

MAXIMUM OF 20 INTERNAL ITERATIONS PER CALL TO SOLUTION ROUTINE

MATRIX PRECONDITIONING TYPE : 1

\author{
SOLUTION BY THE CONJUGATE-GRADIENT METHOD \\ MAXIMUM NUMBER OF CALLS TO PCG ROUTINE $=\quad 40$ \\ MAXIMUM ITERATIONS PER CALL TO PCG $=20$ \\ MATRIX PRECONDITIONING TYPE $=$ \\ RELAXATION FACTOR (ONLY USED WITH PRECOND. TYPE 1) $=0.10000 \mathrm{E}+01$ \\ PARAMETER OF POLYNOMIAL PRECOND $=2$ (2) OR IS CALCULATED : $\quad 2$ \\ HEAD CHANGE CRITERION FOR CLOSURE $=0.10000 \mathrm{E}-02$ \\ RESIDUAL CHANGE CRITERION FOR CLOSURE $=0.10000 \mathrm{E}+04$ \\ PCG HEAD AND RESIDUAL CHANGE PRINTOUT INTERVAL $=1$ \\ PRINTING FROM SOLVER IS LIMITED(1) OR SUPPRESSED $(>1)=1$ \\ DAMPING PARAMETER $=0.10000 \mathrm{E}+01$ \\ STRESS PERIOD NO. 1, LENGTH $=1.000000$ \\ NUMBER OF TIME STEPS $=1$ \\ MULTIPLIER FOR DELT $=1.000$ \\ INITIAL TIME STEP SIZE $=1.000000$
}

0 WELLS

SOLVING FOR HEAD

CELL CONVERSIONS FOR ITER $=2$ LAYER $=1 \mathrm{STEP}=1 \mathrm{PERIOD}=1 \quad(\mathrm{ROW}, \mathrm{COL})$

$\operatorname{WET}(1,1) \quad \operatorname{WET}(1,2) \quad \operatorname{WET}(1,3) \quad \operatorname{WET}(1,4) \quad \operatorname{WET}(1,5)$

$\operatorname{WET}(1,6) \quad \operatorname{WET}(1,7) \quad \operatorname{WET}(1,8) \quad \operatorname{WET}(1,9) \operatorname{WET}(1,10)$

$\operatorname{WET}(1,11) \quad \operatorname{WET}(1,12) \quad \operatorname{WET}(1,13) \quad \operatorname{WET}(2,1) \quad \operatorname{WET}(2,2)$

$\operatorname{WET}(2,3) \quad \operatorname{WET}(2,4) \operatorname{WET}(2,5) \operatorname{WET}(2,6) \quad \operatorname{WET}(2,7)$

$\operatorname{WET}(2,8) \quad \operatorname{WET}(2,9) \quad \operatorname{WET}(2,10) \operatorname{WET}(2,11) \operatorname{WET}(2,12)$

WET( 2, 13) WET( 3, 1) WET( 3, 2) WET( 3, 3) WET( 3, 4)

$\operatorname{WET}(3,5) \quad \operatorname{WET}(3,6) \quad \operatorname{WET}(3,7) \quad \operatorname{WET}(3,8) \quad \operatorname{WET}(3,9)$

WET( 3,10$) \operatorname{WET}(3,11) \operatorname{WET}(3,12) \operatorname{WET}(3,13) \operatorname{WET}(4,1)$ 
WET( 4, 2) $\operatorname{WET}(4,3) \quad \operatorname{WET}(4,4) \quad \operatorname{WET}(4,5) \quad \operatorname{WET}(4,6)$ WET( 4,7$)$ WET( 4,8$)$ WET( 4, 9) $\operatorname{WET}(4,10) \operatorname{WET}(4,11)$ WET( 4,12$) \operatorname{WET}(4,13) \operatorname{WET}(5,1)$ WET( 5,2$)$ WET( 5,3$)$ WET( 5,4$)$ WET( 5,5$)$ WET( 5,6$)$ WET( 5,7$)$ WET( 5, 8) WET( 5,9$)$ WET( 5,10$)$ WET( 5,11$)$ WET( 5,12$)$ WET( 5,13$)$ $\operatorname{WET}(6,1)$ WET( 6,2$)$ WET( 6, 3) WET( 6, 4) WET( 6, 5) WET( 6,6$)$ WET( 6,7$)$ WET( 6,8$)$ WET( 6,9$)$ WET $(6,10)$ WET( 6,11$) \operatorname{WET}(6,12)$ WET( 6,13$) \operatorname{WET}(7,1)$ WET( 7,2$)$ WET( 7, 3) $\operatorname{WET}(7,4) \operatorname{WET}(7,5) \operatorname{WET}(7,6) \operatorname{WET}(7,7)$ $\operatorname{WET}(7,8)$ WET( 7,9$)$ WET( 7,10$) \operatorname{WET}(7,11) \operatorname{WET}(7,12)$ WET( 7,13$) \operatorname{WET}(8,1)$ WET( 8,2$)$ WET $(8,3)$ WET( 8,4$)$ WET $(8,5)$ WET( 8,6$)$ WET( 8,7$)$ WET $(8,8)$ WET( 8,9$)$ WET $(8,10) \operatorname{WET}(8,11) \operatorname{WET}(8,12) \operatorname{WET}(8,13) \operatorname{WET}(9,1)$ $\operatorname{WET}(9,2) \quad \operatorname{WET}(9,3)$ WET( 9,4$) \operatorname{WET}(9,5)$ WET( 9,6$)$ WET( 9, 7) WET( 9,8) WET( 9,9) $\operatorname{WET}(9,10) \operatorname{WET}(9,11)$ $\operatorname{WET}(9,12) \operatorname{WET}(9,13) \operatorname{WET}(10,1) \operatorname{WET}(10,2) \operatorname{WET}(10,3)$ $\operatorname{WET}(10,4) \operatorname{WET}(10,5) \operatorname{WET}(10,6) \operatorname{WET}(10,7) \operatorname{WET}(10,8)$ $\operatorname{WET}(10,9) \operatorname{WET}(10,10) \operatorname{WET}(10,11) \operatorname{WET}(10,12) \operatorname{WET}(10,13)$

\section{CALLS TO PCG ROUTINE FOR TIME STEP 1 IN STRESS PERIOD 1} 94 TOTAL ITERATIONS

HEAD/DRAWDOWN PRINTOUT FLAG $=1 \quad$ TOTAL BUDGET PRINTOUT FLAG $=1$

CELL-BY-CELL FLOW TERM FLAG $=0$

OUTPUT FLAGS FOR ALL LAYERS ARE THE SAME:

HEAD DRAWDOWN HEAD DRAWDOWN

PRINTOUT PRINTOUT SAVE SAVE

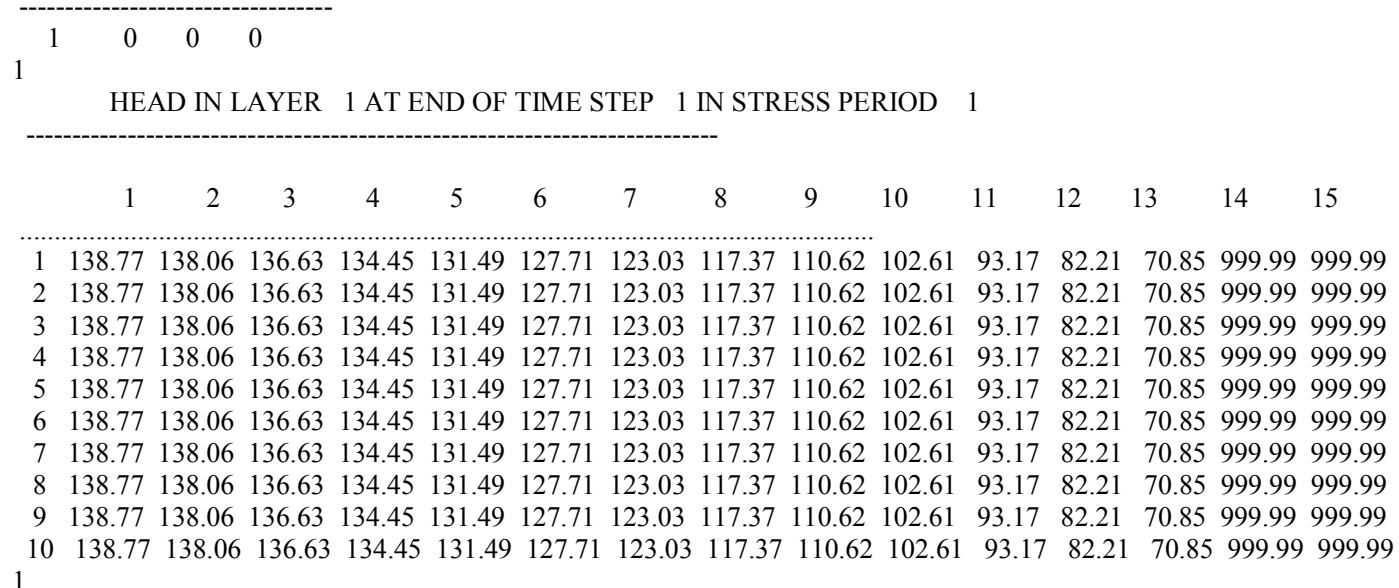

HEAD IN LAYER 2 AT END OF TIME STEP 1 IN STRESS PERIOD 1

\begin{tabular}{|c|c|c|c|c|c|c|c|c|c|c|c|c|c|c|c|}
\hline & 1 & 2 & 3 & 4 & 5 & 6 & 7 & 8 & 9 & 10 & 11 & 12 & 13 & 14 & 15 \\
\hline 1 & 137.30 & 136.56 & 135.07 & 132.81 & 129.73 & 125.76 & 120.82 & 114.77 & 107.42 & 98.46 & 87.44 & 73.56 & 55.35 & 29.38 & 1.42 \\
\hline 2 & 137.30 & 136.56 & 135.07 & 132.81 & 129.73 & 125.76 & 120.82 & 114.77 & 107.42 & 98.46 & 87.44 & 73.56 & 55.35 & 29.38 & 1.42 \\
\hline 3 & 137.30 & 136.56 & 135.07 & 132.81 & 129.73 & 125.76 & 120.82 & 114.77 & 107.42 & 98.46 & 87.44 & 73.56 & 55.35 & 29.38 & 1.42 \\
\hline 4 & 137.30 & 136.56 & 135.07 & 132.81 & 129.73 & 125.76 & 120.82 & 114.77 & 107.42 & 98.46 & 87.44 & 73.56 & 55.35 & 29.38 & 1.42 \\
\hline 5 & 137.30 & 136.56 & 135.07 & 132.81 & 129.73 & 125.76 & 120.82 & 114.77 & 107.42 & 98.46 & 87.44 & 73.56 & 55.35 & 29.38 & 1.42 \\
\hline 6 & 137.30 & 136.56 & 135.07 & 132.81 & 129.73 & 125.76 & 120.82 & 114.77 & 107.42 & 98.46 & 87.44 & 73.56 & 55.35 & 29.38 & 1.42 \\
\hline 7 & 137.30 & 136.56 & 135.07 & 132.81 & 129.73 & 125.76 & 120.82 & 114.77 & 107.42 & 98.46 & 87.44 & 73.56 & 55.35 & 29.38 & 1.42 \\
\hline 8 & 137.30 & 136.56 & 135.07 & 132.81 & 129.73 & 125.76 & 120.82 & 114.77 & 107.42 & 98.46 & 87.44 & 73.56 & 55.35 & 29.38 & 1.42 \\
\hline 9 & 137.30 & 136.56 & 135.07 & 132.81 & 129.73 & 125.76 & 120.82 & 114.77 & 107.42 & 98.46 & 87.44 & 73.56 & 55.35 & 29.38 & 1.42 \\
\hline 10 & 137.30 & 136.56 & 135.07 & 132.81 & 129.73 & 125.76 & 5120.82 & 2114.77 & 107.42 & 98.46 & 87.44 & 73.56 & 55.35 & 29.38 & 1.42 \\
\hline
\end{tabular}

CUMULATIVE VOLUMES L L*3 RATES FOR THIS TIME STEP L**3/T 


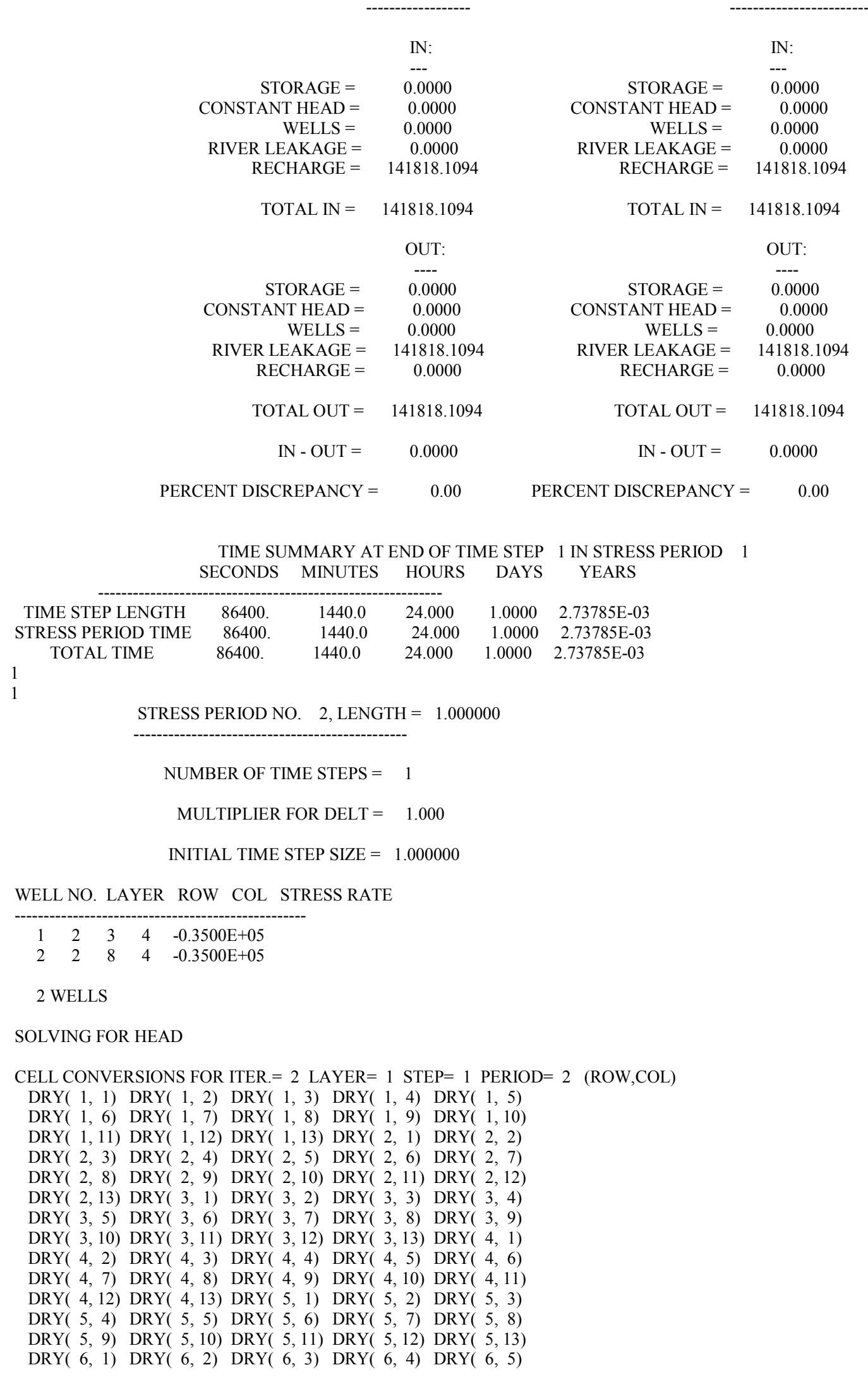


$\operatorname{DRY}(6,6) \quad \operatorname{DRY}(6,7) \quad \operatorname{DRY}(6,8) \quad \operatorname{DRY}(6,9) \quad \operatorname{DRY}(6,10)$ $\operatorname{DRY}(6,11) \operatorname{DRY}(6,12) \operatorname{DRY}(6,13) \operatorname{DRY}(7,1) \operatorname{DRY}(7,2)$ $\operatorname{DRY}(7,3) \quad \operatorname{DRY}(7,4) \quad \operatorname{DRY}(7,5) \quad \operatorname{DRY}(7,6) \quad \operatorname{DRY}(7,7)$ $\operatorname{DRY}(7,8) \quad \operatorname{DRY}(7,9) \quad \operatorname{DRY}(7,10) \operatorname{DRY}(7,11) \operatorname{DRY}(7,12)$ $\operatorname{DRY}(7,13) \operatorname{DRY}(8,1) \quad \operatorname{DRY}(8,2) \operatorname{DRY}(8,3) \operatorname{DRY}(8,4)$ $\operatorname{DRY}(8,5) \operatorname{DRY}(8,6) \quad \operatorname{DRY}(8,7) \operatorname{DRY}(8,8) \operatorname{DRY}(8,9)$ $\operatorname{DRY}(8,10) \operatorname{DRY}(8,11) \operatorname{DRY}(8,12) \operatorname{DRY}(8,13) \operatorname{DRY}(9,1)$ $\operatorname{DRY}(9,2) \quad \operatorname{DRY}(9,3) \quad \operatorname{DRY}(9,4) \quad \operatorname{DRY}(9,5) \operatorname{DRY}(9,6)$ $\operatorname{DRY}(9,7) \operatorname{DRY}(9,8) \operatorname{DRY}(9,9) \operatorname{DRY}(9,10) \operatorname{DRY}(9,11)$ $\operatorname{DRY}(9,12) \operatorname{DRY}(9,13) \operatorname{DRY}(10,1) \operatorname{DRY}(10,2) \operatorname{DRY}(10,3)$ $\operatorname{DRY}(10,4) \operatorname{DRY}(10,5) \operatorname{DRY}(10,6) \operatorname{DRY}(10,7) \operatorname{DRY}(10,8)$ $\operatorname{DRY}(10,9) \operatorname{DRY}(10,10) \operatorname{DRY}(10,11) \operatorname{DRY}(10,12) \operatorname{DRY}(10,13)$

CELL CONVERSIONS FOR ITER $=3$ LAYER $=1 \mathrm{STEP}=1$ PERIOD $=2 \quad(\mathrm{ROW}, \mathrm{COL})$ $\operatorname{WET}(1,1)$ WET( 1,2$)$ WET( 1,3$)$ WET( 1,5$)$ WET( 1,6$)$ WET( 1,7$) \operatorname{WET}(1,8) \operatorname{WET}(1,9) \operatorname{WET}(2,1) \operatorname{WET}(2,2)$ WET( 2,6) $\operatorname{WET}(2,7) \quad \operatorname{WET}(2,8) \operatorname{WET}(2,9) \operatorname{WET}(3,1)$ $\operatorname{WET}(3,2)$ WET( 3,6$)$ WET( 3,7$)$ WET( 3,8$)$ WET( 3,9$)$ $\operatorname{WET}(4,1) \operatorname{WET}(4,2) \quad \operatorname{WET}(4,6) \quad \operatorname{WET}(4,7) \quad \operatorname{WET}(4,8)$ WET $(4,9) \quad \operatorname{WET}(5,1) \quad \operatorname{WET}(5,2) \quad \operatorname{WET}(5,3) \quad \operatorname{WET}(5,5)$ WET( 5,6$) \quad \operatorname{WET}(5,7) \quad \operatorname{WET}(5,8)$ WET( 5,9$) \quad \operatorname{WET}(6,1)$ WET $(6,2) \quad \operatorname{WET}(6,3)$ WET( 6,5$)$ WET( 6,6$) \quad \operatorname{WET}(6,7)$ WET( 6, 8) $\operatorname{WET}(6,9) \operatorname{WET}(7,1) \operatorname{WET}(7,2) \operatorname{WET}(7,6)$ WET $(7,7) \quad \operatorname{WET}(7,8) \quad \operatorname{WET}(7,9) \quad \operatorname{WET}(8,1)$ WET $(8,2)$ WET( 8,6$)$ WET $(8,7) \quad \operatorname{WET}(8,8)$ WET( 8,9$)$ WET $(9,1)$ WET( 9,2) $\operatorname{WET}(9,6) \quad \operatorname{WET}(9,7) \quad \operatorname{WET}(9,8) \quad \operatorname{WET}(9,9)$ $\operatorname{WET}(10,1) \operatorname{WET}(10,2) \operatorname{WET}(10,3) \operatorname{WET}(10,5) \operatorname{WET}(10,6)$ $\operatorname{WET}(10,7) \operatorname{WET}(10,8) \operatorname{WET}(10,9)$

CELL CONVERSIONS FOR ITER $=4$ LAYER $=1 \mathrm{STEP}=1$ PERIOD $=2 \quad(\mathrm{ROW}, \mathrm{COL})$ $\operatorname{WET}(1,4) \quad \operatorname{WET}(2,3) \quad \operatorname{WET}(2,5) \quad \operatorname{WET}(3,3) \quad \operatorname{WET}(3,5)$ WET( 4, 3) $\operatorname{WET}(4,5) \operatorname{WET}(5,4) \operatorname{WET}(6,4) \operatorname{WET}(7,3)$ WET( 7,5$) \operatorname{WET}(8,3) \quad \operatorname{WET}(8,5) \operatorname{WET}(9,3) \operatorname{WET}(9,5)$ $\operatorname{WET}(10,4)$

CELL CONVERSIONS FOR ITER $=5$ LAYER $=1$ STEP $=1$ PERIOD $=2 \quad($ ROW,COL $)$ WET( 2, 4) WET( 4, 4) WET( 7, 4) WET( 9, 4)

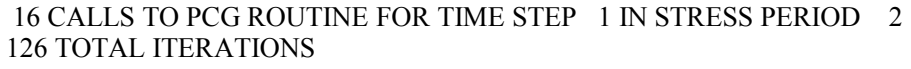




\begin{tabular}{|c|c|c|c|c|c|c|c|c|c|c|c|c|c|c|c|}
\hline & 1 & 2 & 3 & 4 & 5 & 6 & 7 & 8 & 9 & 10 & 11 & 12 & 13 & 14 & 15 \\
\hline 1 & 56.59 & 55.29 & 53.14 & 51.55 & 53.15 & 55.30 & 56.55 & 56.40 & 54.55 & 50.56 & 44.58 & 36.61 & 26.64 & 14.68 & 0.72 \\
\hline 2 & 56.17 & 54.34 & 50.67 & 46.22 & 50.69 & 54.39 & 56.24 & 56.29 & 54.52 & 50.55 & 44.58 & 36.61 & 26.64 & 14.68 & 0.72 \\
\hline 3 & 55.82 & 53.34 & 46.72 & 29.48 & 46.75 & 53.41 & 55.97 & 56.21 & 54.49 & 50.54 & 44.58 & 36.61 & 26.64 & 14.68 & 0.72 \\
\hline 4 & 56.17 & 54.34 & 50.67 & 46.22 & 50.69 & 54.39 & 56.24 & 56.29 & 54.52 & 50.55 & 44.58 & 36.61 & 26.64 & 14.68 & 0.72 \\
\hline 5 & 56.59 & 55.29 & 53.14 & 51.55 & 53.15 & 55.30 & 56.55 & 56.40 & 54.55 & 50.56 & 44.58 & 36.61 & 26.64 & 14.68 & 0.72 \\
\hline 6 & 56.59 & 55.29 & 53.14 & 51.55 & 53.15 & 55.30 & 56.55 & 56.40 & 54.55 & 50.56 & 44.58 & 36.61 & 26.64 & 14.68 & 0.72 \\
\hline 7 & 56.17 & 54.35 & 50.67 & 46.22 & 50.69 & 54.39 & 56.24 & 56.29 & 54.52 & 50.55 & 44.58 & 36.61 & 26.64 & 14.68 & 0.72 \\
\hline 8 & 55.82 & 53.34 & 46.72 & 29.48 & 46.75 & 53.41 & 55.97 & 56.21 & 54.49 & 50.54 & 44.58 & 36.61 & 26.64 & 14.68 & 0.72 \\
\hline 9 & 56.17 & 54.35 & 50.67 & 46.22 & 50.69 & 54.39 & 56.24 & 56.29 & 54.52 & 50.55 & 44.58 & 36.61 & 26.64 & 14.68 & 0.72 \\
\hline 10 & 56.59 & 55.29 & 53.14 & 51.55 & 53.15 & 55.30 & 56.55 & 56.40 & 54.55 & 50.56 & 44.58 & 36.61 & 26.64 & 14.68 & 0.72 \\
\hline
\end{tabular}

\begin{tabular}{|c|c|c|c|}
\hline CUMULATIVE VOLUMES & $\mathrm{L} * * 3$ & RATES FOR THIS TIME STE & $\mathrm{L}^{* * 3 / \mathrm{T}}$ \\
\hline & IN: & & IN: \\
\hline STORAGE = & 0.0000 & STORAGE = & 0.0000 \\
\hline CONSTANT HEAD = & 0.0000 & CONSTANT HEAD $=$ & 0.0000 \\
\hline WELLS $=$ & 0.0000 & WELLS $=$ & 0.0000 \\
\hline RIVER LEAKAGE $=$ & 0.0000 & RIVER LEAKAGE $=$ & 0.0000 \\
\hline RECHARGE $=$ & 283636.2188 & RECHARGE $=$ & 141818.1094 \\
\hline \multirow[t]{2}{*}{ TOTAL IN = } & 283636.2188 & TOTAL IN = & 141818.1094 \\
\hline & OUT: & & OUT: \\
\hline STORAGE $=$ & 0.0000 & STORAGE $=$ & 0.0000 \\
\hline CONSTANT HEAD = & 0.0000 & CONSTANT HEAD $=$ & 0.0000 \\
\hline WELLS $=$ & 70000.0000 & WELLS $=$ & 70000.0000 \\
\hline RIVER LEAKAGE = & 213636.2188 & RIVER LEAKAGE = & 71818.1172 \\
\hline RECHARGE = & 0.0000 & RECHARGE = & 0.0000 \\
\hline TOTAL OUT $=$ & 283636.2188 & TOTAL OUT $=$ & 141818.1250 \\
\hline $\mathrm{IN}-\mathrm{OUT}=$ & 0.0000 & $\mathrm{IN}-\mathrm{OUT}=$ & $-1.5625 \mathrm{E}-02$ \\
\hline CENT DISCREPANCY = & 0.00 & PERCENT DISCREPANCY = & 0.00 \\
\hline
\end{tabular}

\begin{tabular}{|c|c|c|c|c|c|}
\hline & SECONDS & MINUTES & HOURS & DAYS & YEARS \\
\hline TIME STEP LENGTH & 86400. & 1440.0 & 24.000 & 1.0000 & $2.73785 \mathrm{E}-03$ \\
\hline STRESS PERIOD TIME & 86400. & 1440.0 & 24.000 & 1.0000 & $2.73785 \mathrm{E}-03$ \\
\hline TOTAL TIME & $1.72800 \mathrm{E}+05$ & 2880.0 & 48.000 & 2.0000 & $5.47570 \mathrm{E}-03$ \\
\hline
\end{tabular}

Run end date and time (yyyy/mm/dd hh:mm:ss): 2009/08/18 16:17:49

Elapsed run time: 5.335 Seconds 


\section{APPENDIX G}

\section{DATA FROM DBHYDRO}

Hydrological Data

\begin{tabular}{|c|c|c|c|}
\hline Name & Stages & DBKEY & Period \\
\hline LILA1O & yes & UP599 & $02 / 20 / 07$ to 09/22/09 \\
\hline LILA1I_H & yes & SC988 & $01 / 01 / 07$ to 09/22/09 \\
\hline LILA1I_T & yes & SC990 & $01 / 01 / 07$ to 09/22/09 \\
\hline
\end{tabular}

Meteorological Data

\begin{tabular}{|c|c|c|}
\hline Name & DBKEY & Period \\
\hline \multicolumn{3}{|c|}{ Rainfall } \\
\hline LXWS & IX999 & $01 / 01 / 07$ to 09/22/09 \\
\hline \multicolumn{3}{|c|}{ Evapotranspiration } \\
\hline LOXWS & RW485 & $01 / 01 / 07$ to $09 / 22 / 07$ \\
\hline
\end{tabular}




\section{APPENDIX H}

GEOGRAPHICAL DATA

\begin{tabular}{|c|c|c|}
\hline File & type & Description \\
\hline LILA2008 & Raster & Aerial Image \\
\hline AsBuPWH1 & shapefile & Elevation Points \\
\hline M1E_Suerveyed_Elevation29 & shapefile & Tree island Elevation Points \\
\hline M1W_Suerveyed_Elevation29 & shapefile & Tree island Elevation Points \\
\hline Trans-elev1 & shapefile & Elevation Points \\
\hline
\end{tabular}




\section{APPENDIX I}

CALIBRATION DATA

\section{STAGE TIME DATA}
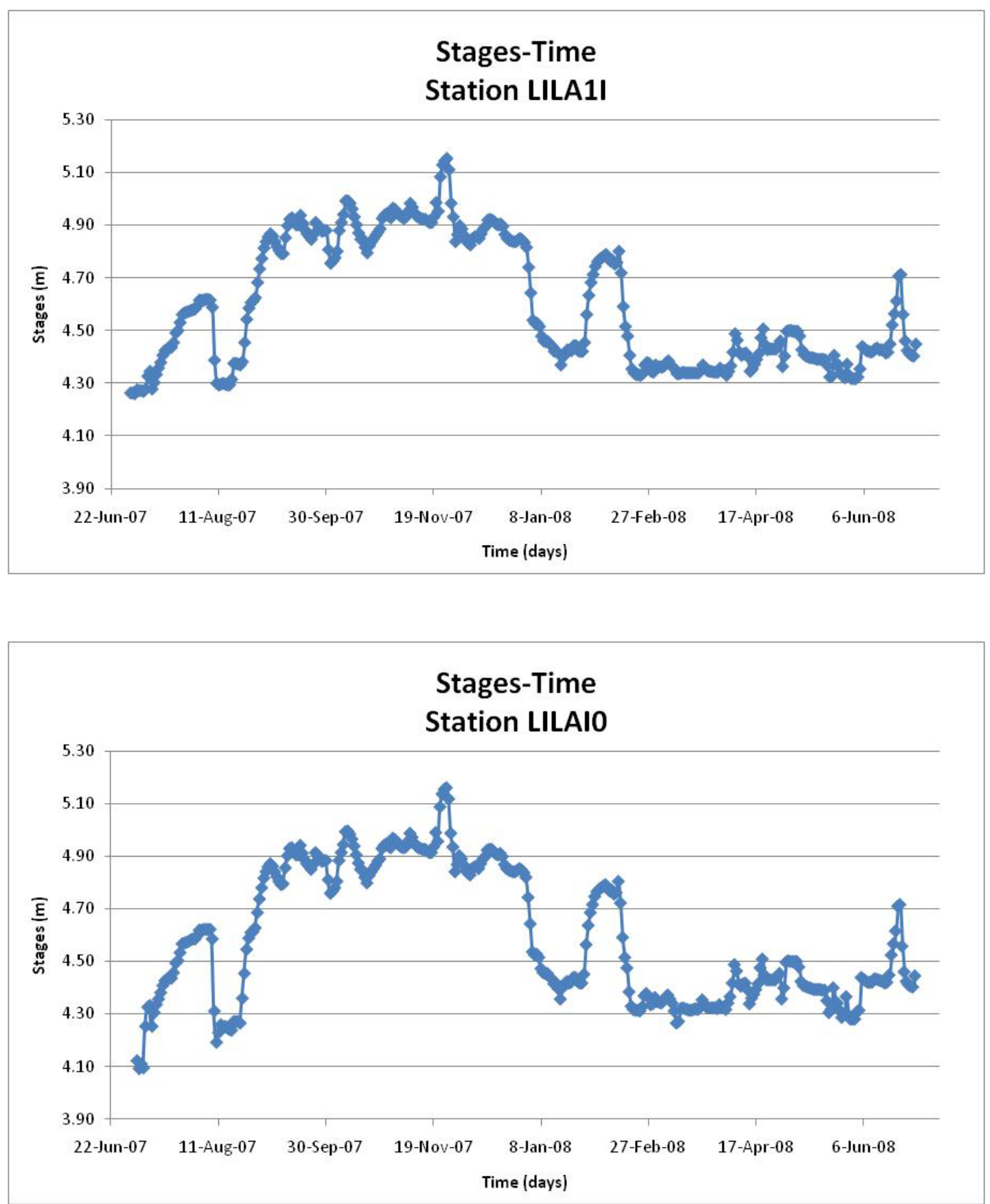
RAINFALL

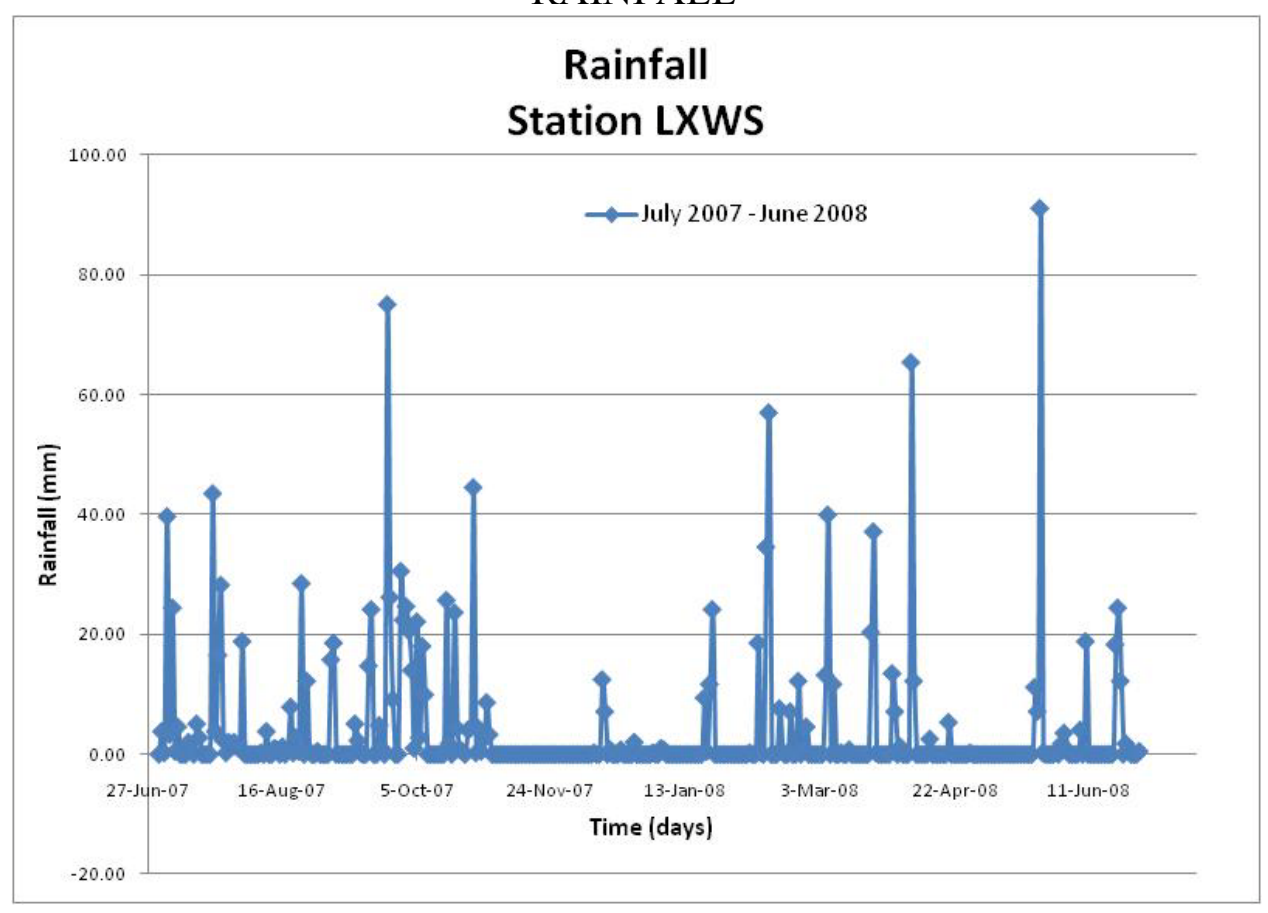

EVAPOTRANSPIRATION

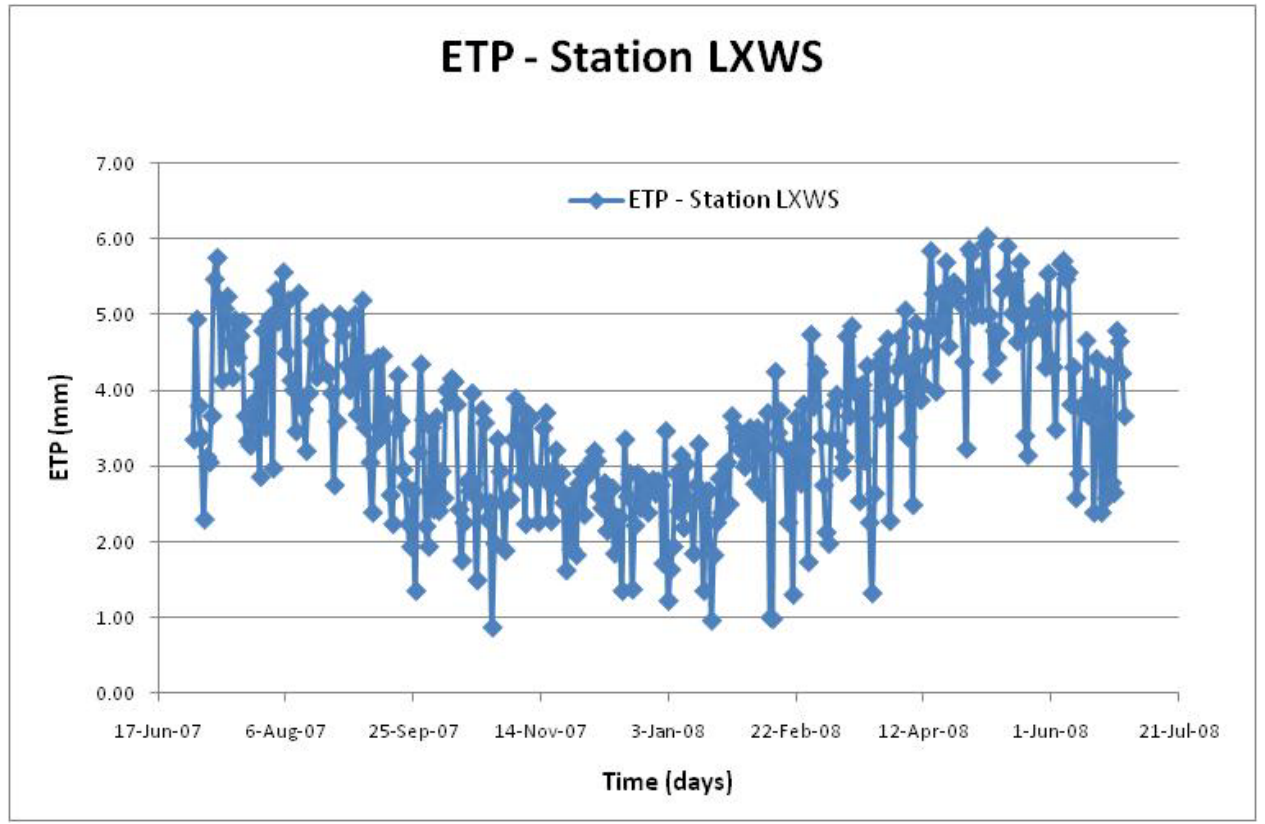




\section{GROUNDWATER DATA}
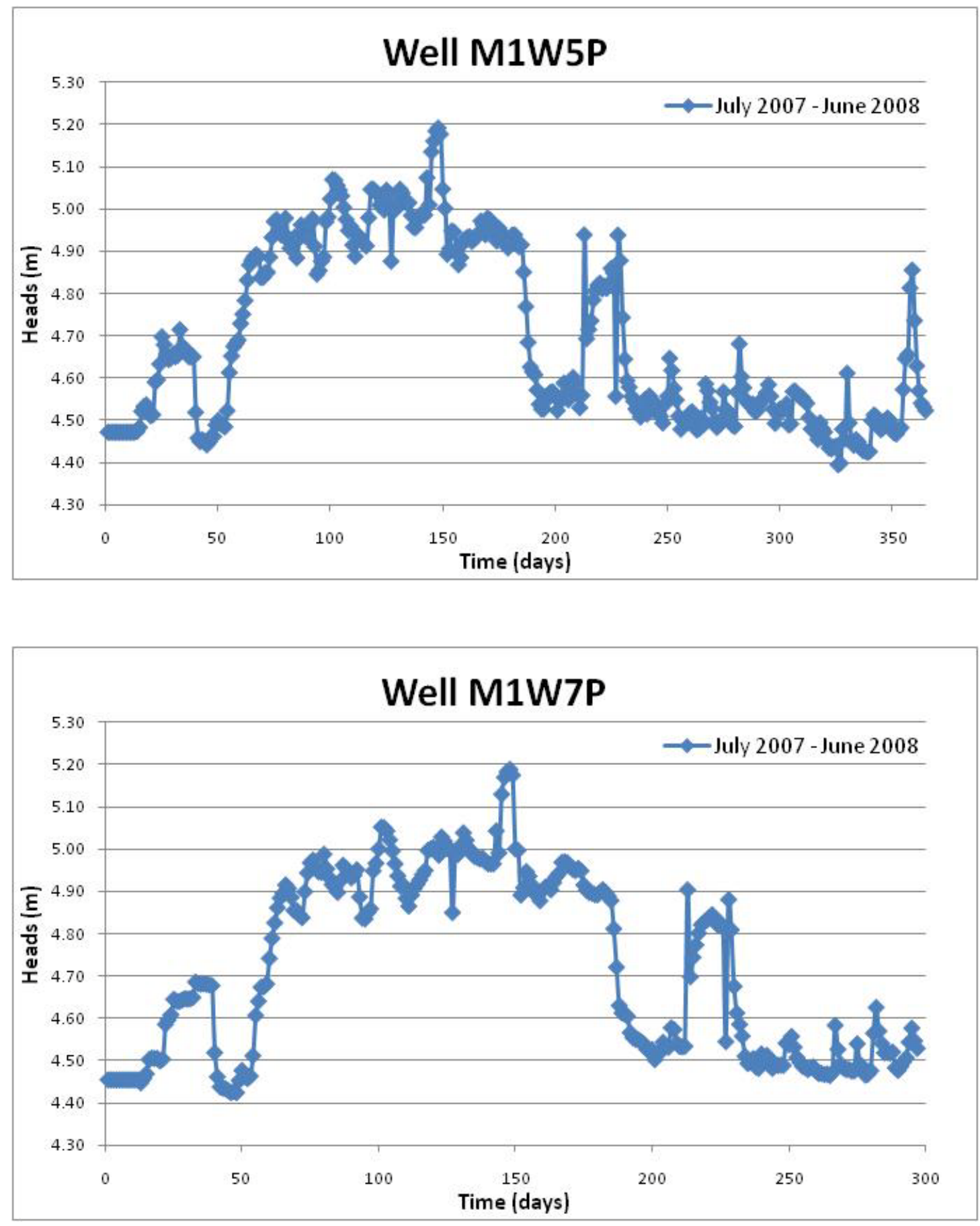

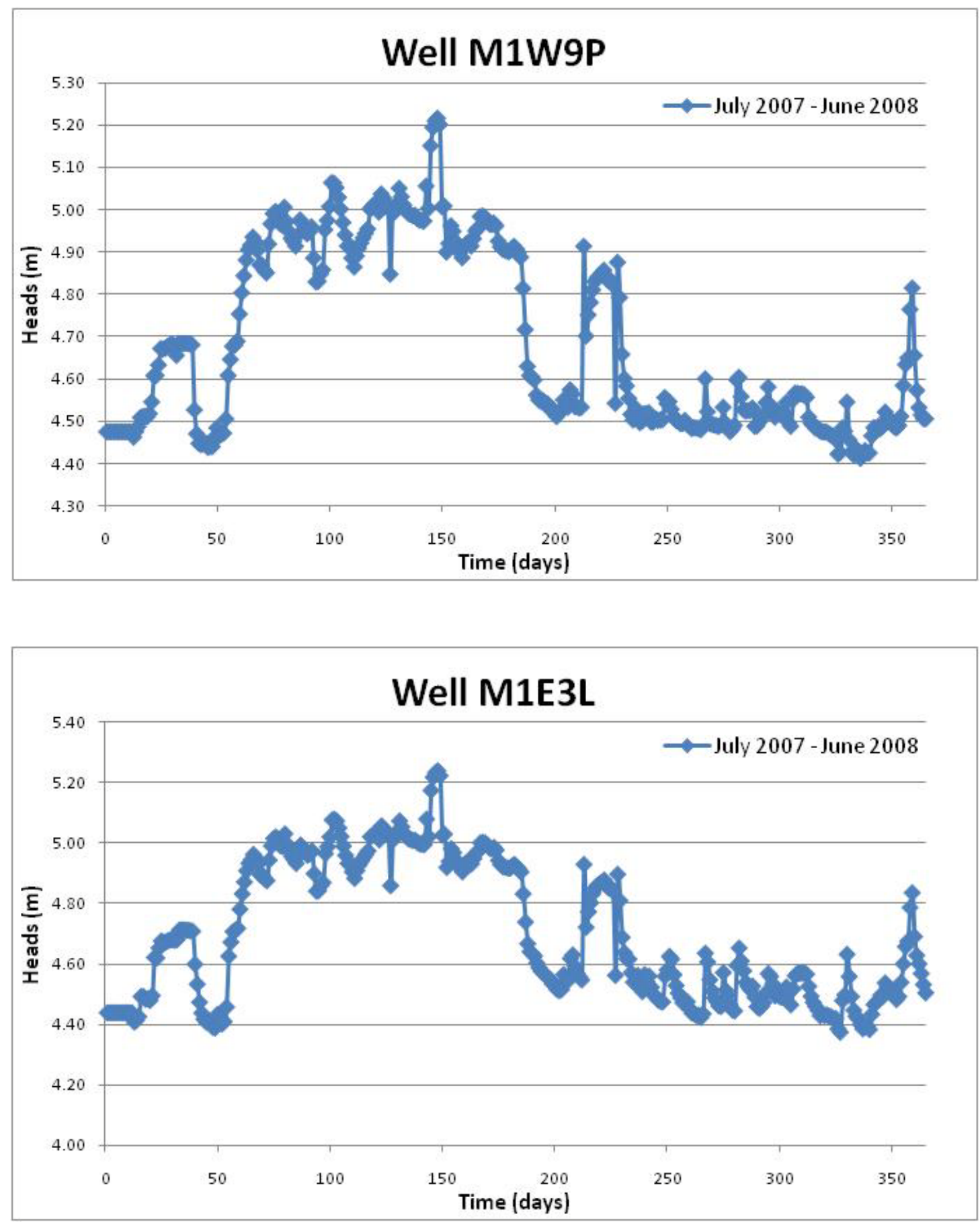

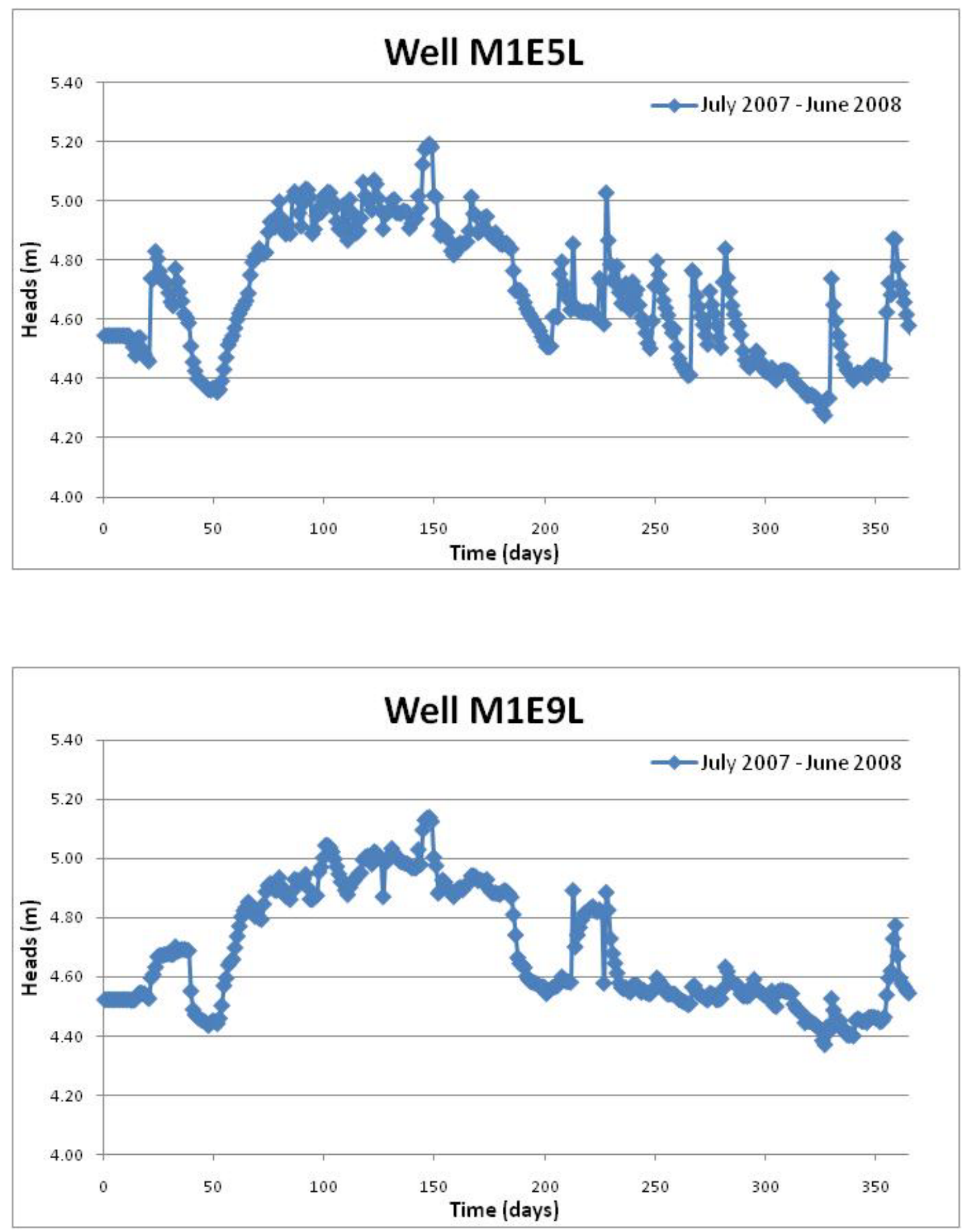


\section{APPENDIX J}

VERIFICATION DATA

\section{STAGE TIME DATA}
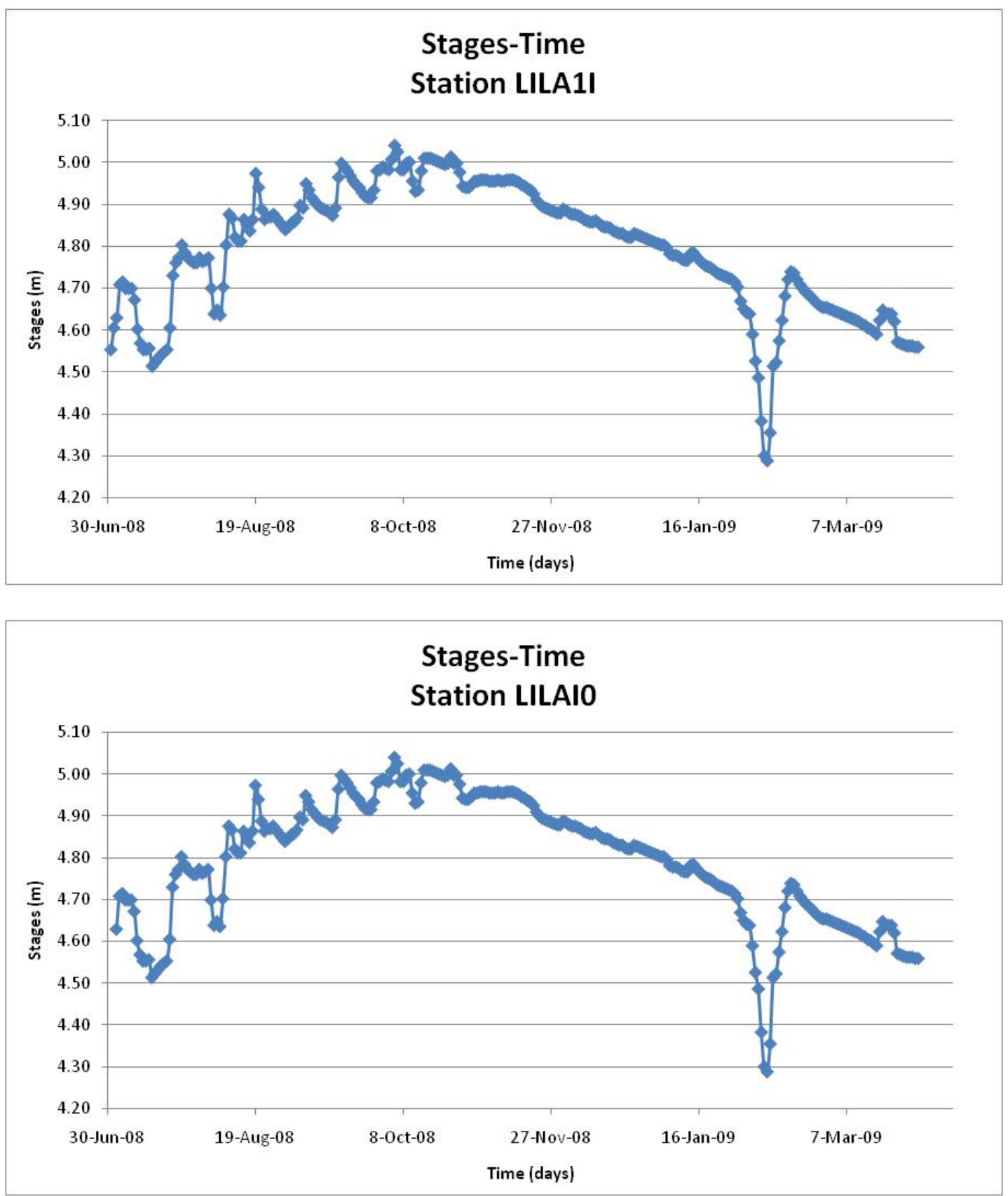


\section{METEOROLOGICAL DATA}

RAINFALL

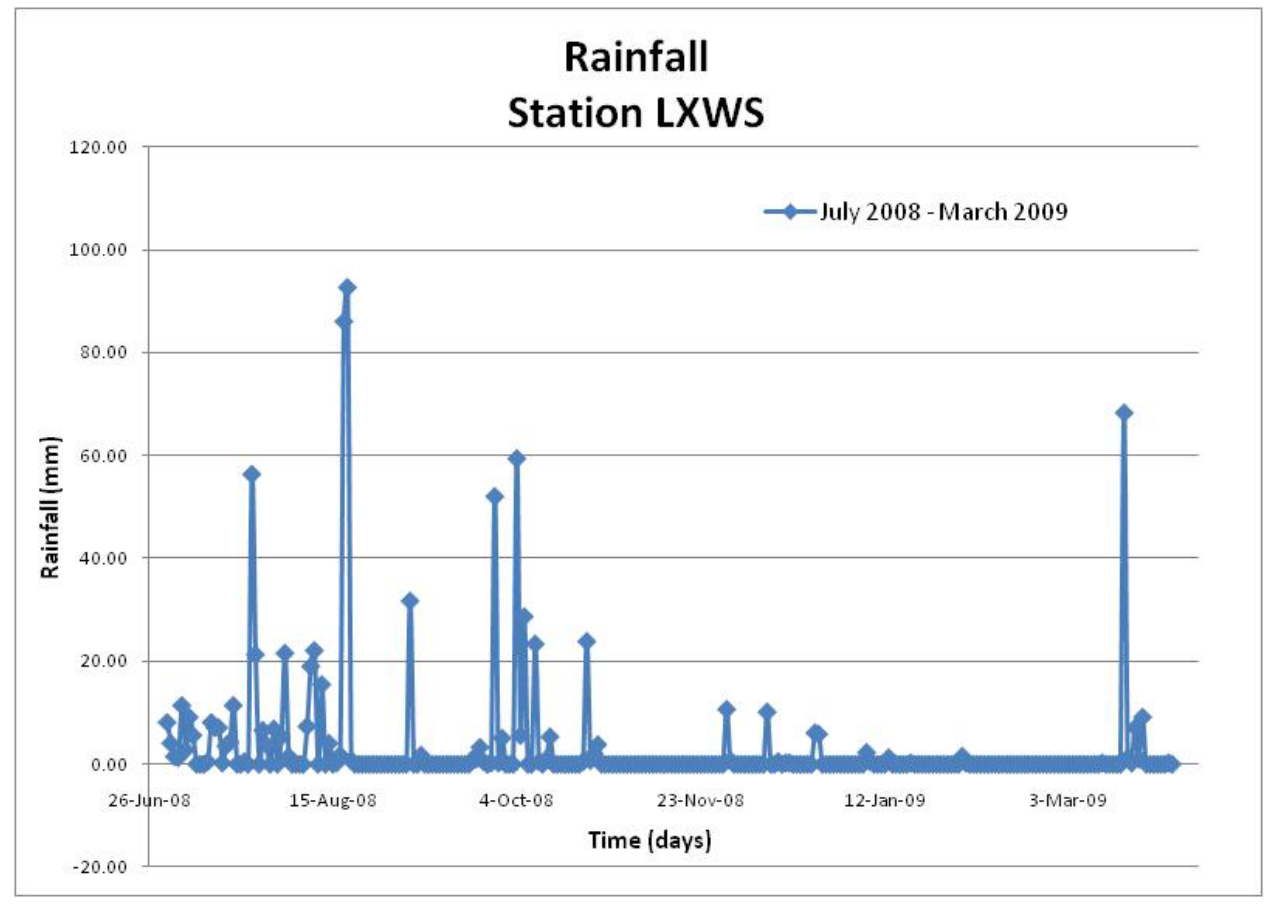

EVAPOTRANSPIRATION

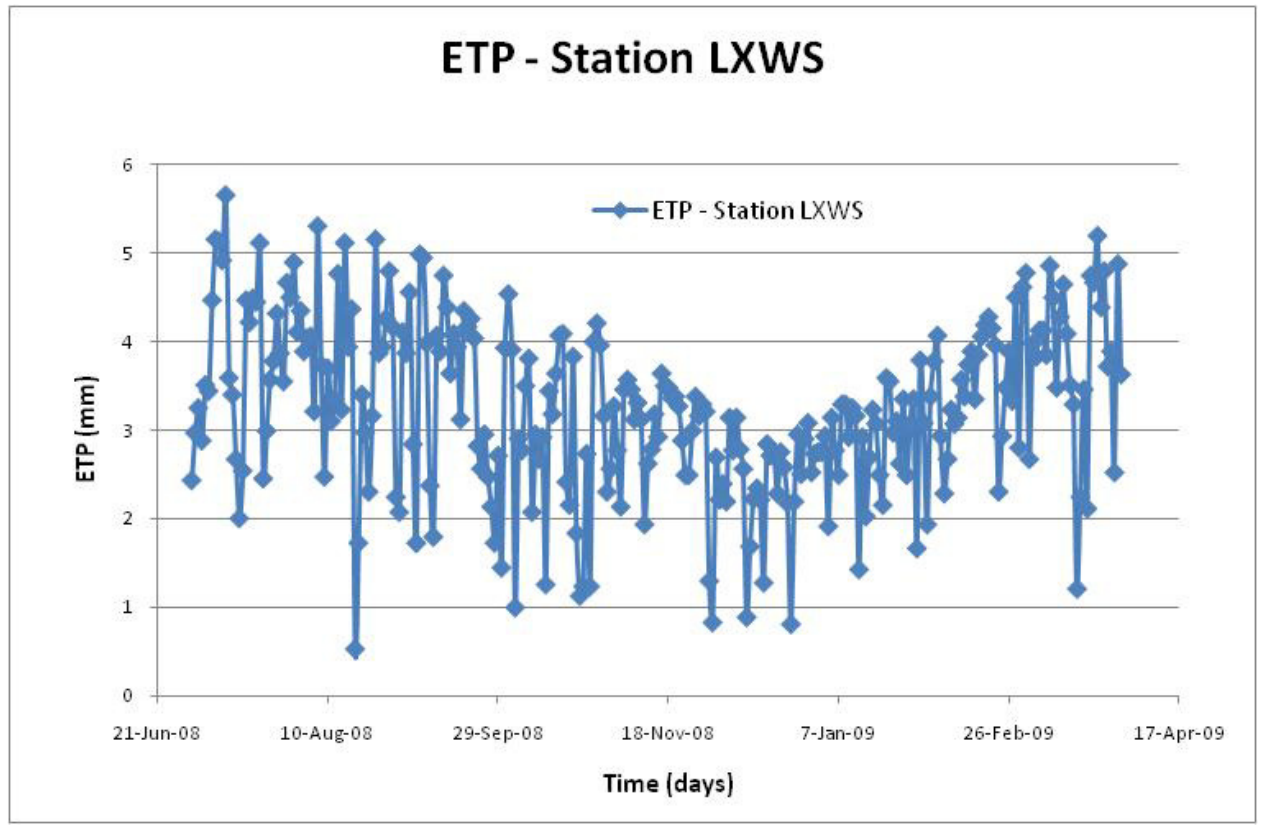


VITA

\section{MAURO NALESSO}

January 24, 1974

$1993-1998$

1998

$1999-2001$

2000

$2000-2003$

$2002-2004$

2003 - present
Born, Caracas, Venezuela

B.A Civil Engineering

Metropolitan University

Caracas, Venezuela.

Sediment Transport in Rivers, Estuaries and Coastal Zones

Course by Dr. Leo Van Rijn (Delf Hydraulics)

Central University of Venezuela

Caracas, Venezuela.

M.Sc. Hydraulic Engineering

Central University of Venezuela

Caracas, Venezuela.

Mountain Rivers and Debris Flow

Course by Dr. Gary Parker (University of Minnesota)

Central University of Venezuela

Caracas, Venezuela.

Associate Researcher

Institute of Fluid Mechanics

Central University of Venezuela

Caracas, Venezuela.

Conventional Time Professor

Department of Civil Engineering

Metropolitan University

Caracas, Venezuela.

Full Time Professor

Institute of Fluid Mechanics

Central University of Venezuela

Caracas, Venezuela. 


\section{PAPERS AND PRESENTATIONS}

González, N., Nalesso M. \& Falcón, M. "Alternate and Central Bars on River Channels", EL RIO ORINOCO, Aprovechamiento Sustentable, book that gather all the works presented at the I Venezuelan Journeys of Research about the Orinoco River, 1998.

Nalesso, M. "The Galipán Debris Flow Experiental Watershed”. International Conference on Mountain Environment and Development, Chengdu, China, October, 2002.

Nalesso, M. "Gli Eventi del 1999 in Venezuela: Cause, Conseguenze e Misure Preventive". Dipartimento di Ingegneria Civile e Ambientale, Università Degli Studi di Trento, Trento, Italia, 16 octubre, 2003.

Solana, P., Castellanos, B., Nalesso, M.. "Measurement of Hydrodynamic and Environmental Variables in Morrocoy, Venezuela". Revista Técnica de la Facultad de Ingeniería, LUZ, Vol. 27, $\mathrm{N}^{\circ}$ 2, pag. $100-113 ; 2004$.

Nalesso, M. "Amenaza por Inundación en el Valle de Caracas y el Edo. Vargas". 1er Seminario de Desastres, Universidad Central de Venezuela, Caracas, Venezuela, 3 abril, 2004.

Nalesso M., González N. "Aludes Torrenciales: Medidas Estructurales y NoEstructurales para la Mitigación de Riesgos". Foro: ENSEÑANZAS DE VARGAS 1999 - 2005. UCV, Caracas, Venezuela 17 de febrero, 2005.

Nalesso M., Sánchez, R., Muñoz, J.“Evaluación Del Método De Aforo Por Inyección De Nacl Para Determinar Caudales En Ríos Torrenciales". XXII Congreso Latinoamericano de Hidráulica. Ciudad Guayana, Venezuela, entre el 9 y el 14 de octubre de 2006. 